\title{
NAUTICAL SYMBOLISM IN CHRISTIAN MAORI ARCHITECTURE
}

\section{SARC 591}

BY

\section{PAMELA RADBURND}

Submitted in partial fulfilment of the requirements for the degree of

Master of Architecture (Prof)

Victoria University of Wellington

March 2011 


\section{ABSTRACT}

It is well known that many Maori cultural traditions and cosmological beliefs are anchored in a sea of knowledge associated with seafaring, navigation and the oceanic environment. Despite the loss of deep-sea voyaging, this thesis explores how nautical reflexes were still very influential on various modes of expression in Christian Maori architecture of three distinct Maori religious movements from the colonial and post-colonial periods. During this investigation, this thesis also identifies a relationship that can be found between the appropriation of nautical symbolism in Christian and Maori architecture.

This relationship is examined on two levels: One, in terms of how Christian and Maori iconography has latent nautical meaning and secondly, how nautical symbolism in Christian Maori architecture is more signal than sculptural. The latter identifies the more powerful, metaphysical symbols in Maori architecture and spirituality which make Christian Maori architecture uniquely different from European Christian architecture. This thesis links these qualities in symbolic Christian maori architecture to the psychic and symbolic territories known to the navigator. In doing so, this thesis discovers how nautical symbols occupy a middle ground, an in-between area bridging the known with the unknown and examines their role as mediators between the present and the past; the individual and the collective.

This thesis finally presents an architectural design which explores specific aspects of research. In doing so, the use of nautical symbolism and water-based pragmatism through architecture explores how such methods and expressions can influence and transform Western notions of knowledge or conventional notions of contemporary (terrestrial) architecture in New Zealand. To achieve this, nautical concepts from case study material are applied to a contemporary design project in order to open up architecture to its metaphysical dimension rather than focussing on the object (sculptural) that is frozen in time. As a result, this design also celebrates and revives the nautical instinct of Maori in terms of how it can offer new and meaningful ways to design architecture in oceania and New Zealand. 


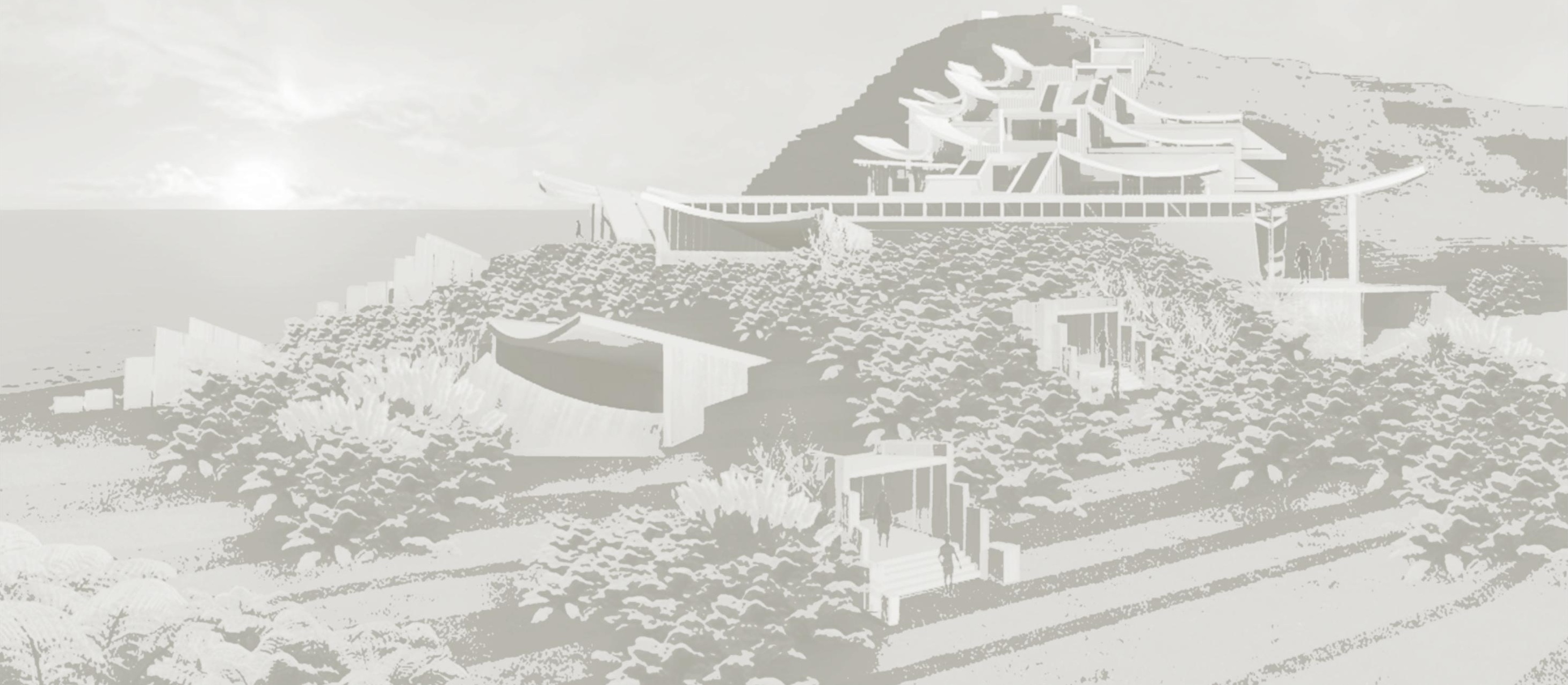




\section{ACKNOWLEDGEMENTS}

I would firstly like to thank Shenuka De Sylva from Victoria University's School of Architecture and Design for her supervision, guidance and support through the course of this thesis.

I would also like to thank Bill Mckay for his valuable time and expertise on the subject of Maori architecture. His guest lectures and private tuition were extremely helpful and inspirational. I would also to thank Bill for providing some of the

photos used throughout this thesis. 


\section{LIST OF FIGURES}

Thesis Cover: Painting by John Bevan from "Cloak" works, "Pacific Rim" series

\section{CHAPTER ONE:}

Figure 1 A \& B: Model of an eighteenth century tipaerua.

Source: Kennedy, A. (2002). Collections: Object: Model Tipaerua (model canoe). Retrieved June 3, 2011, from Museum of New Zealand Te Papa.

Tongarewa: 1

Figure 2 a: Star compass used by Maori for deep-sea navigation

Source: Te Tai Tokerau Tarai Waka Inc. (n.d.). Te Aurere Voyaging - Waka - star compass. Retrieved January 11, 201 1, from Te Aurere:

http://teaurere.org.nz/star_compass.htm

b: Description of the marae by Mike Austin

Austin, M. (1976). A description of the Maori Marae. In A. Rapoport, The Mutual Interaction of People and their Built Environment (pp. 229-241). Mouton: The Hague.

Figure 3: Map showing early sites and known Pa Sites

Source: Image scanned and edited from book: Malcolm McKinnon. (1997). Bateman New Zealand historical atlas = Ko papatuanuku. e takoto nei. Auckland: Bateman in association with Historical Branch, Dept. of Internal Affiars.

Figure 4: Three kowhaiwhai painted by Sydney Parkinson in 1769.

Source: Image scanned from book: Brown, D. (2009). Maori Architecture. From Fale to Wharenui. Auckland: Penguin Group. Raupo book

Figure 5: Distribution of Canoe landing Places throughout New Zealand.

Source: Map scanned from Atlas: Kirkpatrick, R. (2005). Bateman contemporary atlas New Zealand the shapes of our nation. Auckland: David Bateman

Figure 6: Map of Pacific Migrations

Source: Wilson, J. (2009, March 3). Te Ara Home: Nerw Zealand in Brief: History. Retrieved March 2011, 3, from Te Ara - the Encyclopedia of New

Zealand: http://www.teara.govt.nz/en/history/1/1

Figure 7: Storage structures from around lake Taupo in 1844. Painted by George French Angas.

Source: Scanned from Brown, D. (2009). Maori Architecture. From Fale to Wharenui. Auckland: Penguin Group. Raupo book. Pg. 31

Figure 8: Iwikau Te Heuheu's house, illustrated by George French Angus in 1844.

Source: Scanned image from: Brown, D. (2009). Maori Architecture. From Fale to Wharenui. Auckland: Penguin Group. Raupo book. Pg 35 
Source: Earle, A. (1838). File:EarleWarSpeech.jpg. Retrieved March 7, 2011 , from Wikipedia, the free encyclopedia:

http://en.wikipedia.org/wiki/File:EarleWarSpeech.jpg

\section{CHAPTER TWO:}

Figure 2.1: Watercolour by Lieutenant Herbert Meade (1842-1868) depicting Pai Marire ceremony at Tataroa

Source: Alexander Turnbull Library. Reference Number: B-139-014

Figure 2.2: (Background Image) HMS Endeavour

Source: The Art of Age of Sail. (2001). Retrieved March 3, 2011, from HMS Endeavour : http://www.ageofsail.net/aosendv 1.asp

Figure 2.3: Drawing of niu pole from notebook of Te Ua Haumene, c. 1863

Source: Clark, P. (1975). 'Hauhau' The Pai Marire search for Maori identity. Auckland: Wright and Carman Ltd.

Figure 2.4: Maori compass, showing specific terms and also wind names, as given by Mohi Turei of the Ngati-Porou tribe.

Source: Best, E. (1941). The Maori - Volume 2. Wellington: Polynesian Society. Pg 211

Figure 2.5 a \& b: The Rongo niu pole built in 1864 still standing at Maraekowhai (Whanganui River)

Source: deannz. (2007, February 27). deannz - albums - River Rats trip 2. Retrieved February 14, 201 1, from Webshots: http://outdoors.webshots.com

Figure 2.6: Te Ua Haumene (1823-1866), founder of Pai Marire religion, photographed in Auckland 1866.

Source: Paul, C. (1975). Hauhau: The Pai Marire search for Maori identity. Auckland: Auckland University Press.

Figure 2.7: Photograph of Rongo niu pole built at Maraekowhai

Source: Noble, A. (1982). The Collection: Browse Artwork: Hau Hau war pole, Rongo Niu. Retrieved March 3, 201 1, from Auckland Art Gallery Toi o

Tāmaki: http://www.aucklandartgallery.com/the-collection/browse-artwork/8433/hau-hau-war-pole,-rongo-niu

Figure 2.8a,b,c: : Both drawings are from Aporo's notebook depicting references to celestial symbols in Pai Marire religion.

Source: Paul, C. (1975). Hauhau: The Pai Marire search for Maori identity. Auckland: Auckland University Press.

Figure 9: Photograph of Tokanganui a Noho meeting house

Source: Hamilton and Waikato Regional Toursim. (2011). Image Library. Retrieved March 3, 201 1, from HamiltonWaikato.com:

http://www.hamiltonwaikato.com/media/wp-content/gallery/media/b130_tokanganui-a-noho-marae-te-kuiti-medium.jpg

Figure 2.10: Figurative paintings on the vertical porch boards of Te Tokanganui - a Noho

Source: Illustration by Roger Neich (1993) in Painted Histories. Early Maori figurative painting. Pg 183

Figure 2.11: Naturalistic forest scenes on interior rafters of Ringatu meeting house

Source: Reconstructed image by Roger Neich (1993) Painted Histories. Early Maori figurative painting pg. 281 
Source: Josiah Martin Te Kooti. (19th Century). Retrieved February 15, 2011, from Auckland Art Gallery Toi o Tamaki:

http://www.aucklandartgallery.com/media/vernonImages/1971-1980/1973_17_78.jpg

Figure 2.13: Ancestor figures depicted in Victorian style clothing. (In Rongopai Ringatu Meeting house, Waituhi)

Source: Image scanned from book: Neich, R. (1993). Painted Histories. Early Maori figurative painting. Auckland: Auckland University Press.

Pg. 80

Figure 2.14: Poupou ancestor figures becoming more humanised evident through the feet and hands.

Source: Image scanned from book: Neich, R. (1993). Painted Histories. Early Maori figurative painting. Auckland: Auckland University Press.

$\operatorname{Pg} 81$

Figure 2.15: (above) Photograph of Te Tokanganui - a - Noho, taken by Josiah Martin, 1913

Source: Wikimedia commons. (2010, October 13). File:Page 310 - Te Kooti's House.jpg. Retrieved February 15, 2011, from Wikimedia commons:

http://commons.wikimedia.org/wiki/File:Page 310 - Te_Kooti's_House.jpg

Figure 2.16: Photograph of the Temepara at Ratana Pa

Source: Cowan, C. (2009, September 19). cjcowans photostream: Ratana Church, Ratana Pa. Retrieved February 2011, 15, from Flickr:

http://www.flickr.com/photos/cjcowan/393490270

Figure 1.17a,b,c: Detailed photographs of celestial symbolism on the gate and roof of the Temepara.

Source: Sheehan, G. (2010). The Founding of a faith - Story Images. Retrieved February 15, 201 1, from New Zealand Historic Places Trust:

http://www.historic.org.nz/en/Publications/HeritageNZMagazine/HeritageNz2010/HNZ10-Ratana.aspx

Figure 2.18: Interior of the Temepara showing whetu marama symbolism around walls and barrel vault ceiling

Source: Image scanned from Brown, D. (2009). Maori Architecture. From Fale to Wharenui, pg 111

Figure 2.19a \& b: Photograph of Manuao Building Complex showing seven migratory canoes and European ships the Endeavour and Heemskerk

Source: Photographs Sourced from personal photo collection of Bill Mckay. January 20, 2011

Figure 2.20: Portrait of T.W Ratana, founder of Ratana faith (artist unknown)

Source: Hagger, A. (2003, November 8). T.W.Ratana. Retrieved January 11, 201 1, from Te Haahi Ratana: Ratana Established Church of New Zealand: http://www.theratanachurch.org.nz/twratana.html

Figure 2.21 a \& b: Figure a and b whetu marama symbols around the walls and shining in the windows

source: Hagger, A. (2003, July 28). Temepara Tapu: Temple Project. Retrieved February 15, 2011, from Te Haahi Ratana

http://www.theratanachurch.org.nz/temple.html

Figure $2.21 \mathrm{c}$ : Whetu marama symbol can also be found in the shape of a garden - slightly visible to the left of the path. 78

Source: Bill Mckay's Private photo collection: Received via e-mail January 20, 2011

Figure 2.22: Photograph of the Manuao building complex at Ratana Pa.

Source: juliannasong. (1999, August 30). Ratana Pa, New Zealand. Retrieved February 15, 201 1, from webshots:

http://family.webshots.com/photo/1000133072000113731 
Source: Bill Mckay's Private collection: Received via e-mail January 20, 2011

Figure 2.24 a \& b: Nga Tapuwae-o-te-Mangai, Opened at Te Kao in 1952

Source: Ibid

Figure 2.25 a \& b: Te Reo Powhiri Church Opened at Te Hapua in 1954

Source: Ibid

Figure 2.26: Painting of Noah's Ark by Edward Hicks

Source: Edward Hicks (1846) Noah's Ark. Retrieved February 14, 201 1, from Wikipedia, the free encyclopedia: http://en.wikipedia.org/wiki/Noah's_Ark

\section{CHAPTER THREE:}

Figure 3.1: Hawaiki by Wilhelm Dittmer.

Source: Royal, T. A. (2009, March 4). Hawaiki - Home of the gods. Retrieved January 28, 2011, from Te Ara - the Encyclopedia of New Zealand

http://www.teara.govt.nz/en/hawaiki/2

Figure 3.2: The Garden of Earthly delights by Hieronymus Bosch.

Source: Wikimedia Foundation, Inc. (2010, May 18). Garden of Eden. Retrieved May 20, 2010, from Wikipedia:

http://en.wikipedia.org/wiki/Garden_of_Eden

Figure 3.3: Image showing typical detail of tensile (post- tensioned) whare construction. By R.T. Wallace, C. J. Irwin \& R. Neich

90

Source: Sundt., R. A. (2010). Whare karakia : Mãori church building, decoration and ritual in Aotearoa New Zealand. 1834-1863. Auckland: Auckland

University Press. P. 55

Figure 3.4: A: Te Tokanganui in early $19^{\text {th }}$ Century

Source: Hemara, W. (2010). Chapter Five: Town Haul 1950's and 1960's. Retrieved March 3, 201 1, from Scoury Molls and a Pack-0- Huas:

http://wharehuia.wordpress.com/part-i/chapter-five/

B: Photograph of Te-Toganganui-a-Noho 1989

Source: Pegler, E. (1899). Tokanganui a Noho meeting house, King Country. Retrieved February 15, 201 1, from Auckland Art Gallery Toi o Tamaki:

http://www.aucklandartgallery.com/media/vernonImages/1981-1990/1990_14_33.jpg

C: Te Tokanganui-a-Noho Today.

Source: Hamilton and Waikato Regional Toursim. (2011). Image Library. Retrieved March 3, 201 1, from HamiltonWaikato.com

http://www.hamiltonwaikato.com/media/wp-content/gallery/media/b130_tokanganui-a-noho-marae-te-kuiti-medium.jpg 
Source: Taonui, R. (2009, March 4). Canoe navigation. Retrieved January 27, 201 1, from Te Ara - the Encyclopedia of New Zealand:

http://www.teara.govt.nz/en/canoe-navigation/2/3

Figure 3.6: Illustration showing the relationship between meeting house, marae and the natural environment.

Source: Austin, M. (1980). A description of the Maori marae. Study Paper 30, pg. 233

Figure 3.7: Nui Pole.

Source: Clark, P. (1975). 'Hauhau' The Pai Marire search for Maori identity. Auckland: Wright and Carman Ltd.

Source: kuaka. The New Zealand Journal . 31 August 2008. 3 March $2011<$ http://thenewzealandjournal.blogspot.com/2008_08_01_archive.html>

Figure 3.9: Use of pare (door lintels) in niu pole

Source: deannz. (2007, February 27). deannz - albums - River Rats trip 2. Retrieved February 14, 201 1, from Webshots: http://outdoors.webshots.com. Figure 3.10: Typical pare (door lintels) found in meeting house

Source: Morris, John R. "The Collection: Browse Artwork: Carved Maori door Lintels II." 1895. Auckland Art Gallery Toi o Tāmaki. 3 March 2011

$<$ http://www.aucklandartgallery.com/the-collection/browse-artwork/6433/carved-maori-door-lintels-ii>.

Figure 13.1: Use of Wahoroa (gateway) to create threshold between the sacred and profane

Source: Bill Mckay's personal photo collection received via e-mail on January 202011

Figure 12: Interior rib-like structure of Te Tokanganui - a - Noho.

Source: Neich, R. (1993). Painted Histories. Early Maori figurative painting. Auckland: Auckland Unversity Press, p. 179

Figure 3.13: Old St Pauls church in Wellington.

Source: Wikipedia. (2011, January 30). Old St Paul's, Wellington. Retrieved February 14, 2011 , from Wikipedia, the free encyclopedia:

http://en.wikipedia.org/wiki/Old_St._Paul's,_Wellington

Figure 3.14: The Hull-shaped ceiling in the Temepara

104

Source: Brown, D. (2009). Maori Architecture. From Fale to Wharenui. Auckland: Penguin Group. Raupo book. P. 111

Figure 3.15: Painting by Edward Hicks, depicting Noah's Ark.

Source: Hicks, E. (1846). Noah's Ark. Retrieved February 14, 2011, from Wikipedia, the free encyclopedia: http://en.wikipedia.org/wiki/Noah's_Ark

Figure 3.16: Showing typical construction inside interior of a ship

Source: Oregon State University Archives. "Ship building." 9 July 2009. Flickr. 3 March 2011

<http://www.flickr.com/photos/osucommons/3708636876/>.

Figure 3.17: Manuao building complex

Source: Bill Mckay's personal photo collection received via e-mail on January 202011. 
Source: Tane-nui-a-Rangi. Auckland: University of Auckland, 1988

Amoamo, T., T. Tupene and Roger Neich. "The complementarity of history and art in Tutamure meeting-house, Omarumutu Marae, Opotiki." The

Journal of the Polynesian Society Volume 93, No. 1 (1984): P. 32

\section{CHAPTER FOUR:}

Note: All Images created by Author unless otherwise stated:

Figure: Title page Image: Showing perspective view of the overall design: The wharekura

114

Figure (Background Image to introduction of Site) Looking past Point Halswell in early morning

Source: Suisted, Rob. Narure' Pic Images. 2011. 2011 March 3 http://www.naturespic.com/newzealand/image.asp?id=11232

Figure 4.1: Longitudinal section showing flow of water along main building axis. (Section A-A)

Figure 4.2: Site plan of building

125

Figure 4.3: West Elevation of wharekura

126

Figure 4.4: Perspective drawing showing entry/exit to thoroughfare near memorial.

127

Figure 4.5: Wellington City Council District Plan Map (13) showing Mataki-Ka-Poinga Landscape Feature Precinct

Source: WCC. Wellington City Council. 3 March 2011. www.wellington.govt.nz/plans/district/volume3/pdfs/v3map 13.pdf>.

Figure 4.6: Site Plan 1:2000

Figure 4.7: Terrestial relam of learning Floor Plan: 1:500

Figure 4.8: Celestial realm of Learning Floor Plan: 1:500

Figure 4.9: section AA showing how water is designed to flow down north-south axis of building 1:1000

141

Figure 4.10: Close Up area of section AA showing terrestrial realm of learning 
Figure 4.12: A sensual learning experience created through structure in the celestial classrooms

147

Figure 4.13: Perspective Section Showing Passive cooling System created through Structure (East Wing of Celestial Classrooms)

Figure 4.14: Perspective Section Showing Passive cooling System created through Structure (West Wing of Celestial Classrooms) 149

Figure 4.15: View Toward Celestial Realm of learning After Climbing first flight of stairs (From waka building 153

Figure 4.16: The experience of time through architecture through staircases

155

Figure 4.17: (Next to Title: The boat as an architectural Symbol):Showing the waka as a symbol in the roof

157

Figure 4.18: Section showing waka roof and structure 1:250

159

Figure 4.19: Perspective Section through Centre of waka

161

Figure 4.20: Perspective showing sailing roof scheme on East wing, celestial classrooms

Figure 4.2 1: East Elevation of whole building in landscape (memorial and Gun barracks at either end)

163




\section{TABLE OF CONTENTS}

\section{CHAPTER ONE:}

INTRODUCING NAUTICAL SYMBOLISM IN CHRISTIAN MAORI ARCHITECTURE

\section{Introduction}

The Maori: From Deep-sea navigator to life on land.

The Maori as a deep-sea explorer and navigator

\section{CHAPTER TWO:}

INDENTIFYING NAUTICAL SYMBOLISM IN CHRISTIAN MAORI ARCHITECTURE

Pai Marire/Hauhau Christian Maori Movement

The Niu Pole - An Appropriation of the European ship mast 
The boat as an architectural symbol in the Temepara and Manuao building complex.

\section{Chapter Summary}

\section{CHAPTER THREE \\ CHRISTIAN MAORI ARCHITECTURE: AS SIgNAL RATHER THAN SCULPTURE}

\section{Introduction}

What is Paradise? - Hawaiki versus The Garden of Eden 


\section{CHAPTER FOUR: \\ RESEARCH + DESIGN}

Introduction

\section{Site and Context}


Architecture Programme

\section{Design interpretation and Evaluation}

Introduction 
The waka as both Shelter and Symbol

\section{Discussion and Conclusions}




\section{APPENDICES AND REFERENCES}

\section{Appendix A}

The link between the waka and stars through the legend of Tama-rereti

Example of an Early Form of Prayer designed for Voyaging: Karakia

The Link between the Waka and the Legend of the First House: The wharekura 
Appendix B

186-192

A Brief History of Point Halswell from two Cultural Perspectives

Appendix C

194-200

Various Images associated with site analysis and design 


\section{CHAPTER ONE:}

INTRODUCING NAUTICAL SYMBOLISM IN CHRISTIAN MAORI

ARCHITECTURE 


\section{INTRODUCTION}

In oceanic societies particularly found in the Asia-Pacific, nautical symbolism appears in both religious and domestic architecture. Many years ago, Ronald Lewcock and Gerald Brans identified the boat as an architectural symbol across various examples of buildings in the Asia-Pacific. Here they explain how "communities do not build 'symbols', they build houses according to an inviolable tradition of which symbolism is the generator and the essence” (Lewcock \& Brans, 1975, p. 116). This implies the boat was a subconscious expression of a distinct way of thinking and conceptualizing the intimate connection between shelter and symbol. According to Dr Carl Gustav Jung's theories on the meaning and use of symbols, this is quite possible. Jung explains how symbolic form relates to the human psyche, consisting of various archetypes of conscious and unconscious mental activity. The following archetypes have been summarised from Carl G. Jung's book Man and his symbols (1968):

\section{Preconscious}

Personal unconscious

Collective unconscious
- mental faculties and memories which can be readily summoned into consciousness.

- perceptions, experiences and repressed desires which we can occasionally access as they surface into consciousness through dreams or sudden flashes of recollection.

- instinctive thought and behaviour that millennia of human experience have shaped into what we now recognize as emotions and values. 
Jung's theory on the collective unconscious gives validity to ideas explored in this research which identifies and examines the meaning of nautical symbolism in Christian Maori architecture. Using three case study examples of religiopolitical movements in the colonial and post-colonial periods, this research explores how seafaring and navigation have a latent connection to symbolic expressions of spirituality and culture in religious Maori architecture. Therefore, this research investigates nautical symbols that occupy a middle ground, an in-between area bridging the known with the unknown and examines their role as mediators between the present and the past; the individual and the collective.

A valuable body of research has been written on oceanic spatial environments and their influence on architecture. Sumet Jumsai (1959) probably provides the most extensive argument for 'water-based' architecture against those that are 'land-based' in his book, Naga: cultural origins in Siam and the West Pacific. Here, Jumsai highlights the flexible and adaptive nature of water-based architecture as well as their ability to communicate abstractly and instinctively through nautical symbols. This offers a stimulating architectural argument that has had extensive coverage by New Zealand writers who have compared Western (terrestrial) notions of architecture against the architecture of Maori. For example Bill Mckay and Antonia Walmsley (2003) have noted how Maori architecture does not conform to the Western (terrestrial) model of the three dimensional object in space, and is rather understood as existing in time rather than space. This conveys an important way to comprehend nautical symbolism in terms of understanding its contribution to symbolic inter-relationships between form, space and time in Maori architecture. Another well-known contributor to the field of nautical architecture is Mike Austin who has discussed how water and boats distinguish Pacific (Maori) architecture from Western, land-based architectures:

"Water and boats affect Oceanic architecture in many ways from structure to construction to detail to ornament. In the Pacific, sails become floor mats (and vice versa), old boats are used as storage structures, and both buildings are held together by a technology of weaving and tying". Furthermore, Austin highlights how Pacific notions of the temporal oceanic 
environment relate to a spatiality and motion that is "thoroughly imbricated with the technologies, mythologies and aesthetics of movement” (Austin, 2004, p. 226).

He notes how this condition of movement creates an ephemeral temporality in the built environment that contrasts with Western architecture's aspirations of "fixity" (p. 226) and their traditional concerns of enclosure and weather resistance which ignore or resist temporal flows and relationships with the environment.

Many other academics such as Jeremy and Sarah Treadwell, Deidre Brown and Roger Neich have contributed to this field, as have Antonia Walmsley, Albert Refiti and many others. Despite this large body of material, there is minimal writing which compares and contrasts the use of nautical symbolism in the European Christian church and Christian Maori architecture in the colonial and post-colonial periods. This is unusual considering there is a large body of evidence that still links many aspects of the boat, seafaring and navigation to Christian Maori architecture of this period. Even more interesting is how nautical symbolism continued to emerge through the appropriation of Christian symbols that had nautical significance or were given such meanings through Christian-Maori religious concepts. Bronwyn Elsmore (2000) and Judith Binney (1995) have thoroughly examined how Maori identified with specific aspects of the Old Testament and Christianity. Some of these reflect Christian appropriations which resonate with religious concepts and mythopoetical ideas found in oceanic cultures. Although these were interesting, they were complex ideas that were often hard to apply to an architectural argument. On another note, religious historian Jean Rosenfeld (1999) has suggested that celestial symbolism was appropriated from the bible because it resonates with their Polynesian history and experiences. (J. E. Rosenfeld 204) Despite this interesting reference, Rosenfeld does not see an underlying connection between celestial symbols and navigation. This grants opportunity for new research on an interesting and important topic in the field of Christian Maori architecture.

This thesis aims to contribute to this new area of exploration by seeking the relationship that can be found between nautical symbolism in Christian and Maori religious architecture from three distinct religio-political movements in the colonial and post-colonial periods. This research first identifies and examines nautical symbolism in Christian Maori 
architecture, followed by an investigation into the careful appropriation of Christian nautical symbols are their meaning in Christian Maori architecture. A relationship is discovered whereby similarities and differences found in the adaptation or appropriation of nautical symbols echo either oceanic or terrestrial notions of space, form and time in architecture. Using a qualitative approach, this research relates these findings in Christian Maori architecture to life experiences, legends and religious concepts of Maori in their seafaring days. Due to the fact that nautical symbols are associated with two separate cosmologies (a European (Christian) cosmology or a Maori cosmology) this research also explores how nautical symbols have hermeneutic interpretations. This means that some Christian symbols in religious Maori architecture may not have an immediate connection to navigation, seafaring or some aspect of their maritime past. Nevertheless, there is a relationship between the two in which particular biblical symbols have been appropriated as an unconscious or conscious act to maintain or revive a psychological and spiritual connection to their maritime culture and traditions.

This thesis, then, presents design research that explores how nautical symbolism and water-based pragmatism can influence and transform Western notions of knowledge or conventional notions of contemporary (terrestrial) architecture in New Zealand. This design aims to achieve this by evaluating, reinterpreting and employing nautical symbolism used in case study examples of Christian Maori architecture into contemporary design. This particularly focuses on notions of space and time that opens up architecture to a metaphysical dimension according to the psychic and symbolic territories known to the navigator. In doing so, this opens up contemporary architecture to its outside, loosening the architectural boundary and making spaces of exchange. Furthermore, the waka (boat) is used as an architectural symbol to celebrate waka traditions and its long association with Maori architecture. Ultimately, the design exploration revives the significance of nautical symbolism in a way that demonstrates the ongoing contribution that Maori architecture can have in a contemporary context while also providing a water-based architectural solution that echoes the indigenous seafaring lifestyle and environment unique to New Zealand. 
Chapter one sheds some light on the maritime history of Maori and their extraordinary ability to navigate the ocean. This describes the more spiritual aspects of the Maori seafarer in his deep-sea voyaging days, especially concerning the connection between cosmology and navigation. This provides some valuable insight into the hidden meanings behind celestial symbols identified in examples of Christian Maori architecture in the following chapters. This segment of research also looks at the amphibious life and architecture of Maori in the pre-contact era. This gives a brief description of the relationship between the waka and nautical symbols in early Maori architecture. This outlines only a few examples of an exhausting list of nautical symbols found in Maori architecture. Nevertheless, this research reveals the transition of navigation knowledge and cosmology applied to the new found land and their architecture.

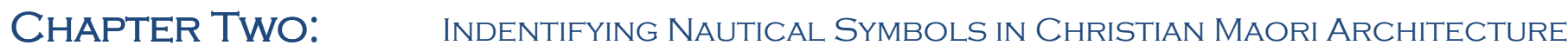

This chapter identifies and examines nautical symbolism in the religious architecture of three distinct, Maori religious movements. These include the Niu Pole of the Pai Marire religious Movement, selected examples of Ringatu Meeting houses and the Temepara and Manuao building complex of Ratana faith. This research particularly examines how Christianity influenced and changed the cosmological and symbolic universe of Maori. This is demonstrated through nautical symbols that were adapted and given new Christian Maori meanings. This reveals the appropriation of nautical Christian symbols that were reconstructed with new narratives and based on Maori cosmology or Maori nautical symbols that were given new Christian meanings. Either way, nautical symbolism was torn between two different cosmologies - a Christian European cosmology or a Maori cosmology. This research aims to unravel and expose Christian Maori symbols that appear to fundamentally have some symbolic link to navigation, seafaring or maritime traditions. This is particularly the case with most case study examples which appropriated celestial symbolism or Christian sky deities based on their mystical link to navigation. Due to the adaptation of nautical symbols as well as the appropriation of Christian symbols, this research also identifies a growing shift toward expressions of the land rather than the ocean and navigation in religious 
Maori architecture. Despite this shift to land (particularly symbolized in Ringatu meeting houses) this research reveals how Maori architecture is subliminally linked to seafaring through a nautical reflex which influences many themes of expression in Christian Maori symbolism. In doing so, this research examines three subsequent religious Maori movements, each revealing a process of evolution from the more obvious use of nautical symbolism toward the use of nautical symbols with more layered and discrete meanings. As a result, this distinguishes the symbolic language of a water-based culture that has transitioned to land and the influences upon it.

\section{Chapter ThreE: $\quad$ Christian MaOri Architecture: As Signal Rather than Sculpture ${ }^{1}$}

This Chapter explores the relationship between nautical symbolism in European Christian architecture and religious Maori architecture by comparing and contrasting case study examples from the previous chapter. Various examples of Christian Maori architecture across all three religious movements are used to demonstrate universal concepts in religious Maori architecture rather than being case specific. Therefore this research deters from the subject of religious iconography and objective aspects of nautical symbolism in favour of a more holistic research approach. This identifies the more powerful metaphysical symbols in Maori architecture and spirituality that collectively makes Christian Maori architecture uniquely different from European Christian architecture. In this case, the relationship between Christian and religious Maori architecture is discussed as mostly conflictive based on oppositions and contrasts that can be made. The basis for these oppositions (and comparisons) is examined through this research.

\footnotetext{
${ }^{1}$ This heading derives from the words of Mckay and Brown who note how in Ratana buildings, "image takes precedence over form and the architecture is more signal than sculptural”. (Mckay \& Brown, 'Buildings of the Morehu: Te Ao Hou' in M Linzey and R Jenner (eds), 1992, p. 129)In this title I use this quote to imply the major differences between Christian and Maori religious architecture: Christian Maori architecture is metaphysical as opposed to Christian architecture that is concerned with form or the 'sculptural'.
} 
This begins by introducing the fundamental differences between Maori and Christian Europeans in terms of a spiritual paradise. In this case, Christian architecture pertains to the ideals and technologies of a terrestrial scene (The Garden of Eden) as opposed to those of an oceanic, environment (Hawaiki). Based on this fact, this research investigates how pragmatic and poetic principles associated with seafaring, vessels and navigation have been used in their Christian Maori architecture. This research discusses how this has given Christian Maori architecture a distinct metaphysical aspect where the more immaterial and ephemeral meanings are privileged in their symbolic architecture. This forms a contrast with Christian European architecture which relies on form and space to communicate spiritual ideas.

The metaphysical or 'signal' rather than 'sculptural' aspects of Christian Maori architecture are investigated in terms of navigation theory applied to symbolism and architecture. This forms the basis of an investigation into the intimate relationship between Christian Maori buildings and their context in contrast with Christian churches that are typically disconnected with their surroundings. This leads into a discussion on the extraordinary senses developed by Maori navigators who applied this to the sensual qualities between space and place in order to create a temporal spatial dynamic in their religious architecture. Despite all these difference, this chapter ends by finding 'common water' between Christian and Maori religious architecture based on the use of the boat as an architectural symbol. This research then demonstrates how Christian and Maori architecture are linked to the boat both poetically and pragmatically.

\section{CHAPTER FOUR: RESEARCH + DESIGN}

This chapter implements ideas from research into a contemporary design project, whereby nautical symbolism is used in new and meaningful ways in the design of a school (wharekura) dedicated to the ancient Maori study of 'celestial' and 'terrestrial things'. Based on the situation where contemporary (terrestrial) building materials and technologies are used to create nautical Maori architecture, this design learns from Christian Maori case study buildings which adapted and appropriated terrestrial symbols and values of Western Christian church buildings to meet their own needs. Similarly, this design adapts and exploits contemporary (terrestrial) materials and technology using water-based pragmatism and nautical 
symbolism to meet the needs of the building programme and charge the wharekura with symbolic meaning. In doing so, this design aims to create a culturally significant building that revives the inviolable architectural tradition of which nautical symbolism is the 'generator and the essence'. ${ }^{2}$ Ultimately, this demonstrates an architecture that responds to the indigenous seafaring lifestyle and environment unique to New Zealand rather than the timeless, object-orientated ideals pre-dominantly found in terrestrial (Western) contemporary architecture in New Zealand.

The design process begins by analyzing the site in terms of its existing natural and built features as well as the historic significance of the site. This leads into various design implications which discuss the siting of the wharekura in terms of navigation tactics. Overall, a strong axis is created through the building which provides connectivity between the existing built features and divides the building into symbolic areas associated with the compass. Following a site analysis is a description of the building programme and plan. This describes the function of the building and outlines aspects of the plan according to a contemporary translation of the ancient school of learning, the wharekura. The final design is then examined with a written interpretation and evaluation, discussing specific ideas implemented from research.

Finally, this thesis ends with a comprehensive discussion and conclusion that brings together chapters two, three and four. This outlines the main relationships that were discovered between nautical symbolism in Christian and Maori religious architecture which led to strong themes carried out in design. The design discussions and conclusion bring these discoveries into a contemporary project which discusses the importance of learning from nautically inspired architecture to create more meaningful and interesting architecture. In this respect, the design conclusion discusses how Western notions of architecture in New Zealand can be challenged in order to create architecture that adds more metaphysical and scientific concepts in architecture. This leads into how the design problem was met, whereby the metaphysical and pragmatic dimensions in architecture were pushed to create architecture that responds better to maritime New Zealand.

${ }^{2}$ Lewcock and Brans note how communities "do not build 'symbols', they build houses according to an inviolable tradition of which symbolism is the generator and the essence”. (Lewcock \& Brans, 1975, p. 116) 
THE MAORI: FROM DEEP-SEA NAVIGATOR TO LIFE ON LAND. 
THE MAORI: FROM DEEP-SEA NAVIGATOR TO LIFE ON LAND.

This research investigates nautical symbolism in Christian Maori architecture. The definition of nautical according to the oxford dictionary is "having to do with sailors or navigation," also termed as "maritime"(Soanes, 2001). Therefore this chapter aims to give a brief introduction into the nautical background of Maori in his glorious days as a deep sea navigator as well as the early maritime culture in pre-contact New Zealand. This research particularly examines the close connection between navigation and cosmology which continues to be found in various examples of Christian Maori architecture. This chapter also describes the historic significance of the waka taua (war canoes) in Maori culture and society and how strong waka traditions have affected traditional Maori architecture. 
THE MAORI AS A DEEP-SEA EXPLORER AND NAVIGATOR

If there is any culture that fully embraces a nautical tradition, Maori certainly did. Historically, the world of Maori was defined by the sea. This oceanic context has led to long generations of seafarers who fearlessly explored the ocean, developing great navigational skills and a spirit to traverse far and wide. Elsdon Best, a well known scholar in Maori studies describes the extent of this nautical expertise in the following passage:

"Maori traversed the vast expanse of the Pacific as western peoples explored a lake",.. "he was probably the most fearless Neolithic navigator the world has seen.” (Best, 1923, p. 6)

This was largely due to the impressive navigation knowledge which involved a combined practice of astrology and considerable astronomy. Travellers and fishermen would consult and contemplate the stars with a well practiced eye. Rising and setting points of the brightest and most distinctive stars and planets were assessed with sophisticated star compasses, ${ }^{3}$ (fig a \& b) and then memorised. These were anchored in the memory of Maori through strong oral tradition where imaginative mythological stories personified the stars and planets. (See Appendix A)

\footnotetext{
${ }^{3}$ At day Navigation was gauged by celestial objects such as the rising and setting points of the sun. Navigators also knew that the arcs of the sun and other stars cross the sky at different heights depending on the time of year. A star compass was then marked out on the railings of a canoe depicting a $360^{\circ}$ horizon divided up into different sectors named whare (houses). See image
} 

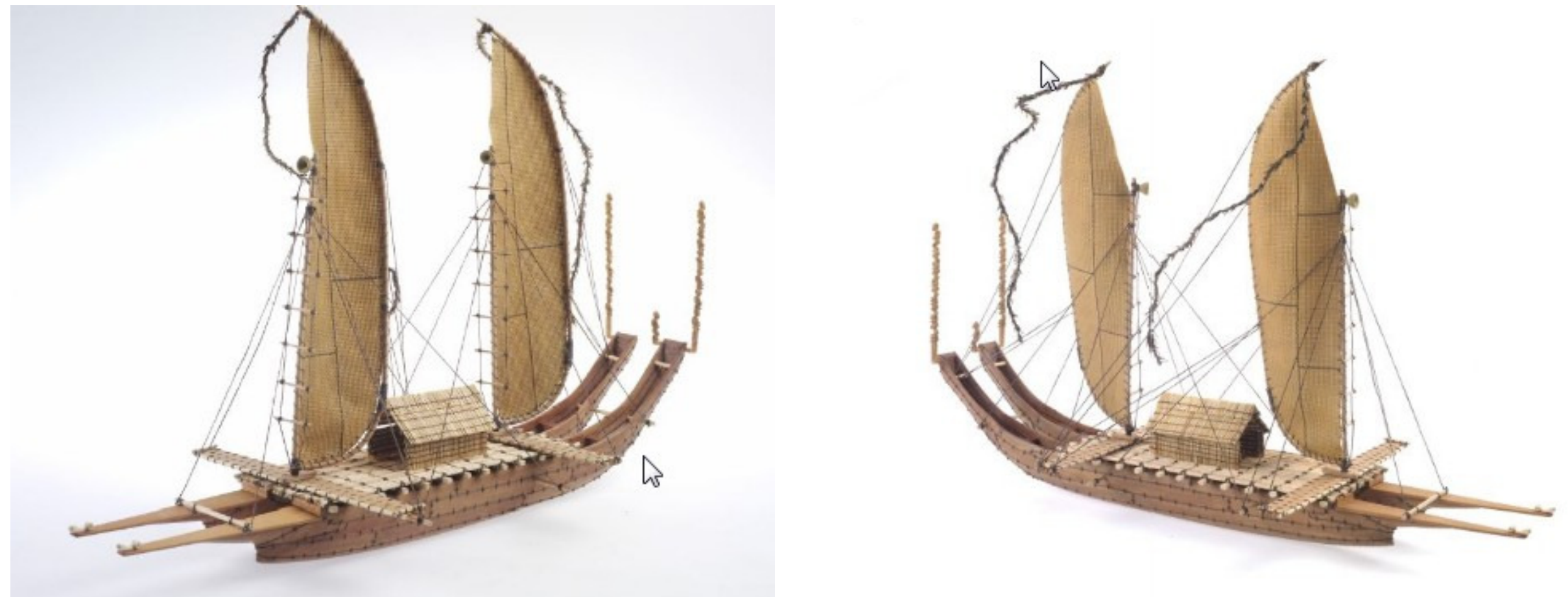

Figure 1a \& b: This is a model of an eighteenth century tipaerua - a double-hulled sailing vaka (canoe) from Tahiti in the Society Islands. It is possible that many of the great voyages to Hawai'i and New Zealand were made in vessels similar to tipaerua. Their low prows and upturned sterns are a feature typical of many large Maori waka (canoes) to this day. 
Such mythological stories also endowed the seafarer with confidence, whereby immortal gleaming stars were seen as gods that assisted the voyage. Maori believed, that if nothing was done to alienate the gods, then a vessel placed under their care could not possibly come to harm (Best, 1923, p. 52). This brought the practice of priestly experts which sanctified vessels, involving customary rituals and performances to ensure the satisfaction and allegiance of the 'Heavenly Bodies' and mythological beings that arise out at sea (See Karakia Appendix A). Natural phenomena such as rainbows, comets and meteors were regarded as aria, as well as more material forms such as lizards, birds and fish. Maori came to personify these as Gods and integrate them into a cosmological framework. For instance it was well known among Maori seafarers that Kahukura (personified form of the rainbow) was a famed guide of the Takitumu waka from Hawaiki to New Zealand:

"He stood in the heavens before the prow of the vessel as a guide during the day. At night he retired to the stern thwart of the vessel, and his sister, Hinekorako (a pale luminous arch in the heavens), went to the front as a guide." (Best, 1923, p. 59)

This legend and many others show how navigational symbols are associated with cosmology. To Maori, the law of science was based on an understanding of the actions and attributes of their Gods. It should be recognized then, that the eventual use of nautical symbols in Christian Maori architecture is inevitable. This is particularly the case with navigational symbolism - a sign of guidance, offering hope to the intrepid Maori seafarer. 

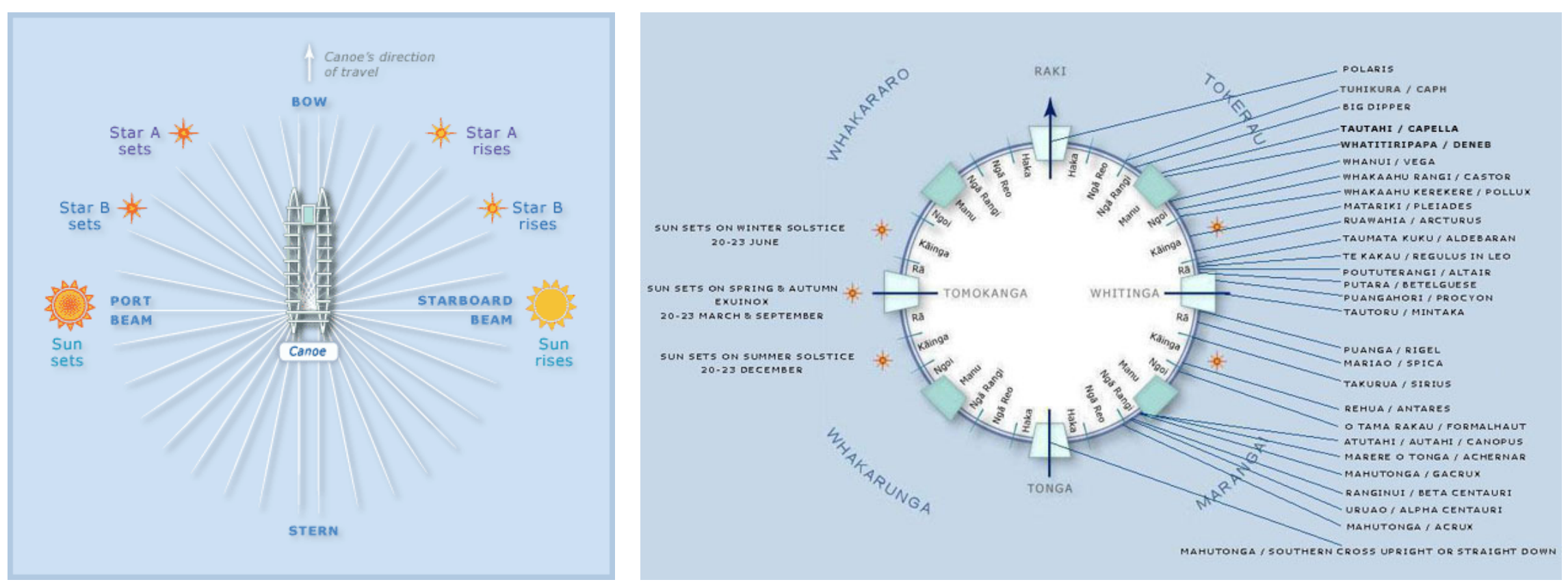

Figure 2a \& b: Showing the star compass used by Maori for deep-sea navigation 


\section{MARITIME CUlture in PRE-CONTACT NeW ZEALAND}

So far I have introduced the Maori as a skilful and imaginative sea rover. However, it is also important to shed some light on Maori life on land. This can be understood as an amphibious lifestyle, the canoe being a necessity for travel between settlements that were typically located near oceans lakes and rivers (see fig 6). Therefore the canoe (waka) retained its importance on land, allowing for expeditions across lakes, up and down rivers and along coastlines. With the loss of deepsea voyaging, boat building efforts were invested in the Maori war canoe, or waka taua. The waka taua reached its highest peak of craftsmanship in the use of decoration before its significance eroded in the face of colonialism (Hiroa, 1950, p. 204). In pre-European times, the war canoe was viewed as the main symbol of tribal identity, unity and pride. It was an expression of the Gods in material form. His work was therefore charged with mana (spiritual power) and the act of carving itself was tapu (sacred). This was because it was an art acquired from none other than Tangaroa, the mighty god of the sea. ${ }^{4}$ This is the mythological source for the intricate arts of Maori carving - clearly an oceanic inspired art, evident in the fluid formwork and depiction of amphibious creatures

206 With the loss of deep-sea voyaging, the whare (house) also became increasingly important in Maori settlements. Ultimately, water and boats continued to influence the oceanic architecture in many ways, from structure to construction, to detail to ornament, making it somewhat amphibious. Architectural theorist, Mike Austin states: "In the pacific, sails become floor mats (and vice versa), old boats are used as storage structures, and both buildings and boats are held together by a technology of weaving and tying" (Austin, 2004, p. 226). Furthermore, their buildings portrayed nautical themes relating to cosmology, myth, history and navigational knowledge. . One interesting example of nautical symbolism is found in the design of tukutuku wall panels found in the prehistoric Maori house. The elaborate weaving found on these wall panels are said to derive from star charts carried by ancient navigators (Hagger, 2003).

\footnotetext{
${ }^{4}$ This is demonstrated in the link between Tangaroa's underwater house which is said to have influenced the art form and themes of whakairo rakau,(carved house) especially among Northland Maori. Legend tells that the art of wood carving came from Tangaroa the sea god explained through the legend of the koha of Ruatepupuke
} 

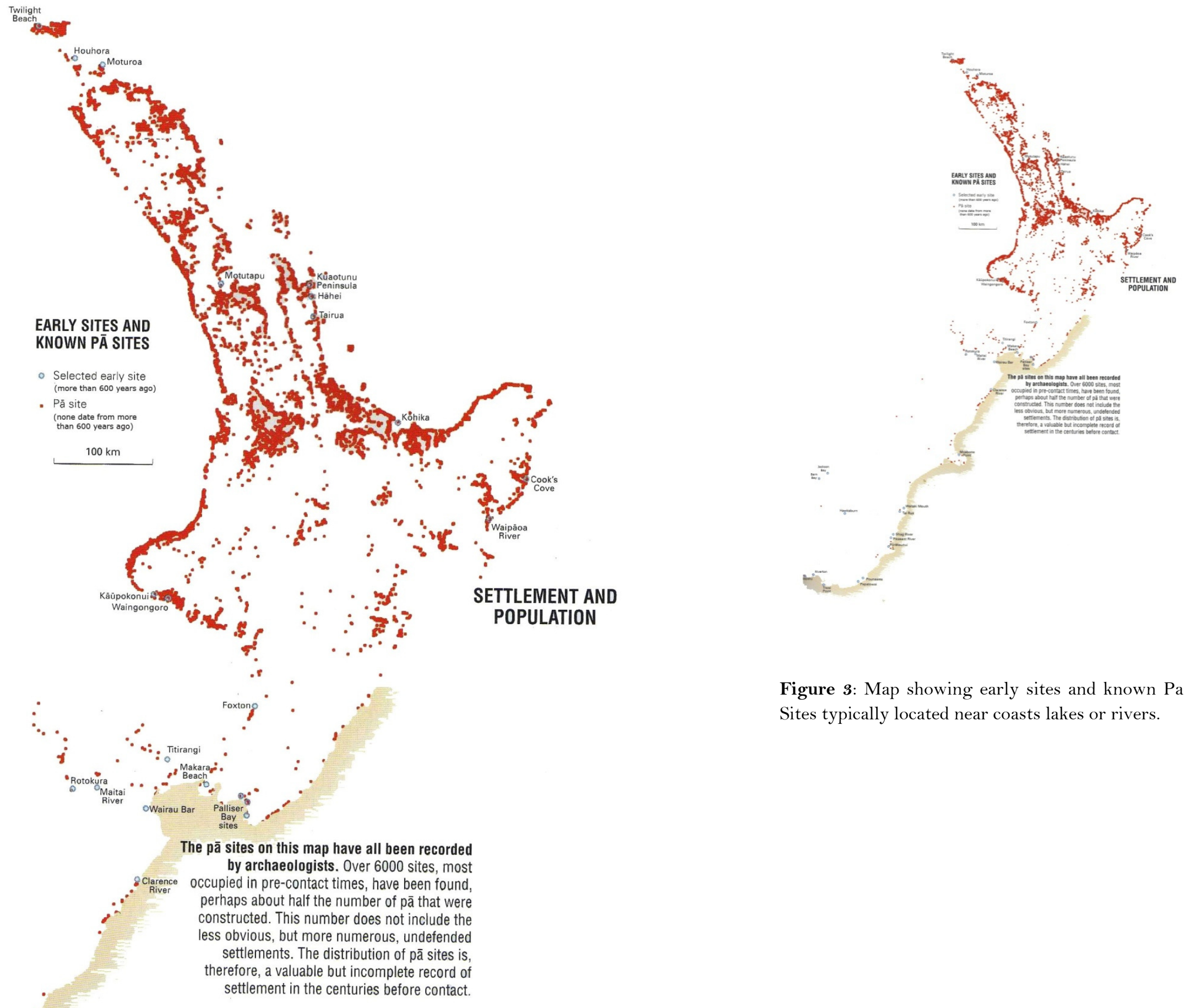

Figure 3: Map showing early sites and known $\mathrm{Pa}$ Sites typically located near coasts lakes or rivers. 
Nautical symbolism in pre-contact Maori architecture was also influenced by the decorative arts associated with the canoe. One such example is the decorative kowhaiwhai on the front of pataka (fig 7) and much later, in the meeting house. It is said that the kowhaiwhai pattern originally came from canoe paddles and the underside of war canoes (Auckland museum, 1998). These were symbolic of chiefly authority and genealogical mana, therefore its transition to important buildings was a logical step.

These are some of many examples where nautical symbolism can be found in Pre-European Maori architecture. As we will find, nautical symbolism continues to appear in religious Maori architecture particularly due to the inextricable link between cosmology and navigation. Furthermore a strong seafaring tradition and an amphibious lifestyle have intellectually conditioned Maori for centuries, creating what is now part of their "collective unconscious"5 (Jung). As this research goes on to prove, this nautical reflex influences the way Maori co-ordinate the built environment and express their religious beliefs through architectural symbols.

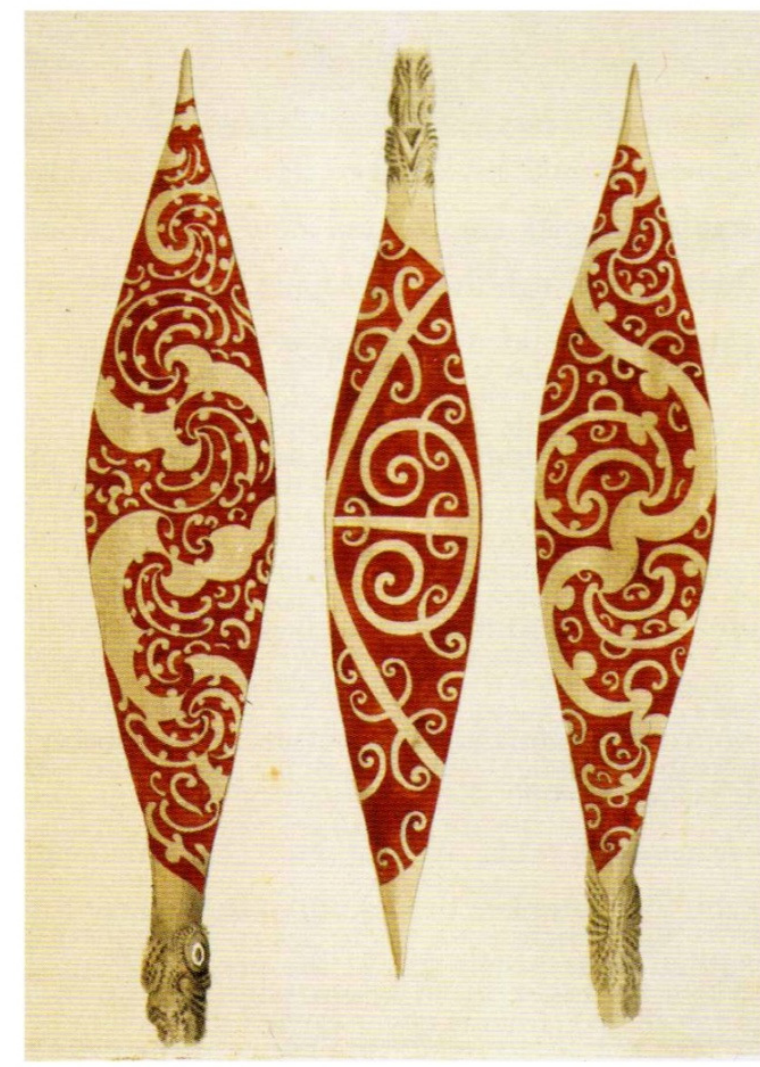

Figure 4: Three kowhaiwhai painted by Sydney Parkinson in 1769

\footnotetext{
${ }^{5}$ Collective unconscious - instinctive thought and behaviour that millennia of human experience have shaped into what we now recognize as emotions and values. (Jung, 1968)
} 


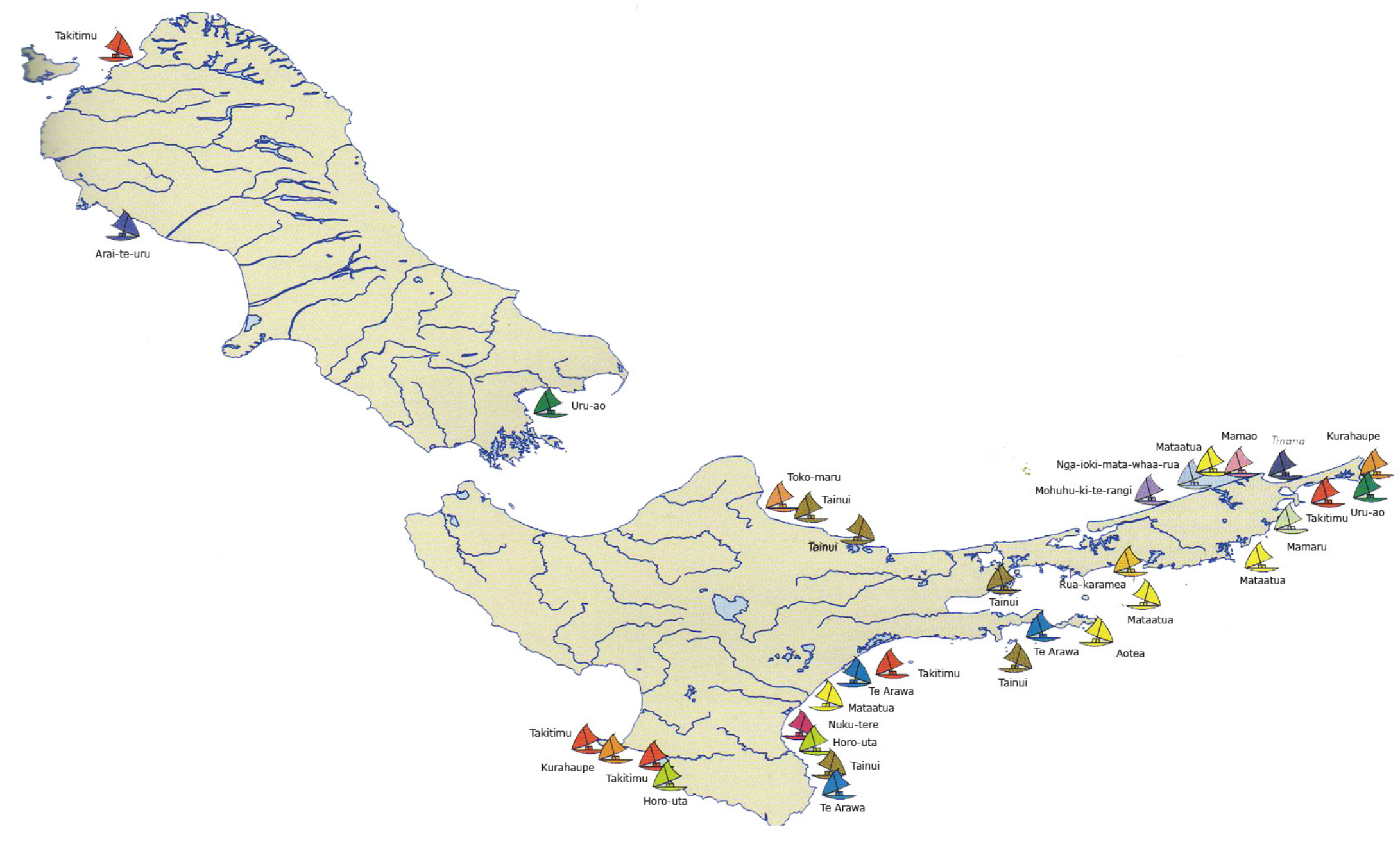




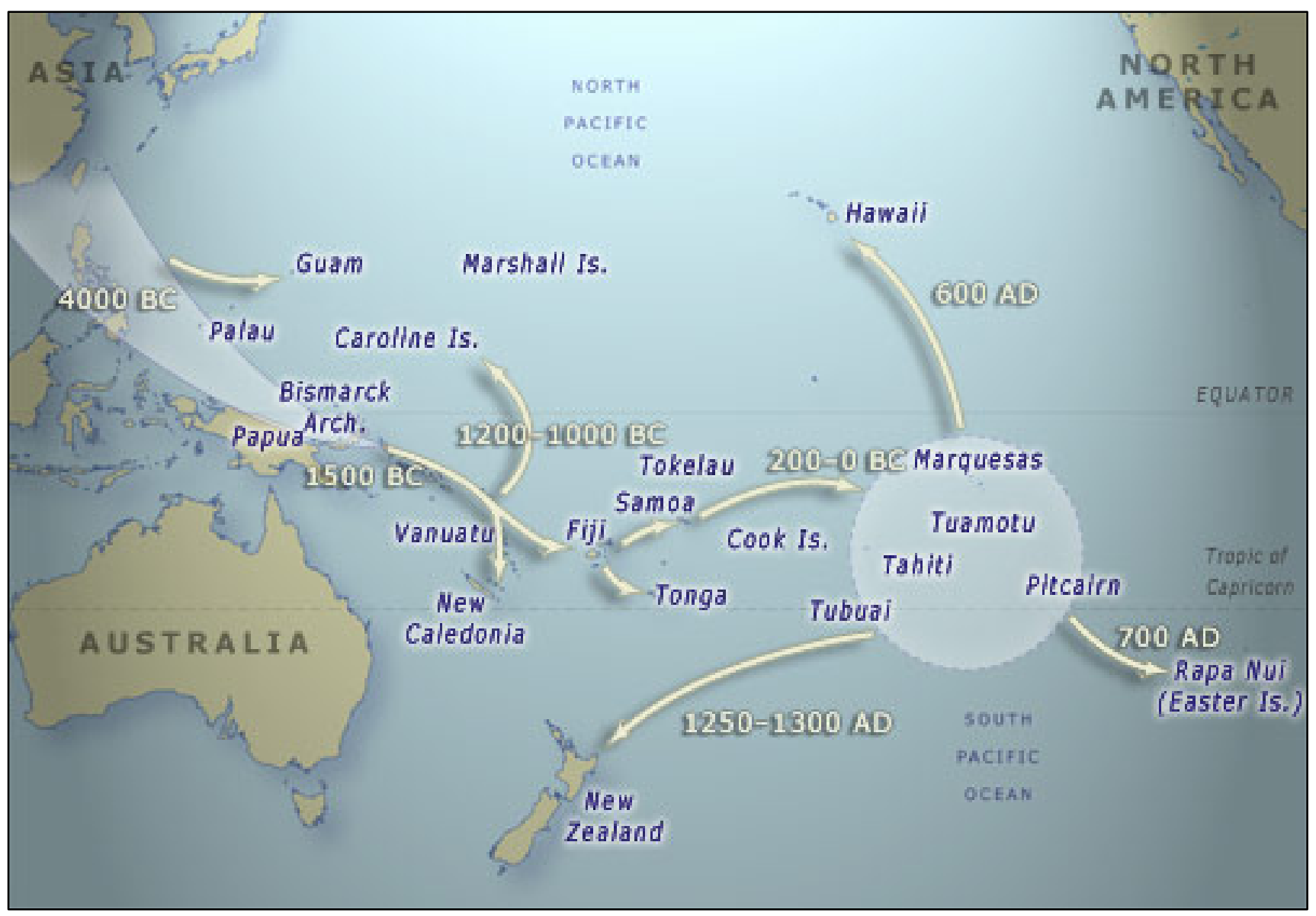

Figure 6: Map of Pacific Migrations showing dates of the first people to reach New Zealand. These were Polynesians who set out from the central Pacific on deliberate voyages of discovery in large canoes. 


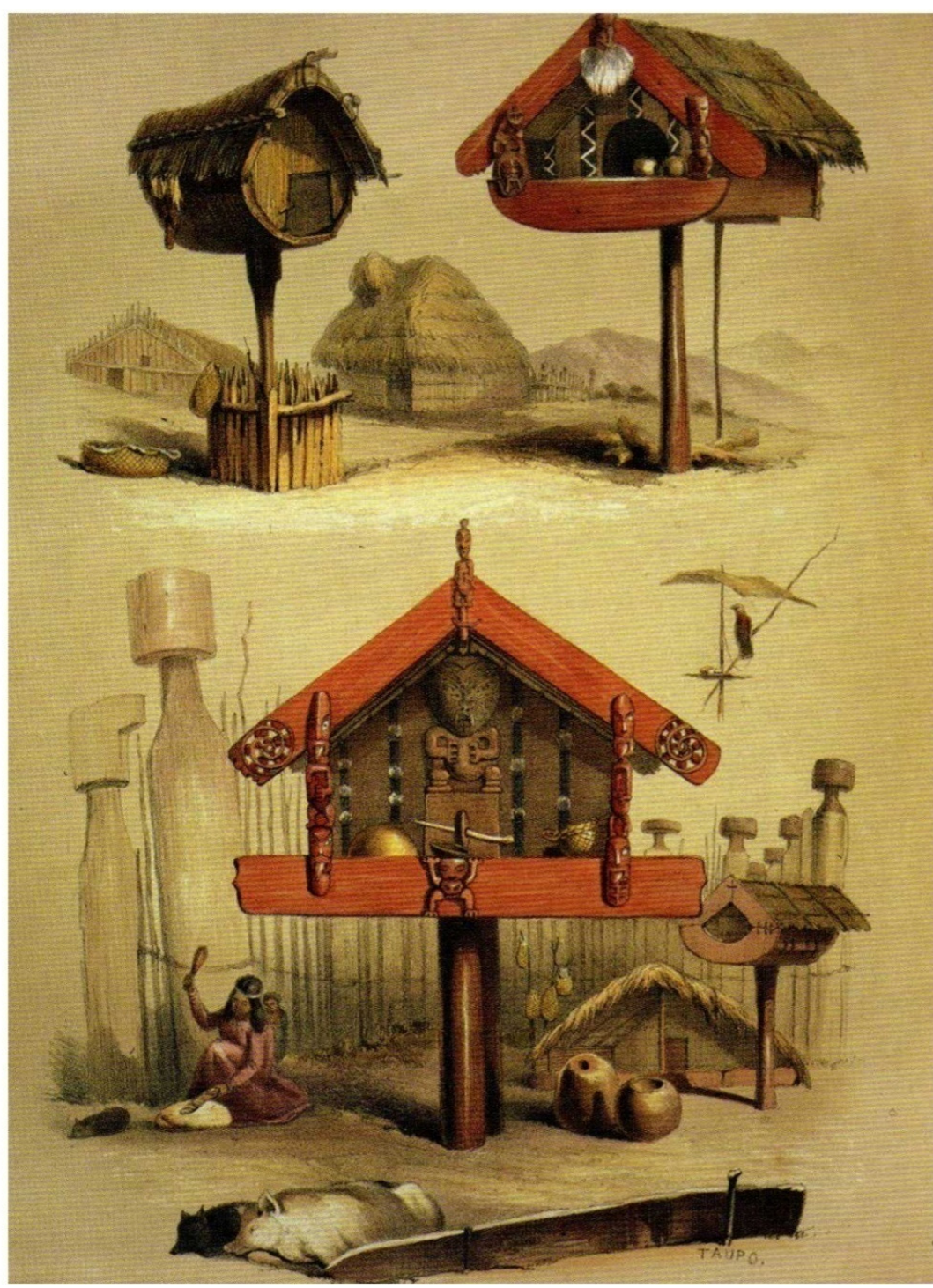

Figure 4: Storage structures from around lake Taupo in 1844. Painted by George French Angas.

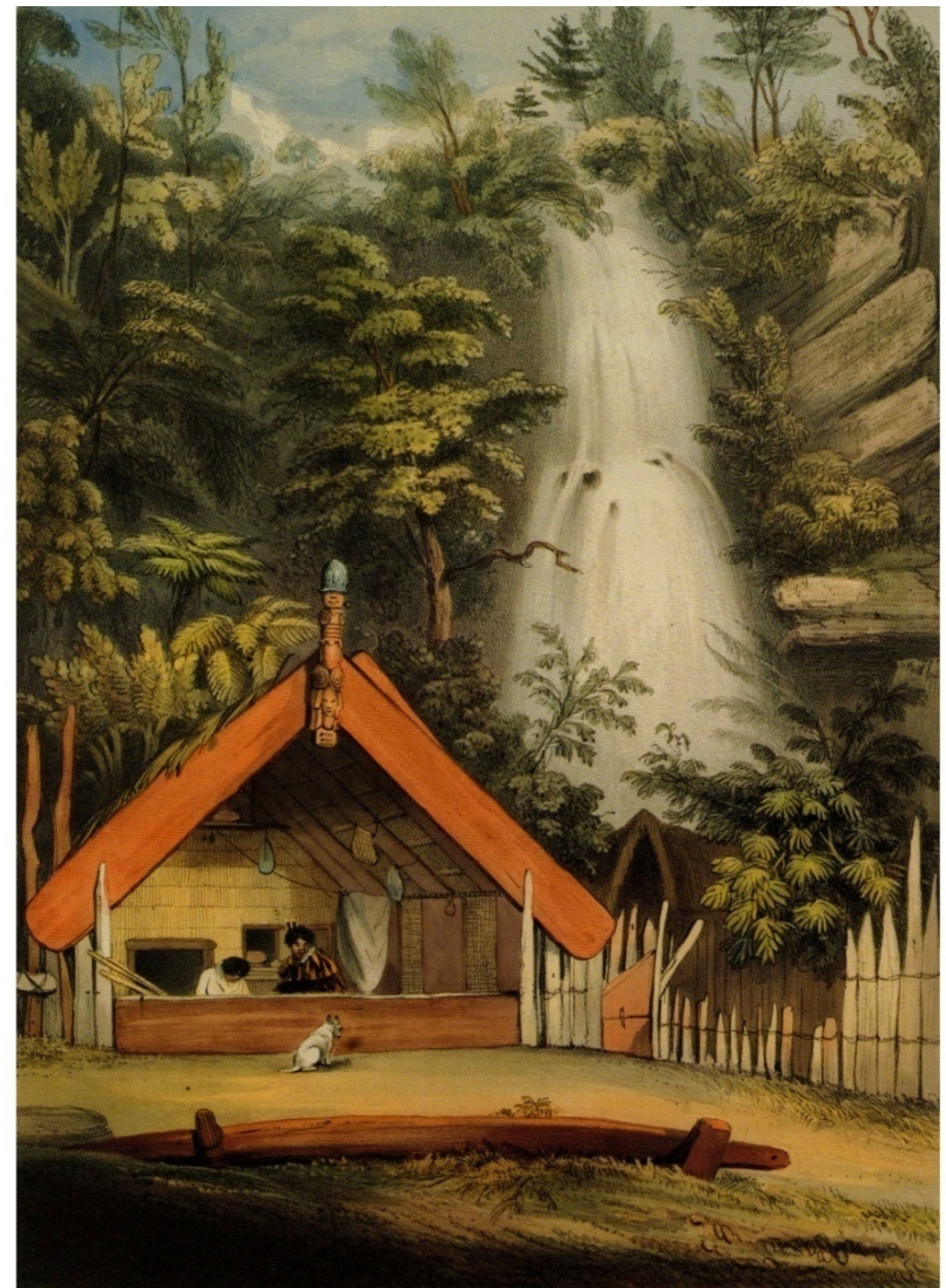

Figure 3: Iwikau Te Heuheu's house, illustrated by George French Angus in 1844. This is an example of a chiefly whare puni. 


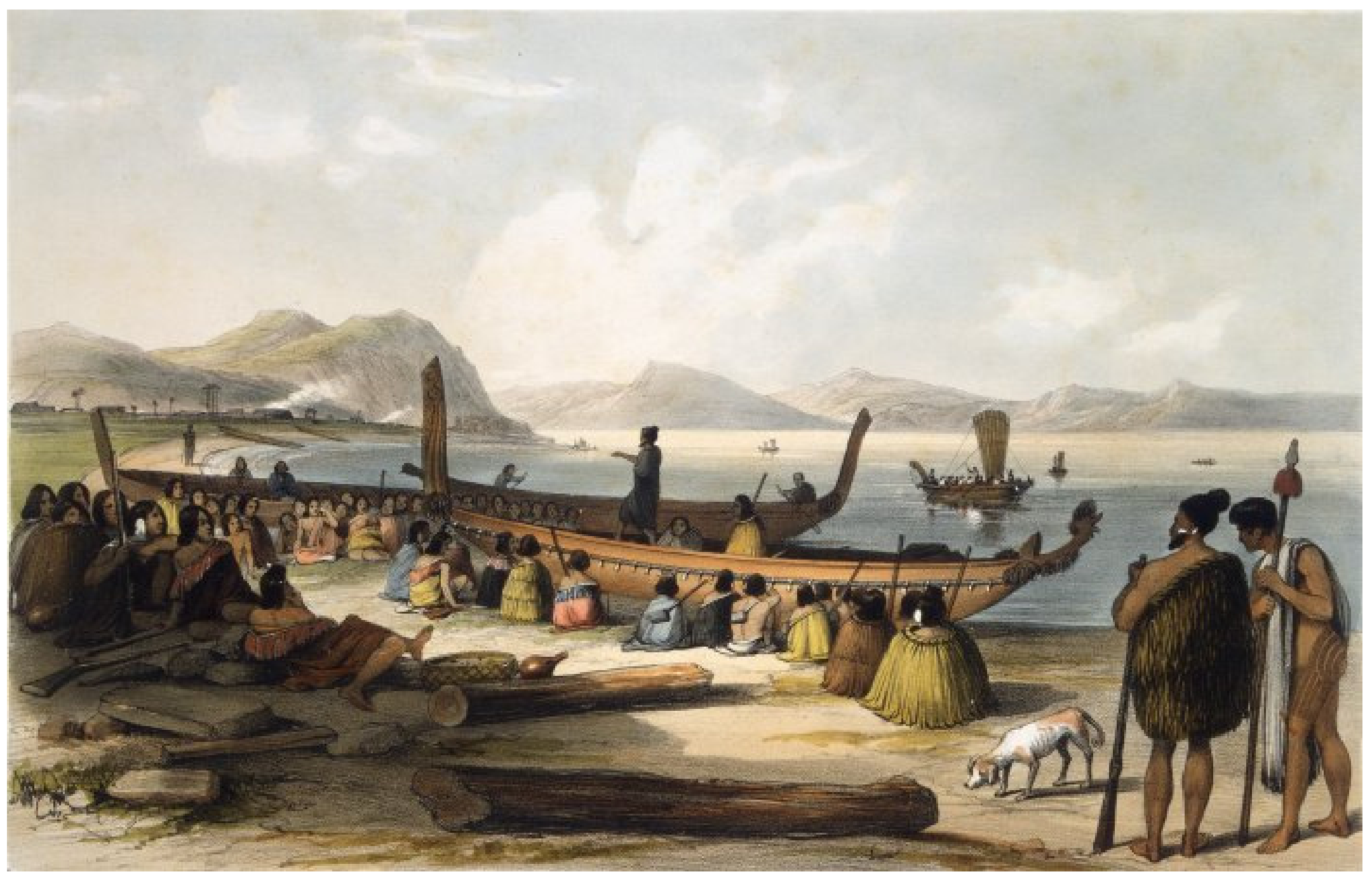

Figure 9: 'War Speech', by Augustus Earle, depicting typical Waka taua (war canoes) found between 1827-8 
CHAPTER TWO:
NAUTICAL SYMBOLISM IN CHRISTIAN MAORI ARCHITECTURE

NAUTICAL SYMBOLISM IN CHRISTIAN MAORI ARCHITECTURE

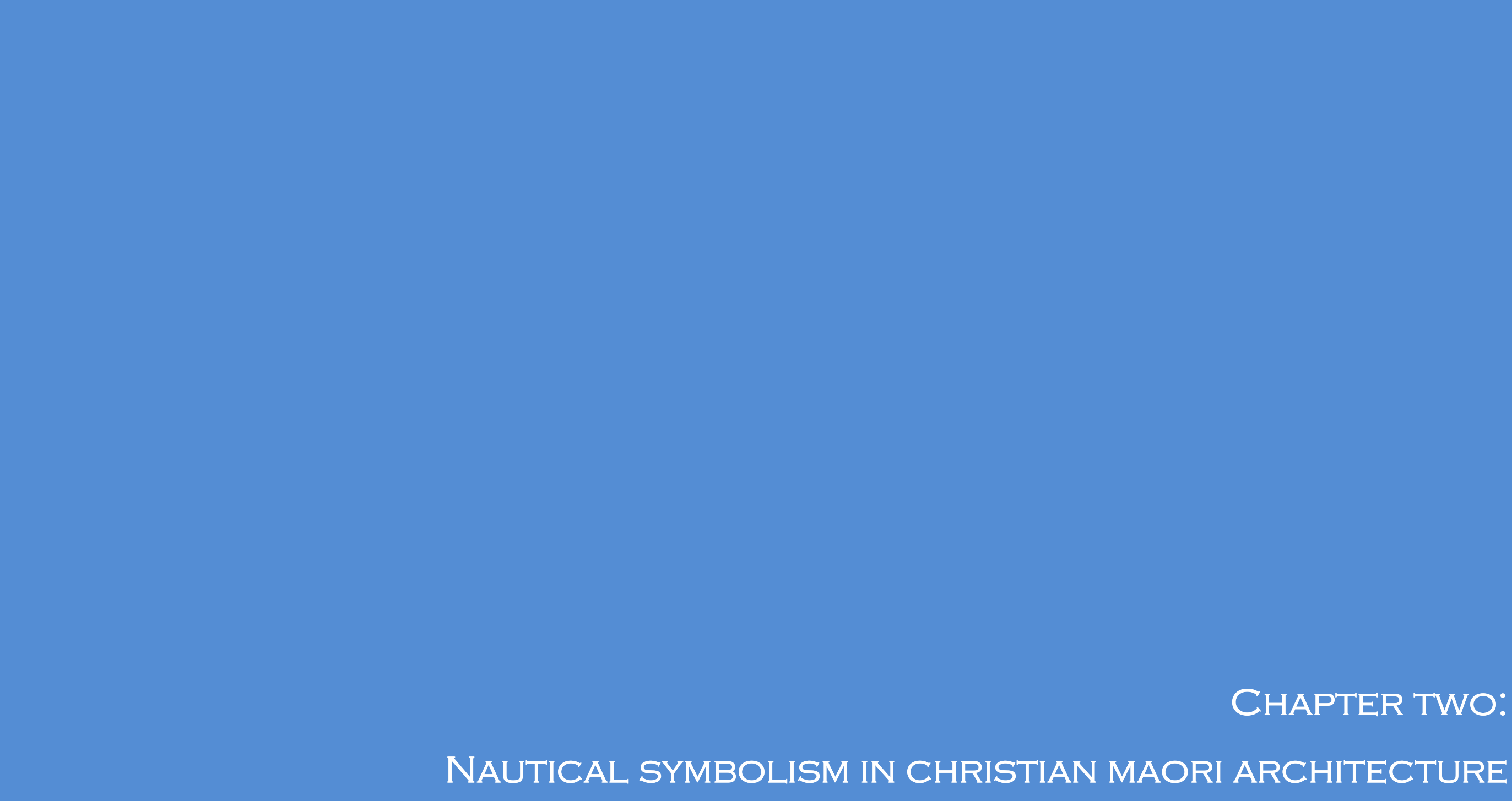




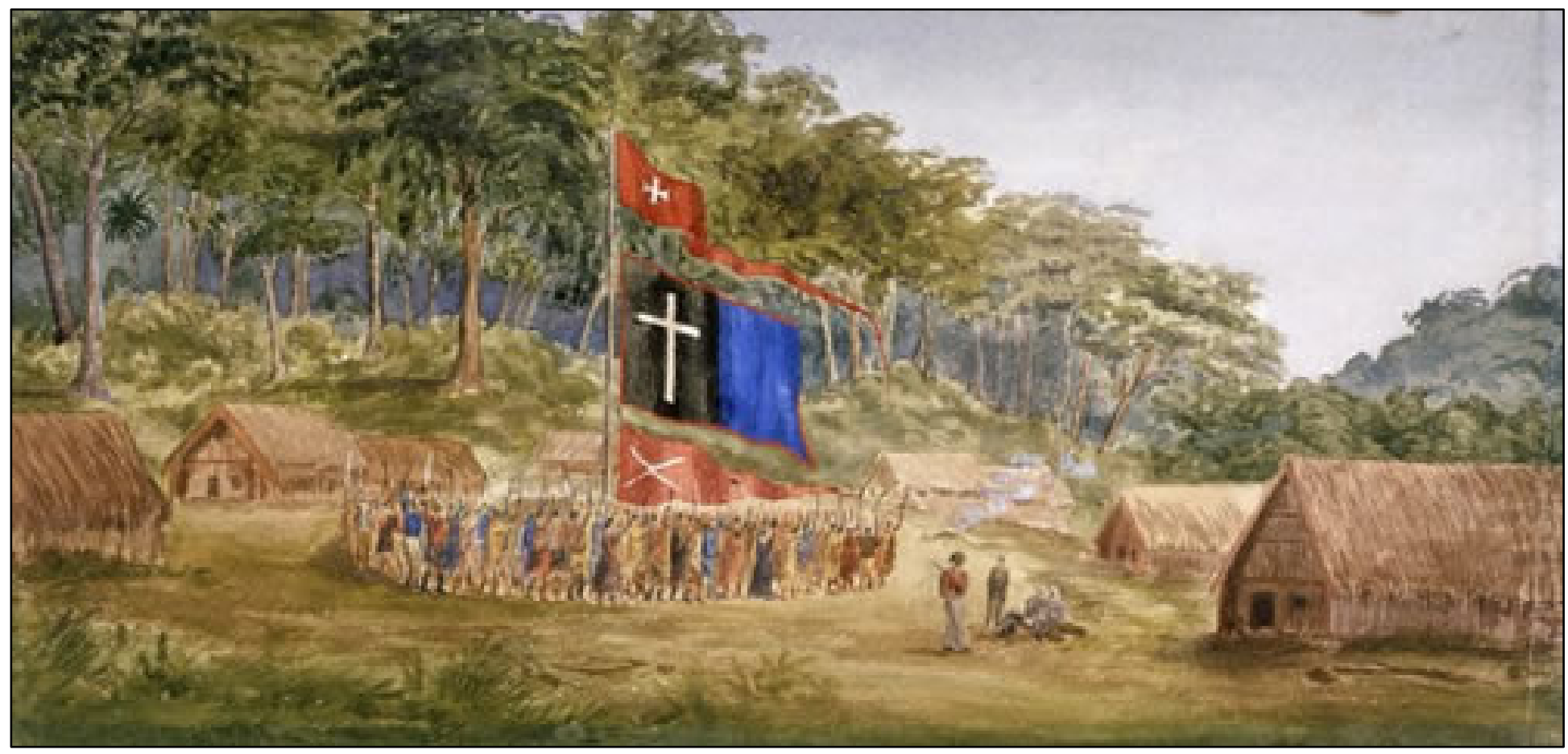

Figure 2.1: Watercolour by Lieutenant Herbert Meade (1842-1868) depicting Pai Marire ceremony around niu pole at Tataroa in 1865. 
INTRODUCTION

The Pai Marire (Good and peaceful) religion was one of the first religions based on Maori understanding of the bible and pre-contact Maori spirituality (Brown, 1998). Founded by Te Ua Haumene in 1862, niu poles became a common sight in Maori villages where at least 50 are known to have been built in the North Island during the New Zealand Wars. Its predominance owes to its simple ship-mast form which meant it could be quickly erected during times of conflict.

This segment of research investigates nautical symbolism associated with the niu pole by beginning with an investigation into its iconic ship-mast form. This research examines how this form was an appropriation of the European ship-mast which Maori associated with Europeans, technology and their Christian God. This is followed by an investigation into the niu pole which was also conceived as a spiritual compass. Here, the crossed yardarms of the niu pole are compared to a spiritual compass. This research examines how these relate to spiritual aspects of navigation used by Maori and in some respect, their interpretation of European navigation methods. 
Interestingly, the ship wreck of Lord Worsley in 1862 marked the beginning of this movement where the first niu was indeed the mast of this very ship (Babbage, 1937, p. 29). The ship had sunk off the coast near Te Namu, crossing the sacred boundary, aukati. During this time, the Angel Gabriel appeared to Te Ua (founder of Pai Marire) and told him to 'Go, back to your house and erect a niu,' which would there on acquire the "languages of all the races upon the earth." (Babbage, 1937, p. 29)Te Ua chose the mast of lord Worsley as his first niu pole, a model from which all niu would follow. Lord Worsely was not the last time a ship mast was used to construct niu. Another such example was the Kuranui nui in the Kaimai ranges which is said to be constructed from the yards, stays, tackle and mast of Mary Jane. This vessel sank in 1865 at Whangamata while it was leased to three Maori men (Brown, 1997, p. 263). According to elders, these men were emotionally attached to 'Mere Heni' as they called her, writing a lament about their love for the sailing craft. Therefore the niu pole was a symbol of respect to this valued ship, as well as a representation of Pai Marire faith. Their attachment to the ship is understandable considering the war canoe has traditionally been given the utmost respect on many levels. (Refer chapter one)

Given the canoe was traditionally the centre of Maori material culture, Maori were impressed by European sea craft, aspiring to own or lease them for trading purposes or for mere prestige (Neich, 1993). Therefore it is likely that Te Ua, impressed and fascinated with the elaborate sail rigging in European boats, applied the ship mast and developed it into the niu pole. This appropriation was more than materialistic. It was a way of obtaining technological and material status to regain the supremacy of the Maori race. In the Maori mind, this was also a way of expressing mana. ${ }^{6}$ This gave Maori a sense of power by taking a symbol of British dominance and using it against them. This echoed the power struggle and frustration felt by Maori at this time. Not only was their symbolic universe under scrutiny by Christian teachings, the loss of land to Europeans was displacing their sacred relationship to Papatuanuku, the earth mother. Hence the niu pole was

${ }^{6}$ mana is a supernatural force in a person, place or object. Mana goes hand in hand with tapu, one affecting the other. The more prestigious the event, person or object, the more it is surrounded by tapu and mana. (Moorfield, 2003) 
employed as a supernatural weapon of power and knowledge. By incorporating symbolism from Christianity, British dominance (technology) and Maori spirituality, the Maori felt empowered, obtaining a knowledge that superseded what the Pakeha had taught. As one disciple of Pai Marire explained, "We received our Christianity from you formerly, and now we give it back again, having found some better way, by which we may be able to keep possession of our country" (Rosenfeld, 1999, p. 179).

In Polynesian society, voyaging was equally a physical and spiritual experience. Similar to the waka, European vessels were deemed to hold the same spiritual reverence. However, Maori did not know which of their own myths to connect them too. It seems that the niu pole was an attempt at understanding European cosmology and its association with the boat. This connection may have been made through the visual likeness of the Christian cross and the ship-mast. This could have influenced the decision to create a sacred space inside the niu fence and regard it with similar veneration as the Christian cross at the altar (Brown, 1998, p. 1). Whatever the case, the Niu pole uses the axis mundi ${ }^{7}$ as an expression of connecting and communicating with the spiritual world. For Maori, this traditionally applies to the legend of Tane, whose 'toko' or 'poles' separate Heaven and earth. For Europeans, this was the Christian cross.

Another reason for obtaining the ship mast was based on the ritualistic behaviour and supernatural beliefs in makutu (Maori witchcraft). This was a popular belief among Maori whereby the possession of something from an enemy was at the mercy of the tohunga's malicious powers. By obtaining enemy possessions and pronouncing powerful karakia and curses over it, the enemy's hau - his life-essence, his vital source - lied in the hollow of the tohunga's hand (Cowan, 1911, p. 328). In this case, the ship-mast was a way of obtaining the powers of a new God, and even power over European ships and thereby possibly the Europeans. This was certainly the case for worshippers at Opitiki who thought they had driven

\footnotetext{
${ }^{7}$ The axis mundi in religion or mythology is the world centre and/or the connection between heaven and Earth. (Wikimedia
} Foundation, Inc, 2011) 
a departing boat called eclipse back to its shore of departure (Brown, 1997, p. 271). This reveals how Maori place great importance on material objects to mediate and interact with their Gods. Therefore the ship-mast was understood as an object with its own spiritual energy (or hau) that could be used to the benefit of Pai Marire adherents.

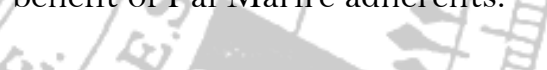

Whatever the reason for appropriating the ship-mast, each is equally valid. More or less, each interpretation of the ship-mast reflects a complex Maori understanding of the bible and an attempt to express this through architecture. Fundamentally, the niu pole was an architectural device that allowed Maori to communicate with a new God that seemed to arrive by ship. allowed Maori to communicate with a new God that seemed to arrive by ship. Hence the ship mast form was used as a medium for connecting the human and divine realms. This was not a foreign concept to Maori who had previously associated their own waka with similar spiritual veneration. Most importantly, the ship-mast gave Maori a sense of empowerment in a time when their cosmological world was threatened by Christianity and the loss of land. Through the appropriation of the ship-mast, Maori could invoke the powers of the Christian God and utilize these based on Maori ritual and religion.

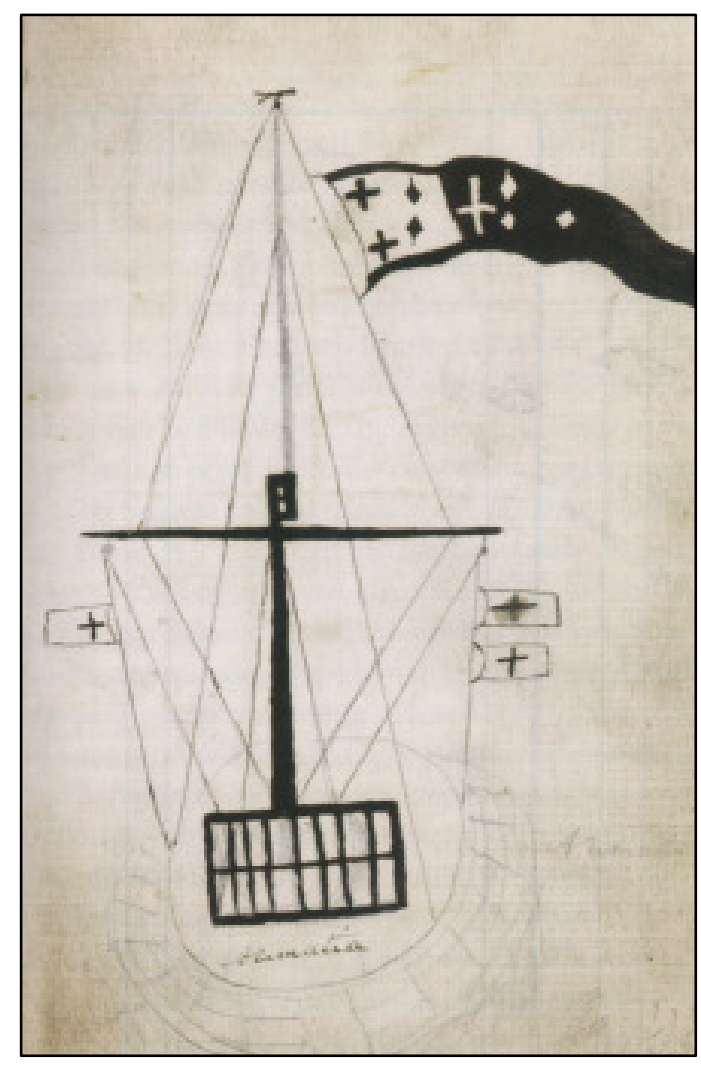

Figure 2.3: Drawing of niu pole from notebook of Te $\mathrm{Ua}$

Haumene, c. 1863

The Niu Pole as a SPIRITUAl Compass 
Another fascinating interpretation of the ship mast form was the symbolic use of the directional yardarms as a spiritual compass. These yardarms correspond to the four cardinal directions - the relative positions of Riki and Ruru showing whether or not a meeting would be peaceful (McLintock, 1966). Deidre Brown (1997) suggests that the crossed arms of niu at Arimatia, Maraekowhai and Tataroa were designed with points of the compass in mind. Each of these refer to the four hau (winds) associated with the four 'toko' or 'poles' supporting Ranginui (the sky father) (Brown, 1997, p. 54). Te Ua believed that the four winds were angels sent by Jehovah where people assembled around Niu could "receive news by wind" (Paul, 1975, p. 90). A typical niu ritual would involve speaking in hau; ${ }^{8}$ a powerful mix of musical chanting consisting of nautical, military and biblical origin (McLintock, 1966).

In respect to the nautical origins of these chants, Cowan notes that Te Ua "boxed the compass like any Pakeha sailor"9 (Cowan, 1956, p. 10). This reveals how Maori were fascinated with maritime technology and practices. Here they discovered a foreign concept of navigation that was unlike anything they had ever known. Naturally, the Maori people tried to project spiritual connotations to European technologies in order to grasp their validity. Similar to their own cosmological world, European Gods were understood as a multiplicity of Gods that enabled Europeans to use superior technologies. This was certainly the case with the compass on Europeans boats. A compass was considered “the White man's god, who directs them safely to different countries, and then can guide them home again” (Earle \& McCormick, 1966, p. 196) .

With regard to the niu pole, Te Ua understood this to be compass that was controlled by wind Gods. He supported this idea through Christianity in the first chapter of John and the First Epistle of John. Here it describes how wind, breath and spirit express the creative power of God the Father and God of the Son (Rosenfeld, 1999, p. 151). This led to a new set

${ }^{8}$ The term "Hauhau", which Pai Marire became known as, corresponds to the exclamation "Hau!" at the end of a chorus like the Christian use of "amen". This literally means "wind" but it's more esoteric meaning applies to the life principle of man, the vital spark. (Paul, 1975, p. 93).

9 "Boxing the Compass" was a basic skill of any sailor, being the ability to repeat all 32 points of the compass (in 1/4 points). 
of compass directions based on Maori Gods and Christian deities. Te Ua personified the cardinal winds after Christian Angels Michael and Gabriel as well as hauhau gods, Riki and Ruru. When the crossed yard arms of the niu moved in one direction, the wind was thought to summon any one of these Christian - Maori Gods. Thus the spiritual compass revived old customs and proclaimed new laws based on the superior authority of celestial gods. This gave Maori a sense power by restoring the people's access to celestial sources of power and knowledge through architecture and ritual. This also allowed Pai Marire to believe they had obtained the powers of the Pakeha Gods who controlled the compass on European boats. In some cases Pai Marire followers believed that Rura had the power to push away all European ships. (Appendix to the Journals of the House of Representatives, 1864, p. 13). In this sense, Maori thought they could control the wind Gods that guided these massive European ships. Ultimately, Maori were placing the same spiritual concepts to European boats and their navigation methods as they did their own.

In Maori seafaring and religion, the wind children (descendents of Tawhirimatea, God of weather) are said to denote various points of the compass. The names given to each wind direction are subject to tribal variations. Figure four is based on the wind names or 'hau' as prescribed by the Ngati-Porou tribe. The wind names do not purely target points of direction; they also personify the wind with an intrinsic, humanistic, quality. Around the niu pole, the Christian Angels, Michael and Gabrielle are adopted into the Maori wind family and referred to in the east and west compass directions. These winds controlled the direction of the yardarms, a spiritual compass, which informs the nature of the ritual around the niu.

Considering the niu pole was usually erected in the marae space in front of the meeting house, a metaphorical connection can be made between the niu pole, as the waka, in the ocean, sailing in the wind. This metaphorical relationship is supported by the etymological connection with marae: a space associated with both sea and wind. Elsdon Best notes that 
the plaza of the Wind Children is known as Marae-nui and the marae of Hine Moana, the Ocean Maid, is the vast expanse of the ocean (Best, 1921, p. 7). Therefore it seems that the niu pole mimics a sailing vessel on a purely spiritual level. The niu pole plays out the sound and sight of a sailing ship through its wailing flags and ringing guy ropes. Meanwhile the immediate marae space evokes the open, fluid ground of the sea and plaza of the wind children. In light of this connection, the wind is most certainly associated with the wind compass used by Maori seafarers and to some extent, applied to the control of the European boats (and their compass) by wind ${ }^{10}$. Fundamentally, the niu pole reveals nautical symbolism and ritual that is not far removed from traditional cosmological symbols of navigation and religious beliefs (especially in wind gods) associated with the waka. Therefore, despite the appropriation of the European ship mast and Christian deities, Pai Marire religion and symbolism was still based on Maori religious concepts founded by ancient seafarers.

Figure 2.4: Maori compass, showing specific terms and also wind names, as given by Mohi Turei of the Ngati-Porou tribe.

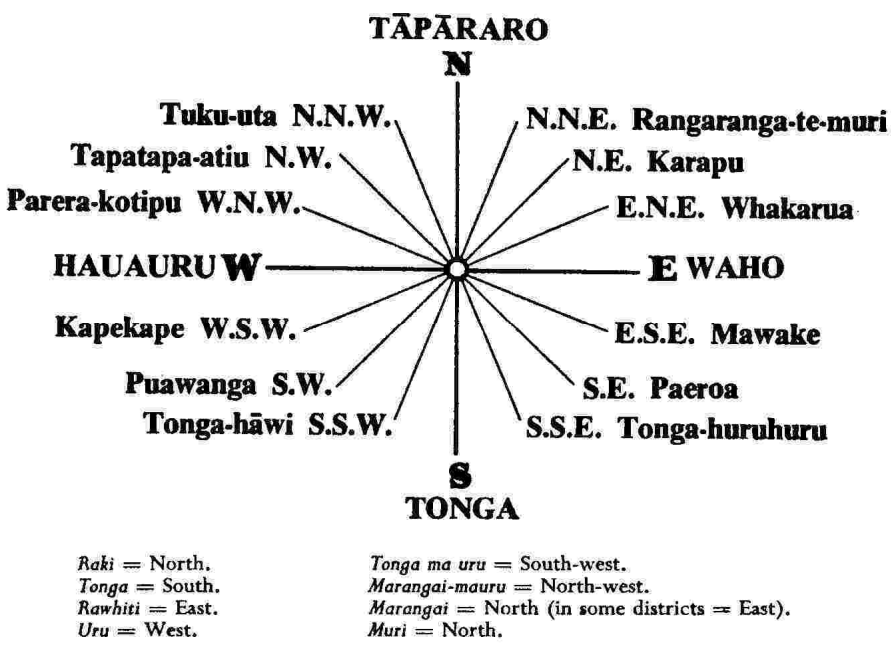

\footnotetext{
${ }^{10}$ Maori thought they could push away European ships by invoking the wind god, Rura
} 

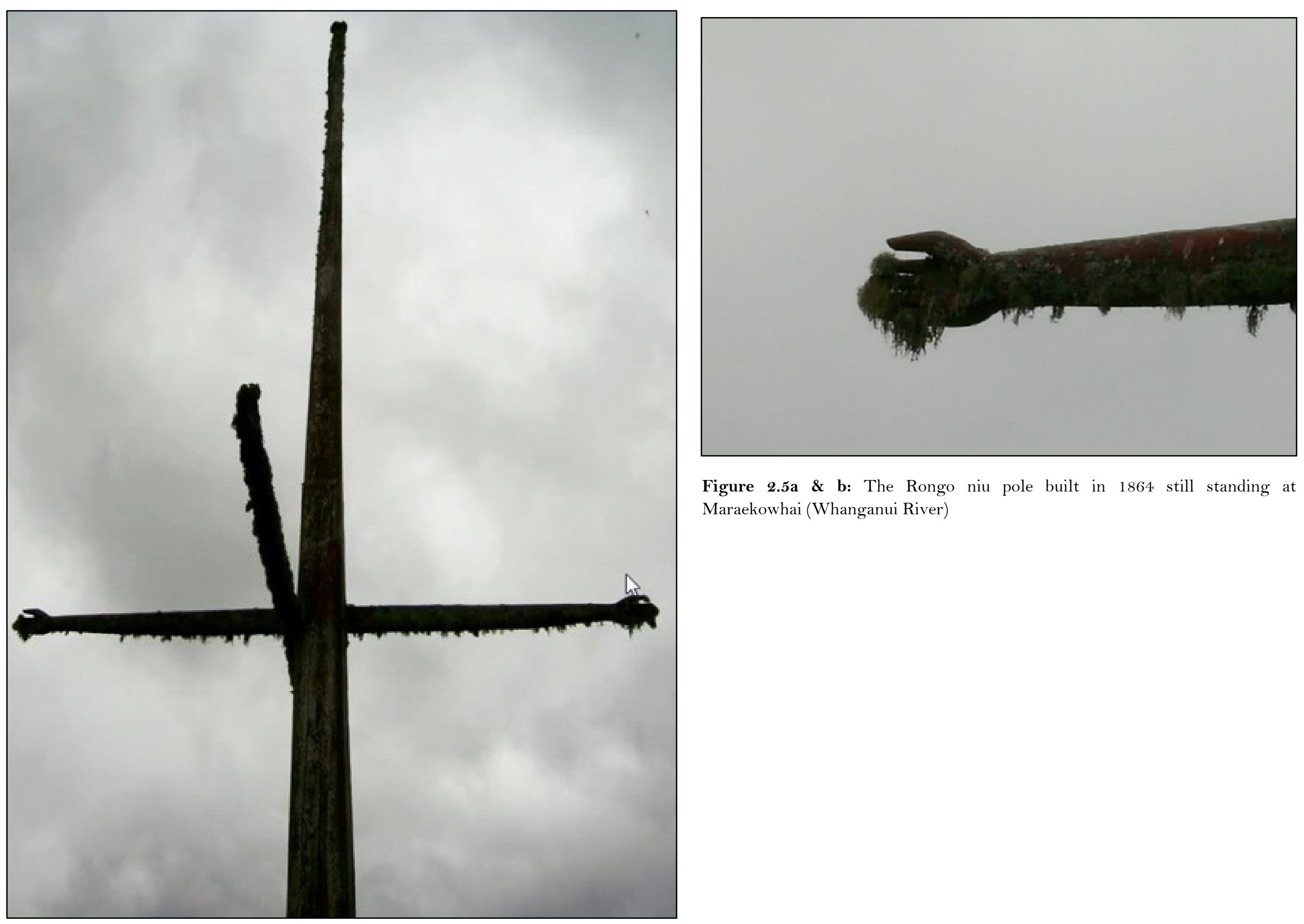

Figure 2.5a \& b: The Rongo niu pole built in 1864 still standing at Maraekowhai (Whanganui River) 


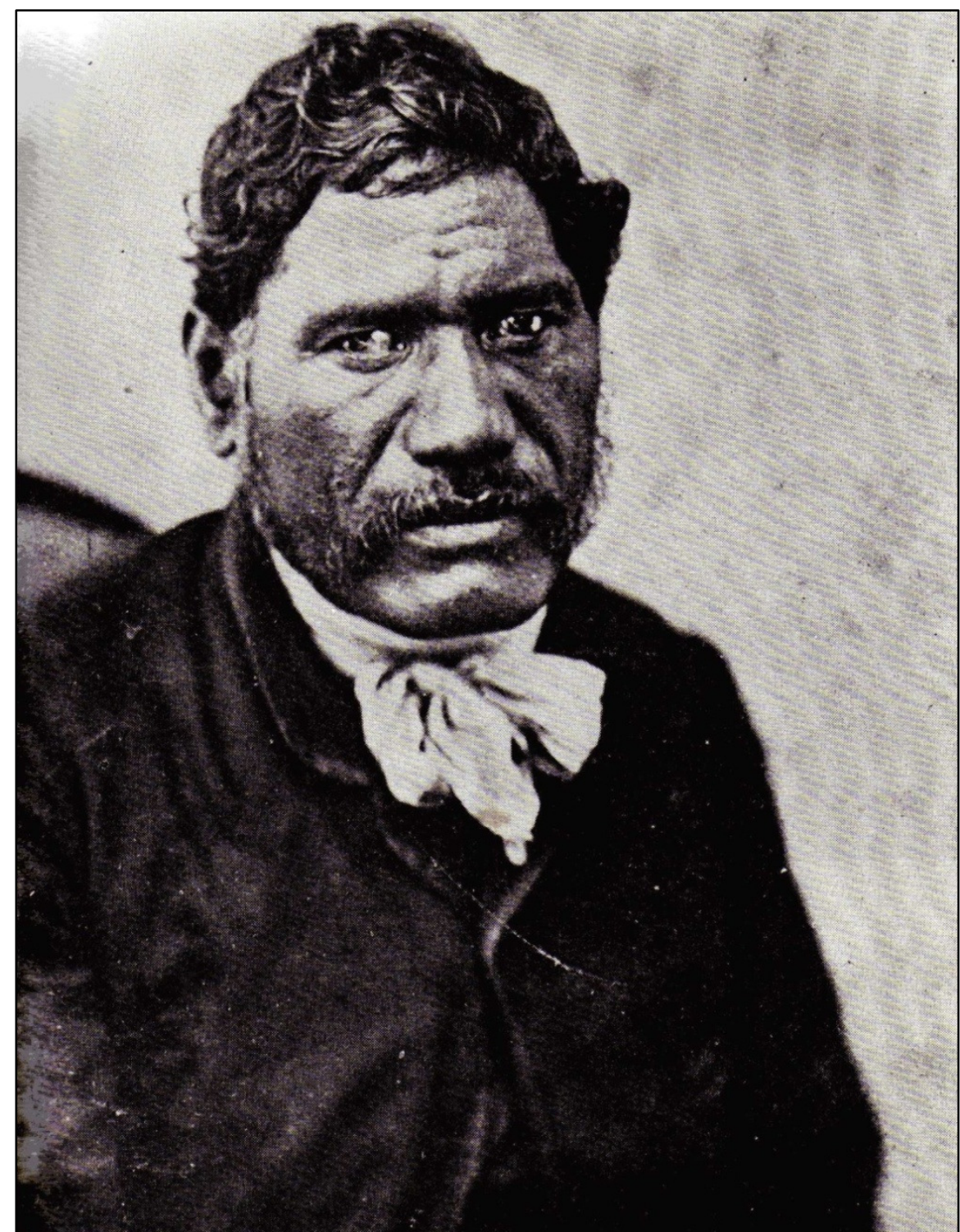

Figure 2.6: Te Ua Haumene (1823-1866), founder of Pai Marire religion, 1866 


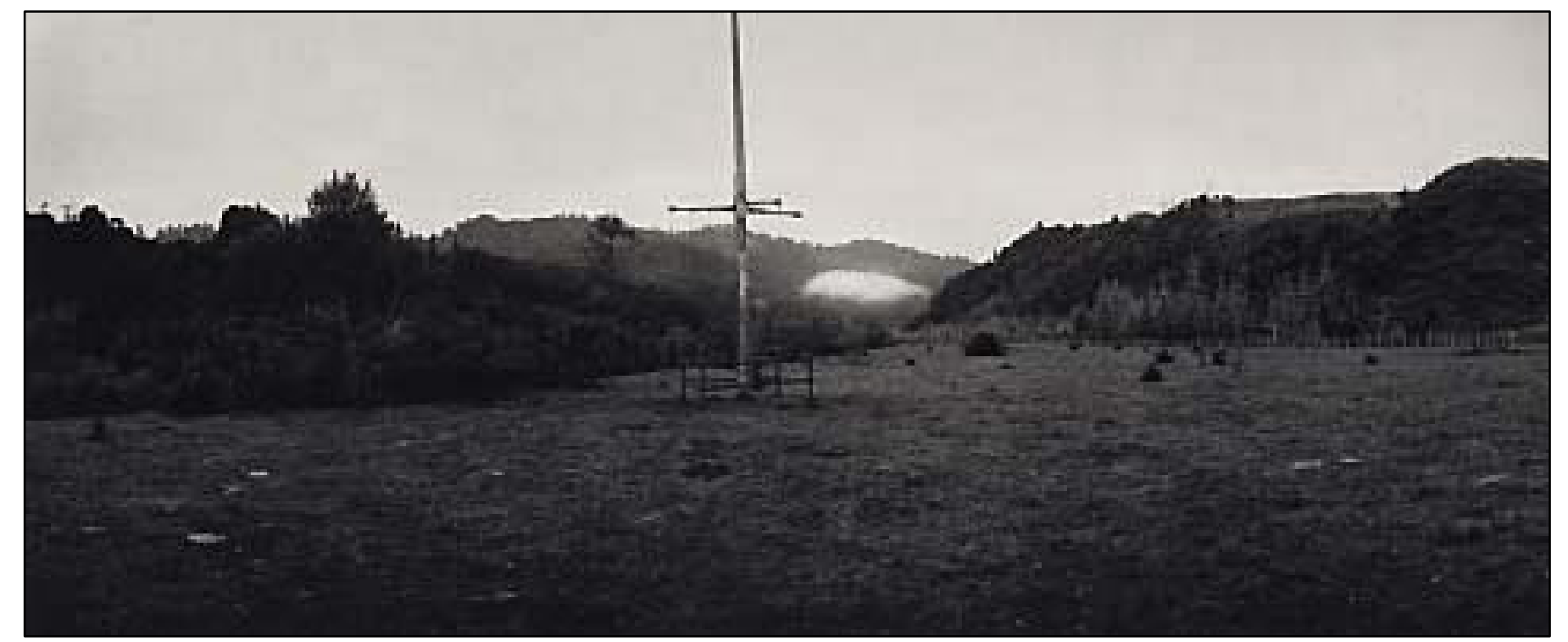

Figure 2.7: A sense of ocean space is created by the marae: Photo of Rongo niu pole built at Maraekowhai: Gelatin silver print by Anne Noble. 

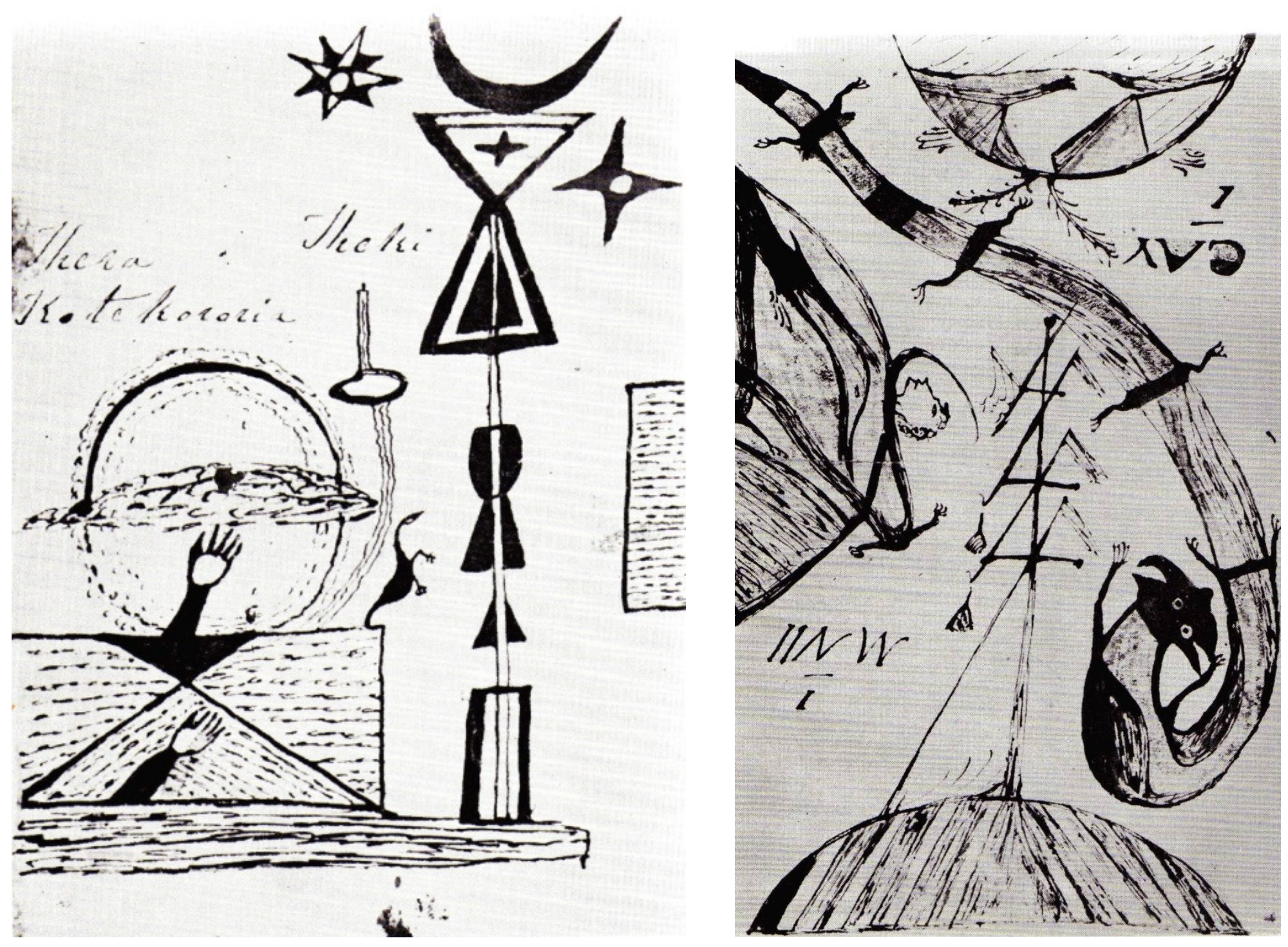

Figure 2.8a \& b: Both drawings are from Aporo's notebook depicting references to celestial symbols in Pai Marire religion. Figure a (left): On the right, the niu pole is 'the key' to 'the glory of the sun' for supplicant Maori, represented by the upraised hand. Figure b (right) Shows a European soldier and reptilian form symbolic of evil, swirling around the niu pole. 


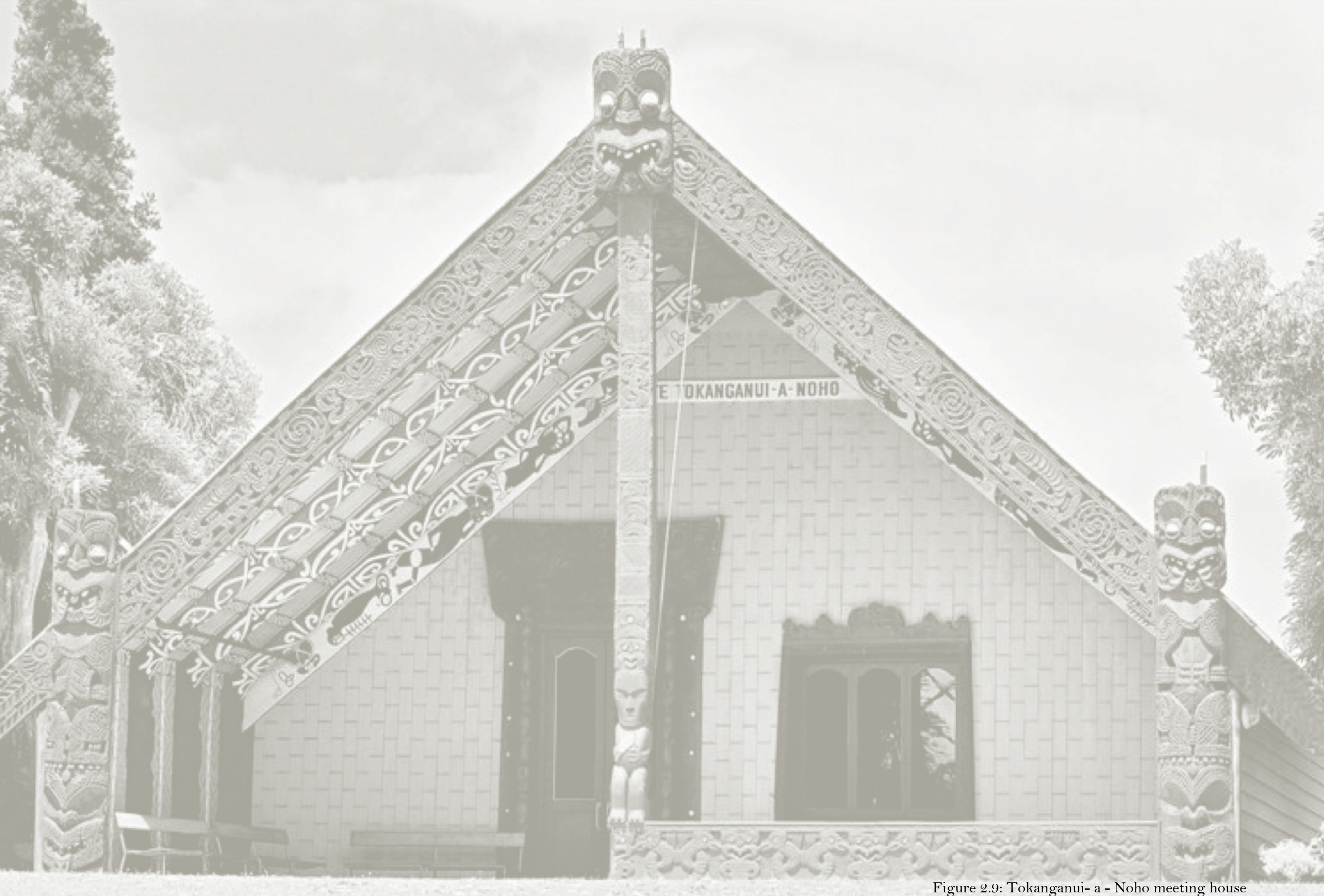


Part of this chapter focuses on the Ringatu meeting houses of Te Kooti. These meeting houses are significant to this research because they arose during a time when religion and material culture associated with the waka was shifting to spirituality and material culture more focused on the meeting house. This research first investigates this transition by briefly introducing the traditional meeting house in terms of its stylistic and symbolic similarities with the canoe. This provides some context into nautical symbols found in Ringatu meeting houses based on their connection to the waka. This research then looks at how Christianity has influenced how nautical symbols in meeting houses evolved to suit new religious and political ideas that were still founded on traditional Maori concepts. Using Te Tokanganui-a-Noho as an example, this research highlights how this is particularly evident in the use of star symbolism associated with harvesting and planting festivals in Ringatu religion.

This is followed by an investigation into various new themes and subject matter in Ringatu meeting houses. Research examines how this was due to the Christian prophetic tradition which evoked a new sense of history that was still based on navigational instinct; this research speculates that symbolism in Ringatu meeting houses was still based on cosmological relationships between people and their environment based on this navigational instinct. This provides some valuable insight into oceanic cultures who continue to interpret and understand their terrestrial environment as they would like out on the ocean. 


\section{THE LINK BETWEEN THE WAKA, NAVIGATIONAL SYMBOLISM AND}

\section{Ringatu MEETING Houses}

To begin, it is important to note how meeting houses sprung from a period of transition between canoe building traditions to religio-political architecture. Traditionally the Maori war canoe was the major symbol of tribal identity, reaching the highest achievement of Maori material culture before the arrival of European settlers (Neich, 1993, p. 73). Sadly, the importance of the war canoe diminished with the arrival of magnificent European coastal schooners and large ships. Maori were impressed by such vessels, aspiring to own these vessels for trading purposes or mere prestige. Consequently, the symbolic function of Maori war canoes eroded and alternatively, meeting houses were developed as major symbols of tribal identity. As a result of this, specialist canoe carvers turned their skills to carving the meeting house. This meant much of the symbolism based on war canoes was incorporated into new meeting houses, and in some cases, even old war canoes were actually used in parts of the structure and decoration (Neich, 1993, p. 93). Te Kooti (founder of Ringatu) ensured their on-going development by bringing a ritual aspect into the meeting house concept, along with its political activities.

Consequently, Ringatu meeting houses had many stylistic and symbolic similarities with the canoe. With the rise of Christianity these were challenged or re-interpreted, leading to their gradual adaptations or loss. In Ringatu meeting houses the loss of kowhaiwhai (canoe paddle derived art) gave rise to the use of celestial symbolism. ${ }^{11}$ What is interesting is that although celestial symbols are not related to designs found on the canoe, they are still significant in light of their connection with navigation. This is certainly the case with symbolism found in a renowned Ringatu meeting house called Te Tokanganui - a -Noho.

\footnotetext{
${ }^{11}$ Roger Neich notes how interior rafters painted with discrete symbolic patterns such as "star within circle" were used instead of traditional kowhaiwhai (Neich, 1993, p. 184).
} 
Te Tokanganui -a- Noho was a meeting house re-stored under the direction of Te Kooti for King Tawhiao. King Tawhiao had formed a cult known as Tariao (morning star) which was very influential at the time. Tariao drew heavily on Pai Marire teachings and emphasized the role of certain stars (Venus) as protective deities. These were stars that were important in Maori cosmology and Christianity. For Maori, the stars are considered mythical beings, many of whom appear as some form of light (Best, 1923). Tariao supported the same mythopoetical reference to stars through Christianity. For instance, the worship of Tawera (Venus) was a deliberate reference to the Book of Revelation, asserting Tawhiao's lineage as the son of God in the line of the Jewish kings: 'I am the root and the offspring of David, and the bright and morning star' (Binney, 1990). Although Te Kooti did not place the same emphasis on stars as deities, stars continued to have important meaning in Ringatu meeting houses. In Te Tokanganui-a-Noho stars were particularly found painted on the interior rafters and vertical porch boards. These have been illustrated by Roger Neich (1993) in the figure below. Particular attention should be placed on examples $\mathbf{g}$ and $\mathbf{i}$ which illustrate painted designs such as star within circle and circle surrounded by spots.

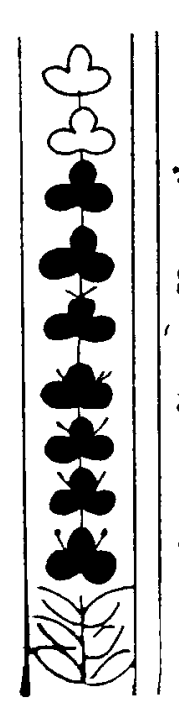

a

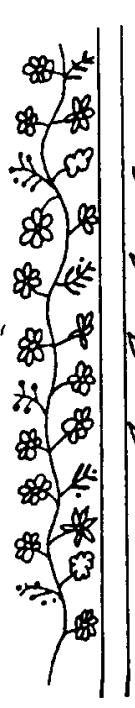

b

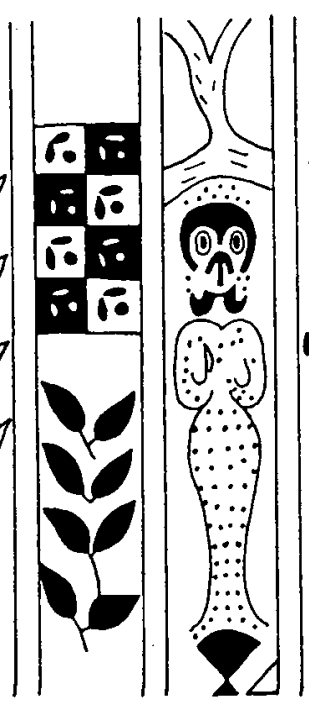

d

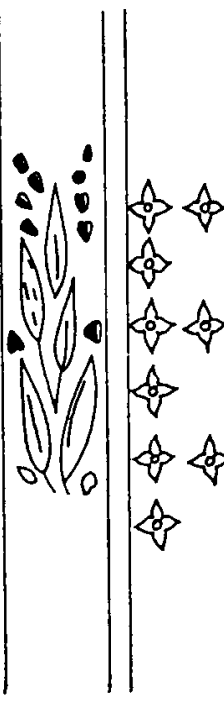

f

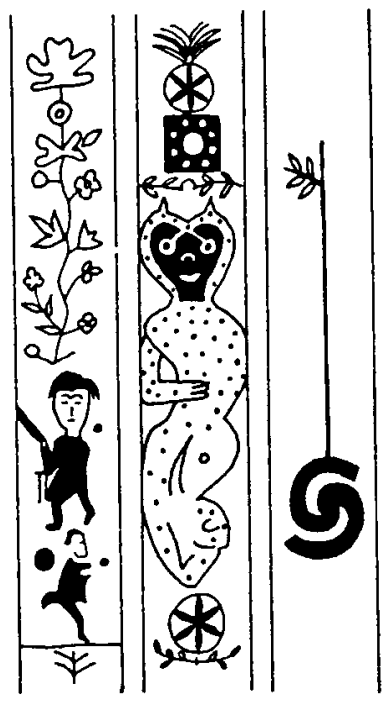

h

i

j

Figure 2.10: Figurative paintings on the vertical porch boards of $\mathrm{Te}$ Tokanganui - a Noho. 
In Ringatu tradition, the use of star (and plant ${ }^{12}$ ) symbolism may be associated with star lore related to harvesting and planting festivals. The most significant event celebrated in Ringatu religion is the helical rising of the star, Matariki (Pleiades). This is an old Maori tradition which celebrates the sacred time for planting and harvesting. Te Kooti supported this concept through Christianity in Exodus 34:22 and Deuteronomy 26:2 (Binney, 1995, p. 420). Although Matariki has become a symbol associated with the cyclic rhythm of the land and its fruits, Matariki is also a constellation long associated with seafaring. Traditionally Matariki signalled the times to set sail. When it was low, this was a dangerous time to sail. When it was high, the time was safe to set sail for trading between Pacific Islands (Hall, 2002). Now the stars are looked upon for guidance as to how successful the coming season would be; the brighter the star constellation the warmer the year was destined and the better the harvest was thought to be. ( Tai Tokerau Maori and Cultural Tourism Association, 2010) Therefore Matariki celebrates a particular time of the year originally linked to seafaring. With the loss of deep-sea voyaging, this knowledge became localised and applied to Maori agriculture.

In Te Tokanganui - a - Noho, it appears that stars represent past and present theologies in Ringatu religion. Te Kooti may use star symbolism to express Tariao or to represent the cycle of seasons in traditional star lore. Whatever the case, Maori are a visual culture who use architectural symbols to stir the imagination and form portals to memories and beliefs. Although the use of stars was recently emerging in religious Maori architecture, it certainly evoked much more than its recent Christian-Maori meaning. The stars conjure memories of their seafaring ancestors who followed the stars halfway across the world. Stars also represent genealogy: They are sometimes referred to as the left eye of great chiefs who watched over and guided many seafarers throughout the voyage..$^{13}$ The stars also remind Maori of their remote ancestors, or

${ }^{12}$ Plants that varied according to leaf colour and ripeness of the fruit represent Ringatu harvest festivals (huamata). These were usually signalled by various stars (Neich, 1993, p. 213).

${ }^{13}$ The Atua tonga (divinity or soul) was thought to be located in the eyes-each eye was believed to have a separate immortality-the left eye ascending to heaven, and becoming a star, unless swallowed promptly, the right eye becoming a spirit and taking flight for the Reinga or leaping-place unless similarly “incorporated” by the victor (Robley, 1896, p. 160). 
friends who have passed away to the spirit-world while, or before, the star was invisible (Best, 1923, p. 4). Therefore star symbolism was a new Christian Maori symbol anchored in traditional aspects of Maori culture. Stars represent Christian ideas founded on Maori concepts and the localization of navigational knowledge (applied mostly to agriculture). Also, on a more subconscious level, stars can signify memories of places, events and people from the past.

\section{The Christian Prophetic TRADITION: THE Rise OF TERRESTRIAL SYMBOLISM}

One of the most radical changes to symbolism in the meeting house was due to a new historical consciousness introduced by the prophetic tradition in Christianity. In the traditional meeting house, cosmological systems and ideal relationships were modelled on a timeless, unchanging world. Te Kooti was one of the first to illustrate how Christianity could break away from an eternal sense of recurrence. Te Kooti achieved this by using the prophetic tradition from the bible to "evoke a new sense of future by the new notions of fulfilment and redemption" (Binney, 1984, p. 347). Although the prophetic tradition is a biblical appropriation, it certainly suggests a much older tradition of prophecy used by tohunga. ${ }^{14}$ In this case the skills of the expert navigator are brought to mind. These were experts in interpreting and observing the marine environment. Their senses were constantly engaged with phenomenological forms in the ocean environment: star patterns, sea-swell and current patterns, bird, fish and marine-mammal sightings, wind directions and submarine phosphorescence. Therefore sensing one's environment was a navigational system based on knowledge and ordering of the natural world (Strongman, 2008 , p. 13). Consequently, observations and experiences in the oceanic environment became inspirational art forms used in the traditional meeting house and waka decoration. This is certainly evident in the fluidity of the art form and the amphibious sea creatures often depicted. This reveals how symbols are essentially the material form of observations and experiences from their maritime environment.

${ }^{14} \mathrm{~A}$ tohunga is an expert practitioner of any skill or art, religious or otherwise. Tohunga may include expert priests, healers, navigators, carvers, builders, teachers and advisors (Wikipedia, 2010). Bronwyn Elsmore (2000) and Judith Binney (1984) have made many comparisons between Hebrew prophetic leaders and Maori tohunga. Both were intermediaries between God and the people as well as political leaders (Elsmore, 2000, p. 88). 
Under the influence of prophetic tradition in the Old Testament, Ringatu meeting houses recorded a new sense of history based on spiritual and cultural symbols associated with their current situation on land rather than their maritime past. Despite the loss of seafaring tradition, Maori were still projecting sub-conscious meanings from nautical symbols into new Christian Maori symbols. Instead of traditional carved forms, figurative paintings were employed to record the passing of history, and to some extent, impressions of what the new world would look like (Neich, 1993, p. 155). Here we see Maori symbolism in meeting houses descend from its watery beginnings, to life on land. The animalistic depiction of ancestors became humanised, plants and land animals were more commonly depicted and representations of the modern European world became popular. Although this meant the loss of nautical symbols in the meeting house, it did not deter the overall nature of art that was influenced by the creative aspirations and thought processes of an oceanic society. In this sense, symbolism in Ringatu meeting houses still found inspiration by 'navigating' the context of their buildings. For instance, navigational symbols such as birds, stars and sea creatures were replaced with native birds, plants, and animals on land. Ultimately, this shows that Maori symbolism still draws from a nautical instinct - one which associates cosmological meaning to navigation signs. Interestingly, these are the signs that give character and context to places and their people.

This was a sub-conscious reaction to interpreting and understanding one's environment in terms of navigation and therefore echoed a similar cosmological framework. For instance, migratory birds were important beacons for nearby land, and their importance was emphasized by designating certain birds as mediums for divine communication between Maori and their gods (Riley, 2001). The significance of birds is traditionally represented in the meeting house through the manaia design: a mythical bird-headed being, usually with a fish tail. The bird, human, and fish aspects in the design refer to the air, land, and sea and the balance between these elements. In Ringatu meeting houses the bird's association with seafaring was alternatively applied to the symbolic relationship between people and the land. Rather than signifying birds through abstracted anamorphic figures, specific native birds were used to signify the territory of Ringatu meeting houses and their tribes. For instance in Uawhaki, the huia was used to identify their tribal territory: "we are the people who live in the homeland of the most noble bird" (Neich, 1993, p. 214). 
Ultimately Christianity encouraged Maori to find new sources of artistic inspiration in their meeting houses that were much different from the eternally recurring themes and traditional symbols usually used. Essentially, this distanced Maori from their seafaring traditions while also separating Maori from Christianity. Therefore nautical symbols were a hermeneutic response to both these distances. On one hand, symbolism was used to interpret their latent connection to seafaring in a way that was suited to their current situation on land. On the other hand, they were trying to appropriate ideas from Christianity into their own Christian Maori cosmology. Ultimately, the influence of Christian iconography and the transition from ocean to land, led to a new historical consciousness. This was expressed through symbols based on interpretations and understandings of the world according to the tohunga, navigator - the depiction of people, plants and animals being an evolution of navigation symbols and seafaring instinct reinterpreted within a new Christian Maori cosmology.
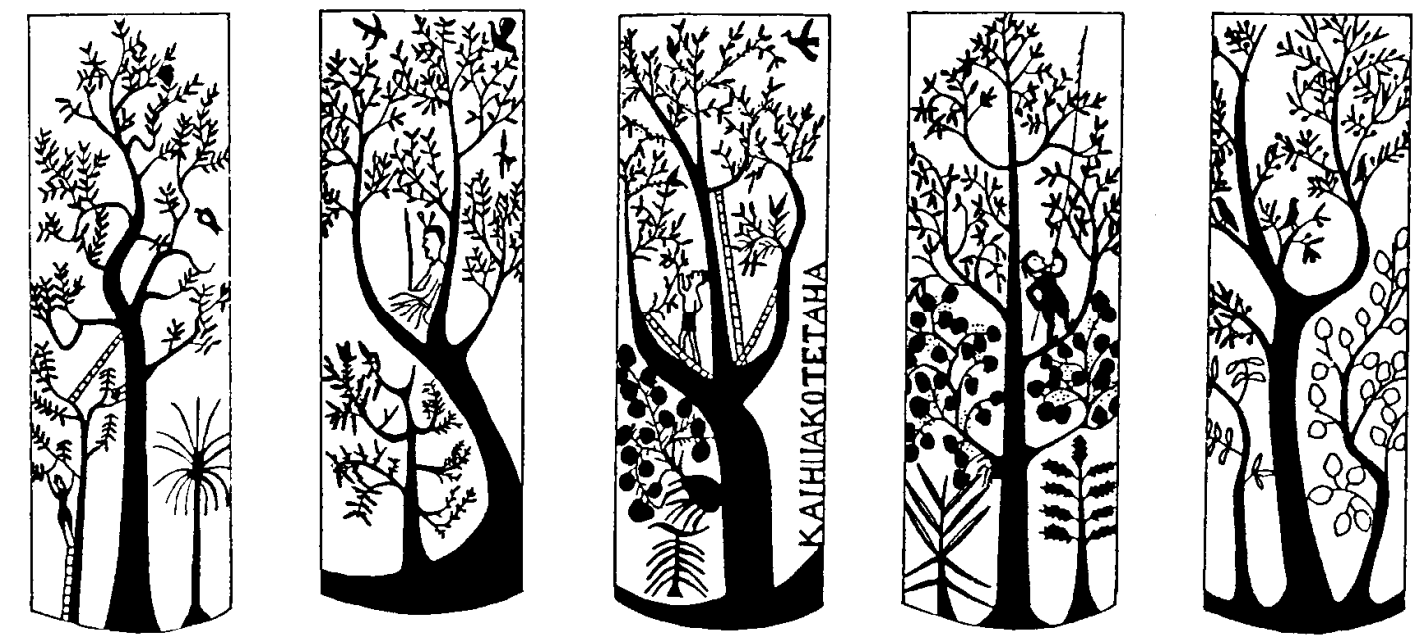

Figure 2.11: Naturalistic forest scenes on interior rafters of Ringatu meeting house: Te Whai -a-Te-Motu, Mataatua Marae, Ruatahuna. 1888. Bird hunting scenes depict old famous chiefs awaiting the approach of some unsuspecting 'flapping child of Tane'. 


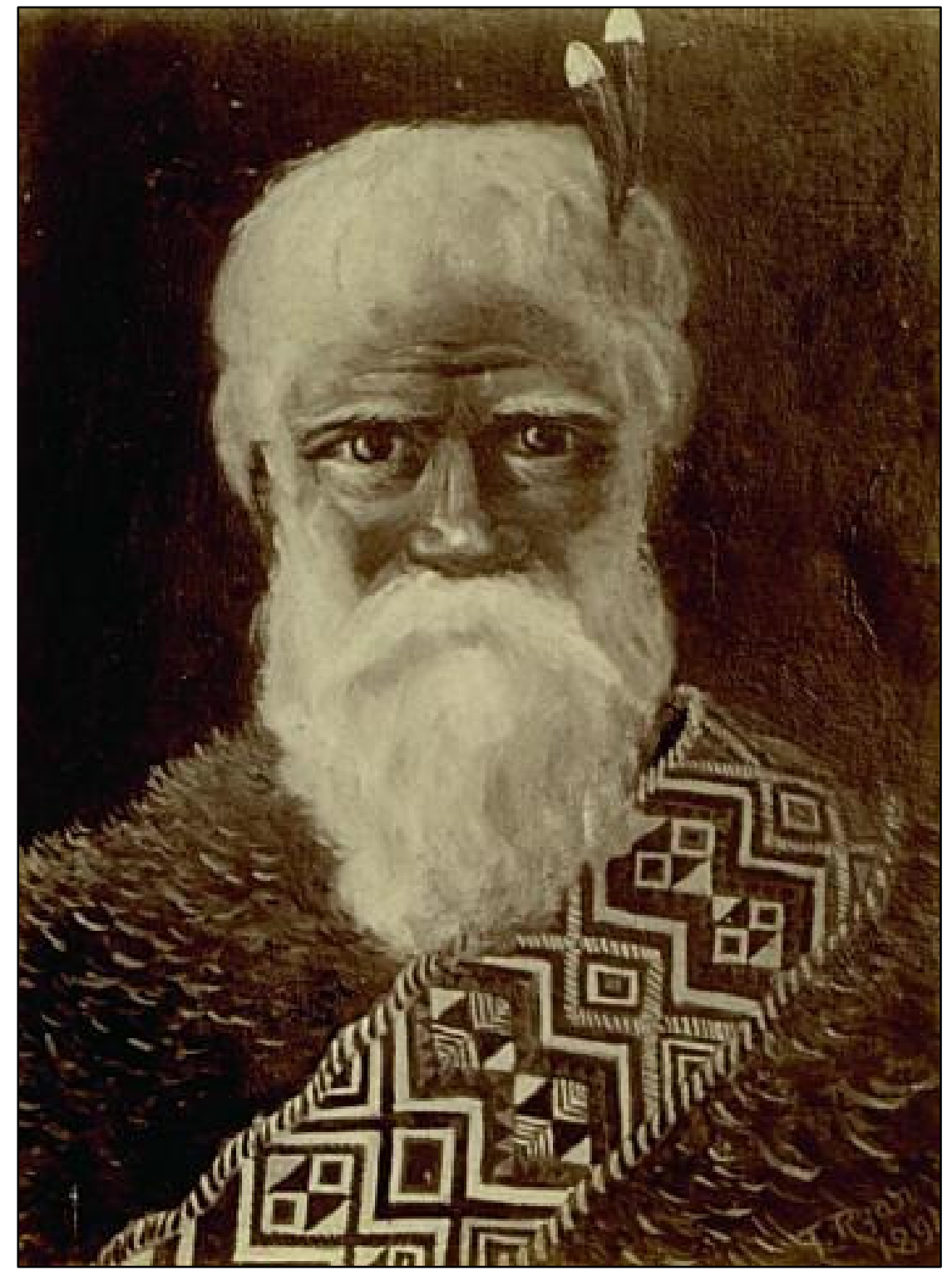

Figure 2.12: (Left) Probably the best known picture

purporting to be a likeness of Te Kooti Rikirangi, is a

painting by Thomas Ryan. This image is a photographic

reproduction by well known photographer, Josiah Martin 


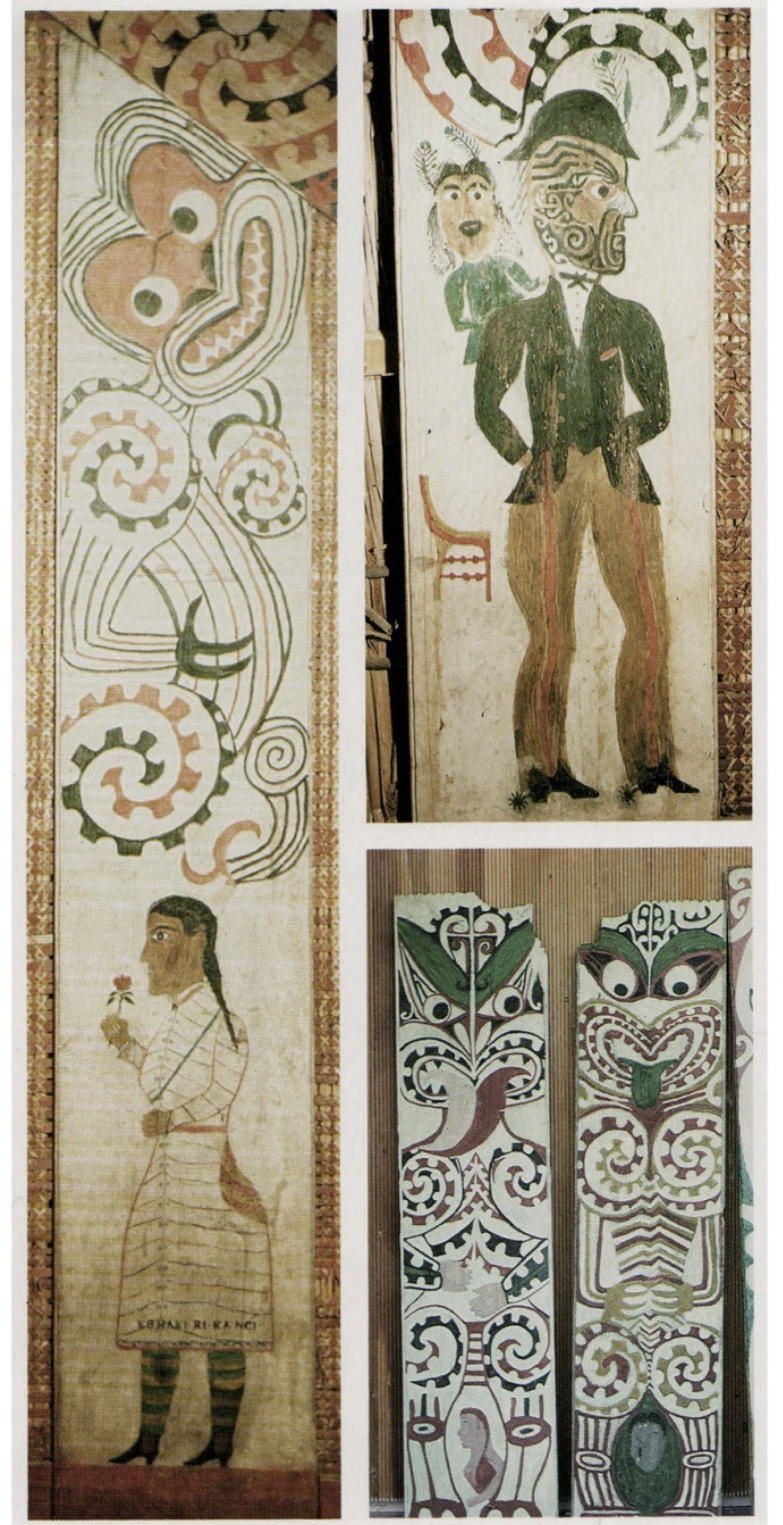

Figure 2.13: Ancestor figures depicted in Victorian style clothing. These reflect a new sense of history being introduced into the symbolism in meeting houses. (In Rongopai Ringatu Meeting house, Waituhi)

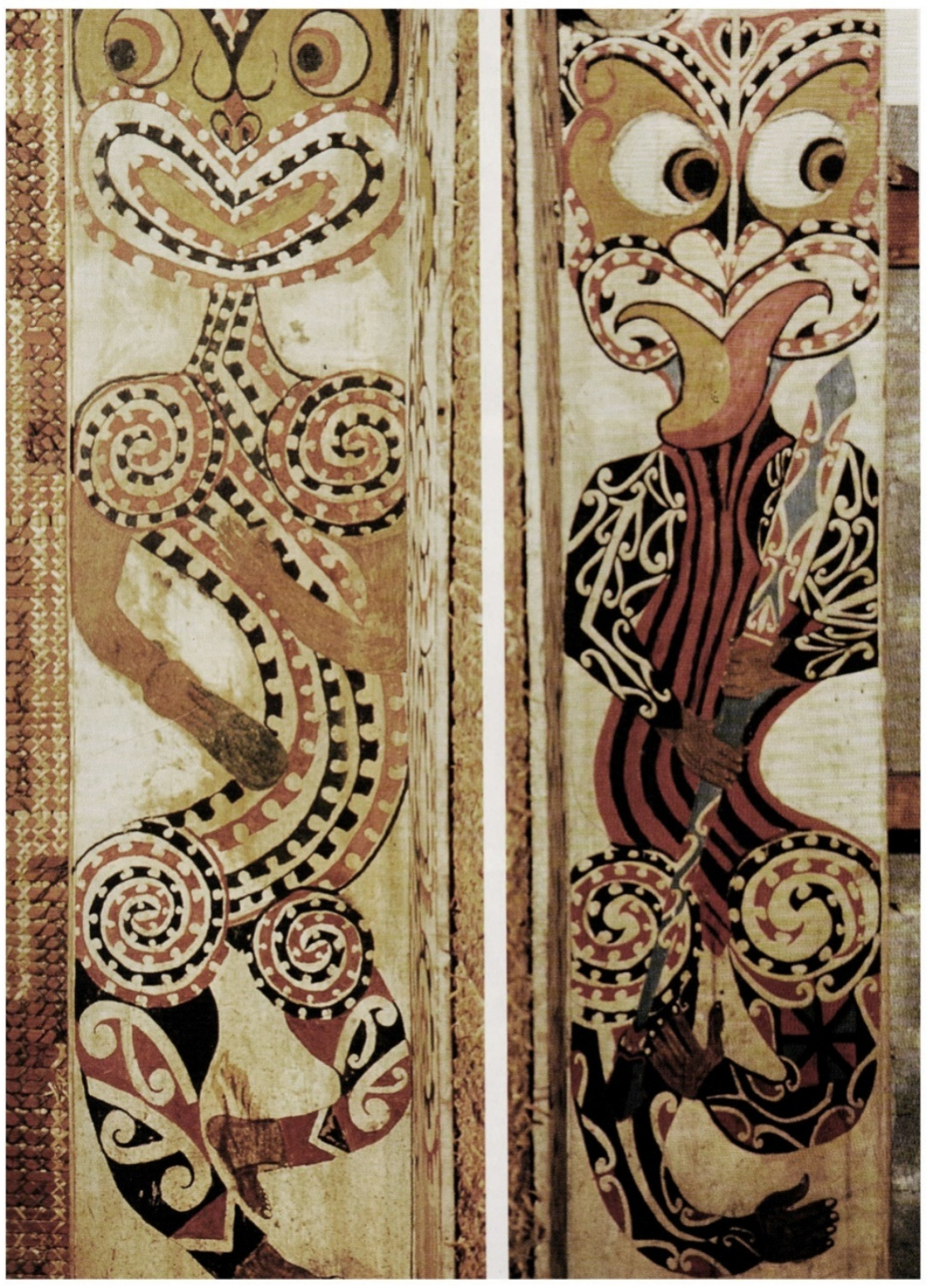

Figure 2.14: Poupou ancestor figures becoming more humanised evident through the feet and hands. Elements of fluidity still present in the use of kowhaiwhai (In Rongopai Ringatu Meeting house, Waituhi) 


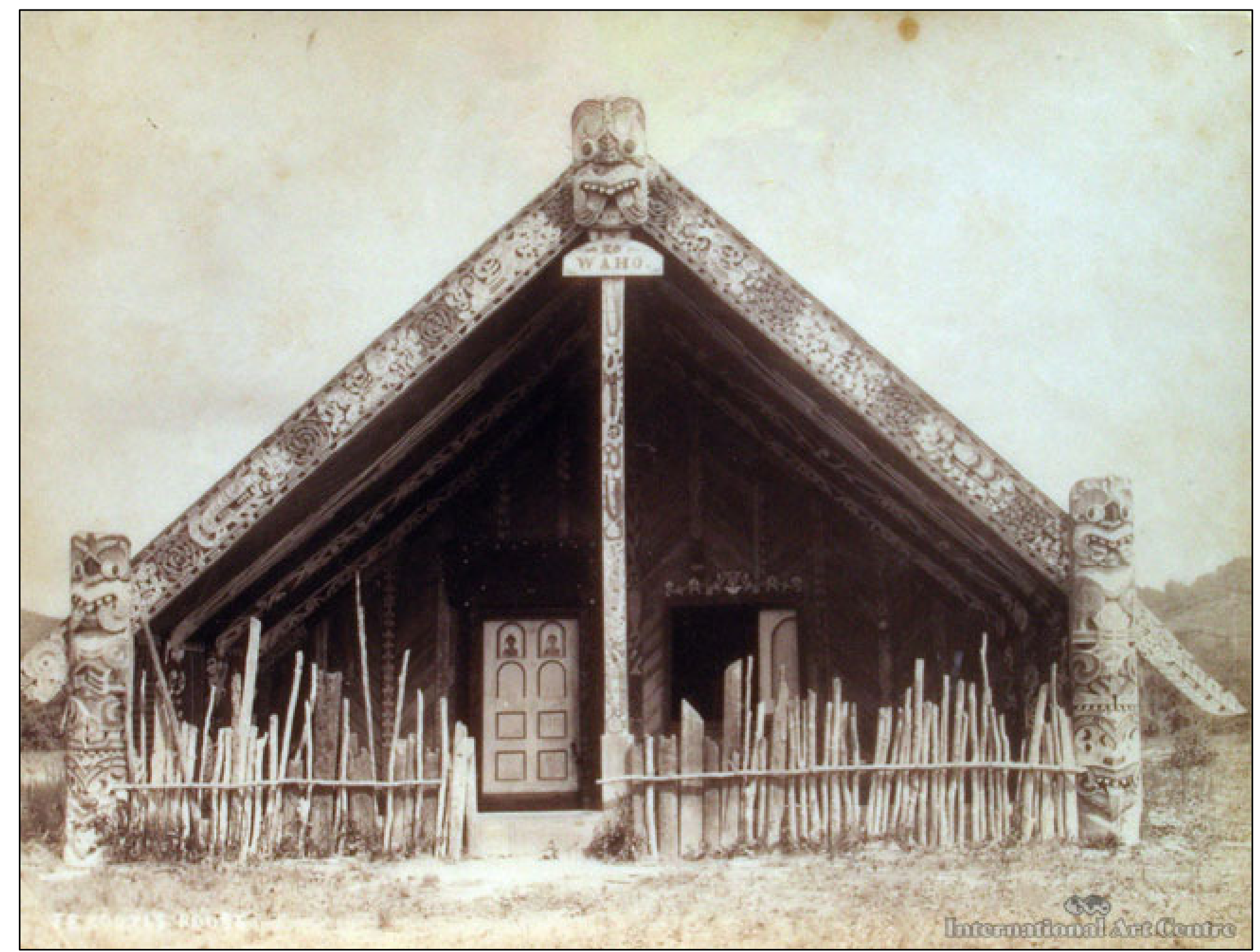

Figure 2.15: (above) Photograph of Te Tokanganui - a - Noho, taken by Josiah Martin, 1913 

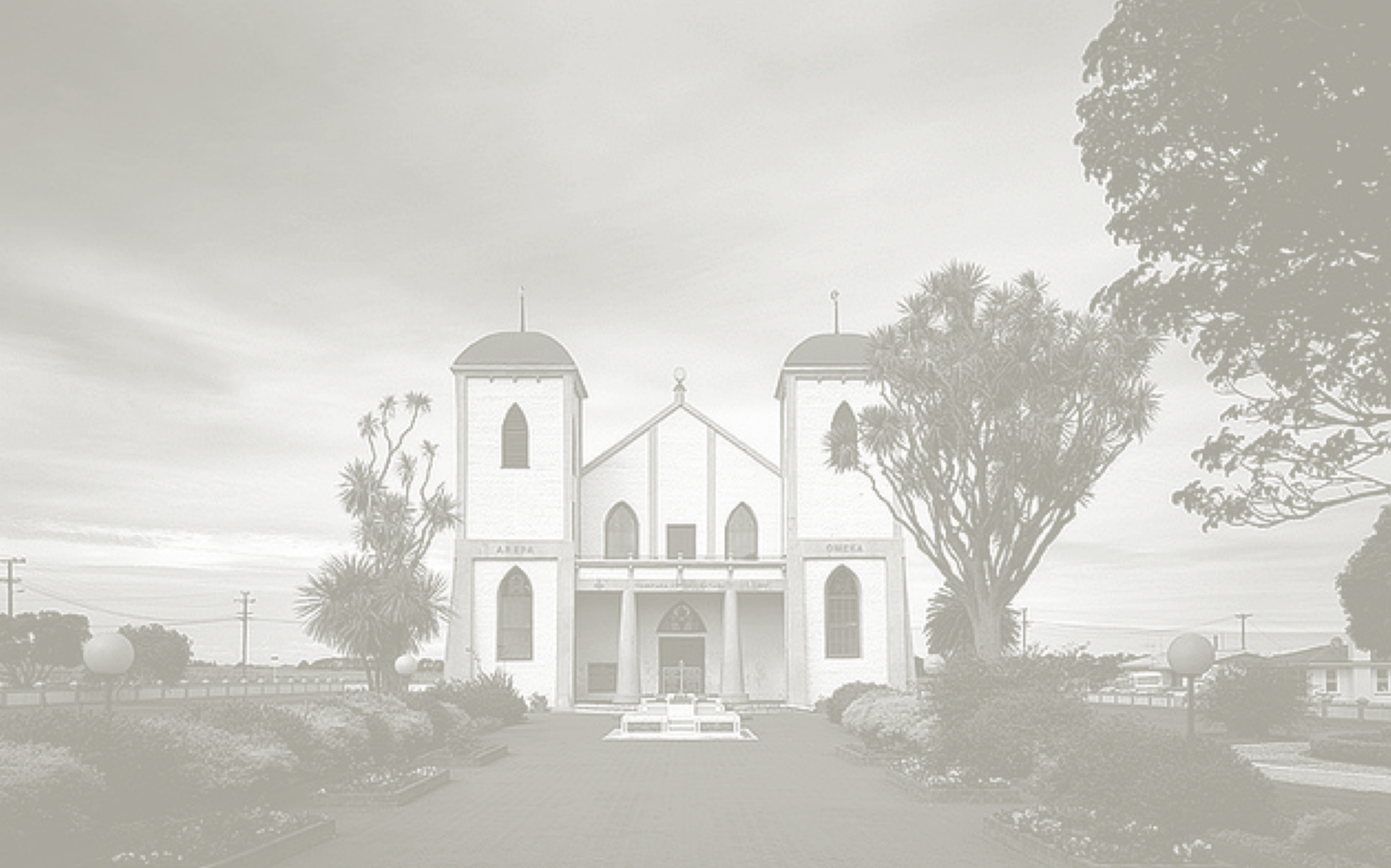


\section{CHRISTIAN MAORI ARCHITECTURE: THE RATANA CHURCH}

The Ratana church was founded in 1925 by whanganui-based faith healer Tahupotiki Wiremu Ratana. This final case study focuses on two of his most important buildings both located at Ratana pa; the 1000-seat Temepara, or 'Temple' built in 1927 and the Manuao building complex built in 1938. Part of this research specifically examines the whetu marama (star and moon) symbols used on both these buildings, followed by an investigation into the use of the boat as an architectural symbol. Beginning with an investigation into the most enduring symbol of the Ratana church, the whetu marama, this research examines how this symbol has an interesting connection with traditional (navigation) star lore and Christianity. Based on the symbols link to navigation, this generates a basis for analysis on the symbolic position and articulation of whetu marama throughout the building.

Part of this research then investigates the boat as an architectural symbol based on the Christian appropriation of an Ark in the Temepara and Manuao buildings. This research firstly examines the popular appropriation of Noah's Ark in Ratana architecture due to its close connection with Maori-Polynesian mythology and their seafaring history. The focus is then turned to the religio-political references of the Manuao building complex, conceived as a European war ship or even a waka taua (Maori war canoe). This leads into an investigation of the symbolic meanings behind the seven, migratory canoes and the European ships presented on the Manuao building. 


\section{NAUTICAL SYMBOLISM: THE WHETU MARAMA}

One of the most enduring symbols of the Ratana church is the whetu marama. This was the main symbol of the movement developed by Ratana during his world tour in 1924. It was said that whetu marama shone brightly while Ratana and his members sailed the Mediterranean Sea aboard the steamship SS Barrabool. Ratana took this as a tohu (mark, sign, proof) that guided them on their journey, and was thereafter used as a prominent symbol in Ratana religion (Newman, 2006, pp. 192-193). It is likely that Ratana was thinking of his ancestors while he gazed upon this star, similarly feeling a strong sense of guidance and destiny as his intrepid seafaring ancestors did. In fact when asked by his followers why he wore the six pointed star emblem Ratana replied: "Ko te tohu tenei a ooku tupuna", "This is the emblem of our ancestors" (Newman, 2006, p. 191).

The whetu marama is also a symbol that manifests a fountain of ideas in traditional Maori star lore. Best (1923) has covered many aspects of this, beginning with its earliest significance in respect to voyaging. The whetu marama alludes to some of these astronomical concepts particularly when Ratana suggests the luna and star occultation was a 'sign' or 'tohu'. He gives this Christian importance by comparing it to the star which guided the three wise men, (the Star of Magi (Newman, 2006, p. 193). This Christian appropriation associates the star as some divine form of guidance and in some aspects personifies a star as the Messiah or Jacob. ${ }^{15}$ Similarly, Maori star lore (particularly associated with the prophetic tradition) understood certain stars to be Gods who could control the future in terms of the coming seasons and weather (Best, 1923, p. 28). Due to this reason, stars were also believed to possess great potency for good or ill will to Maori people. When Ratana saw the star close to the moon, he knew this was considered an important omen according to Maori tradition. In this case, the waxing moon and star together was symbolic of the heavenly light out of darkness, signalling a new beginning (Mckay \& Brown, 1992, p. 126).

\footnotetext{
${ }^{15}$ The Star Prophecy from the Old Testament (Numbers 24:17) was used by radical and revolutionary Jews from 70 B.C.E., to stir and comfort with the foretelling of the "Star of Jacob," which was interpreted by some theologians as the coming of a Messiah: I see Him, but not now; / I behold Him, but not near; A Star / shall come out of Jacob; / A Scepter shall rise out of Israel, / And batter the brow of Moab, / And destroy all the sons of tumult. (Nielson, 2010)
} 

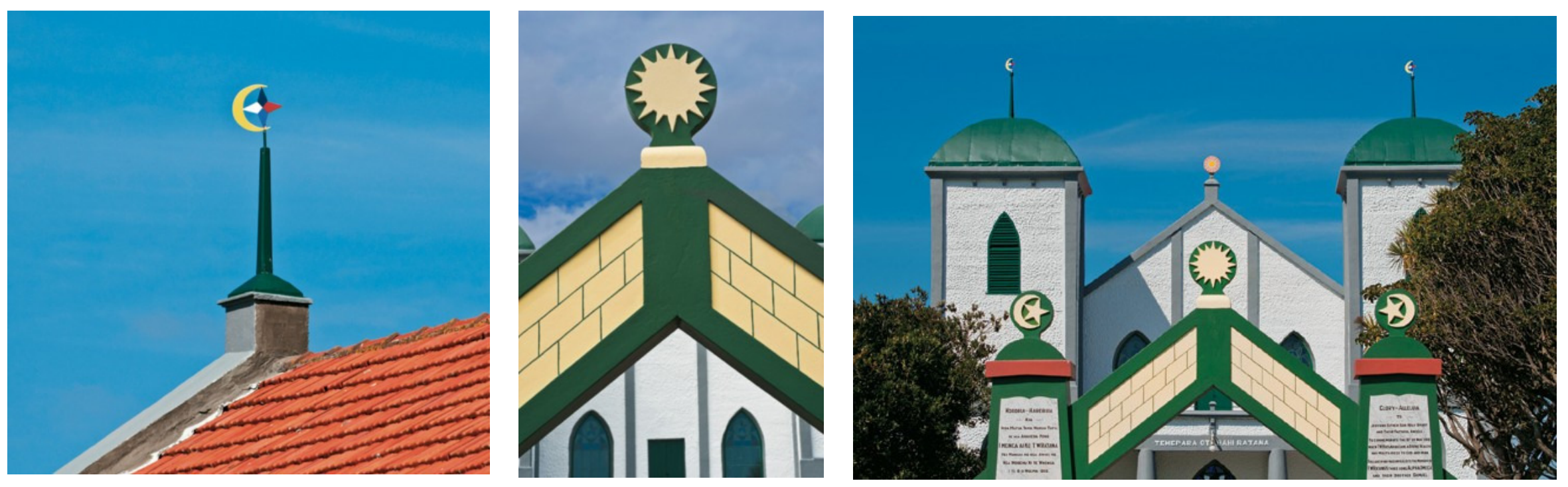

Figure 2.17a,b,c: Detailed photographs of celestial symbolism on the gate and roof of the Temepara. 
Although the whetu marama is founded on traditional Maori star lore, Ratana designed the star so that each of its five points is coloured, representing different parts of the Holy trinity. Anti - clockwise from the top of the star, the first point is blue representing God, the next is white, for the Son, the bottom is purple, for the faithful angels, and the last point is red, for the Holy Spirit. Ratana then added himself as the fifth yellow point. The positions of these points differ among various buildings of Ratana $\mathrm{Pa}$ to accentuate different aspects of the Holy trinity. In the Temepara, points of the Father and Son are upward, the angel and spirit point outwards and the gold point of enlightenment is aimed at the earth. Again, this changes on the Manuao building complex where the points of the blue star aim down, symbolizing the 'second Ark', 'Te Aka' built by Ratana and the covenant buried

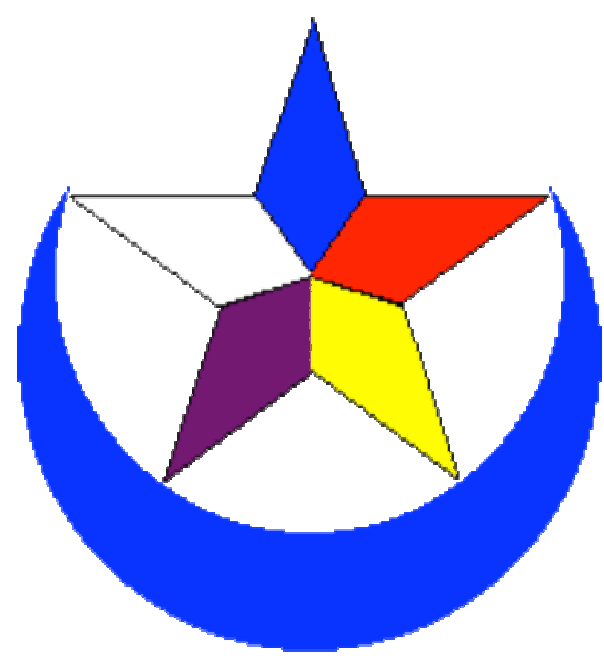
beneath the building foundations (Newman, 2006, p. 194).

This careful articulation of whetu marama reinforces the importance of reading the stars so that their true meaning is unveiled. Ratana used these symbols to represent 'maramatanga', 'enlightenment'. He believed this was an acquired knowledge by those who could see with spiritual eyes; the symbols of the Temepara were like a 'window' that could reveal the mysteries of the spiritual world that our natural senses cannot (Hagger, 2003). Therefore Ratana places great emphasis on reading the stars, recalling an old tradition of the expert star-gazers, who were versed in the lore of tatai arorangi, Maori astronomy. In the Temepara, the stars must be read with the same precision in order to realise their true significance. So it can be said, people who first enter the Temepara are like a lost voyager looking for a star which will help guide the way. In a spiritual and physical sense, the congregation is literally guided by the tactful placing of whetu marama. On the Temepara, the whetu marama symbol is found on each apex of the twin bell towers and the altar end of the gable roof. 


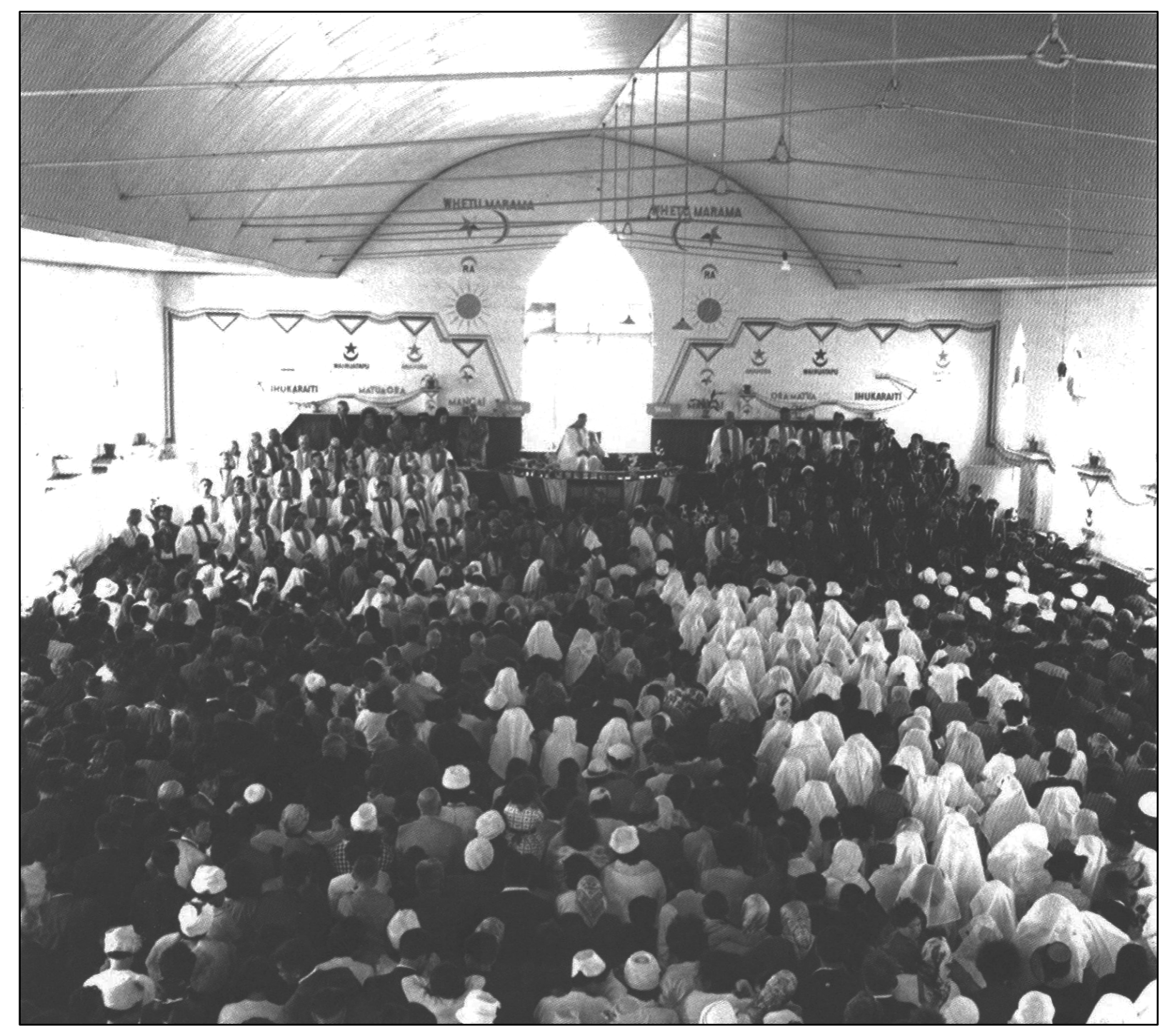

Figure 2.18: Interior of the Temepara showing whetu marama symbolism around walls and barrel vault ceiling. 
Whetu marama are also used in a repeating sequence around the church walls connected by a chain of Rosary beads. The sequence comes to a climax, mirror imaged above the pulpit, accentuating the sacred area and two 'ra', 'sun' motifs. Furthermore, whetu marama function similarly to carved door lintel (pare). Here, the symbol appears at important thresholds (such as gateways and doorways) to accentuate various internal and external areas or earthly and sacred (celestial) worlds (see Temepara gateway fig 17c). The sacred (celestial) realm inside the church is reinforced by whetu marama which shine brilliantly through stain glass windows around the room (fig $24 \mathrm{~b}$ and $25 \mathrm{~b}$ ).

Overall, the whetu marama is an identifying characteristic of the Ratana movement used on almost all Ratana buildings (Brown, 2003). Similar to many celestial symbols used in previous Maori religious movements, Christian sky deities continued to be a popular appropriation because of their mystical link to navigation and therefore their traditional celestial gods. This is because celestial symbols are highly symbolic of Maori star lore and spiritual concepts founded in navigation knowledge. Ratana essentially re-establishes this connection by proclaiming new laws to traditional Maori celestial gods, and therefore created a Maori Christian alliance. As well as representing spiritual ideas associated with navigation, whetu marama help define sacred areas and signify important thresholds. Their placement reinforces the celestial significance of these symbols while also providing a poetic link to navigation through the idea of a voyage from which stars lead the congregation on a spiritual journey. This idea is reinforced in the following segment which identifies the meaning behind the hull-shaped ceiling in the Temepara. 


\section{THE BOAT AS AN ARCHITECTURAL SYMBOL IN THE TEMEPARA AND MANUAO}

\section{BUILDING COMPLEX.}

One of the most distinctive features inside the Temepara is the hull-shaped ceiling. Symbolically this refers to the Ark built by Noah to save his family and animals from the Great Flood. The Ark is a universal symbol used throughout the Christian bible which according to religious theorist Timothy Scott (2008) has two fundamental meanings: the ark as the divine "vehicle" (boat, ship, chariot) and the Ark as the "house of God" (Scott, 2008, p. 8). For Maori, the Ark as a divine boat stirs strong comparisons to waka traditions as well as Polynesian and Maori mythology. As research has already revealed, the waka taua was given divine capacity through the great ancestor Tane (who personifies the boat) and its symbolic carvings. The idea of an Ark, as either house or boat also evokes the strong connection between the two. In Polynesian mythology, Austin has discussed the relationship between the house and boat to be one and the same. For instance Polynesian ancestral stories have claimed that their houses were upside-down boats and vice versa (Brown, 2009, p. 25). Also, Maori Astronomy researchers Kay Leather and Richard Hall (2004) have discussed the roof of the meeting house as the upturned waka on land:

"The keel of the canoe like the ridge pole of a house symbolised the tribal or chiefly genealogy, while the poupou (upright slabs forming the framework of the house) are like the tauware or thwarts on which the paddlers sat" (Leather \& Hall, 2004, p.34).

Initially the Temepara may have appealed to the idea of a boat-shaped ceiling based on the Christian concept of an Ark. However, as Carl Jung (1968) has implied, symbols are the means by which humans represent "ideas that lie beyond the grasp of reason" (Carl G. Jung, 1968, p. 4). Therefore it is possible that the boat-shaped ceiling in the Temepara conjures many nautical concepts associated with seafaring and navigation much like the whetu marama. 
Ratana reinforces this connection through the manuao building complex. This building is conceived as an old naval warship called The Man-O-War (the transliteration of Manuao meaning man-o-war). The inspiration for the building is said to come from Ratana's wife Te Whaea who dreamed of a great flood:

"A ship (the church) came to save the Morehu whose faith was strong whilst the unfaithful (who were weak) were drowned.

The ship's guns (the four quarters) were firing and the shells represented the ideas of the people concerning the Treaty of Waitangi."

(Mckay \& Brown, 1992, p. 126)

Therefore, similar to the Temepara, the Manuao building complex is conceived as a divine vessel or 'second ark', 'Te Aka'. Unlike the delicate depiction of Noah's Ark, Ratana appealed to a great war ship because it probably identifies with the physical and spiritual aspects the waka taua (the war canoe). Similar to the waka taua Ratana describes the building as a shelter and strong hold in the battle of the spirit, and that the power of the Holy Spirit dwelled within. It was said that the "Covenant", The Tiriti O Waitangi ${ }^{16}$ was buried into the foundations which endowed the building with a certain Mauri (life-force) (Hagger, 2003).

\footnotetext{
16 Te Tiriti Waitiangi acknowledges the special place of the Māori people as tangata whenua (the people of the land) - that is, indigenous. They understand it to be a covenant and a taonga tapu (a sacred treasure). The Treaty also provides the moral basis for the presence of all other peoples in Aotearoa-New Zealand and guarantees reciprocal rights and obligations between the Crown and Māori. (Healy)
} 
Ratana reinforces the significance of the covenant (the treaty of waitiangi) by using the waka as a symbol for the Treaty of Waitangi. This is because the waka has traditionally had a strong political function in Maori culture. This is best explained by Rawiri Taonui who states:

"Waka traditions are accounts of arrivals, dispersal and settlement. They tell of how tribes came into being and occupied their tribal lands"... "They define territorial boundaries and intertribal relationships.”

(Taonui, 1996, p. 87)

Ratana symbolized this through the carved images of the seven canoes from the 'Great Migration' alongside Abel Tasman's Heemskirck and Captain Cook's Endeavour. These were placed above each pillar holding up the veranda, along with the name of each waka or ship. In respect to the covenant, the boats are an expression of the religious and political union of Pakeha and Maori who sail together as one fleet. Ratana projects the same spiritual and ancestral ideologies of the Maori canoe to the Pakeha ships by referring them to 'spiritual life boats' and tracing their iwi back to that particular vessel.

Therefore the Manuao and Temepara are symbolic of the boat. This is an iconic symbol for Maori that manifests poetry and politics, history and myth, fact and legend through symbol. Ratana captures a Maori audience by introducing the idea of a warship into the biblical concept of Noah's Ark. This demonstrates how nautical concepts in Christianity were appropriated and then modified to affirm the identity of Maori culture. In both buildings, the eminent meaning behind the boat is both political and spiritual. In a political sense, it expresses the right to land for both Pakeha and Maori through their ancestral canoe. Spiritually the boat signifies the church conveying its members to safe harbour and the unanimous belief in one God for all of New Zealand. 

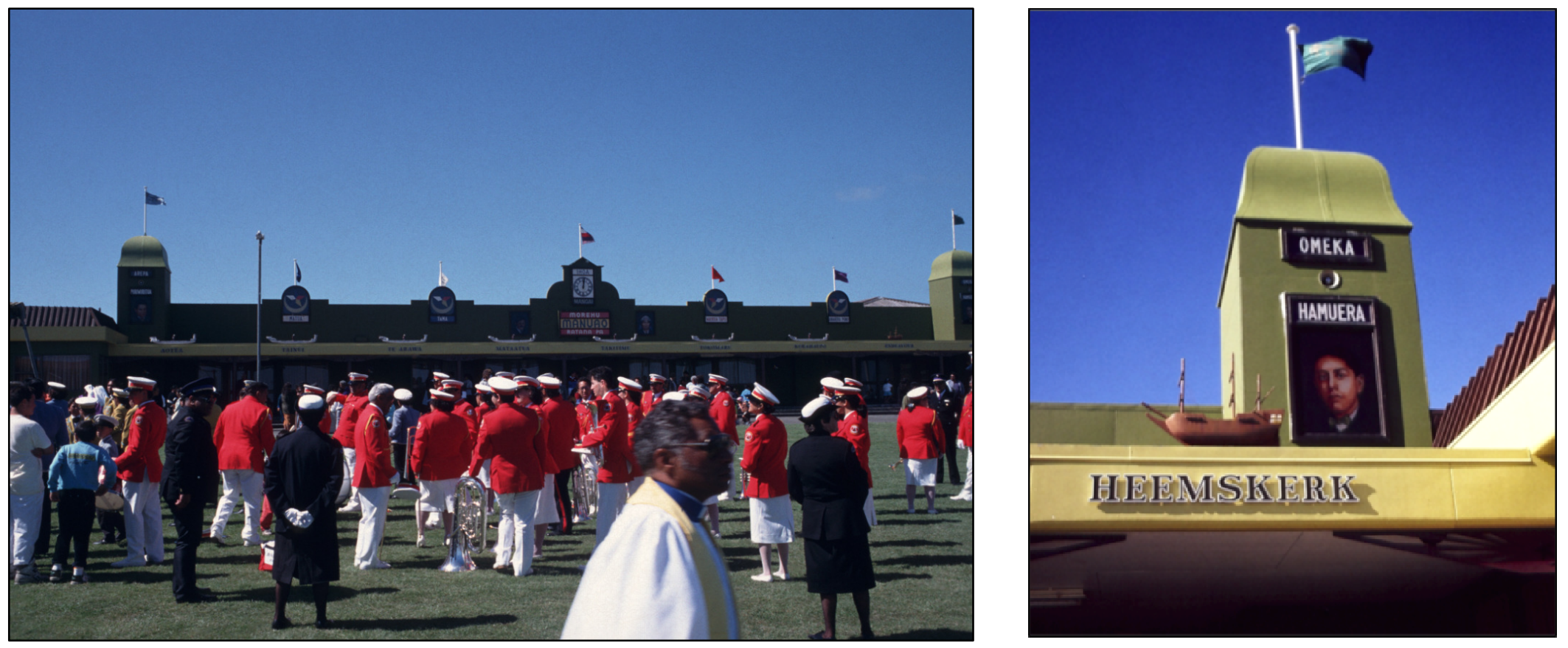

Figure 2.19 a \& b: Photograph of Manuao Building Complex showing seven migratory canoes and European ships the Endeavour and close-up of Heemskerk. 


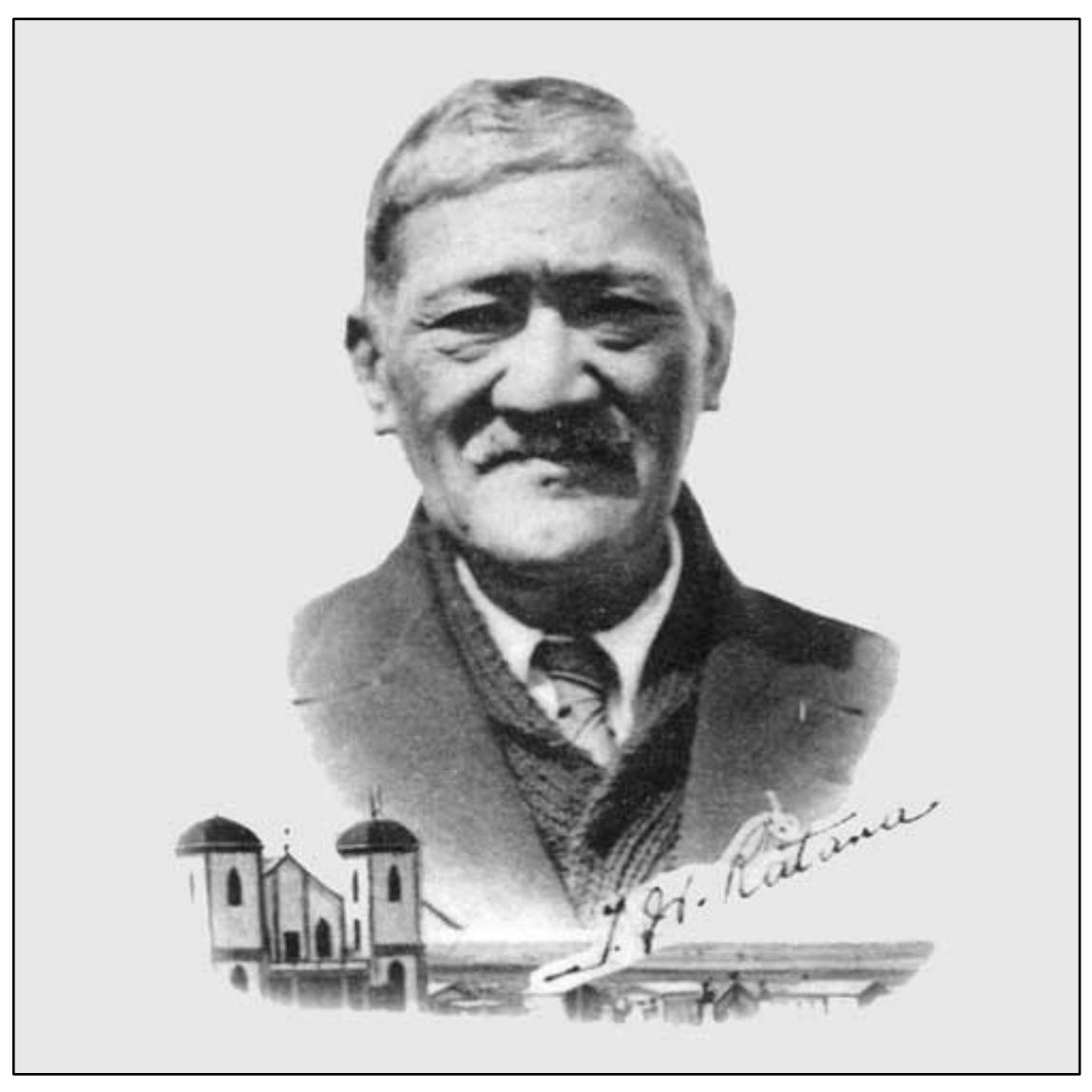

Figure 2.20: Portrait of T.W Ratana, founder of Ratana faith (artist unknown)

Figure 2.21 a, b, c: Figure a and b whetu marama symbols around the walls and shining in the windows. Whetu marama symbol can also be found in the shape of a garden - slightly visible to the left of the path. Also notice the use of plants beneath whetu marama inside the church to symbolise the earthly and celestial realm.

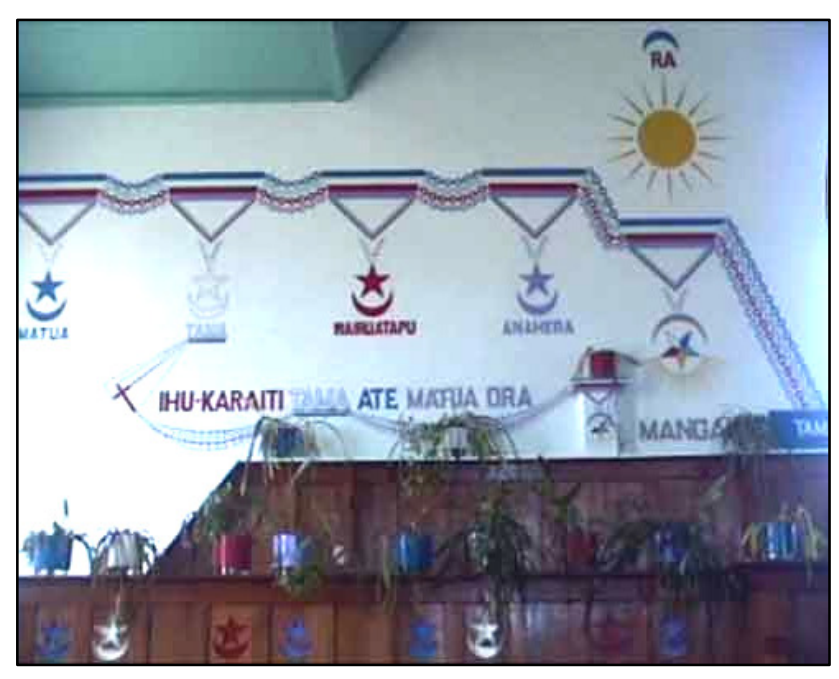

A

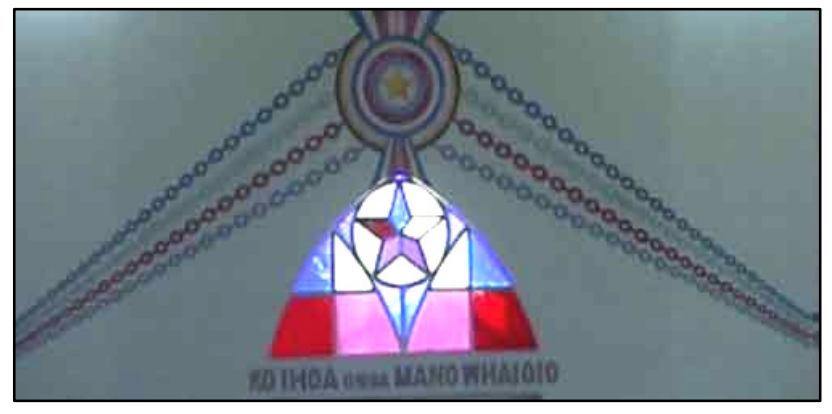

B

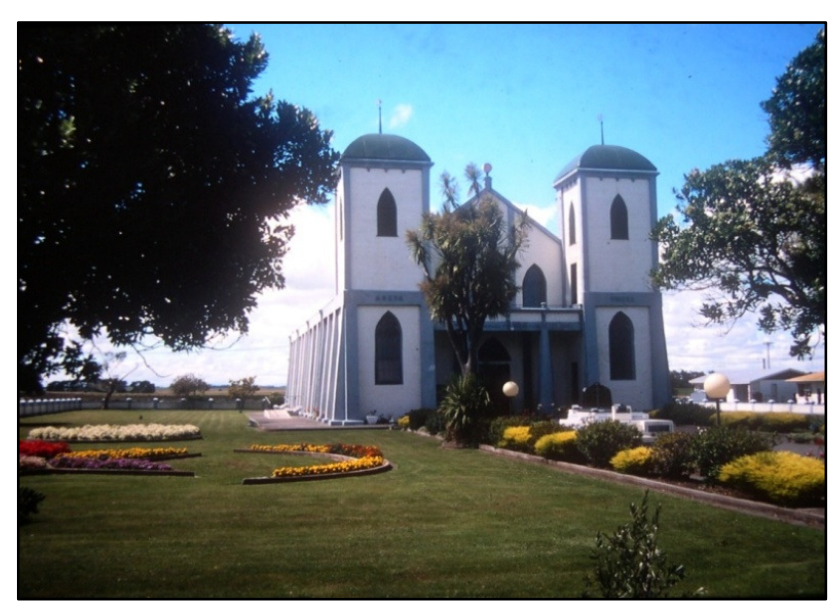




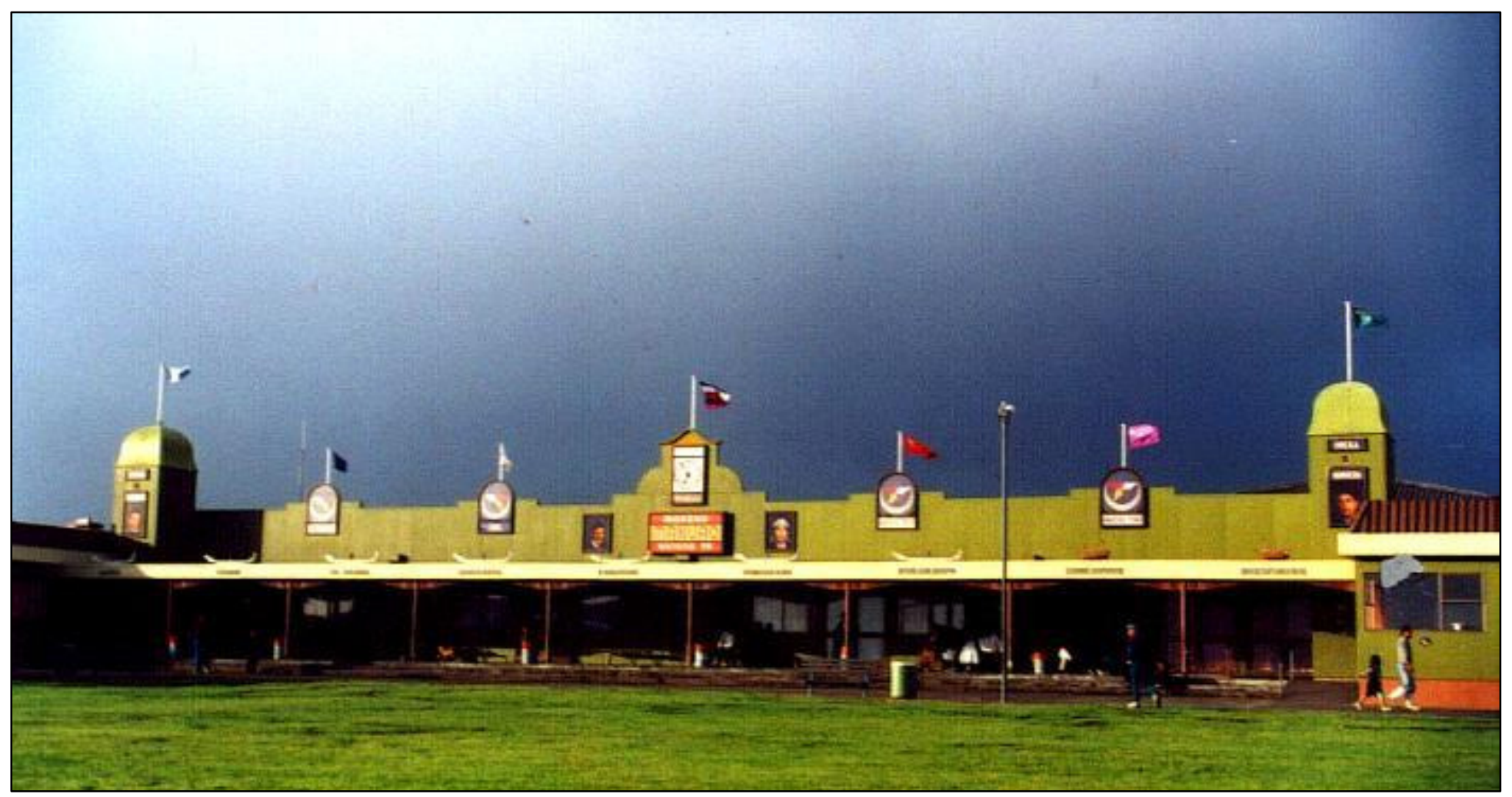

Figure 2.22: Photograph of the Manuao building complex at Ratana Pa. On the left are the offices of the church; on the right is the kitchen and dining hall. In the middle are three large sleeping halls. The grassed area is the marae area of the Pa: 
TE RITO-O-TE-TEMEPARA MATUA HAHI CHURCH

OPENED AT MANGAMUKA IN 1947

Figure 2.23 a \& $b$
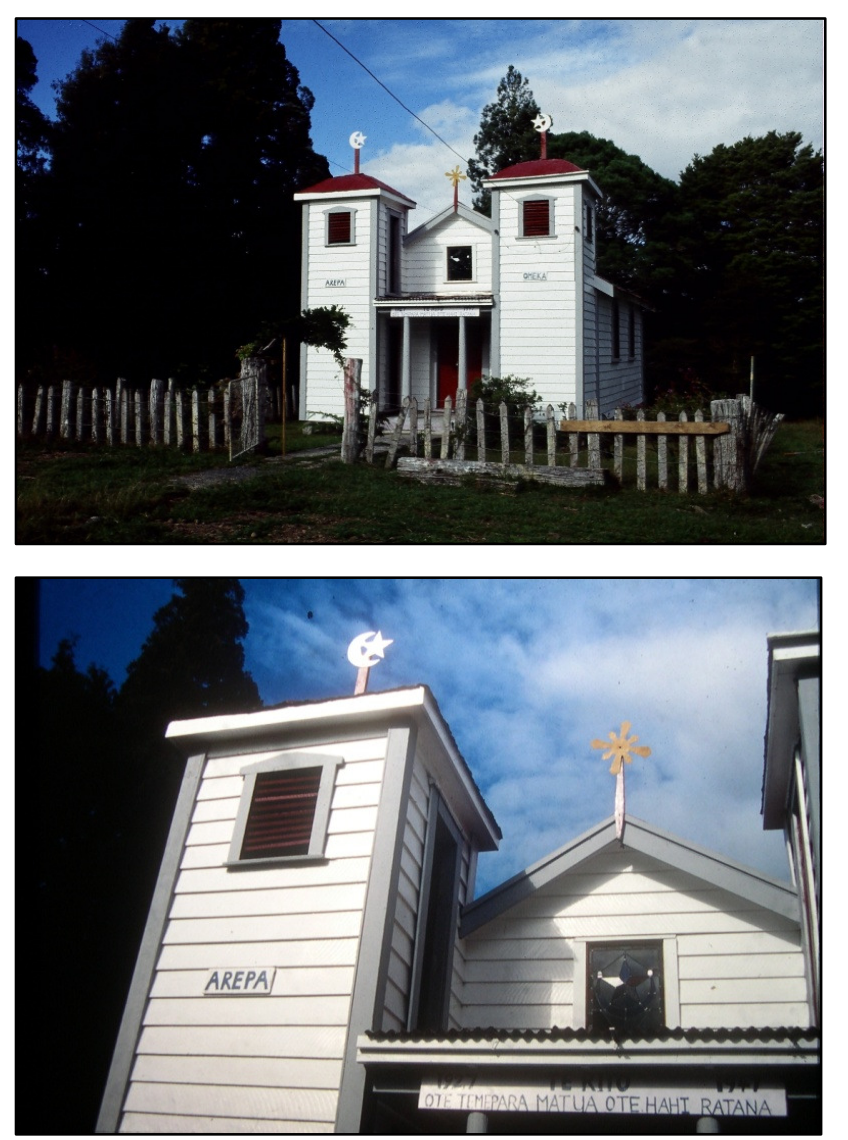

NGA TAPUWAE-O-TE-MANGAI

OPENED AT TE KAO IN 1952
TE REO POWHIRI CHURCH

OPENED AT TE HAPUA IN 1954
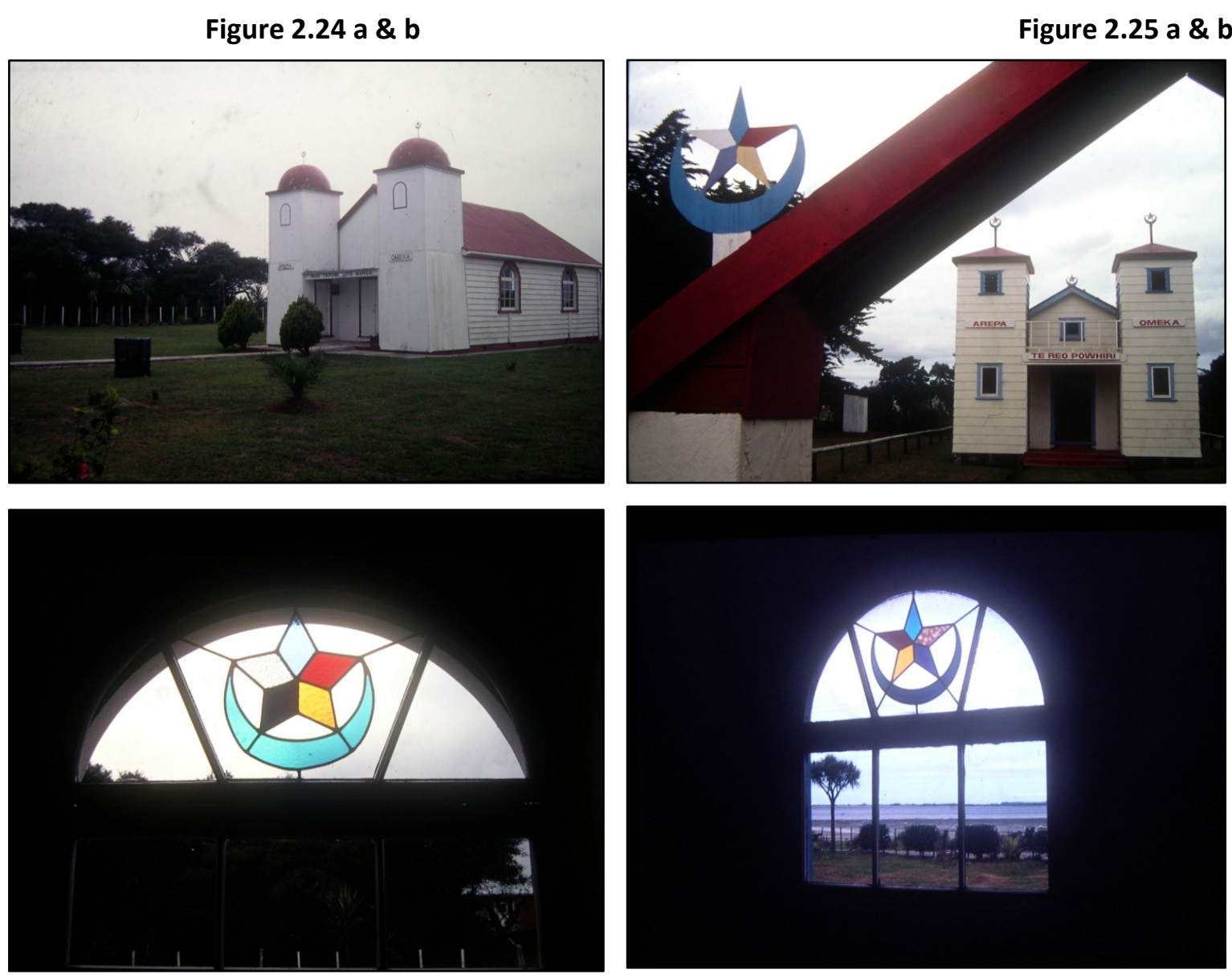

After Ratana's death in 1939 the architecture form and decoration of Ratana's Temepara were reinterpreted by the faithful in other North Island communities who continued to build branch churches in likeness to the Temepara. 


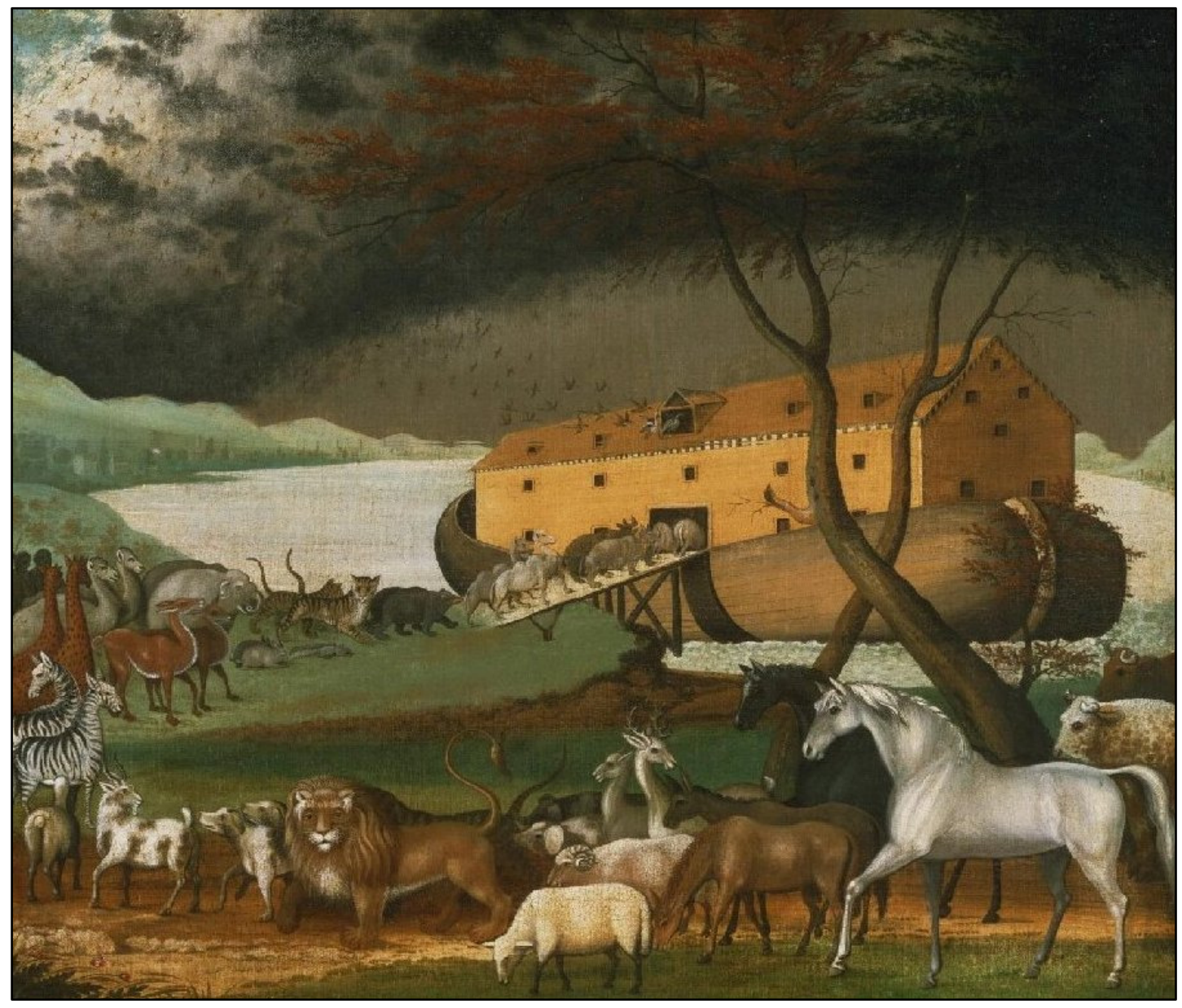

Figure 2.26: Painting by Edward Hicks (1846) Noah's Ark. 


\section{CHAPTER SUMMARY}

This chapter has proved how nautical symbolism is important in Christian Maori architecture because it links important histories, legends, people, knowledge and cosmological ideas from the past and into the present. This research has also discovered an interesting relationship between Christian and Maori architecture based on the appropriation of nautical Christian symbols. In doing so various examples of nautical Christian Maori symbols with hermeneutic interpretations have been discovered. On one hand, nautical symbols represent Christian concepts based on Maori cosmology. On the other hand, nautical symbols represent navigation concepts and waka traditions which are all important aspects of spirituality and cultural identity in Maori maritime culture. Therefore it seems that the relationship between nautical symbols in Christian and Maori architecture is one that links Christianity to a Maori cosmology.

One of the most popular Christian appropriations was evidently, the use of celestial symbolism. This research has revealed how these have been linked to Maori navigation concepts from which Christianity became linked and integrated into a Maori cosmology. As a result, Maori maintained their identity as a maritime culture and the spiritual concepts associated with it.

These ideas are discussed in greater detail at the end of this thesis from which nautical symbols in Christian Maori architecture are discovered to have more meanings embedded in their metaphysical dimension of understanding. Consequently, symbols mentioned in this chapter are reinforced by broader, nautical concepts discussed in the following chapter that investigates how nautical symbolism in Christian Maori architecture is more signal than sculptural. 


\section{CHAPTER THREE:}

CHRISTIAN MAORI ARCHITECTURE: MORE SIGNAL THAN SCULPTURAL 


\section{INTRODUCTION}

The main purpose of this chapter reveals how Christian Maori architecture has a distinct metaphysical aspect because it privileges the more immaterial and ephemeral meanings in symbolic architecture. This research relates this to dynamic architectural solutions that are symbolically and technologically linked with seafaring, vessels and navigation. This is compared to Christian architecture that objectifies spiritual ideas through pure dimensions of form and space, and in doing so becomes disconnected from the environment and the valuable metaphysical dimension of architecture.

Using case study examples from the previous chapter, part of this research begins by examining the differences between Christian and Maori religious architecture in terms of how their architecture responds poetically and pragmatically to their archetypal context. This particularly focuses on how structure and symbols are creatively interwoven through Christian Maori architecture in interesting and abstract ways. When compared to the fixed and solid construction methods

of Christian architecture, this research identifies how Christian Maori architecture still responds to what can be termed a 'water-based' architectural solution. 
Focussing more on relationships between the built and natural environment, this research then examines how Maori site their buildings according to navigation principles. In doing so this research examines how the buildings orientation and marae space help form spatial and symbolic links between the built and natural environment. These give Maori religious buildings a broader symbolic and sensual aspect compared to Christian architecture which is somewhat singular and objectified by space and form. Considering the importance of time in navigation, this research also investigates how time in Christian Maori architecture adds a metaphysical dimension unlike what is found in 'timeless' materials and frozen forms in European Christian churches.

This research finally examines Noah’s Ark as a popular nautical symbol used in both Christian Gothic churches and Christian Maori architecture. What is interesting is how Maori represent Noah's Ark much differently through architecture. It seems Christian architecture is more concerned with the technological aesthetic of a ship meanwhile Christian Maori architecture is more concerned with what it represents. Once again, this reinforces the main body of this chapter which highlights how Christian Maori architecture is more signal than sculptural. 


\section{AN INTRODUCTION:}

\section{WHAT IS PARADISE? — HAWAIKI VERSUS THE GARDEN OF EDEN}

In terms of religion, the sea generates two very different perspectives for Pakeha and Maori. These differences reflect how each culture perceives their ultimate place of paradise. For Pakeha, paradise is portrayed in the bible as The Garden of Eden, and for Maori, paradise is found in the mythical homeland of Hawaiki. In Maori tradition Hawaiki is described as an Island of abundance, where all fish and greenstone oozed from a sea fountain at Rangiriri just off Hawaiki's shore. It was also believed that man originated from there, along with lizards, insects and other creatures that all came to New Zealand on canoes of their own (Orbell, 1991). According to Christian tradition, mankind's origin was in a luscious garden. In Genesis, this is known as a lost paradise in the Garden of Eden. Unlike the oceanic paradise of Hawaiki, the Garden of Eden speaks of a much more terrestrial scene, abundant with fertile and luxuriant vegetation; "I made me gardens and orchards, and I planted trees in them of all kinds of fruits" (King James Bible, 1611, Ecclesiastes 2.5).

Both Hawaiki and the Garden of Eden do not represent an actual geographical place, but rather a cultural memory of simpler times when man lived off Gods bounty, or in the case of Hawaiki, lived as demi- gods. In the Garden of Eden, man is hunter and gatherer on land and on the Island of Hawaiki, man is predominantly fisherman and seafarer. This provides an archetypal context where intuition and imagination was first tutored and has since shaped and patterned the traditions of a culture. 


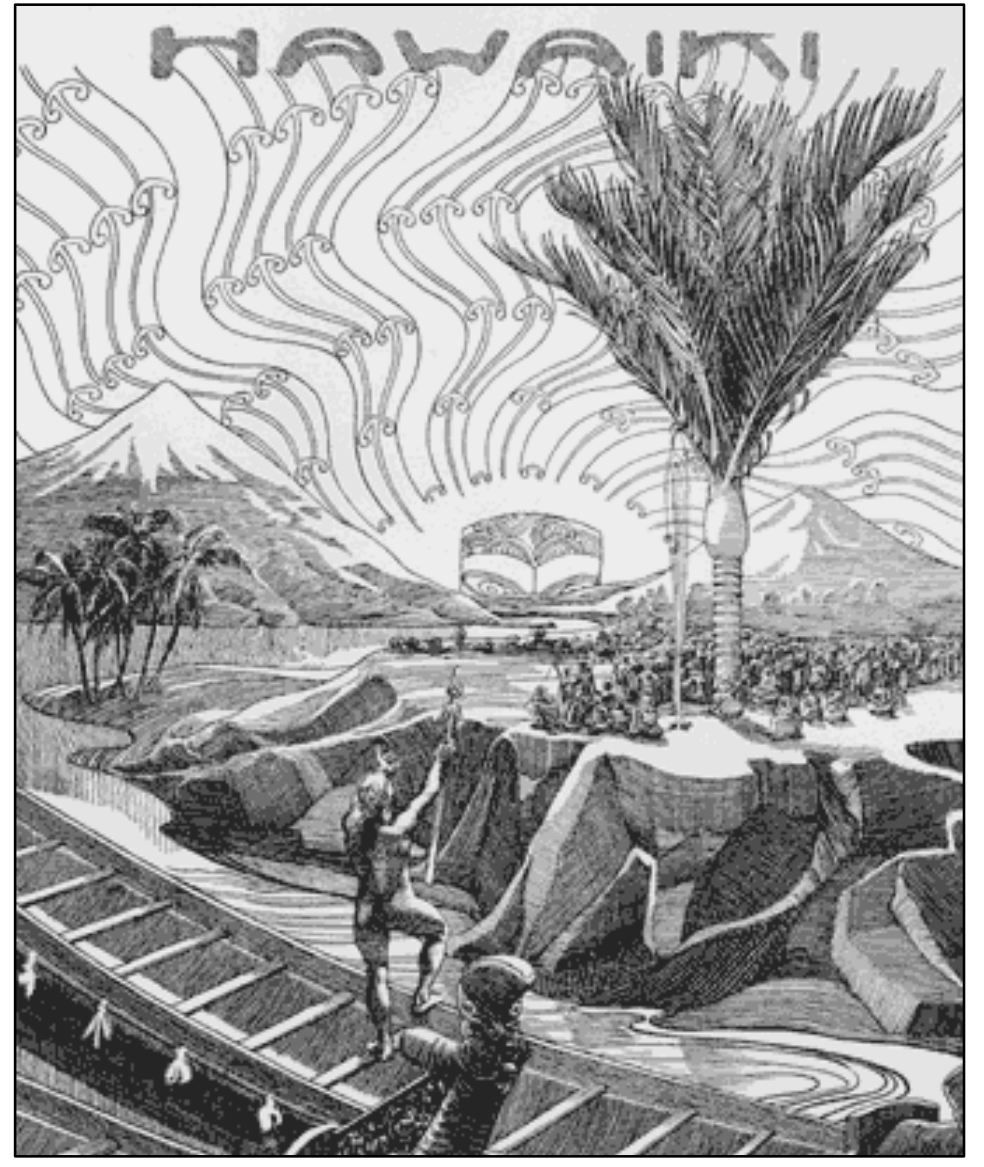

Figure 3.5: This imaginative reconstruction of the Māori homeland, Hawaiki, was drawn by artist Wilhelm Dittmer and published in his book Te tohunga: the ancient legends and traditions of the Maori in 1907.

Figure 3. 2: The Garden of Earthly delights - The Earthly Paradise (The Garden of Eden) by Hieronymus Bosch

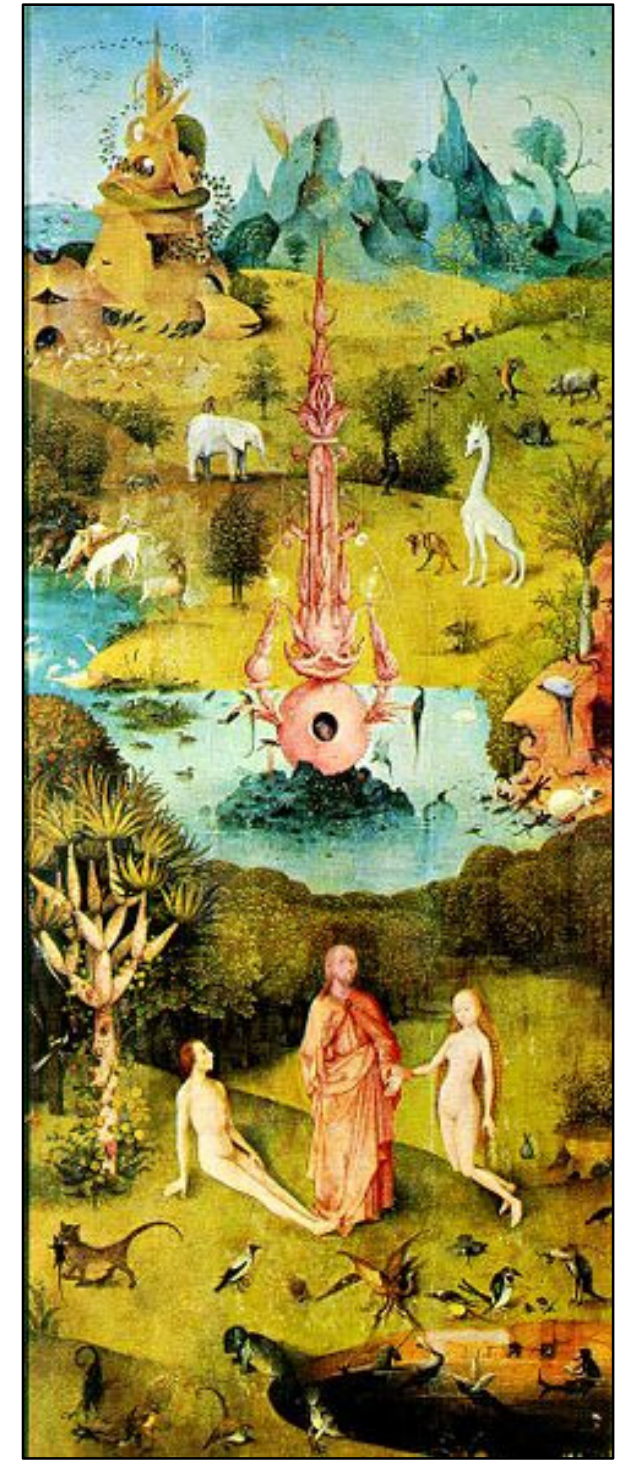


This defines two very different aspects of religion and architecture that correspond to what Sumet Jumsai (1939) links to either a 'land-based' or 'water-based' civilization. The Old Testament's origin reflects the ideological desert setting of landbased civilizations that were more familiar to Northern hemisphere dwellers than Maori. As a result, the sea was unfamiliar and perceived as something dangerous and menacing. For example, the Old Testament ${ }^{17}$ often depicts Yahweh (the God of the Jews and the Christians) fighting the sea. His enemy was also portrayed as menacing sea elements such as the deep or abyss, a sea deity or a monster(s) of the deep (King James Version, Psalms 74:13). This anti-sea is also expressed in the story of the Great Flood, the drowning of the Egyptians in the Red Sea and the fear of the sea and deep waters.

In contrast Hawaiki typifies an oceanic context highly familiar to Maori and water-based civilizations. As suggested through the legend of Hawaiki, the sea has gained religious significance through its importance as a medium for travel by boat and as a valuable seafood resource. Ultimately the major differences between Hawaiki and the Garden of Eden reflect humanities interest in their existential roots: a place where man first grasped vital relations in their environment to give meaning and order to events and actions in the world. Consequently, this led to symbolism in Christian and Maori religious architecture that is psychologically and technologically very different.

This archetypal context forms the basis for many differences found between European and Maori architecture. This chapter particularly explores how familiar perceptions of either a terrestrial Eden or oceanic Hawaiki have conditioned different notions of building and expression in spiritual architecture.

${ }_{17}$ The Old Testament was more popular in the colonial and post-colonial periods. Bronwyn Elsmore has widely documented the Maori

"Israelite" movements, in her book: Like Them That Dream. The Maori and the Old Testament. 
Water-based architecture prompts to attention the convincing theory of Sumet Jumsai (1939) who distinguishes that architecture is either 'water-based' or 'land-based'. This notion is also shared by Albert Refiti who suggests that the "ocean is the single most powerful architectural device in the evolution of Polynesian architecture and culture" (Quoted from Austin \& Treadwell, 2009, pg. 37). These statements refer to the technologies and characteristics of Maori-Polynesian architecture that are much different to those of European, 'land-based' cultures. In the oceanic environment, architecture required greater flexibility and adaptability and therefore tensile structures and materials were predominantly used. Austin has related this type of architecture to the temporal environment of the ocean in which Pacific space has a sense of spatiality and motion that is "thoroughly imbricated with the technologies, mythologies and aesthetics of movement" (Austin, 2003, p. 226). Austin believes that these are temporal qualities found in fleeting lightweight constructions and their porous spatial qualities. "Pacific walls breathe and are permeable as and screens" (Austin, 2002, p. 7).

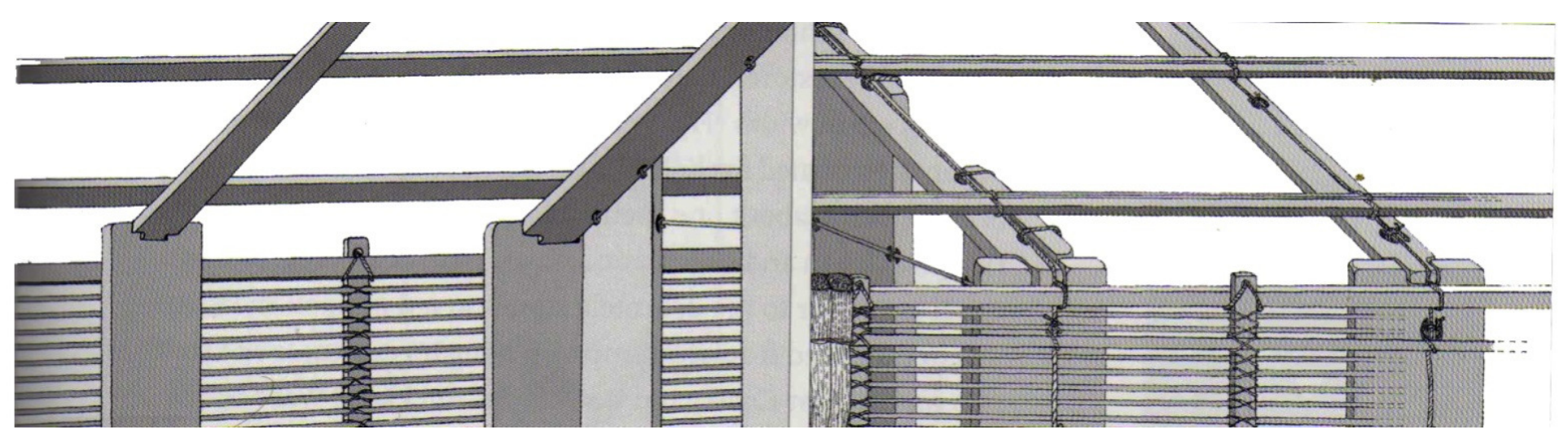

Figure 3.3: Image showing typical detail of permeable and tensile (post- tensioned) whare construction. By R.T. Wallace, C. J. Irwin \& R. Neich 

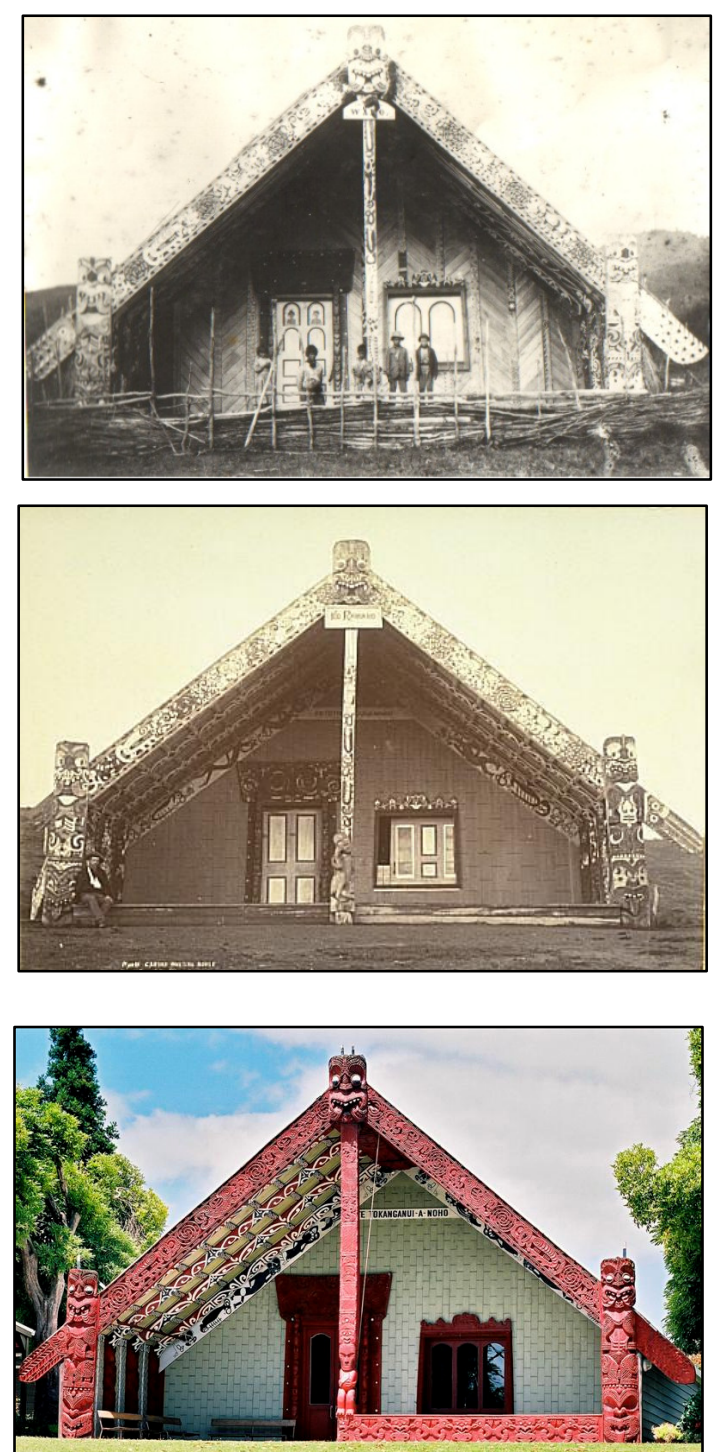

Figure 3.4 a,b,c: Te Tokanganui - a - Noho restored and relocated between the $19^{\text {th }}$ and $20^{\text {th }}$ Centuries.
In relation to Christian Maori architecture, Te Tokanganui - a - Noho (fig $4 \mathrm{a}-\mathrm{c}$ ) is a great example of transient shifting architecture. The lightweight construction of the meeting house allowed for the building to be relocated twice and rebuilt four times. Also, Ringatu meeting houses and Ratana churches used temporal materials that were allowed to decay and eventually be repaired if necessary. This condition of movement and the ephemeral quality of religious Maori architecture contrasts with the permanent, terrestrial reality of Christian churches in the colonial and post-colonial periods. This is because Christian architecture derives from a land-based context (an Eden or desert) in which solid materials and compressive construction methods were commonly used. Even when local, tensile materials were used in Christian architecture, their buildings continued to recreate the style and technologies of Western vernacular buildings that look and behave like stone or compressive buildings.

Canoe building traditions have also influenced Maori-Polynesian architecture. Austin suggests that the prehistoric Maori house derives from canoe building technology because of the way it is constructed from the top down and its use of lashing and post-tensioning (fig 3). Ringatu meeting houses use similar tensile construction methods and even use of old war canoes in parts of meeting house. Neich (2001) has noted examples of meeting houses that reuse old war canoes as koruru at the apex of maihi or in some cases; canoe timber was cut up and re-used as poupou slabs and skirting boards in the porch (Neich, 2001, p. 174).

With these pragmatic differences in mind, it can also be assumed that symbolism in 
Christian Maori architecture is 'water-based'. Sumet Jumsai suggests that symbolism corresponds to the intellectual conditioning of water-based civilizations which arose in an environment of flux and flow. Therefore along with flexible and adaptive structures, there came "the ability to create and communicate instinctively and abstractly" (Jumsai, 1939, p. 72). Ultimately this gave symbolism in water based cultures a powerful, metaphysical aspect. This is certainly the case in Maori architecture which has traditionally been inscribed in the arts, oral tradition and total Maori culture. The media of architecture extends further than the object but to symbols that are spatio-temporal (discussed later in this chapter). This is certainly evident in the niu pole where its flags rely on the wind to fully communicate their symbols. Furthermore Ratana symbols have a simplistic and abstract quality that were often misinterpreted by westerners as folk art or flat. As Bill Mckay and Deidre Brown (1992) have noted, this flatness actually indicates a simplification and concentration of intention. This reveals how image takes precedence over form because symbolism is understood by Maori metaphysically. Wiremu Ratana reinforces this idea when he states how symbols are merely portals into a deeper spiritual 'window' (Hagger, 2003). Therefore symbolism in Christian Maori architecture can be considered “more signal than sculptural” (Mckay \& Brown, 1992, p. 129).

In contrast, European Christian architecture relied on form, scale and three dimensional spaces to formally communicate their symbols. Again, this reflects the characteristics of land-based architectures that privilege fixed, solid forms and materials based on their terrestrial reality. As a result, their spiritual architecture was lacking a further dimension of meaning that Maori desired in their spiritual buildings. Although Christian Maori architecture appropriated forms, materials and technologies from Christian architecture, they continued to create buildings that were distinctly a water-based solution. In this sense, the metaphysical dimension of their buildings was maintained by instinctively implementing high levels of pragmatism within elements of symbolism. 


\section{NAVIGATING RELATIONSHIPS BETWEEN THE BUILT AND NATURAL ENVIRONMENT}

Maori-Polynesian navigators were renowned for their intimate skill with angles and their relative values. Altitudes of celestial bodies and their azimuths when rising were well monitored in relation to the vessel. By day the sun and moon were used in the same way. The wind and ground swells were also a matter of understanding and maintaining direction. Consequently, the necessity of knowing one's direction led to a strong set of symbolic values associated with the cardinal directions and relationships in the surrounding context. This segment of research investigates how this navigational capability is a skill that can be applied to architecture. In this sense, this research conceives the waka out at sea as the whare in the landscape. This idea is particularly applied to a system of orientation applied to Ringatu meeting houses and Ratana Churches. This is then compared to the Christian church which is much more disconnected to its site and context. This research investigates how this main difference is attributed to the marae space in front of Christian Maori buildings which provides connections between the built and natural environment.

Just as the waka was orientated relative to distant stars linking places and people to their gods, so were Ringatu meeting house relative to the landscape, its people and their legends. For instance, meeting houses were typically arranged with a seaward/landward orientation referring to the mythical homeland of Hawaiki and New Zealand (Neich, 1993 p. 123). Also, the back and front of the meeting house was arranged so the front opens towards the sea or plains and the back is enclosed by hills, mountains or bush. The landscape features connect the meeting house and its people to the land by defining tribal territory and the local legends and stories attached to them (Austin, 1980, p. 233). Similarly, some Ratana buildings were known to be positioned in relation to significant landscape features. Deidre Brown suggests the Raetihi branch Church may have been rebuilt so that its front entrance faced Mount Taranaki rather than the road. She also speculates that the Omeka Pa Hall in Matamata may have been designed to echo the shape of the hills behind (Brown, 1997, p. 228). 

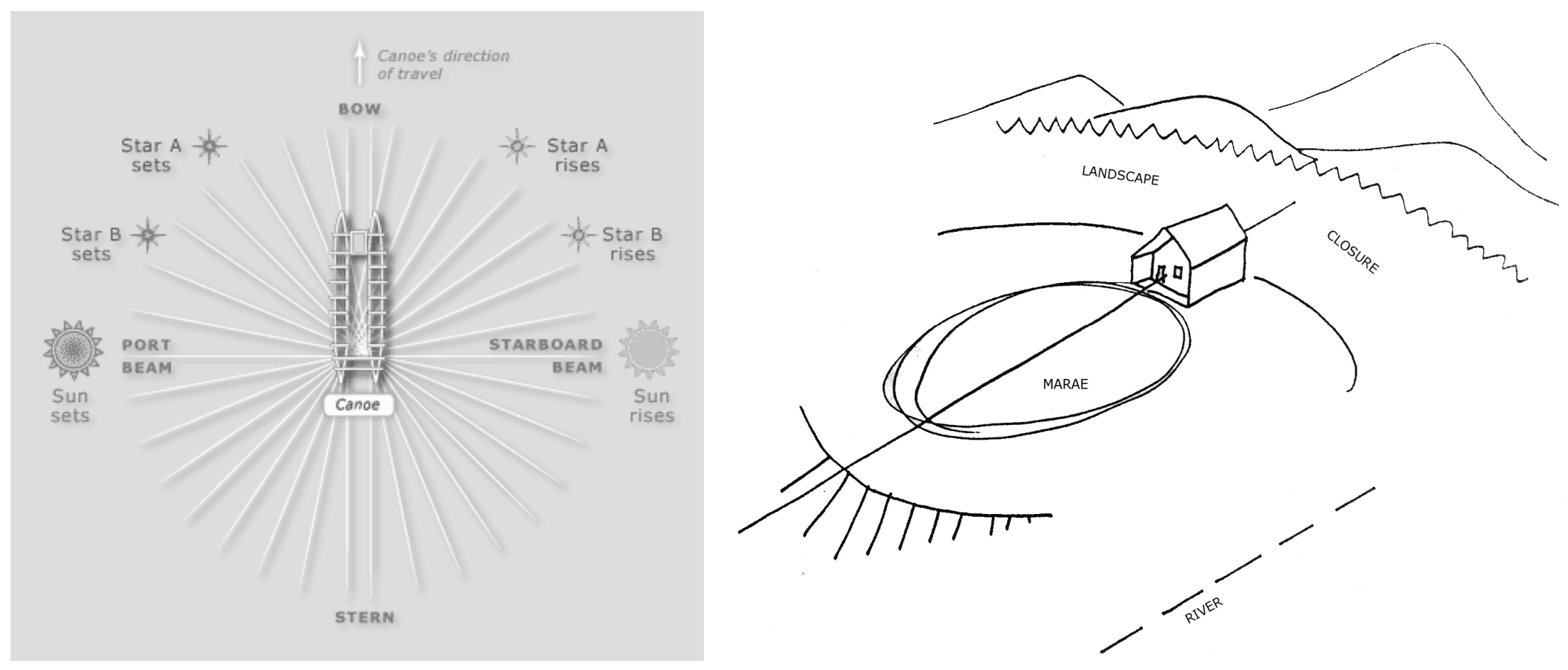

Figure 3.5: (left) A strong relationship to the surrounding environment is always maintained out at sea on the waka. Figure 3.6: (right) Illustration by Mike Austin showing the relationship between meeting house, marae and the natural environment. 
In comparison, the Christian church has little relation to the landscape. Instead, Christian architecture can be seen as a physical object in space. This disconnection emphasized that the church was to be seen as a place apart and different from the world outside. Consequently, Christian buildings and their symbols do not represent their immediate (and ephemeral) surroundings, but instead relate to a specific Christian doctrine. An important aspect this notion lies within the buildings orientation. In the Old Testament, the ancient Jews speak of "the four corners of the earth" (Revelation 7:1) the Christian church was symbolic of this:

"The four parts of the interior of the Christian church symbolize the four cardinal directions. The interior of the church is the universe. The altar is paradise, which lay in the east” (Eliade \& Trask, 1959, p. 61).

Like Christian belief, Maori also associated east with the paradisal land of Hawaiki. East was also important due to astronomical reasons. This is because east was the direction from which the tohunga kokorangi (Maori astronomer) would eagerly await the rising star, sun or moon that would help gauge their vessel by night or day. When this knowledge was transferred to agricultural and local fishing lore in New Zealand, the legend of the first house, the wharekura, reveals a symbolic structure and orientation based on these astronomical (and cosmological) concepts (See Appendix A). It is possible that Ringatu meeting houses also considered astronomical concepts in architecture to reinforce the sacred cycle of the seasons and the rhythm of the land. 
Ringatu gatherings were based on, the cycle of the twelfths, or the reappearance of the new moon at the start of each month. Te kooti supported this concept through Christianity in revelation 22:2 which refers to the tree of life with its twelve fruits (Binney, 1995, p. 420). Each month, ${ }^{18}$ outdoor feasts at 6am in the morning were held on the marae, this being the time from which many morning stars could be seen. In Maori tradition, the rising constellation Matariki and Canopus were greeted with song and lamentation, and possibly with posture dancing (Best, 1923, p. 4). In similar manner, Ringatu celebrated the traditional Maori New Year, signalled by the rising constellation Matariki (Pleiades) and the sighting of the new moon during the winter solstice. ${ }^{19}$

Considering the importance of astronomical concepts in Ringatu religion, it appears that the marae space in front of the meeting house was a distinct way of reinforcing the celestial realm. This is because it offered a sense of openness like that of a vast ocean. This makes sense considering the ocean evokes the vast expanse of sky which glistens on its surface. Mike Austin (2007) reinforces this idea by implying that the marae space is:

"the surface for living that is both smooth and level... it is a recreation of the horizontality of the sea, but also the smooth surface desired by the mariner after the incessant movement of the sea” (p. 7).

Considering that celestial (navigation) symbolism was important in all Maori religious movements, it appears that the marae space was just as enduring throughout all Christian Maori buildings. Rather than relying on representations of celestial symbols, the marae was a stage for their actual presence and guidance. In Ratana churches, the use of fences create an "open air living room" (Austin, 1980. p. 231 \& Firth 1959) similarly found on the marae. Also the porch space in the Ratana church functions as an extension of the marae atea and therefore recalls the openness toward the sea. Also, as I have already mentioned, the ship-mast form of the niu pole literally appears to sail in a sea of open ground offered by the marae.

\footnotetext{
${ }^{18}$ Ringatu gatherings are held on the twelfth day of every month, with special celebrations on 1 January, 1 June, 1 July and 1 December of every year. Morning, afternoon and dinner feasts (hukari) used to be held outside on the marae. Today they are located in a dininghall (Salmond, 1976, pp. 200-202).

${ }^{19}$ This traditional harvesting rite was also given biblical significance, based on references in Exodus 34:22 and Deuteronomy 26:2.
} 
Evidently, navigation principles have been applied to a new geographic space and a new kind of vessel (a church) that was held with similar spiritual veneration. This research has demonstrated how Ringatu meeting houses have an intimate acquaintance with their surrounding context that is similar to the waka out on the ocean. This idea has been reinforced by one of the most enduring spatial concepts in Christian Maori architecture, the marae. It appears that the marae is symbolic of the vast expanse of ocean and sky linking the interior and exterior of the building. This creates an intimate connection between buildings and celestial phenomena much like the waka out in the ocean. Once again, this reveals how symbolism in Christian Maori architecture does not require representations of three dimensional forms to communicate spiritual ideas. Instead, nautical instinct allows Maori to communicate in abstract and more meaningful ways where symbols are part of the environment rather than how it is represented.

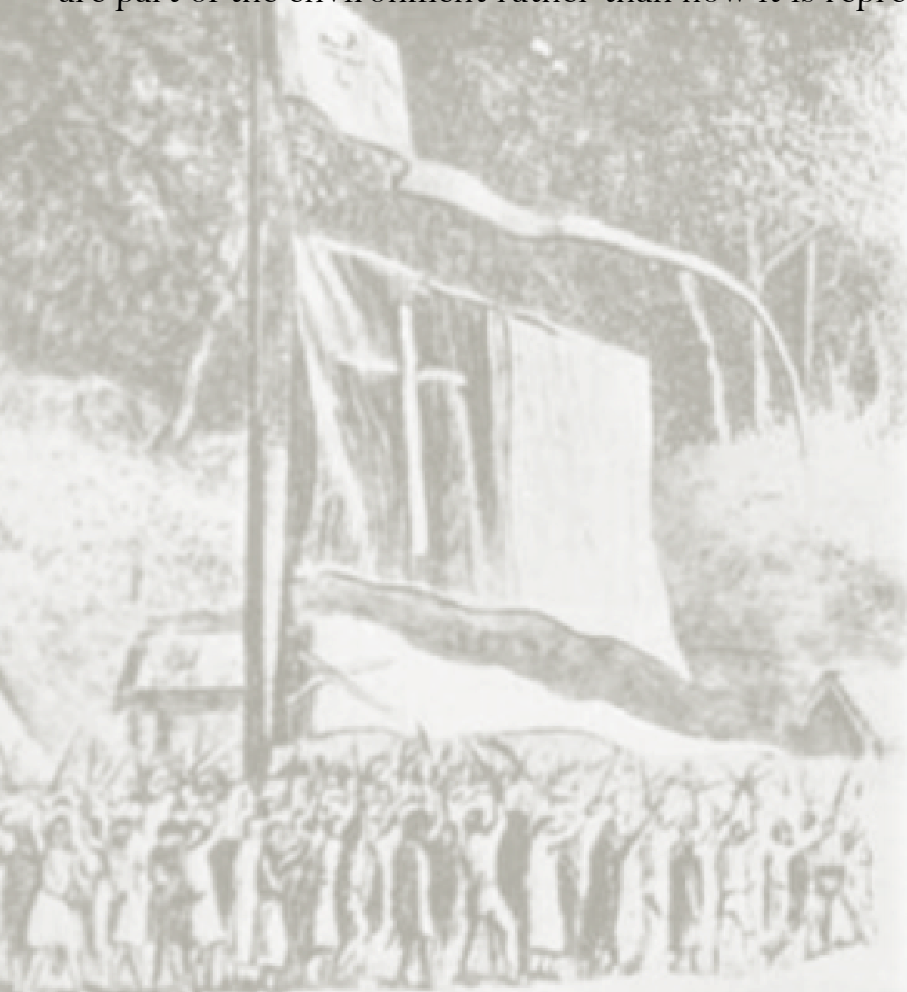

Figure 3.7 


\section{SENSING ARCHITECTURE: EXISTING IN TIMERATHER THAN SPACE}

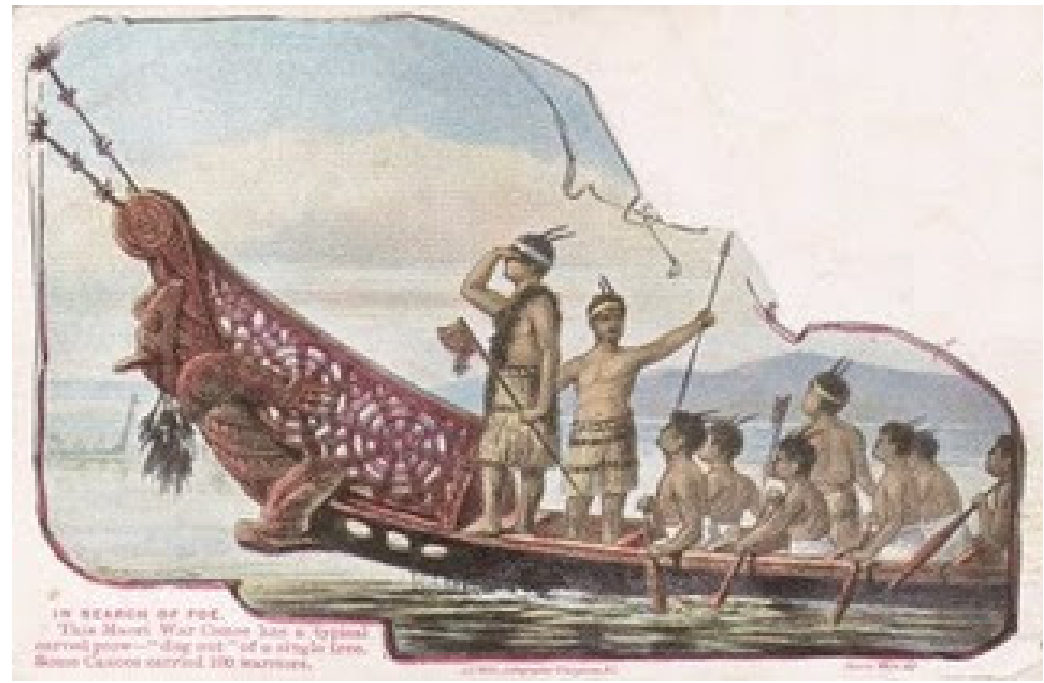

Figure 3.8
The Maori navigator was engaged with the Pacific environment in what Europeans would call humanistic, metaphysical and phenomenological modes of experience. This is certainly evident in the way they read the ocean in a rather haptic sense. Here, the Maori navigator could feel out the rhythm and patterns of the ocean chop and swell, senses attuned to the slightest detection of change in birdlife, fish, marine-mammal sightings, submarine phosphorescence and clouds. What Europeans might see as a blank expanse, was rather an abundant space full of natural, readable information.

This segment of research examines how these modes of experience have influenced how Maori co-ordinate their natural and built environment in a very sensual way. Despite the influence of the Christian church which emphasized the use of formal interior spaces, part of this research examines how Maori appropriated Christian spatial concepts in a way that maintained a sense of openness and close relationships between the built and natural environment. Consequently, this allowed Maori to engage and experience time in architecture. 
With the rising popularity of Christian architecture, the natural environment was increasingly being shunted from the Maori religious experience. Formerly, traditional Maori religious rites were conducted in open space more familiar to the experience on the waka. ${ }^{20}$ Alternatively, the Christian church emphasized a contained sensory experience within an architecturally choreographed space. Christianity also emphasized a different dimension of spirituality in which the senses were directed more towards abstract feelings of spirituality based on Christian doctrine. Similar notions of sensory experience can be applied to European navigators who needed little more than the constructs of an artificial Cartesian system. The haptic senses were disengaged and the natural environment was little more than a representation on paper. This was the reality Maori were facing when Christian architecture tried to harbour their religious experience. It was like trying to tell them how they should ride their boats.

When the missionaries were marginalised during times of war and political unrest, Maori Christian architecture developed under its own terms. Distinct Maori religious movements chose to appropriate the idea of an internalized religious space over time. However, a connection to the outdoor space remained vital during early developments of Christian Maori architecture. This is because the external environment was the realm of their own gods. Pai Marire was first to interpret the interior of the church by establishing an altar space (with a niu pole as its crucifix) from which Pai Marire leaders would administer a liturgy to their followers. Although this was not an interior space in a physical sense, it offered the same sense of sacredness and protection. The altar space was not distinguished in a physical, architectural sense, but through spiritual energy. This spiritual energy was manifest in the natural surroundings, particularly the wind. This indicates the niu pole was not an object of worship, but a place of worship. Unlike Christian "faith in things unseen", traditional Maori-Polynesian religion is based on the experience; one which involves the interaction with their gods (Charlot, 2006, p. 22).

\footnotetext{
${ }^{20}$ Before Christianity, religious ritual was conducted in a secluded place away from the village (Neich 1993, p. 93).
} 
As well as the need to interact with their gods, the environment was a medium that reinforced Pai Marire symbolism - the piping and blowing of the wind helped transmit the symbols of the flag - a spiritually woven signal. This demonstrates how emphasis is fully placed on communicating symbols unlike Christian churches which objectify their symbols through pure physical dimensions of form and space.

Although Christian Maori architecture eventually appropriated vast interior spaces, the use of paepae (thresholds) became an increasingly important concept in architecture. These were symbolic spatial devices that allowed Maori to move through their buildings in time rather than space. This evokes the traditional world of Maori who are reminded of history by deeply living in time and focussing on the spatial world and its possibilities. Walmsley and Mckay (2005) relate this to the voyager who depends on the infinite promise of stars (and undoubtedly the predictable rhythm and knowledge of surroundings) to promise his future:

“The Maori space-time construct can be thought of more like a constellation with the past and the people of the past always felt in the present, like the constellations of the sky to the voyager - enmeshing, surrounding, always before you, always behind, forming patterns that can be interpreted in various ways" (Walmsley \& Mckay, 2003, p. 92).

Walmsley and Mckay (2003) describe how time is experienced by physically and mentally negotiating these paepae. These are the steps, portals or gateways leading the way through different dimensions of the spiritual world. In the Temepara, the main paepae (threshold) is experienced through the main gateway (waharoa) marking the entrance to the Temepara complex. This was where some Maori left material belongings such as watches and handbags at the gate before entering the Temepara, to emphasize the transition between earthly and sacred realms (Brown, 1997, p. 383). Ringatu meeting houses are experienced through a series of approaching steps, or 'pae', both inviting and challenging. One significant paepae is experienced when passing through the porch and then under the house pare (door lintel) of the meeting house. This final paepae is regarded with the same sense of trepidation as boarding a waka taua (Brown, 2009, p. 25). 


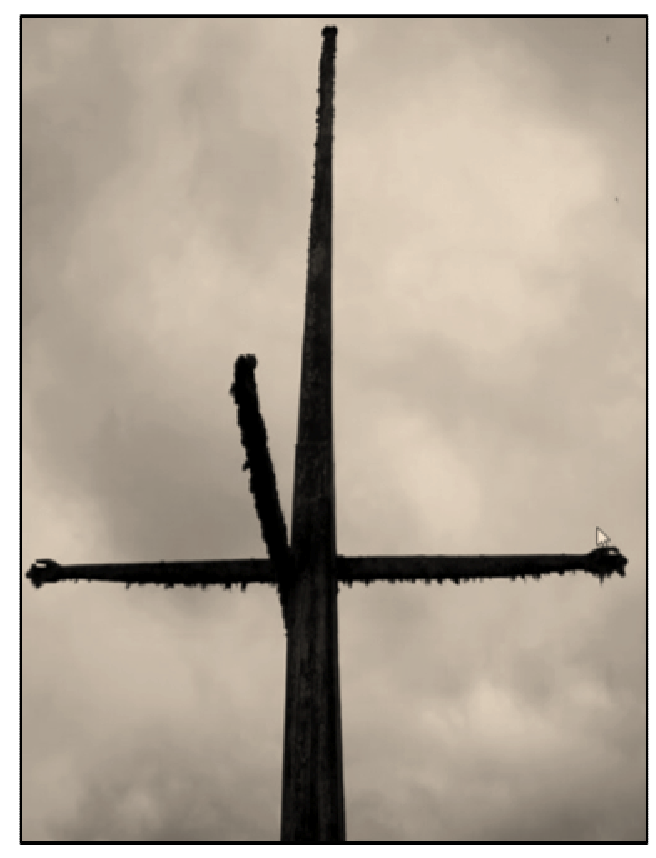

Figure 3.9: Use of pare (door lintels) in niu pole

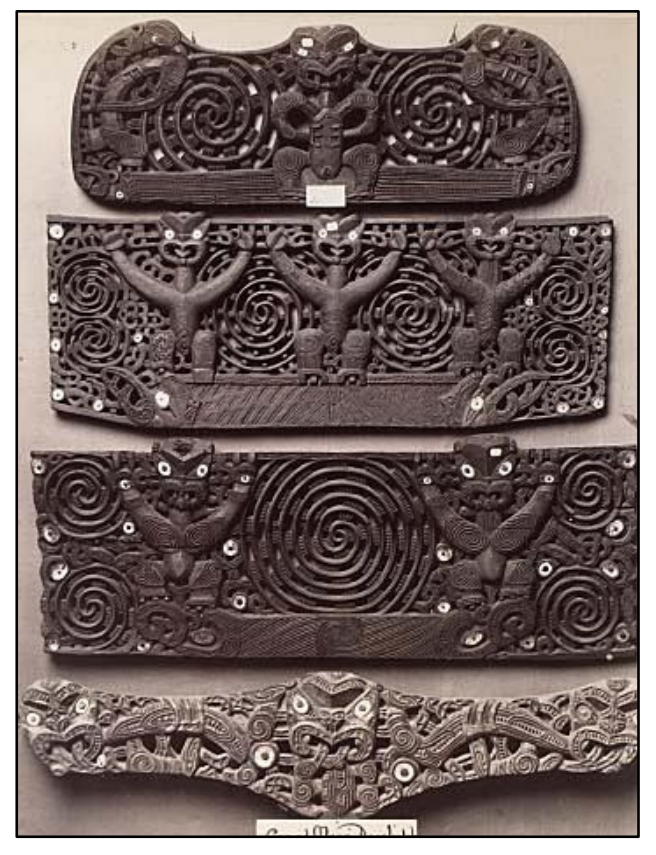

Figure 3.10: Typical pare (door lintels) found in meeting house

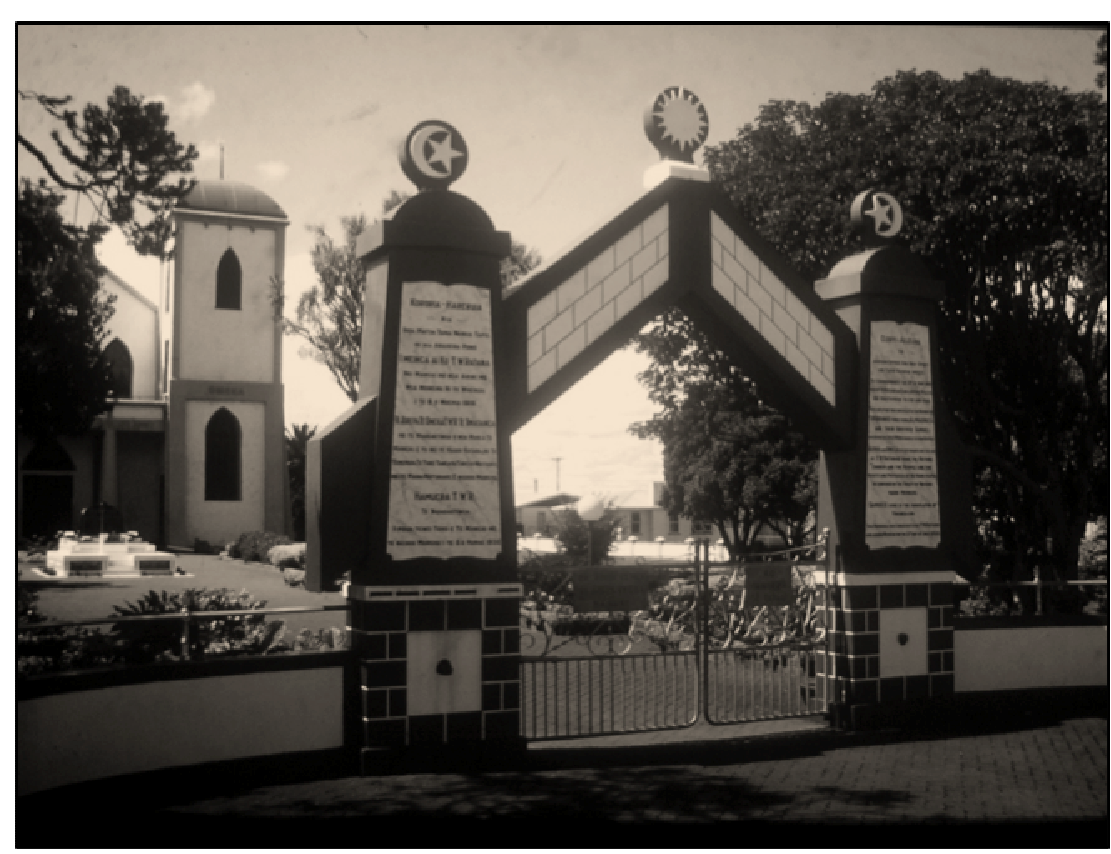

Figure 3.11: Use of Wahoroa (gateway) to create threshold between the sacred and profane 
Deidre Brown has also noted that the crossed yard-arms of the niu pole had the same transitory associations as Maori door lintels (pare). Brown explains how these could be interpreted as doorways between protected and unprotected realms (Brown, 1998, p. 2). Ultimatley, these paepae not only engaged Maori in time becasue it took time to negotiate them. These paepae also provided thresholds between different realms of time echoed in transitions between interior and exterior, present and past the sacred and profane and so on.

In contrast, the European Christian church is timeless. In the bible, the Christian God is omnipresent and described by Isaiah in 57:15 as the 'high and lofty One who inhabits eternity'. This speaks of God as either timeless or simply everlasting. This is a testimony to Christian architecture, where time is frozen in physical dimensions of form and space. Time is manipulated by plan, surface, geometry and forms that are carefully defined by an interior space. An interior focus also means time is lost by isolating relationships between the internal and external environment. Instead, the external environment is contested by durable materials and solid construction methods which allow the building to remain unchanged through time. As we have discovered, Christian Maori architecture exists primarily in time rather than space. Like the seafarer, the haptic senses are constantly engaged through architecture. Symbolic spatial devices such as paepae are used to evoke spiritual rather than physical boundaries and provide relationships between the built and natural world. This engages the occupant in symbols that echo the complex phenomenological world rather than one that is merely representational. 


\section{NOAH'S ARK, THE WAKA AND GOTHIC ARCHITECTURE}

When Christian - Maori concepts of Pai Marire faith were developed further by Ringatu believers, the idea of an internal religious space grew among Maori Christian church builders. Deidre Brown's article, The Maori Response to Gothic Architecture reveals how the dramatic, vertical infinite ceiling space of Gothic Christian architecture was admired by the Maori people. The founder of Ringatu faith, Te Kooti Arikirangi Te Turuki, was said to be involved in recreating gothic spatial concepts in the construction of Manutuke's Gothic church. Brown suggests that this is where Te Kooti would have gained the knowledge of large-scale building that was later used for constructing various Ringatu meeting house projects (Brown, 2000, p. 262). ${ }^{21}$ This final segment of research examines the connection between Christian gothic architecture and Christian Maori architecture in light of its symbolic connection to a boat. What is interesting in Christian Maori architecture is that rather than emphasizing verticality and feelings of infinite space, the large, one-celled space of the Christian gothic church was appropriated for different reasons that did not focus of form and scale. It seems gothic building principles transferred to the meeting house were applied for symbolic reasons more familiar and fundamental to the meaning of vessels in Maori culture.

${ }^{21}$ The large scale of a Gothic church was particularly found in the large Ringatu meeting house Te Tokanganui-a-Noho (considered the prototype for Ringatu meeting houses). 


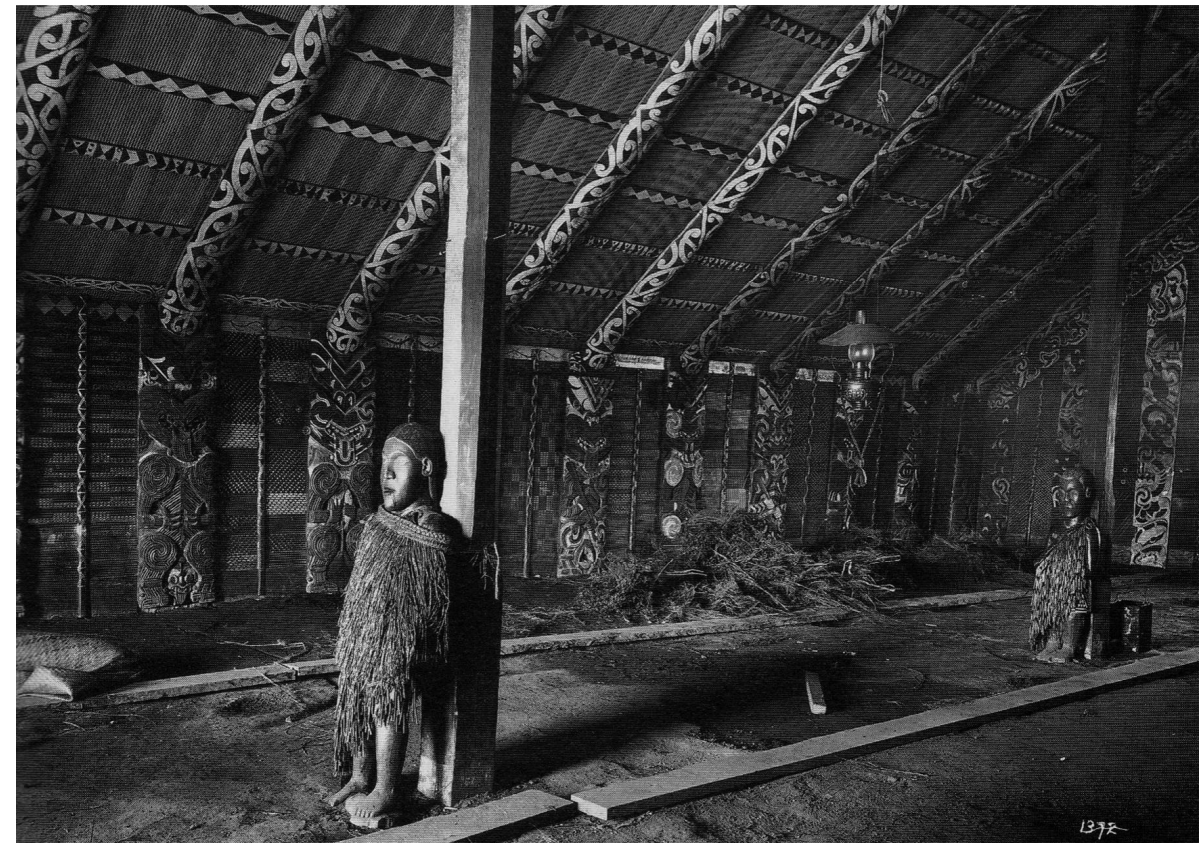

Figure 3.12: Larger, gothic scale interior of Te Tokanganui - a - Noho

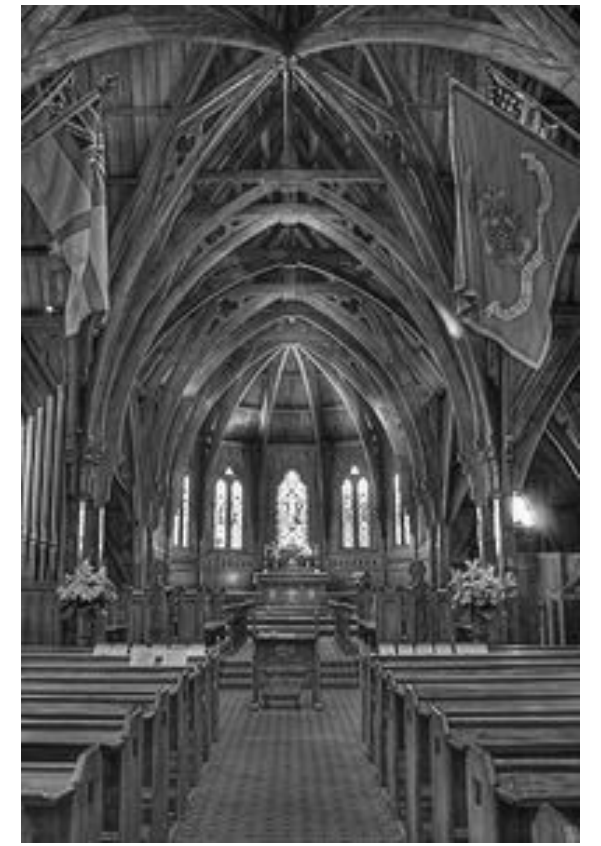

Figure 3.13 Old St Pauls church in Wellington: 19th-century Gothic Revival architecture

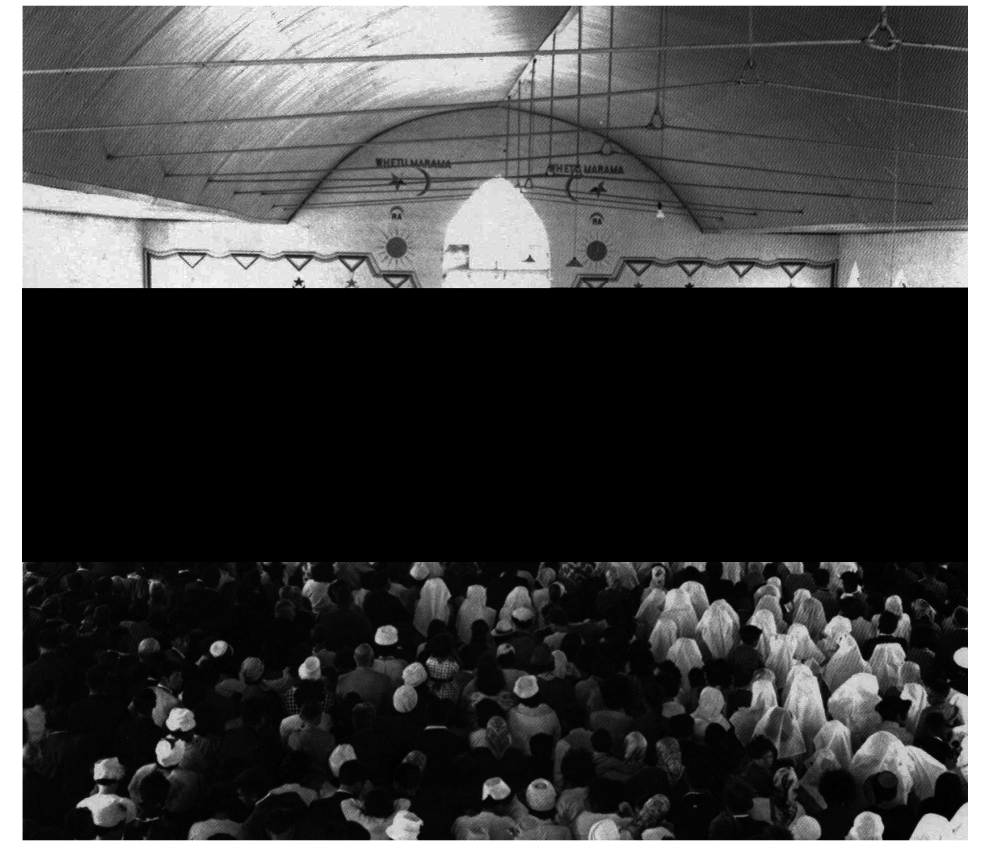

Figure 3.14: The Hull-shaped ceiling in the Temepara. 
In order to realise the Maori appropriation of the Gothic church interior, it is important to note the symbolic relationship between the structure of the Gothic church and the structure of a ship. In this sense, Christian and Maori architecture find common 'water' in that both land and water based architectures derive from the technologies of seafaring people. Reginald A. P. Rogers has found interesting theory on the origins of gothic architecture which states in the Historian's History of the World (1908):

"Gothic architecture in both its branches, Saxon and Norman, has evidently sprung from a sea-faring people. The nave of the Gothic cathedral, with its round or pointed arches is the inside of a vessel with its timbers, and merely raised upon posts and re-versed" (Rogers, 1915, p. 15).

The same writer adds that the name for the main body of the church, called the navis or nave, means the 'ship' of the building. Austin and Treadwell (2009) have also compared the structural composition of the whare and the waka. He notes how the whare follows canoe building technologies because of the way it is constructed from the top down and its use of lashing and post tensioning.

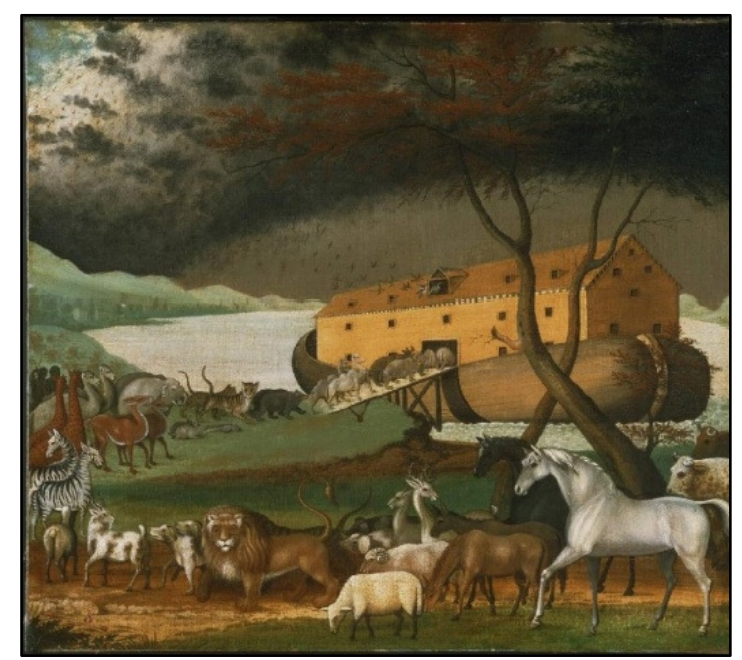

Figure 3.15: Painting by Edward Hicks, depicting Noah's Ark in a house like from

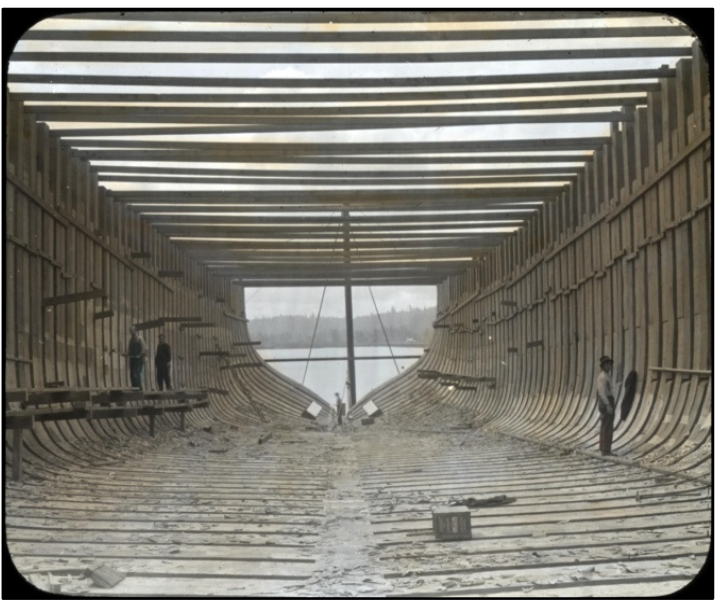

Figure 3.16: Showing typical construction inside interior of a ship 
Considering this fact, Christian Maori architecture may have appropriated gothic church symbolism and technologies based on their association with European boat-building. After all, Te Ua appropriated the European ship mast as the niu pole because it was believed that the Christian God and European ship were spiritually interconnected. Also, Te Kooti (founder of Ringatu) was probably aware of the connection between gothic architecture and European boat building due to his experience on European schooners. ${ }^{22}$

If a technological link was not made, surely a symbolic reference to the Christian gothic church as a ship of refuge was known by Maori. This refers to the biblical story of the great flood in Noah's Ark. The story tells of an Ark that was blown upside-down and then used as a dwelling or temple - this being the origin of Gothic architecture (Rogers, 1915, p. 16). This idea resonates with stories across oceanic cultures in the Asia-Pacific where legend suggests the upturned boat was the first house. ${ }^{23}$ Ratana makes this symbolic connection by comparing the barrel-vault ceiling in the Temepara to the shape of a ship's hull. Ratana also establishes a second Ark (Te Aka) in the Manuao (Man-of - war) building. The Manuao presents on its facade the seven migratory canoes including the Endeavour and the Heemskerck which he refers to as spiritual lifeboats.

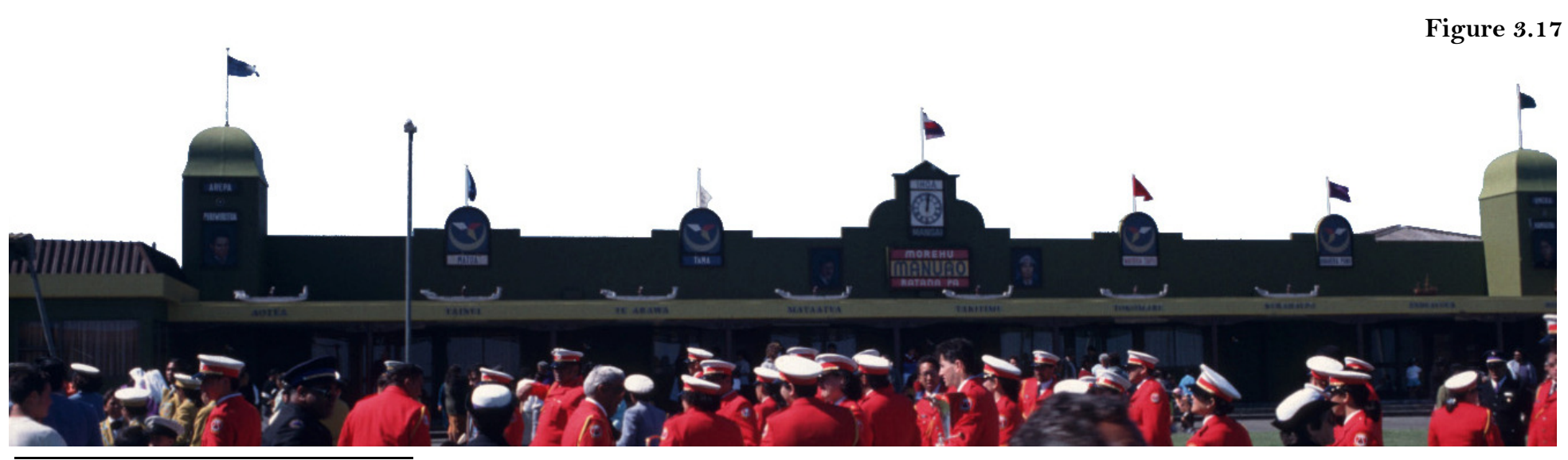

22 Te Kooti had quite a reputation as a sailor. He acted as supercargo on a Maori trading schooner for some voyages and later commanded another. (Fowler, 1957).

${ }^{23}$ Michael Austin has recorded Polynesian ancestral stories which claim that houses were upside-down vessels and vice versa (quoted from Brown, 2009, p. 4) 
In Pai Marire and Ringatu faith, Noah's ark is not an architectural symbol. However, both movements were undoubtedly inspired by this biblical story. Instead natural manifestations or 'aria'24 seen out on the marae became linked to the biblical story. In this respect, Maori were able to conjure spiritual connections with God based on divine experience rather than through symbolic form and space. For instance, Pai Marire followers performed rituals that would invoke the rains of the Christian flood myth around the niu pole (Peschel, 1971, p. 121). For Ringatu, the rainbow (Gods promise to Noah) is understood as a sign of God's covenant with Ringatu adherents. Consequently, different manifestations of rainbows were waited upon to signify daily decisions and fulfil Ringatu prophecies (Binney, 1988, p. 168).

Due to the popularity of Noah's Ark, it is possible that internal religious spaces became increasingly common because of its symbolic link to the boat rather than Christian gothic aspirations of dramatic scale and form. This reveals one of many examples of how nautical Christian symbols were appropriated because they resonated with their Maori history and experience. The roof as an upside-down boat is particularly important to Maori because it implies a very tight social (religious) organization as on a waka. It also implies symbolic relationships between sea and land, man and community, the individual and his ancestors, death and the continuation of life and so forth. Therefore, in the words of Allan Hanson, (1990) nautical Christian symbols were given "Maori roots" and "Christian Branches"25. Ultimately, this means many nautical Christian concepts and symbols in architecture were still founded on Maori concepts. In doing so, this allowed Maori to maintain a strong sense of identity as a maritime culture and the cosmological world associated with it. Where Noah's Ark was not symbolized in form and space, Maori relied on temporal, symbolic manifestations of nature to conjure feelings of spirituality. This is where we see the importance of maintaining relationships between the built and natural environment through the marae in Christian Maori architecture. This follows Maori tradition where the experience out on the marae was more significant than faith in things 'unseen'.

\footnotetext{
${ }^{24}$ Natural phenomena observed at sea such as rainbows, comets and meteors were regarded as aria, as well as more material forms such as lizards, birds and fish. Maori came to personify these as Gods and integrate them into a cosmological framework associated with navigation. (See Maori as deep sea navigator and explorer).

${ }^{25}$ Hanson, Allan. (1990) History of Religions, Vol. 30, No.2 Christian Branches, Maori Roots: The cult of Rua
} 
In evaluating space, form and symbols in Christian Maori architecture, it can be said that Maori interpretations of Noah's Ark focused on signifying socio-spatial concepts rather than scale and form. It can also be said that the appearance of rainbows and other natural manifestations in Noah's Ark were conceived as aria, which are linked to navigation. In this sense, Maori were interested in the meaning and concept behind Noah's Ark rather than how it was represented through form and space in architecture. This reveals how Maori focus on the immaterial and metaphysical dimension of architecture even when they are faced with dramatic architectural forms that most Europeans would find spectacular and awe inspiring. 


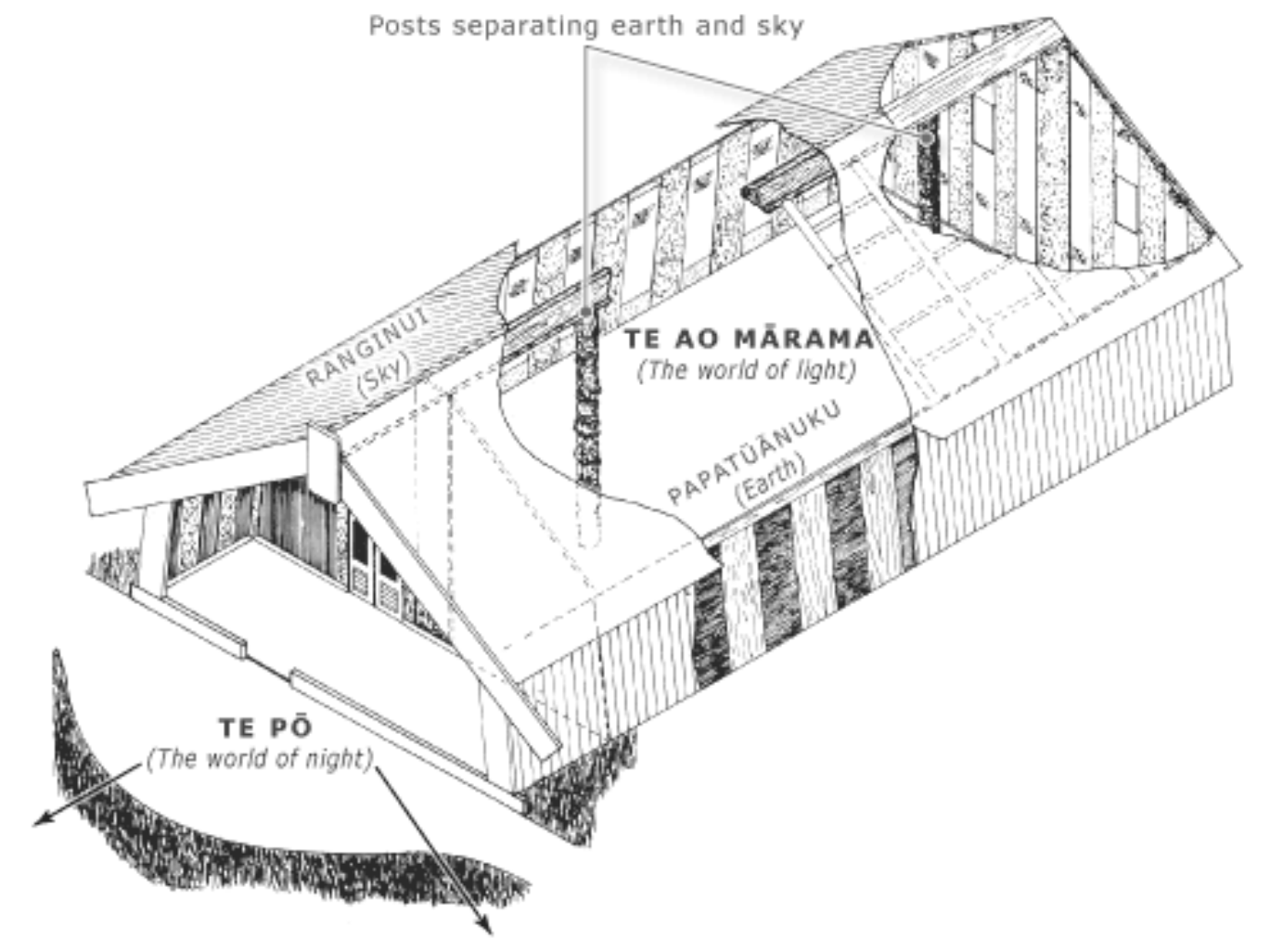

Figure 3.18: This diagram shows the symbolic dialogue between Te Po (the marae space in front) and the Te Ao Marama (inside the meeting house) the porch is the threshold between these two worlds. 


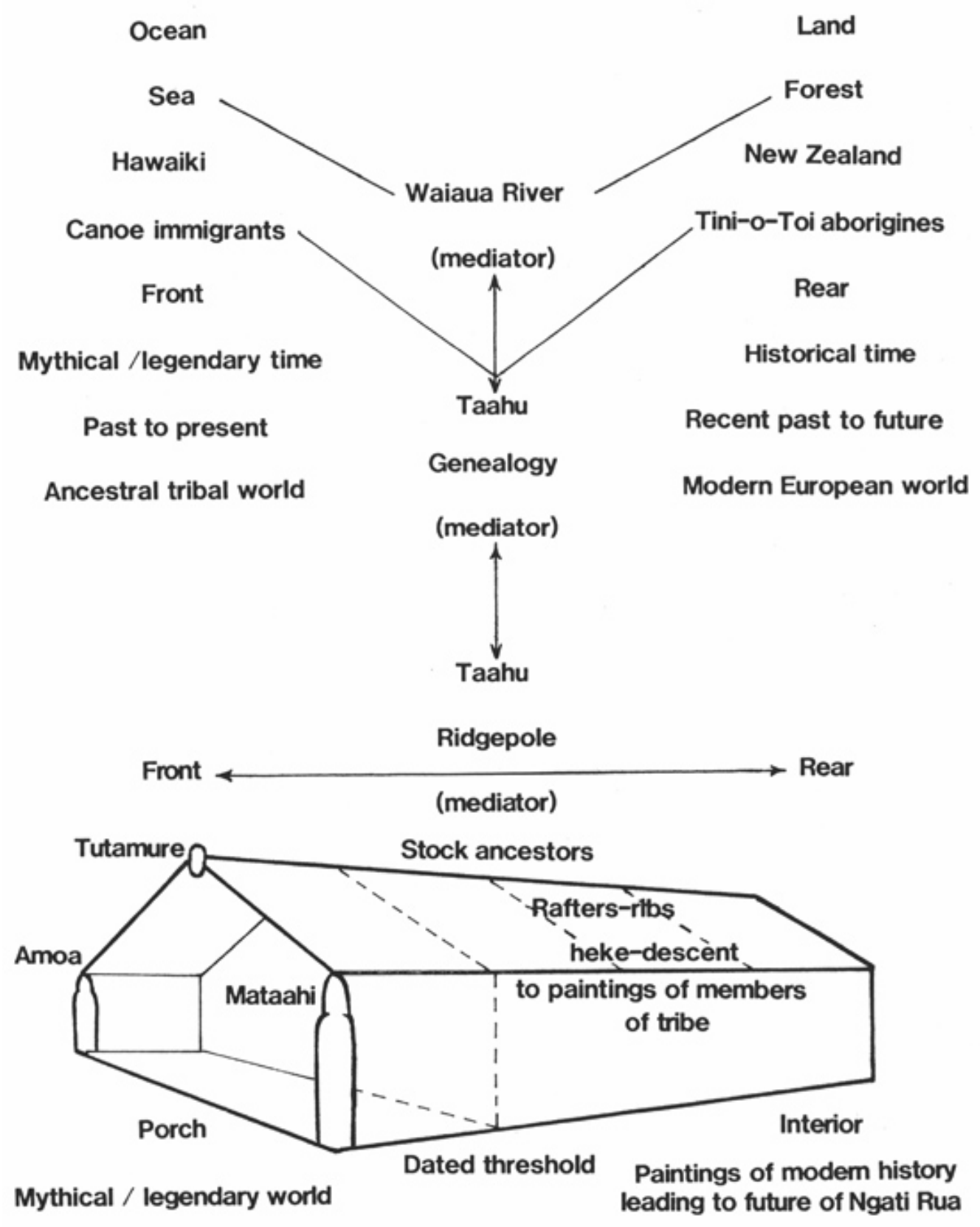

Figure 3.19: Typical arrangement of meeting house showing relationships between the meeting house and its environment (similar to the waka out on the ocean). 


\section{CHAPTER SUMMARY}

This chapter has revealed an important difference between Christian and religious Maori architecture that is ultimately related to the context of either a European or Maori concept of paradise. In light of Hawaiki, (the paradisal land of Maori) a transient lifestyle on their boats led to an intimate understanding of living and responding to constant states of flux and flow in the oceanic environment. Consequently, Maori developed a critical understanding of more immaterial, sensual and ephemeral meanings from which Maori have continued to represent and implement this understanding through their religious architecture and symbolism. As a result, their religious architecture speaks of the New Zealand environment much more than the fixed and permanent nature of land-based architecture that is found in contemporary New Zealand. What is exciting about this research is the potential to learn from nautical symbolism in Christian Maori architecture that can transform contemporary notions of New Zealand architecture through design. In this respect, nautically inspired design has the potential to add a new dimension of space, form and symbolism in architecture that enriches our understanding of how we can live in a world that is closely connected to the ocean environment and its ecosystems. This forms a strong basis for design exploration which is explored in more detail in the following chapter: Research + Design. 
RESEARCH + DESIGN 


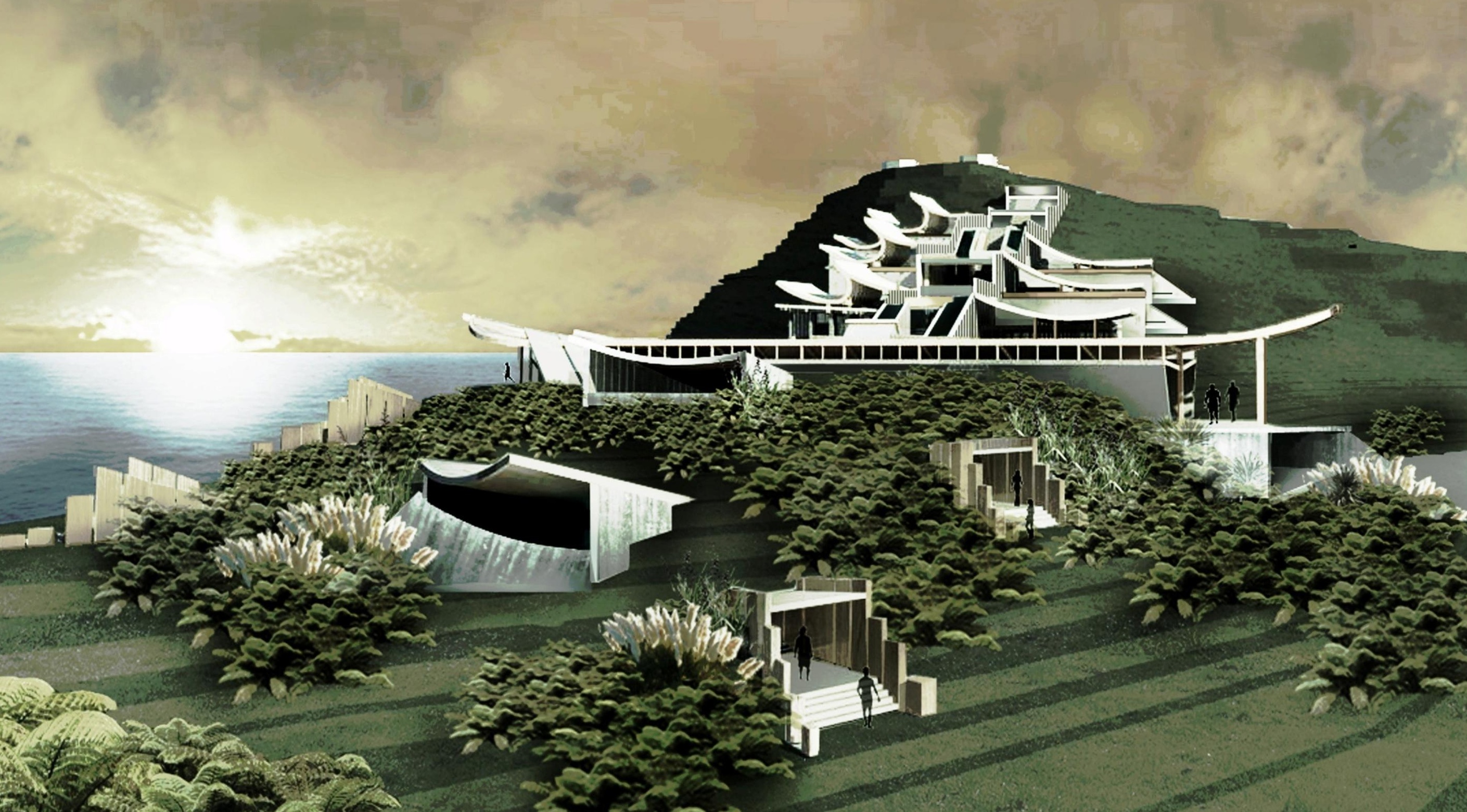




\section{INTRODUCTION}

The majority of contemporary architecture in New Zealand is anchored in a terrestrial (Westernized) reality which privileges pure dimensions of form and space. Furthermore, technological progress is based on aspirations of durability, weather resistance and solidity. As an Island nation, these Western architectural values fail to recognize qualities that correspond to the ephemeral oceanic context in which we live. Unfortunately, this means New Zealand architecture generates 'timeless' forms of expression that are disconnected from the environment.

These terrestrial values in architecture have previously been challenged by Maori who carefully selected and appropriated new materials, forms shapes and symbols from Western Christian church building to serve in their own architecture of faith. Ultimately Christian Maori architecture (in the colonial and post colonial period) maintained its integrity symbolically and pragmatically as a 'water-based' architecture that responded specifically to the oceanic, New Zealand context and their maritime traditions. This not only identifies what Maori value in their cultural and spiritual buildings. It also highlights how Western church architecture led to new innovations and adaptations in Maori architecture that still distinguished them from European (terrestrial) building ideals. Consequently, Maori architecture and symbolism

maintains a sense of cultural grounding based on their desire to generate and adapt new symbols from Christianity that still define Maori as a maritime culture and therefore, are responsive and symbolic of their oceanic, New Zealand context. 


\section{PURPOSE OF DESIGN:}

This design explores how nautical symbolism and water-based pragmatism can influence and transform Western notions of knowledge or conventional notions of contemporary (terrestrial) architecture in the design of a school (wharekura). This will revive the intimate relationship between occupant, architecture and the surrounding natural and spiritual context already proven to exist in Christian Maori architecture. At the same time, the wharekura also responds to the ephemeral oceanic context by rejecting timeless values in contemporary terrestrial architecture.

A contemporary (terrestrial) architectural project applied to a culturally sensitive programme offers a similar situation to Christian Maori case study buildings which adapted and appropriated terrestrial values of Western Christian church building and symbolism into their own architecture of faith. Learning from research into the nautical symbolism and architecture of case study buildings, the wharekura aims to improve the performance, experience and spatial composition in contemporary architecture in a metaphysical and pragmatic way. Similar to case study buildings, this is achieved by making use of current technologies and materials to facilitate and enhance the sensual qualities of space and place that change in time. In doing so, this opens up contemporary architecture to its outside, loosening the architectural boundary and making spaces of exchange. Furthermore, occupants engage in time by experiencing fluctuating degrees of pace and rhythm created by thresholds (paepae) throughout the building. As a result, this explores the power of ephemeral architecture connected with the psychic and symbolic territories known to the navigator. 
One of the more significant and direct nautical symbols in the wharekura is expressed through the boat as an architectural symbol. As a tribute to the waka and its association with Maori architecture, the celestial and terrestrial divisions of learning are united through the upturned waka on land. This signifies a water-based culture that is still distinctly so, but has transitioned to life on land. This makes a strong statement about Maori who currently lead a lifestyle more similar to land-based civilizations, but do not conform to terrestrial ideals in contemporary architecture. Instead, the wharekura celebrates the waka as both shelter and symbol in architecture while reinforcing other ideas (relating to seafaring) explored in design.

\section{DESIGN PROCESS AND OUTCOME}

The challenge of this project lies in the creative ability to reinterpret nautical cultural symbols and oceanic architectural solutions in a way that not only ensures they relate to the building programme, but also reinvigorates their purpose and meaning in contemporary architecture and the current cultural context of Maori. For this reason, nautical symbolism is not simply replicated from case study precedents, but rather, re-evaluated to convey similar symbolic values expressed in new and meaningful ways. As an individual, as well as a Pakeha, creating new ways of expressing nautical symbolism is somewhat difficult for this project, for as Obeyesekere (1982) notes, symbolism is "a collective phenomenon" developed by an ethnic group (Neich, 1993, p. 152). In this case, where research informs design, the circumstances are different in which new nautical symbols are based on an academic background that substitutes the instinct 26 in which symbolism is normally created. Another hindrance to the design is the design process which follows a somewhat static process, relying on modes of representation that freeze architecture into either a three dimensional model form or on two dimensional paper. This contradicts Maori notions of time in architecture that are discussed as an important part of this

\footnotetext{
${ }^{26}$ Jung suggests symbols of the collective unconscious are generated by instinctive thought and behaviour from millennia of human experience (see introduction).
} 
design. In this respect, the wharekura (Maori school) is based on Western design processes because it relies on static modes if representation to convey ideas. Consequently, this is why the wharekura focuses on implementing Maori notions of time into the Western field of architecture. The outcome of this design is a culturally significant building that revives the inviolable architectural tradition of which nautical symbolism is the 'generator and the essence'.27 Ultimately, this demonstrates architecture that responds to the indigenous seafaring lifestyle and environment unique to New Zealand rather than the timeless, object-orientated universal ideals pre-dominantly found in terrestrial (Western) contemporary architecture in New Zealand.

${ }^{27}$ Lewcock and Brans note how communities "do not build 'symbols', they build houses according to an inviolable tradition of which symbolism is the generator and the essence". (Lewcock \& Brans, 1975, p. 116) 
SITE \& CONTEXT 


\section{INTRODUCTION}

This area of design research deals with the site and its contribution to architectural design. First, the site is analyzed in terms of its existing physical and natural features followed by a brief history of the site from two cultural perspectives.

The first analysis led to important design decisions that ensure the new building would be sympathetic to the natural landscape and the existing built features. Further research into the history of the site proved to have significance for both Maori and Pakeha. This revealed a need to acknowledge both histories through architectural design. Finally, some direct design implications from the site are discussed. This focuses on the siting of the building, and initial practical and symbolic implications for integrating water from the site into architectural design. 


\section{SITE DESCRIPTION}

The building site is located near Point Halswell - a tranquil site, set amongst the striking backdrop of Wellington's surrounding harbour. The Peninsula points north while the western hill faces the city, and eastern hills, toward the mountainous Rimutaka landscape. Point Halswell is the landmark headland of Wellington harbour. The area is currently protected under the Mataki-kai-poinga landscape feature precinct (Fig 5). The new building ensures the natural landscape is retained with native planting and traditional crop terracing. Parts of the building emerge from the natural setting, creating a subtle, built landmark of cultural significance.

Previously, the only built feature on site was the Massey memorial. The memorial was built to commemorate the site's long association with defence and serves as a burial ground for William Ferguson Massey and his wife Christina. ${ }^{28}$ The memorial also has strong architectural significance and sentimental meaning that is heightened by its remote, peaceful setting. Consequently, one end of the school is designed underground, therefore ensuring minimal visual impact. However, a discrete opening in the landscape provides a path leading underground from near the memorial, eventually reaching to the upper slopes of Miramar Peninsula where a series of old gun barracks can be found (Fig 4). This acts as a thoroughfare, and water channel that assists access and movement to all aspects of the building.

Overall, the major considerations for the existing site were; maintaining the area as a significant landscape feature of Wellington, providing connectivity to the memorial and gun barracks as well as respecting the isolated setting of the war memorial. Although the area is currently a protected landscape feature, the new building shall now become a built landmark feature that is subdued by heavy planting. This will create attention to Point Halswell and Miramar Peninsula as a cultural landmark which will attract tourists and prospective students.

\footnotetext{
${ }^{28}$ William Ferguson Massey (often known simply as Bill Massey or "Farmer Bill") served as the 19th Prime Minister of New Zealand from 1912 to 1925. Massey led New Zealand through the First World War and was the only leader in the commonwealth who retained his position after the war.
} 


\section{SITE HISTORY:}

The site was selected for its physical and natural attributes as well as its historic significance for both Maori and Pakeha. For Pakeha, the site is associated with war and long serving Prime minister, Bill Massey who is buried at the site. For Maori, the site has great significance as an area once heavily occupied in the pre-contact period. Numerous pā sites on hills and kāinga on the coast of Miramar Peninsula reveal a typical living arrangement of seafaring folk. In Appendix B, more detailed information can be found on the history of the site during the pre-contact era of Maori occupation to the colonial and post-colonial periods when the land was seized by the crown. This led to various design implications that are elaborated on below.

\section{DESIGN IMPLICATIONS}

From looking into the history of the site and how it exists today, there are many cultural and physical aspects to consider. During the initial stages of design a line was drawn, connecting the war memorial and the old gun barracks. This line established a relationship between two nationally significant built features associated with historic people and events. This approach to siting the building stems from the Maori seafarer who was well acquainted with angles and directions based on their relation to distant people, places and the legends associated with them. In this sense the line represents a locational system which defines the territorial boundary between the wharekura and two existing built features which refer to a time and event in New Zealand's history. Also, the juxtaposition of the wharekura between two permanent stone features creates a poetic dialogue between notions of temporal versus timeless architecture, thus reinforcing some of the ideas explored through design. 
This line was transformed into a pathway that provides access to all areas in the wharekura and provides a linear progression from the war memorial at the base of the hill to the gun barracks at the top. By siting the building between these two built features and allowing it to function as a thoroughfare, the design is sympathetic to its existing context while also uniting two associated buildings which were originally separate and dislocated from each other. This axis also provides an approximate north-south progression through the building. This is symbolic of the cardinal opposites regarding the terrestrial (Earth Mother) which lies north and celestial (Sky Father) to the south. (See Appendix A: Te ao tawhito) Therefore the north-south orientation of the wharekura provides a strong sense of orientation and an up or downward progression that relates to the symbolic cardinal directions of the terrestrial or celestial realm of learning. Also, the building is divided into East or West facing classroom wings. This reinforces a strong set of symbolic values associated particularly with the eastern direction which faces the Wellington Rimutaka landscape and the direction of Hawaiki.

After researching the history of the site in relation to Maori, the building gains further value as a place that commemorates the sea-faring folk who used to lived on Miramar Peninsula. Furthermore, Maori, who were the original land owners, are re-acquainted with land which was previously seized by the crown. This is important for Maori who consider land to be sacred for it signifies both their relationship to the earth mother (Papa) and their relative location and position to nature, people, places and the realm of gods. The land is also restored back to traditional Maori agricultural grounds including terraced food crops and native planting that was historically noted at old pā sites in this area.

The decision to integrate a water channel along this pathway was also influenced by the site. Based on evidence of a natural spring source available in the Peninsula, it was decided that water could be integrated into the design. As will be explained later, this gave feasibility to an idea that has symbolic and pragmatic purpose in design. Using a combination of dam techniques and rainwater collection devices, water is designed to run down a series of shallow pools when flooding occurs due to heavy rainfall. The natural spring is only used to slowly fill the uppermost pool to a certain level, which is thereafter, filled with rainwater. This eventually triggers the flood gates to open and release enough water to cause a temporary waterfall down each building tier. The rain and spring water is eventually stored at the base of the hill to be used 
for irrigation and grey water plumbing systems. This will be elaborated later in the chapter: design interpretation and evaluation. Overall, the main axis influencing the orientation and movement through the building is symbolic of a fluid journey between historic built features on site and the symbolic journey between the terrestrial and celestial. The linear progression through the building reflects symbolic cardinal directions and the passage through building in time rather than space.

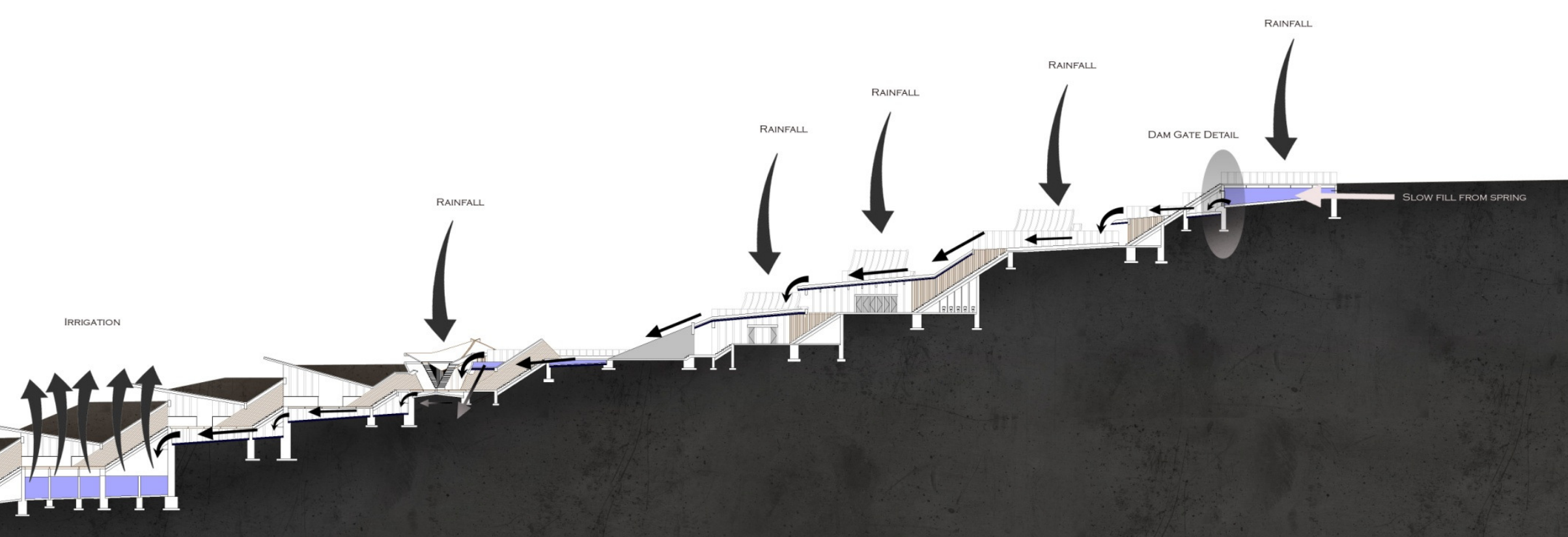



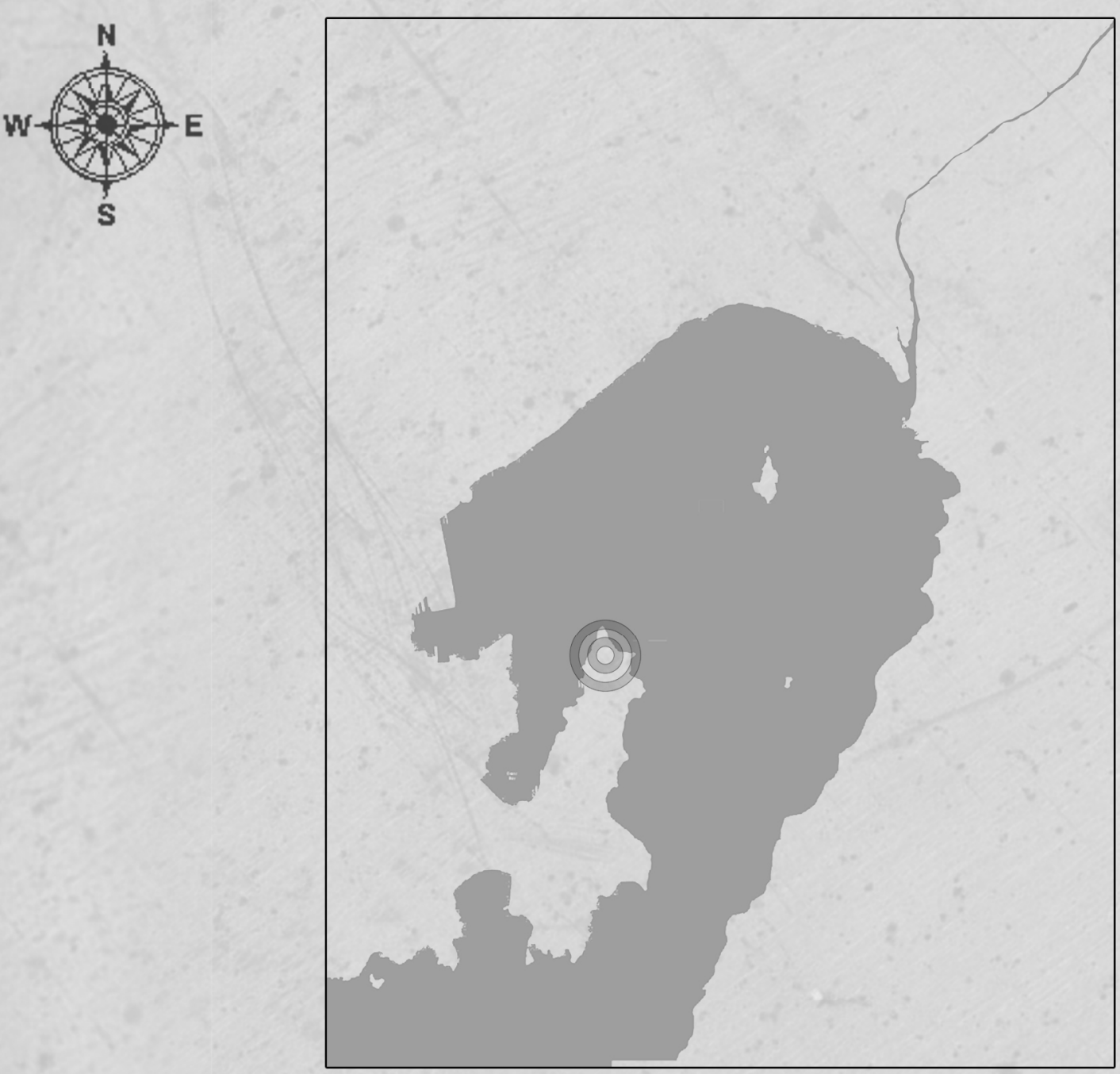

Figure 4.2: (left) Site plan of building showing a major axis connecting the war memorial and the old gun barracks.

This line established a relationship between two nationally significant built features associated with historic people and events. This forms a main passage through to classrooms as well as a public thoroughfare to the war memorial and gun barracks.

(Above) Map showing wider context of Miramar Peninsula surrounded by harbour. (Rimutaka's to the east and city in the west direction) 


$$
-
$$




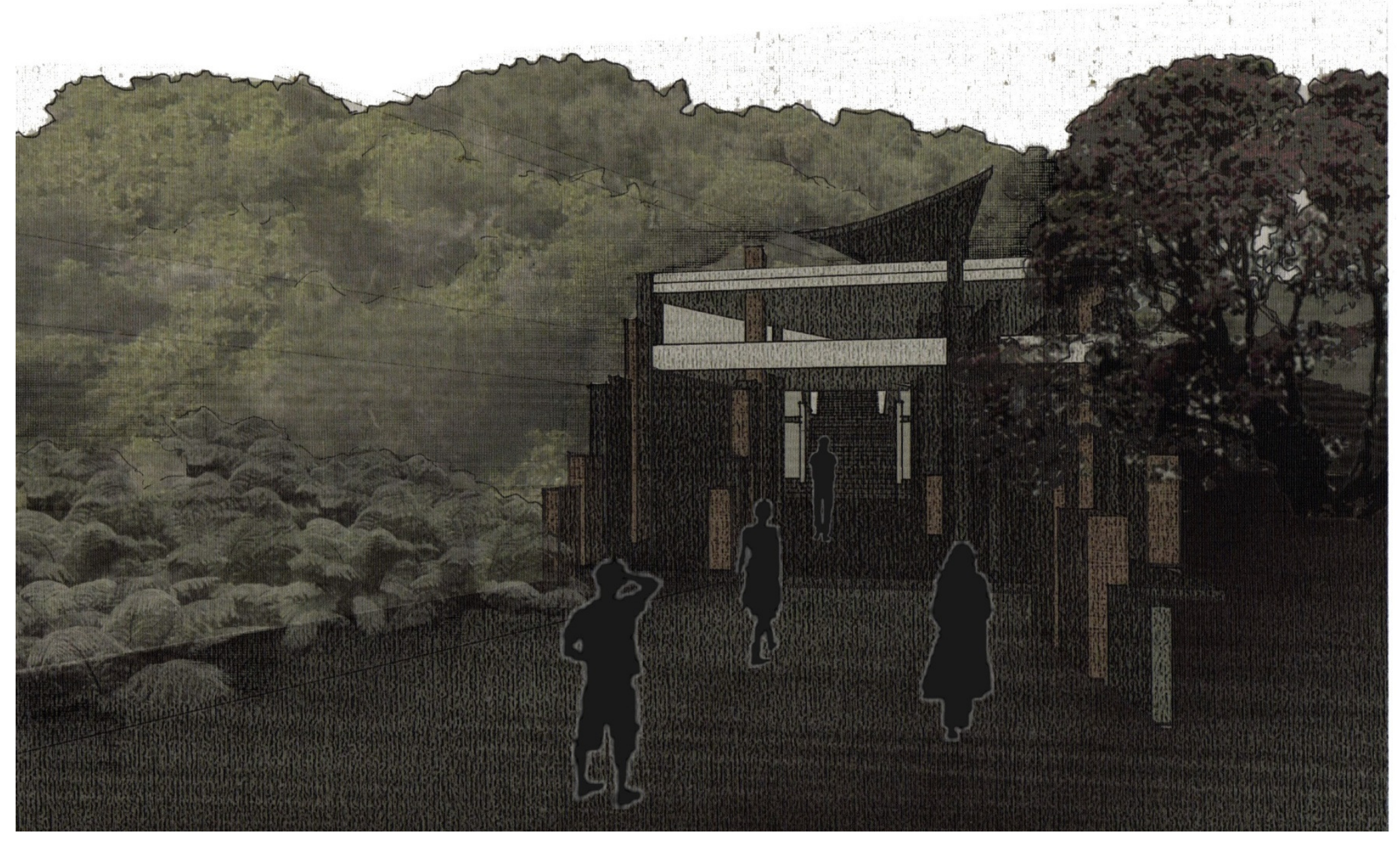

Figure 4.4: Perspective drawing showing entry/exit to thoroughfare leading from the base of the hill near the Massey memorial. 


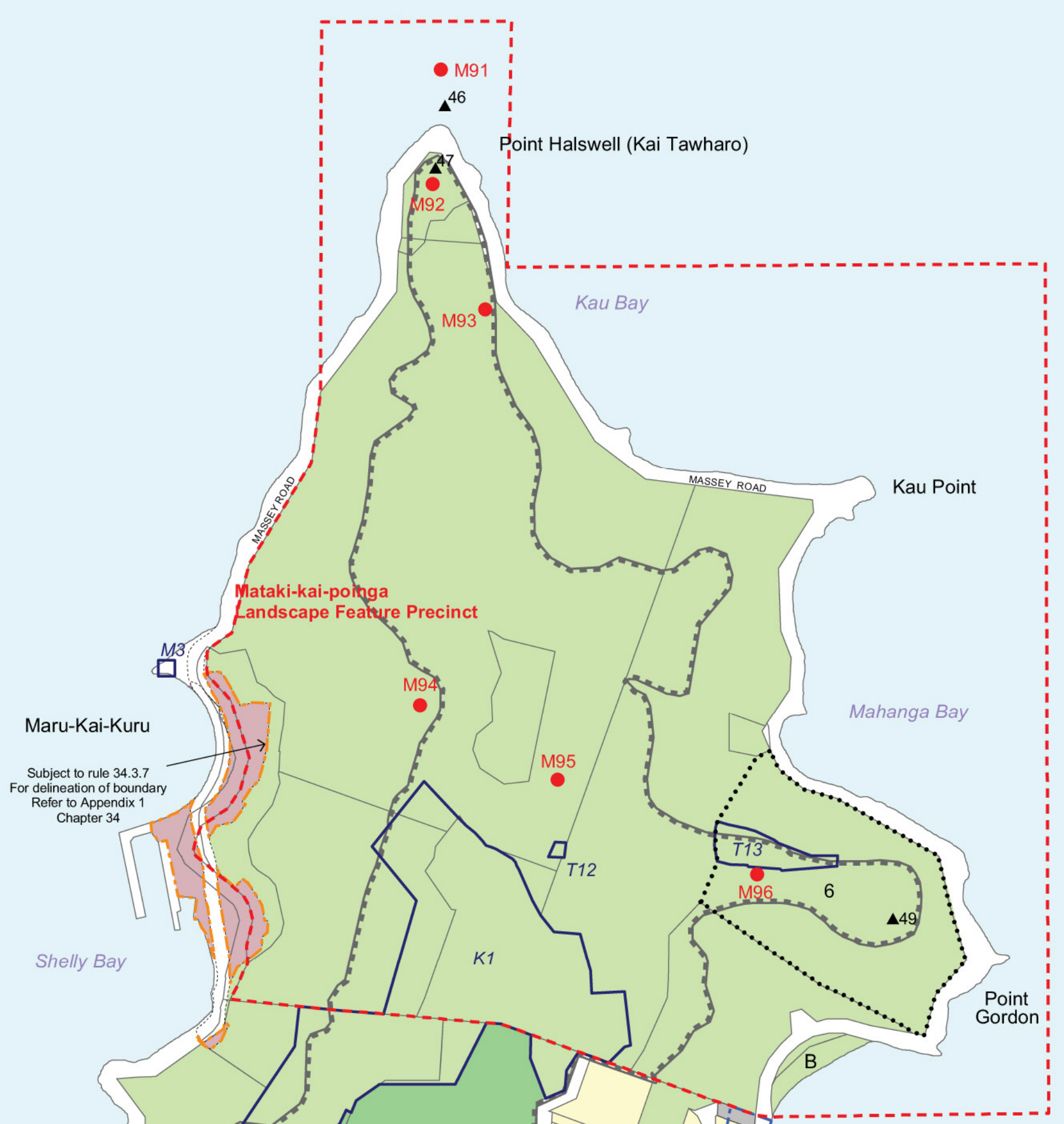

Figure 4.5: Map showing Mataki\%a-Poinga Landscape Feature Precinct tocated near Point Halswell, Miramar Peninsula 2A SA Scorching Bay 
ARCHITECTURE PROGRAMME:

THE WHAREKURA: A SCHOOL DEVOTED to THE STUdy OF AlL THINGS CELESTIAL AND TERRESTRIAL 


\section{ARCHITECTURE PROGRAMME:}

The Wharekura: A School DeVoted to The Study of All Things Celestial and

\section{TERRESTRIAL}

The building programme is based on the ancient Maori school of learning known as the wharekura (or whare wananga). This was a place where all important histories were gathered and taught under a strict hierarchy of learning based on two categories:
1. Te Kauwae-runga (upper jaw)
2. Te Kauwae - raro (lower jaw)

The first branch of learning represents everything pertaining to the gods, the heavens, the origin of all things, the creation of man, the science of astronomy, and the record of time etc. The second branch of learning (lower jaw) deals with the history of the people - their genealogies, migrations, tapu, and all knowledge pertaining to terrestrial matters. In simple terms, the first branch of learning represents 'Celestial things,' and the second, 'Terrestrial things' (Whatahoro \& Smith, 1913). The purpose of the wharekura in the contemporary context is to provide a school that will revive and maintain traditional Maori doctrine and methodology across various disciplines taught in the ancient Maori school of learning (the wharekura). This can be achieved by applying and integrating traditional Maori research and learning within the contemporary methods of education. This brings Maori knowledge from the past and makes it relevant in the present and future. Consequently, this will create new challenges for Maori knowledge and philosophy while providing significant opportunity for Maori development. 
When considering traditional Maori concepts of knowledge and learning, we must consider how the past informs the future. This is because Maori are constantly living in time, constantly aware of everything in their physical world that provokes remembering. ${ }^{29}$ This is a tendency of the seafarer who understood this world as a series of inter-relationships, experienced in time. As a result, many aspects of traditional learning draw from instinctive knowledge and life experiences founded by their seafaring ancestors. Perhaps this is why the terrestrial division of learning was considered 'understudies' because such skills came secondary to seafaring. ${ }^{30}$ In comparison, the study of 'celestial things' is certainly founded on knowledge associated with seafaring. This is because it deals with two major aspects of navigation, one being astronomy and the other being mythology. ${ }^{31}$ For this reason, design emphasis is placed on the celestial realm of learning because it offers a thorough design exploration of nautical (navigational) symbolism drawn from this research, while also reinforcing the learning of 'celestial things' taught in the wharekura. The celestial realm of learning also evokes an architecture of openness and the divine realm of sky gods that were highly symbolic in nautical Christian Maori architecture.

With regard to the programme and its influence on design, the building is also designed to reinforce two distinct branches of learning: the Celestial and Terrestrial. These two distinct themes for design exploration will serve as a base for implementing nautical architectural concepts from research, particularly sensing space and place and experiencing time in architecture.

${ }_{29}$ As Ranginui Walker wrote (1982) "So the Maori faces the present and the past which are in front of him. In this time frame he has before him the living, the forebears, the dead, the founding ancestors, the cultural heroes of mythology and the gods back to the primeval pair Ranginui and Papatuanuku. This time frame is the basis for marae protocol (Walker, 1982, pp. 59-60)

so The first division of learning (upper jaw) were only open to sons of great chiefs. Under certain conditions, second sons might be permitted as "understudies" where agriculture was the principal aspect of learning (Tregear, 1904, p. 376).

${ }^{31}$ For example, rising and setting points of the brightest and most distinctive stars and planets were assessed with sophisticated star compasses, and then memorised. These were anchored in the memory of Maori through strong oral tradition where imaginative mythological stories personified the stars and planets. 


\section{PROGRAMME AND PLANNING.}

The building programme incorporates a range of small classrooms and offices devoted to the research and learning of terrestrial and celestial matters. The celestial classrooms are situated on the upper slopes of the hill and the terrestrial classrooms are located on the lower slopes (underground). The celestial classrooms are divided into east and west facing wings. East facing classrooms are used for the highest level of teaching and west wing classrooms for lower level students. Each classroom is designed with outdoor porch access for outdoor teaching exercises. The terrestrial classrooms are designed underground with access portals to crops and garden areas. This allows students to easily access the surrounding gardens and crops they maintain and harvest. When crops are harvested, facilities for storage and cooking are also provided.

In the main (waka-shaped) building, exhibition and performance areas are provided. The exhibition space will display teacher and student work as well as Maori artefacts. For students and teachers, this will provide a stimulating, cultured learning environment. Exhibitions will also provide on-going opportunities for students involved in organising and performing at ceremonial events. During important events, cooking facilities, (located in the terrestrial learning division) are available to allow events to be catered with traditional Maori food. Most of this food will be provided from various crops planted on site. These will be maintained and harvested by students in the terrestrial division of learning.

A secondary function to the building incorporates a thoroughfare between the war memorial and gun barracks, located at each end of the building. The width of the pathway is based on the dimensions of the war memorial. This also defines a strong axis from which water is designed to cascade down pathway during times of heavy rain and flooding. Ultimately this thoroughfare provides a link between two existing built features on the site and provides a main access route to all classrooms. As I will elaborate later, the pathway and water channel are also significant for symbolic reasons. 


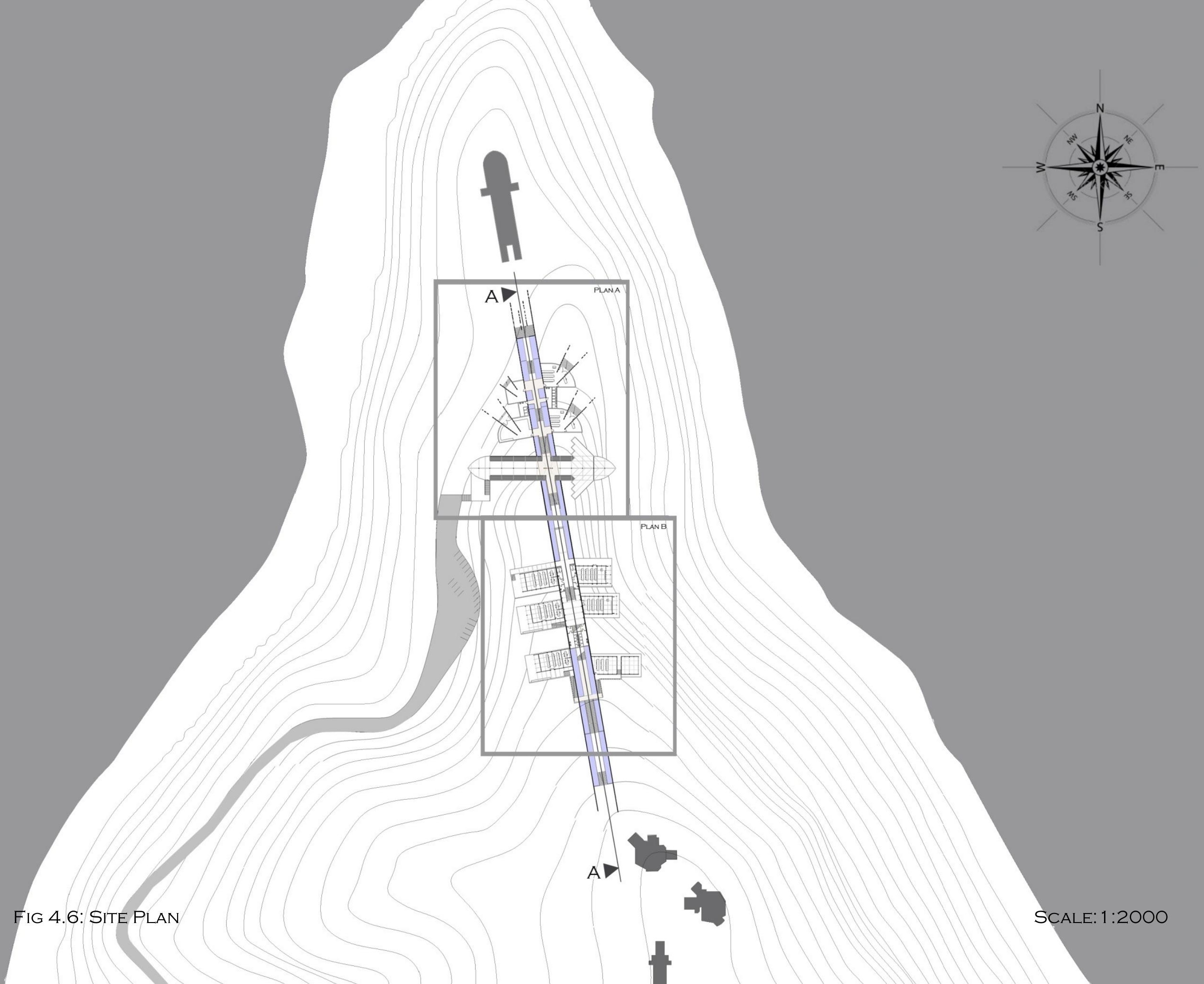




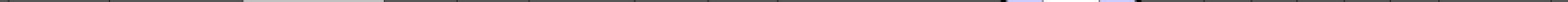



DESIGN INTERPRETATION AND EVALUATION: 


\section{INTRODUCTION}

This design focuses on two major themes from research: Maori perceptions of time in architecture and the waka as an architectural symbol. Based on the highly attuned senses of the navigator, the wharekura firstly focuses on how time can add a further dimension of understanding to contemporary (terrestrial) architecture in New Zealand. This design particularly focuses on how rain and climatic changes can be sensed through architecture and how this can be achieved by using high levels of pragmatism. Finally, the wharekura also looks at how the occupant engages in time through architecture. This explores how architecture is not conceived as an object in space, but rather is something to be experienced in time itself.

The second element of this design demonstrates how the boat is used as an architectural symbol in contemporary design. This aims to celebrate the waka's contribution to architecture (as both shelter and symbol) and its long association with Maori maritime traditions. In doing so, this design uses the waka to make a statement about the connection between Maori and nautical architecture in a contemporary context. Furthermore the waka is used to reinstate the symbolic connections between the celestial and terrestrial realms of learning. Finally, the waka shaped roof is used to express symbolic values associated with the eastern sailing direction, toward Hawaiki. This is expressed through the building by re-enacting the mythological voyage to Hawaiki through architecture. This provokes a range of symbolic ideas associated voyaging and creates a poetic metaphor for the building in the landscape that is similar to the waka out in the ocean 


\section{A MAORI PERSPECTIVE OF TIME IN ARCHITECTURE:}

"The Maori space-time construct can be thought of more like a constellation with the past and the people of the past always felt in the present, like the constellations of the sky to the voyager: enmeshing, surrounding, always before you, always behind, forming patterns that can be interpreted in various ways. The past always resonates in the present" (McKay, 2004, p. 8).

Part of this design explores how Maori concepts of time in architecture can add a further dimension of understanding to contemporary (terrestrial) architecture in New Zealand. This particularly reflects on research which suggests that Maori architecture does not conform to the three dimensional object in space but is rather understood as existing in time rather than space. This perception of time stems from extraordinary senses developed through voyaging. Furthermore, the temporal oceanic environment subject to flux and flow has influenced a time-based spatiality in Maori architecture. 


\section{Sensing Time: Celebrating RainWATER AS A RENEWABle RESOURCE}

The wharekura expresses time through the seasonal flux and flow of water in architecture. Using rainwater collection and dam techniques, a waterfall effect is created during times of heavy rainfall. At the top of the hill, near the gun barracks, a dam is built to release water triggered by the detection of rainwater overflow. When the gates open, a spectacular release of water is seen cascading down the main building axis and pathways. Although the dam gates are designed to open during high rainfall, this is merely a trigger, while most of the water is slowly collected by tapping into a spring water supply known in the area. This water (along with rain-water collected from roofs) is designed to gradually flow into underground water tanks and replenish irrigation and grey water plumbing systems. The dam is also used to harness energy through a water turbine and electrical generator (Appendix C) to reduce running costs of the building, particularly during winter when heating is required (and heavier rainfall is expected).

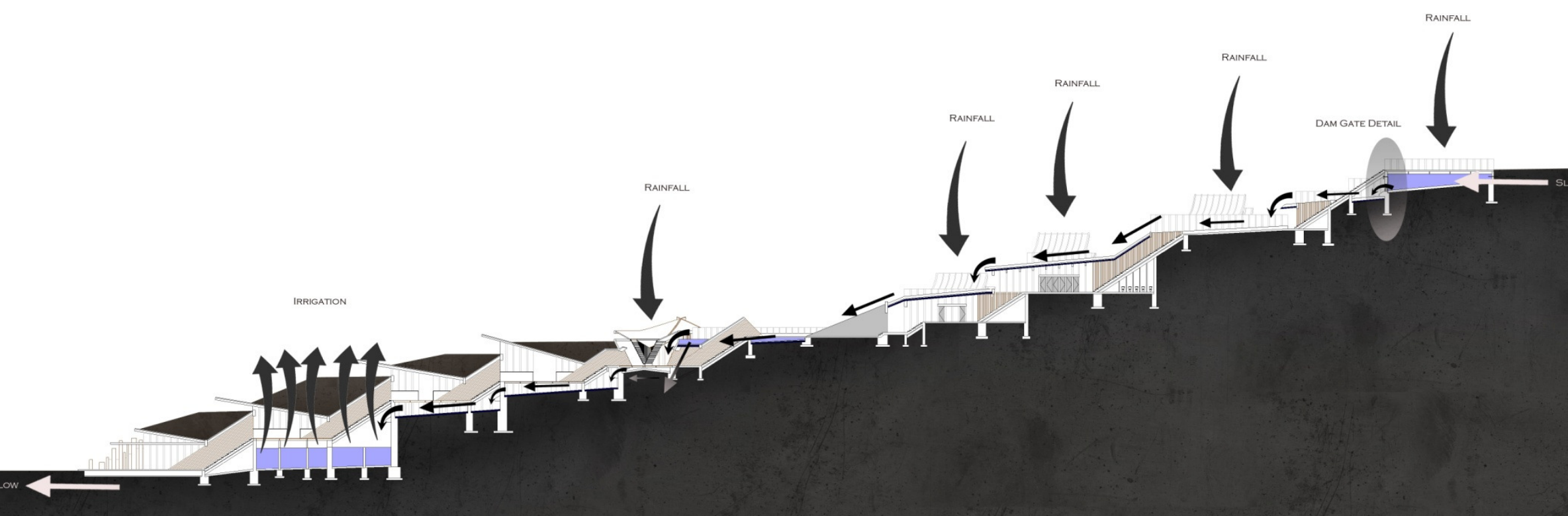




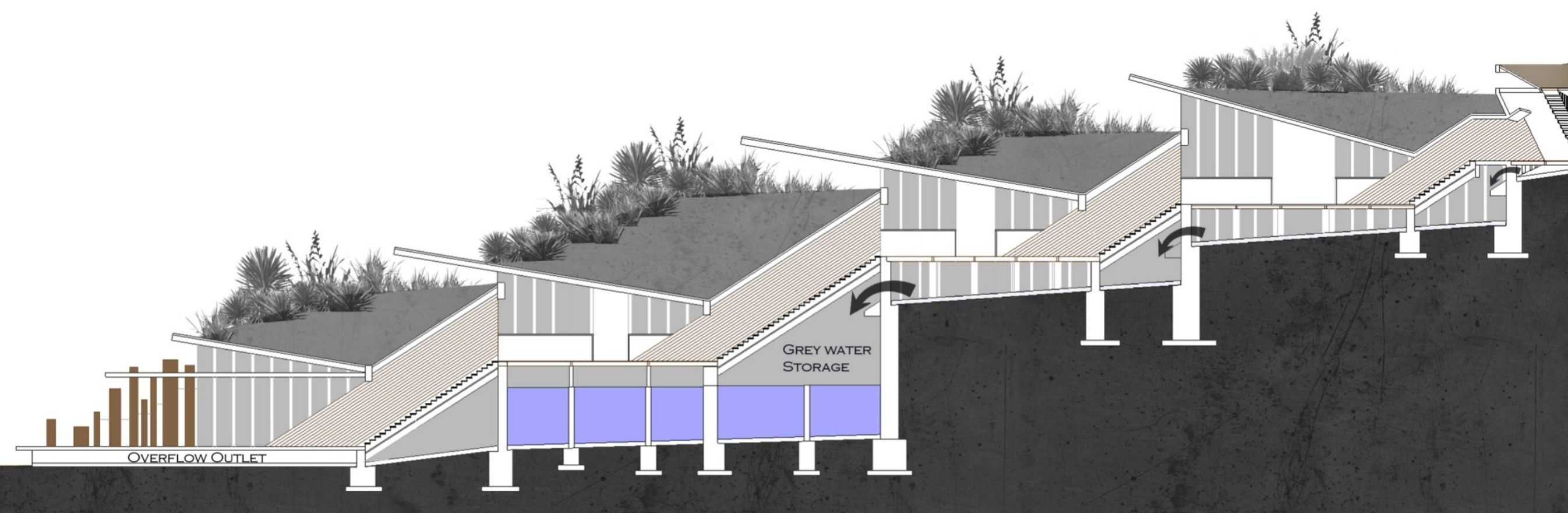




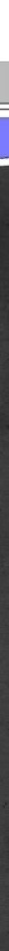


When water is released through dam gates, the building creates an event that celebrates the fertility of land and the life upon it. Through architecture, water becomes a glorified element that is subject to the seasonal flux and flow of water. Rain is animated through water channels, gulley's and roof forms, each designed to welcome the rains and highlight the event of flowing water. Such events are more likely to occur during heavy rain in the winter, and in summer, the exposed, shallow pools of water may even dry up. At this time, the building takes on a different aesthetic, where shallow pools become empty rock beds and receding water lines appear at the pool edge.

Ultimately, this creates a seasonal awareness that is measured by the natural cycle of water through the building. Traditionally, Maori had an acute sense of their natural environment because it was critical for survival, especially when applied to seafaring. This is why Christian Maori religion continued to celebrate the seasons, even reinventing their Maori meanings through Christianity. ${ }^{32}$ Today, many Maori people have lost touch of this skill because time is no longer gauged by sensing changes in the natural world. This is largely due to contemporary, terrestrial societies where time is often artificial or displaced from time itself. ${ }^{33}$ This is certainly evident in contemporary western design where time and the elements are considered enemies to the building. The wharekura re-establishes a connection to the environment by creating architecture that facilitates and tests the senses. As students learn to experience the building as an existential space, ${ }^{34}$ the building becomes further understood and the initial sensory experience becomes part of a greater pattern, associated with the seasonal flux and flow of water through the building.

${ }^{32}$ Ringatu gatherings were based on, the cycle of the twelfths, or the reappearance of the new moon at the start of each month. Te kooti supported this concept through Christianity in revelation 22:2 which refers to the tree of life with its twelve fruits. (Binney, 1995, p. 420) ${ }^{33}$ Bill Mckay and Antonia Walmsley (2003) have noted how Western architecture often wishes to exist in timeless space, an artificial condition of time. They relate this idea to aspirations of the modern era which "aspires to evoke an air of ageless youth and perpetual present” (Walmsley \& McKay, 2003, p. 87).

${ }_{34}$ Norberg Schulz explains how existential space has 'object character'. He also mentions how this relates to the nature of space: '....the nature of space does not reside in more or less extended character of sensations as such, but in the intelligence which interconnects these sensations". (Norberg-Schulz, 1971, p. 17) 
According to ancient learning principals, taught in the wharekura, water is one of the chief constituents or necessities of life. It was believed that moisture causes growth in all things, other necessary agents being the sun, the moon and the stars (Best, 1921, p. 2). Therefore, water has strong associations with astronomical (celestial) origins as well as terrestrial elements such as plant and animal life. This reflects the astronomical concepts of the navigator who understood the natural world as a series of relationships between the sky (celestial) land and sea (terrestrial). These relationships are also expressed through design in which the celestial realm of learning focuses on the collection of rainwater (from celestial origins) and the terrestrial realm of learning is concerned with the utilization of water for sustaining the life of the building and surrounding landscape.

In light of the terrestrial realm of learning, the water channel leading underground brings a temporal element into the otherwise, terrestrial, permanent areas of the building. This idea stems from Ratana churches where plants were hung in the church interior to link the congregation to the rhythm of the land and cycle of the seasons. In the cavernous terrestrial classrooms, the solid concrete materials and underground construction are symbolic of the Earth mother (Papa) who nurtures her children in a womb of protective earth. The polished concrete walls allow light and sound to refract off its hard, reflective surface, intensifying the sound and sight of water reverberating beneath the walkway. Therefore, despite the use of solid materials and construction, the temporal elements of space are heightened through the senses. Furthermore, the flow of water underground reinforces principles taught in the wharekura where, particularly in the terrestrial realm of learning, water is celebrated as a resource that is gathered and released back onto the land, ensuring abundant growth of crops and native plantings.

Fundamentally the wharekura celebrates water as an important element that not only contributes to the sensual experience of the building, but respects water as a valuable, renewable, natural resource. Through rainwater collection systems for irrigation and plumbing systems, the rain becomes a valuable resource unlike western buildings which usually see rain as a nuisance to be flushed away. Overall, the wharekura is designed to welcome and glorify the rain through an architectural event that is subject to the cyclic nature of time. This is achieved with an element of pragmatism from which water is not merely used symbolically, but is also an important part of the buildings energy efficiency and functionality. 
Through various elements of the building, the cyclic nature of rainfall during the seasons engages the senses to heighten the learning experience and remind one of a time when life was attuned to the natural world; when the dry and wet seasons governed the timing and success of agriculture, seafaring, and the way people lived.

\section{SENSING Time: Using NAUtical Symbolism AND PRAgmatism in CONTEMPORARY ARCHITECTURE.}

For the design of the celestial classrooms, the buildings relationship to the sky was a significant factor to consider. This provided a good base for implementing ideas from research. As it has been revealed, religious Maori architecture has consistently acknowledged the sky through the openness of the marae. ${ }^{55}$ This reflects the response of a seafaring culture who sought to sustain a connection with the external elements and surrounding context. Along with creating a sense of openness, Maori religious architecture facilitates a spiritual connection to the outside through the porch and gateways. In this case, Maori religious architecture was designed as a responsive threshold. Rather than having an enclosing boundary, their architecture has a double spatiality of interiority and exteriority. The celestial classrooms of the wharekura are used to express this concept of double spatiality in order to create architecture that can facilitate interactions with the natural environment. Using nautical symbolism and technology in contemporary architecture, these interactions focus on the sensual experience of the celestial realm that is subject to time.

In the design of the wharekura, wind and light are used as two powerful celestial mediums that engage the senses through architecture. This is achieved through a passive wind ventilation system and through the use of coloured triangular glass louvers in the roof. The ventilation system is created through a double skinned roof structure. Firstly, wind is harnessed through a secondary roof structure, designed in a sail - like form. This creates a funnel effect, causing the wind to

\footnotetext{
${ }^{35}$ According to Best the marae-nui-atea is an expression which symbolizes the "vast ocean expanses, the waste of waters, sometimes alluded to as the marae or plaza of hine-moana” (Best, 1918, p. 133).
} 


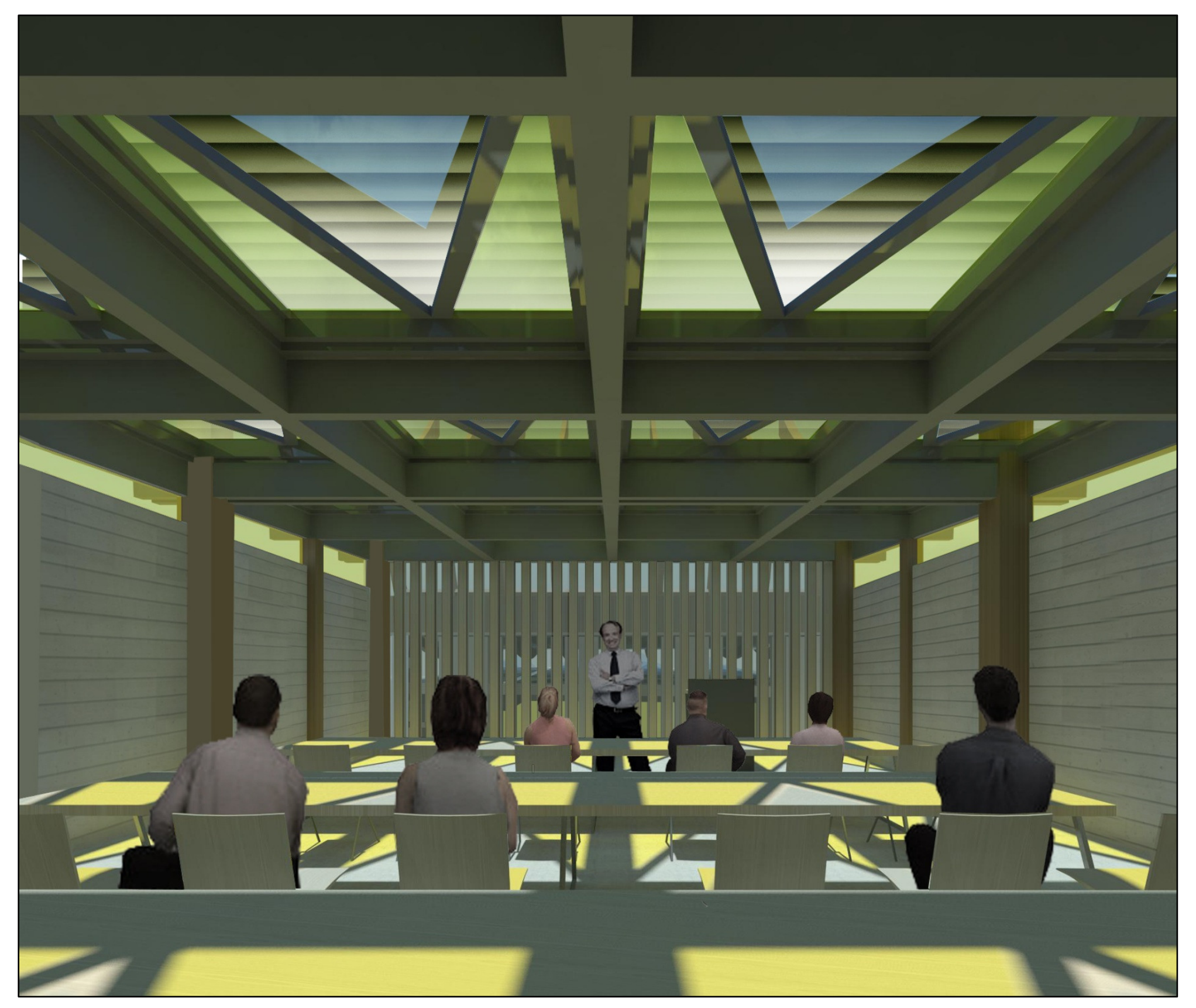

Figure 4.12: A sensual learning experience created through structure in the celestial classrooms 



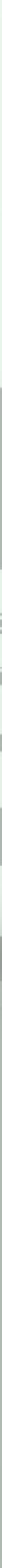

Figure 4.14: Perspective Section Showing Passive cooling System created through Structure (West Wing of Celestial Classrooms) 
flow through certain areas of the roof. This wind is then filtered down and into the classroom through protruding louver operated windows. These triangular windows filter the fresh air down below, providing a passive ventilation system. This creates an airy architecture subject to atmospheric flows of wind (and sun). Beneath the sailing roof is the primary roof structure. This consists of a lightweight post and beam timber structure with elaborate glass ceiling panels. These triangular, coloured glass panes create an interesting lighting effect as the sun moves throughout the day. In Ratana churches, whetu marmama were emblazoned through stain glass windows to reinforce their celestial significance and symbolise enlightenment or 'maramatanga'. Similarly, the ceiling and roof evoke the senses associated with the celestial realm. As one looks at the illuminated glass above, or hears the wind whistle through the roof, one is reminded of a supernatural force at play. Furthermore, the roof structures are used as an important rainwater collection device. Rain water collection is effectively maximised by two roof areas and re-directed to nearby rainwater pools. The skyward gesture of the sloping roof appears to reach for the rains that gather on its surface.

In the design of the wharekura, a secondary roof structure serves to mediate the connection between the internal and external areas of celestial classrooms. This is achieved with a projecting roof structure (similar to a porch) over areas in front of the classroom and over external classroom corridors. More importantly, these soaring roof structures provide fluidity between the interior and exterior space. This is particularly the case for East facing classrooms where bi-fold doors are used to extend the classroom space, out into the open. In a situation where bi-folding doors and louver windows are open, the room becomes an 'open air living room' much like the marae. ${ }^{36}$ This is reinforced by the upward curve of the roof which maximises light and skyward views. This may be useful as a performance space, or art room which requires greater air flow. By implementing shifting boundaries through the use of bi-folding doors and louver operated windows, the building is essentially "imbricated with the technologies... of movement" (Austin, 2003, p. 226). Therefore the architecture allows for the passage of wind and the play of light and denies the external skin as a closed surface. The spectacular views toward the Rimutaka landscape and sea are not merely linked visually, but also sensuously and experientially linked with the classroom environment.

\footnotetext{
${ }^{36}$ Mike Austin describes the marae as 'an open air living room' (Austin, 1976, p. 231)
} 


\section{SENSING TIME IN SPACE}

Similar to the meeting house, the wharekura consists of a series of events that take time. A series of classrooms, scattered above and beneath the landscape do not allow the building to be seen as an object in the round. Instead, the wharekura is experienced through a series of approaching steps, punctuated by a series of stairways with paths in between. One's progression is linear, toward either the celestial or terrestrial realm of learning. One does not see each classroom as an object in space, but rather, emphasis is placed on the journey in between. As the word for 'pae' meaning step suggests, (Walmsley \& Mckay, 2003) the wharekura is experienced through a series of stairways that lead between moments of enclosure and exposure. This subsumes architecture into an experience of thresholds between celestial and terrestrial worlds.

These two worlds are reinforced by the use of water along the passage between classrooms. From the terrestrial realm of learning, toward the celestial, one appears to emerge from the watery depths toward the sound of flowing water. On entering a flight of stairs (from the waka building) which lead up or down toward the two realms of learning, one either descends into darkness or ascends (through a staircase penetrating through a pool of water) into an area of openness and light. Similar to the gateway (waharoa) which separates the earthly and divine realms, each stairway passes through water creating a sense of ascension into a higher state of being or different world. This also echoes a greater level of sacred learning. 


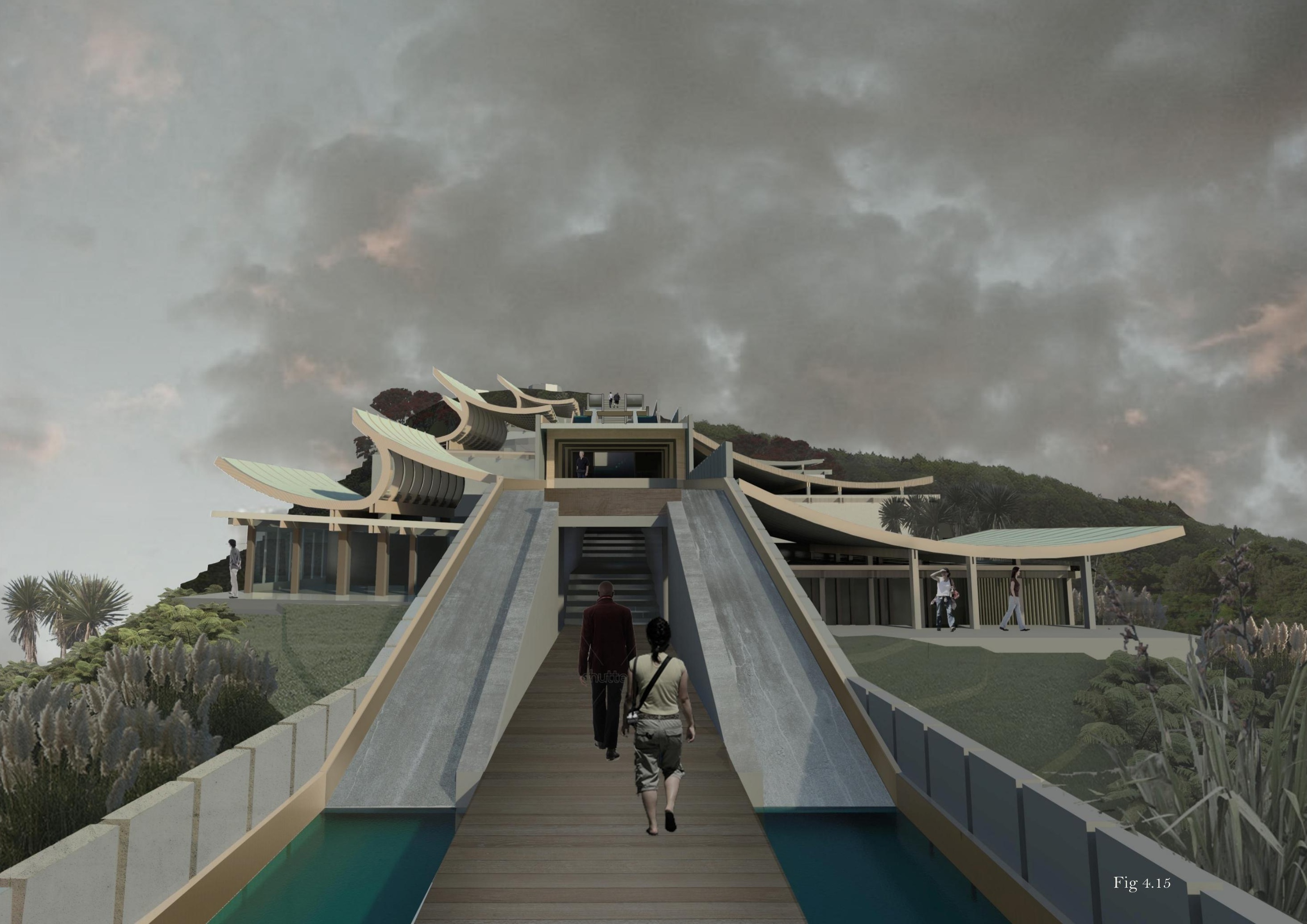


Most significantly, these stairways take time to negotiate by altering the pace and rhythm through the building in a repeating cycle of thresholds. This pace and rhythm is echoed in the repetitive negative detail on the concrete walls defining the passage in between buildings. This is symbolic of time, measured in the swell lines associated with the motion of the waka and its passengers at sea. These walls also offer various degrees of exposure to the elements (through open and enclosed areas) which encourage points of rest or movement along the journey. All areas are never fully enclosed, but rather have breathing boundaries and portals of light flowing between interior and exterior, the quality of the space always changing with the environment. This allows for an experience of time that is either at a leisurely or hurried pace according to levels of exposure to the rain, wind and sun that may occur along the journey in between.

Ultimately, the way one engages with time is not purely spatial, but temporal. This recalls the rhythmic pace and passage of the vessel through the ocean. On the waka, one is constantly immersed in time through either paddling, observing or feeling out their surroundings. Similarly, the passage through the building is deeply engaged in time through the action of movement where levels of pace change according to weather. Furthermore, the surroundings echo the motion of movement, particularly the flux and flow of water in the dry and wet seasons. 


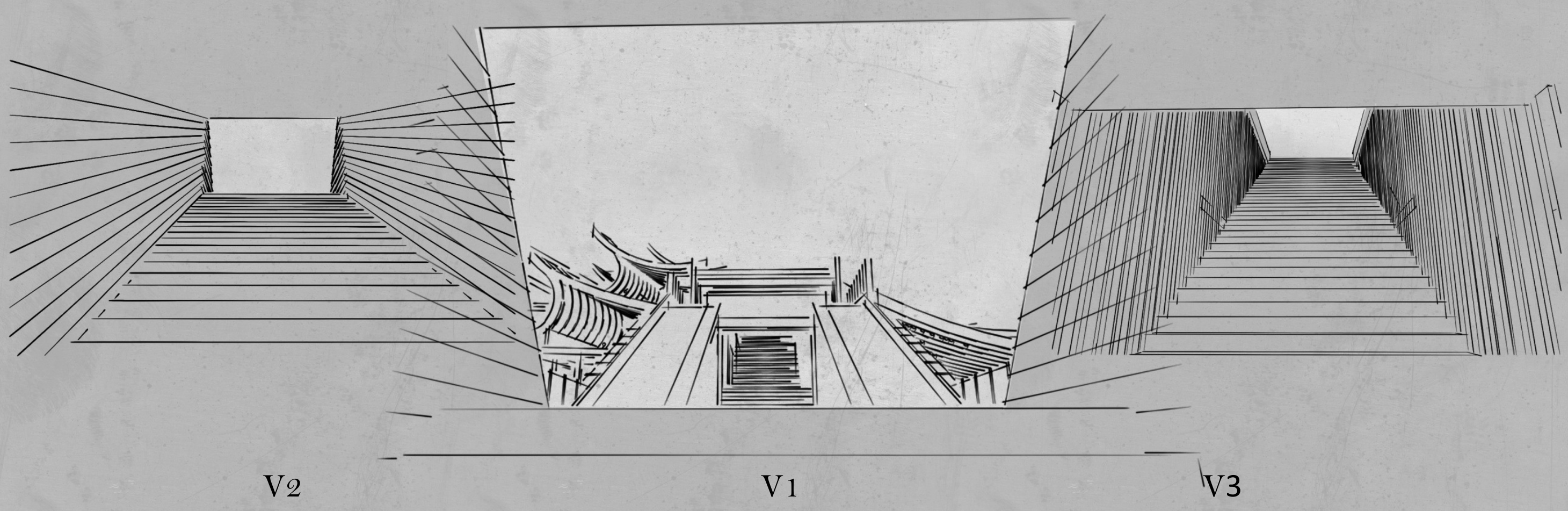

Figure 4.16: The experience of time through architecture through staircases (threshold areas) Each View (V1, V2 \& V3) are referred to in plan. 


\section{THE WAKA as AN ARCHITECTURAL SYMBOL}

"Waka traditions are accounts of arrivals, dispersal and settlement. They tell of how tribes came into being and occupied their tribal lands. They not only explain origins but are also expressions of mana and identity. They define territorial boundaries and intertribal relationships. They merge poetry and politics, history and myth, fact and legend".

(Taonui, 1996, p. 87)

Some of this research has discovered how the upside-down boat was symbolically expressed in the roof of Christian and Maori religious architecture in the colonial and post-colonial era. In Christian Maori architecture, their buildings were conceived as a collective and sacred space like that of a waka. In doing so, this represented environmental, spiritual and contextual relationships between the building and the landscape similar to the waka out on the ocean. Furthermore, the waka expressed in the roof reflects the architectural solution of an amphibious culture from which the waka was used as both shelter and symbol.

Following a quest to celebrate the waka's contribution to architecture (as both shelter and symbol) and its long association with Maori maritime traditions, the wharekura uses the boat as a powerful architectural symbol in the roof. Fundamentally, the wharekura uses the waka to represent symbolic ideas that are discussed above by considering contextual relationships and symbolic concepts from research. However, this design adapts and melds new ways of expressing the boat in contemporary architecture in order to represent more current ideas in nautical Maori architecture and the significance of the waka as a symbol for Maori in a contemporary (terrestrial) context. 


\section{THE WAKA AS SHELTER AND SYMBOL}

The use of the waka as an architectural symbol in the wharekura conveys a strong symbolic connection between the boat as both shelter and symbol. Rather than the usual depiction of the upside-down form of a boat in the roof, the wharekura represents the upturned waka, floating on land. This signifies a water-based culture that is still distinctly so, but has transitioned to life on land. The roof of the building appears to float in the landscape, each end pronounced like the prow and stern of a canoe. Following canoe building tradition, this building is considered the ancestor, Tane. In Maori canoe building tradition, Tane was the threatening figure on the bow who divided the sea before him. This metaphor has been applied to the land beneath the roof. Like water beneath a canoe, the land appears to separate under the force of a canoe hull. The east end of the building is splayed apart before Tane who is said to part the waves before him like a swimmer. ${ }^{37}$ This area opens toward spectacular views of the Rimutaka mountain range, the sea, and the rising heavenly bodies; the stars sun and moon. This provided the perfect space and setting for the performing arts, where dance and song are performed before land, sea and sky.

To understand the intimate connection between the boat as both shelter and symbol, one must appreciate the boat as a medium between elements of sky/weather and water/ocean. This is an intimate relationship recognized in Maori legends of Tawhirimatea (God of weather)Tane (the personified ancestor of the boat) as well as in legends of Tangaroa (god of the sea). Therefore the eventual use of the boat as a symbolic gesture in the roof is logical in Christian Maori architecture, for it maintains an integral relationship between spiritual ideas of the waka, against elements of weather and water. In the wharekura the relationship between roof and water is extended, in which the up-turned boat becomes a large reciprocal for collecting rain water. Here, the upward prow and stern create a welcoming skyward gesture towards the rain. The rainwater is collected from the waka through a large central gully made of glass, encased with copper ribs. This Rain water

37 "Tupare kaukau," literally to spread out the arms in swimming, is applied to the canoe at sea, parting the waves before it like a swimmer. (Cowan, 1930, p. 156) 
is then dispersed into a drain-way beneath a timber deck which gradually leads into storage tanks for irrigation. ${ }^{38}$ The sound of water gushing beneath the floor creates an ambient atmosphere that awakens the senses and provides a raw, temporal quality to the space. As a result, the rain becomes a glorified element through architecture. The boat-shaped roof and sculptural gully celebrate the rain through form and function, all together creating a heightened sense of awareness to this natural phenomenon, the rain.

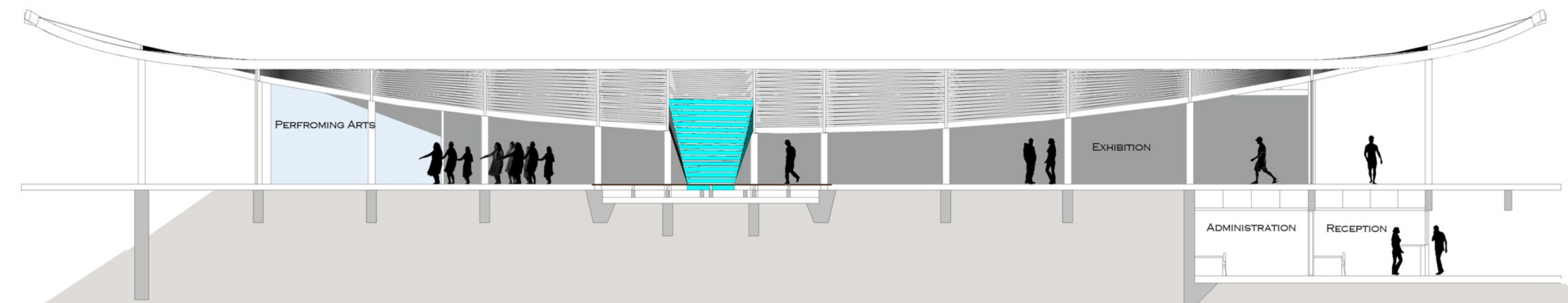

Fig 4.18: Section showing waka roof and structure

Scale: $1: 250$

${ }_{38}$ The sculptural drain highlights the two entrances leading to each division of learning. The timber deck and drainage beneath follow the definitive axis which forms the major path and waterways through the building.

Over the celestial entrance, overflow is permitted to enter down the walls and into under-floor draining 


\section{SPATIAL AND STRUCTURAL SYMBOLISM GENERATED BY THE WAKA}

In Christian Maori architecture, the upside-down boat was a strong expression of unity. In the wharekura, the central hull creates a dividing element through the building. This corresponds to the two branches of learning, taught in the wharekura. Despite this division created by the hull, the space is united through its supportive structure, consisting of central posts and timber struts. In traditional Maori architecture, these refer to the "toko" or "posts" of Tane separating heaven and earth. The space in between symbolises the interior of a meeting house, this being "The World of Light" or "Te Ao Marama”, the world in which we live (Royal, 2009). The central post and beam structure supporting the roof represents the thwarts on which the paddlers sat. Also, the post and beam construction method reflects the integration of technology and symbolism which characterizes the highly pragmatic nature of Maori architecture. The far posts at the East and West of the building are associated with astronomical meanings discussed in the legend of the first house (the wharekura). Kay Leather and Richard Hall (2004) have discussed their significance as astronomical poles denoting the rising and setting positions of the sun, hence their mythological association with life and death. (pp. 44-45). Leather and Hall also note how the poles that hold up the sky (Poutu-te-Rangi) are the "basis for Polynesian astronomy and navigation" (p. 26). Consequently, the boat-shaped roof and structural posts represent the relationship between the vessel and navigation. In the wharekura, the boat raised on posts is symbolic of the intimate bond between seafaring and the celestial realm. This reflects the waka's reliance on the sky to safely guide the vessel through vast oceans. As case study material has revealed, Maori have continuously gravitated toward celestial symbolism in Maori spirituality based on this early bond made between seafarers and celestial navigation. This design revives this connection according to their current situation on land, by reinstating the waka as a vehicle that connects the heavenly and earthly realms of learning through space and structure. 


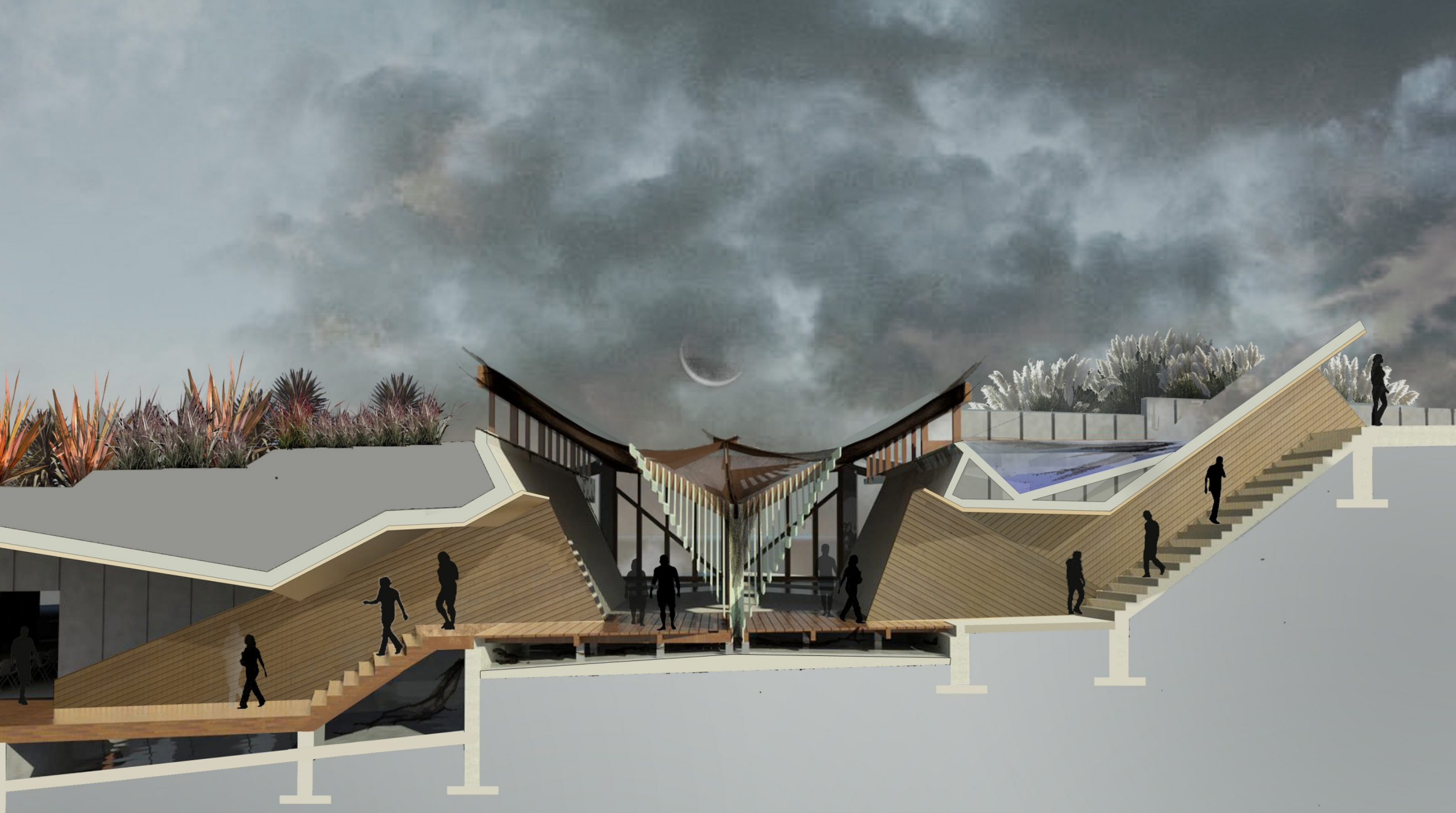

FIG: 4. 19 PERSPECTIVE SECTION THROUGH CENTRE OF WAKA BUILDING 


\section{THE WHAREKURA CONCEIVED AS A FLEET OF BUILDINGS}

Finally, the boat is used in the wharekura to express symbolic values associated with the eastern sailing direction, toward Hawaiki. This is expressed through the east wing of celestial classrooms which resembles a series of boats, sailing toward the sacred direction. Also a part of this fleet is the large, upturned waka on land, proceeding east. This recalls the voyage toward the direction of the mythical homeland in the east, Hawaiki. According to symbolic ideas associated with Hawaiki, the wharekura aims to revive a cultural memory of the past, through the idea of a voyage. As each Maori religious movement has revealed, the past and present are linked through the adaptation and evolution of nautical symbols.

In order to remember the past, the waka awaits the flooding waters so it can be released on its journey back home to Hawaiki. This offers the same sense of anticipation as the Christian Maori notion of a 'great flood' from which their religious architecture was conceived as an Ark that could save the Maori people. Remembering the past is ultimately related back to Maori notions of time, where myth distends into history, where the ancestors are ever present, providing archetypal situations for explaining happenings in the present. This is symbolically expressed in the form and structure of the wharekura. As in the meeting house, where the creation myth is re-enacted through the separation of heaven and earth in the structure, the voyage to Hawaiki is mimicked through the form and structure of the East facing celestial classrooms. The act of sailing is reinforced through the form and function of the roof structure (the capture of wind for ventilation) and the experience in the classroom has a high level of exposure to the elements like found on the waka. Traditionally Hawaiki has been symbolized through the cardinal directions (mainly east), or a seaward/landward orientation in the meeting house (Neich, 1993, p. 123). The wharekura extends the concept of Hawaiki by not merely expressing a distant place through direction, but rather re-enacting myth and history by recreating the mystical experience of the voyage through architecture. This celebrates the return to maritime traditions and the knowledge of their ancestors, who established the wharekura. 


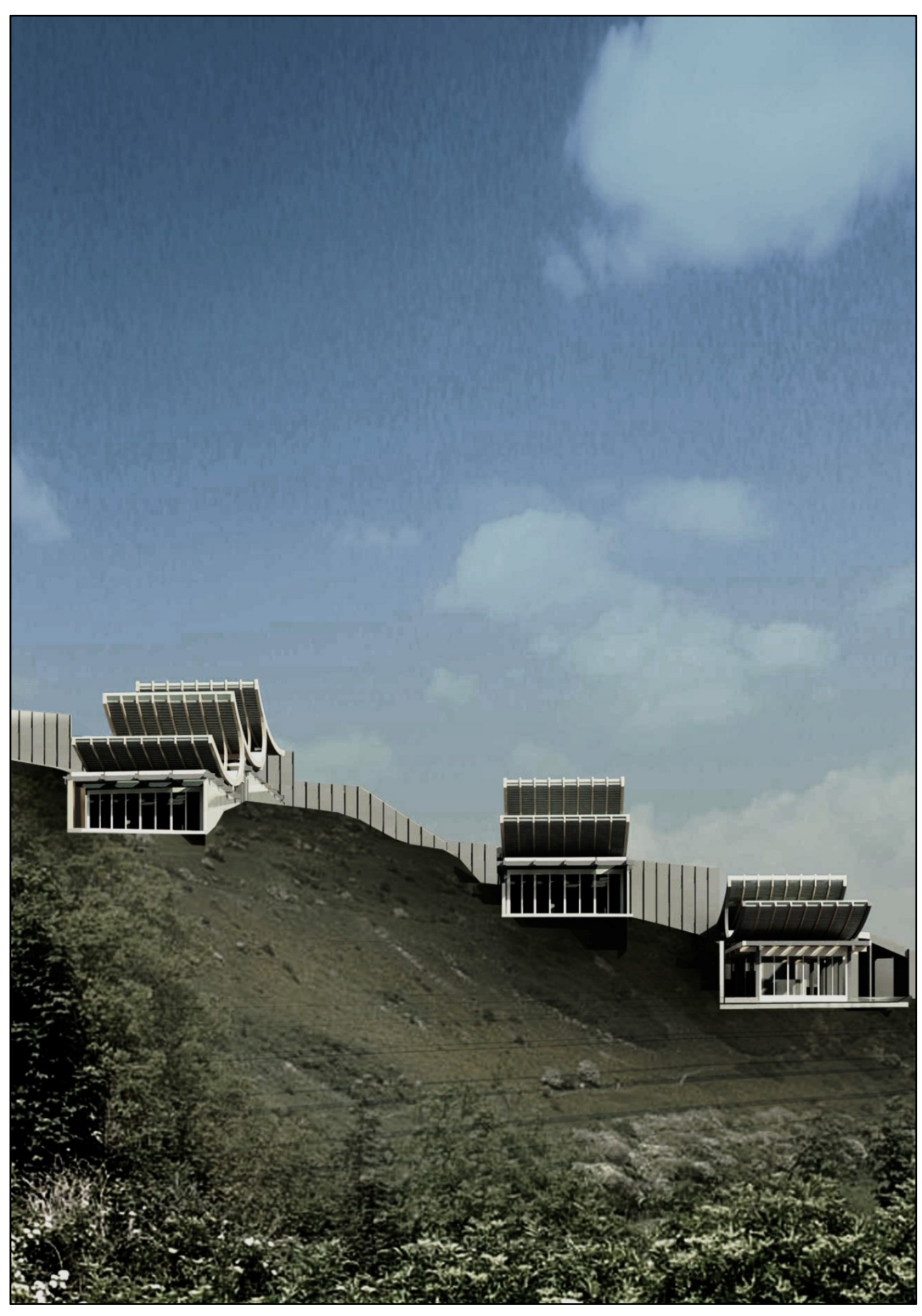

Figure 4.20: Perspective showing sailing

roof scheme on East wing, celestial

classrooms 

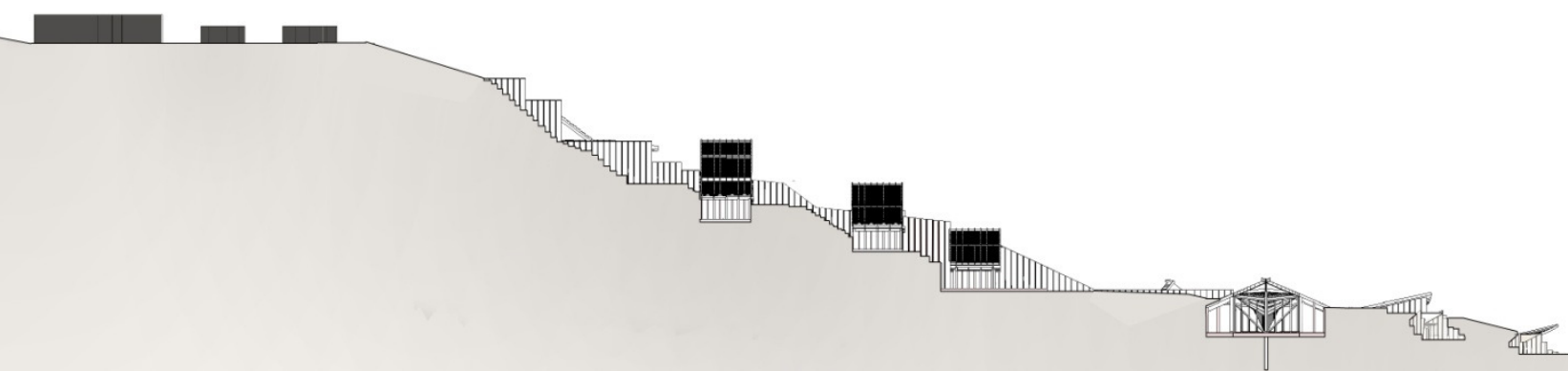

Figure 4.21: East Elevation of whole building in landscape (memorial and Gun barracks at either end) 


\section{DISCUSSIONS AND CONCLUSIONS}




\section{THE APPROPRIATION OF NAUTICAL CHRISTIAN SYMBOLS IN CHRISTIAN MAORI ARCHITECTURE}

Understanding the relationship between nautical symbolism in Christian and Maori religious architecture is the central theme of this research. In light of this investigation, what was certainly found in Christian Maori architecture was the appropriation of nautical Christian symbols. For example the niu pole was symbolically linked to the mast of a ship and the Christian cross. Noah's Ark and European boats (man-O-war) were used to express spiritual ideas in form and space in Christian Maori architecture. Then there was clearly the appropriation of Christian celestial symbols which were strongly linked to spiritual navigation concepts. In many cases, Maori gravitated toward these symbols because they resonated with their traditional cosmological framework associated with navigation. As a result, the appropriation of nautical symbols from Christianity did not represent the assimilation of Maori spirituality into a Christian cosmology. Instead it was a selective and careful appropriation of Christian concepts founded on Maori religious concepts. The same can be said for their architecture which Deidre Brown and Bill Mckay have discussed was "a selective appropriation by Morehus9 of Pakeha methods, forms, and symbolism for their own ends" (Mckay \& Brown, 1992, p. 115).

\footnotetext{
${ }^{39}$ A term used frequently to denote members of various religious Maori movements, particularly of those movements whose buildings are the subject of this research paper.
} 
In a period where Christianity threatened or challenged the symbolic universe of Maori and their place within it, several studies have illustrated how the appropriation or development of new symbols could be related to a process called "identity affirmation". This idea is best summed up by Obeyesekere (1982) who states:

"As a collective phenomenon, identity affirmation is a partly conscious process whereby an ethnic group is impelled to display its unity through visible symbols, and overt symbolic actions, or through the reiteration of grandiose ethnic myths" (quoted from Neich, 1993, p. 152).

This is why many nautical symbols from Christianity (such as Noah's Ark and celestial symbols) were appropriated because they were easier to grasp and interpret. Nautical symbols such as these were appropriated because they helped revive the significance of the waka and Maori navigation concepts by giving them Christian Maori meaning. Therefore the construction of new narratives to nautical symbols enabled Maori to understand how they could intelligibly hold onto their original beliefs and how they could have possibly been misled by them. As obeyesekere (1982) stated, this was a partly conscious process. Therefore nautical symbols appropriated from Christianity were also linked to a process relating to Jung's theory on three archetypes of the human psyche. For an ancient maritime culture who was transitioning to land, it seems nautical symbols related to the repressed desires (personal conscious) or instinctive ideas (the collective unconscious) of Maori who sought to express their maritime past through architecture. This is what makes the study of symbolism so very interesting and complex. Considering that Maori are distinctly what Sumet (1939) terms a 'water based civilisation' it is apparent that nautical symbolism stems from an inviolable tradition of seafaring where boats, navigation and the oceanic environment have had a lasting effect on the nature and meaning of symbolism in Christian Maori architecture. 
In identifying nautical symbolism in Christian Maori architecture it appears that navigation symbols have had the most enduring significance in each Maori religious movement. In the Pai Marire religious movement, navigation concepts were explored in the niu pole which was conceived as a spiritual compass. In the Ringatu movement, navigation star lore was localized and applied to planting and harvesting rituals. They also adopted new symbols based on tribal links to their terrestrial rather than oceanic environment. The whetu marama was also directly associated with navigation because it was referred to as a 'sign' noticed by Ratana during a journey out at sea. These are some of many ways that navigational symbolism has appeared in Christian Maori architecture, each melded with ideas relating to Christianity and Maori cosmology. What seems to be the case in some way or another is that each of these Christian Maori symbols are linked to navigation based on an underlying concept of spiritual direction and guidance. Some symbols may suggest some sort of spiritual guidance based on their more Christian meanings, such as the Christian concept of a spiritual journey ${ }^{40}$. In other circumstances, celestial (navigation) symbols were mostly linked to Maori cosmology and therefore had a much closer association to Maori cosmology.

In each case, navigation symbols in Christian Maori architecture evolved and adapted in a way that would express and explain changing questions of existence under the influence of Christianity. Consequently, this meant Maori were altering their symbolic universe and their place within it. As we know from Maori in his deep sea navigating days, navigation methods are a cosmic system of ordering which explained the mystery of existence, natural phenomena and their relationship to them. Since Christianity, this cosmic system was scrutinized and therefore, as Maori came to appropriate Christian concepts and symbols within their own cosmological framework, they were ultimately altering their relationship to the environment by implementing new (navigation) symbols. As these ideas were changing, Maori obviously felt

${ }^{40}$ In the Book of Genesis, Chapter 1, Verse 14, God is said to have made the sun and moon and stars "for signs" on the fourth day of Creation. Therefore stars were often considered a divine signal to journey towards them. In this respect, stars are symbolic of a spiritual journey in many biblical narratives, e.g. The Star of Magi. 
compelled to express new symbolic relationships through architecture. Despite the adaptation of navigation concepts and their associated cosmology, there is always a broader interpretation regarding their role as symbols. This thesis focused on symbols that are based on their underlying nautical meaning, but for Maori, navigation symbols can demonstrate a multitude of ideas such as mana, mythology, politics as well as religion. What is most interesting about looking at nautical symbols with regard to navigation is that they define how a maritime culture coordinates relationships between the natural and built environment based on an instinctive nautical reflex. This is what makes Maori architecture so unique and harmonious with New Zealand's maritime environment.

\section{Metaphysical Christian MAORI ARCHITECTURE \\ VERSUS \\ FORM AND SPACE IN EUROPEAN CHRISTIAN ARCHITECTURE}

Most of the differences that were discovered when comparing and contrasting European Christian churches in New Zealand with Christian Maori architecture were ultimately related to an archetypal context: one that relates to either a water-based (Hawaiki) or land-based (Eden or desert) context. Despite the appropriation of Christian (land-based) forms, materials, construction methods and symbols, this research has revealed how Christian Maori architecture continued to generate architecture and symbolism that was physically and spiritually very different. One of the major differences I have found is how Christian architecture and symbols follow an artistic tradition which is focused on two and three dimensional forms in space. In contrast, religious Maori architecture and symbolism is more metaphysical and spatio-temporal. Unlike Christian architecture and symbolism where the scene is often apprehended passively, Maori architecture is dynamically moved through as a sequence of spaces and their symbolic meaning unfolds through temporal narratives. In many ways, this research has revealed how this relates to the navigator who relies on phenomenological modes of experience to understand his symbolic universe and his place within it. Furthermore, this research has also discovered how spatio-temporal aspects of religious Maori architecture are linked to the cyclic sense of time which echo notions of Maori fishing and seafaring societies 
which were more attuned to the rhythms of the tides and seasons. In this sense, religious Maori architecture plays an important role in the way it mediates and symbolises relationships between the building, the occupant and the surrounding landscape. In an abstract sense, the building in the landscape coordinates these relationships similarly to the waka in the ocean. This research has emphasized this idea based on the relationship between Maori religious architecture symbolically conceived as a waka among the vast ocean space of the marae (in front of the building). This concept is also reinforced in the way Christian Maori architecture is carefully located and orientated according to navigation methods which are then symbolized through architectural form, iconography and space.

\section{COMMON WATER: THE BOAT AS AN ARCHITECTURAL SYMBOL IN CHRISTIAN AND MAORI}

\section{RELIGIOUS ARCHITECTURE}

Another compelling conclusion drawn from this research reveals how the boat was symbolically recognized in both Christian and Maori religious architecture. As research has revealed, Maori were drawn to the biblical story of Noah’s Ark, symbolically expressed in the boat-shaped ceiling of Christian gothic architecture. Maori were drawn to this concept in architecture because it resonated with many technological and symbolic aspects found in their own architecture. This demonstrates how Maori came to accept Christianity (particularly the Old Testament) based on their nautical concepts. This was particularly found in the Ratana church, where Christian concepts of an Ark (or divine vessel) was appropriated, but still based on Maori religious (and political) concepts of the waka. What can be said about this popular architectural concept in both European and Maori religious architecture is that both appealed to the poetic and pragmatic form, technologies and spatial concepts of a boat. It implies an intimate relationship between shelter and symbol and implies a religious organization that is tight like the social organization found on a boat. Furthermore, both cultures attached spiritual significance to the boat for its important role in their history and development. Although Christian and Maori attitudes toward sea may differ, the boat has proved to be an important role for both European and Maori and, undeniably, the spread of religion. After all, man lives on a planet that is nearly three quarters covered by water where the boat has been the centre of history and adventure among many water and land-based civilizations. Based on Maori navigation theory, voyaging proved to have greater spiritual significance and has ever since been symbolized in their religious Maori architecture. 
This design set out to explore nautical symbolism in a contemporary project that could influence and transform Western notions of knowledge or conventional notions of contemporary (terrestrial) architecture in the design of a school (wharekura). This design discussion and conclusion focuses on how this was accomplished by focussing on three specific outcomes of design. These include how nautical symbols were used to maintain Maori waka traditions through architecture. This design also discovers how the wharekura creates a new dimension of understanding to Western notions of architecture by using powerful metaphysical concepts of nautical symbolism from Christian Maori architecture. Along with a metaphysical aspect in Christian Maori architecture came a high level of water-based pragmatism. Therefore this conclusion also discusses how high levels of poetic pragmatism can open up contemporary architecture to new possibilities that will enrich our understanding of how we can live in New Zealand.

\section{MAINTAINING MAORI WAKA TRADITIONS THROUGH SYMBOLISM IN CONTEMPORARY ARCHITECTURE}

In Christian Maori architecture, the roof form expressed as an upside-down vessel represents a distinct way of thinking and conceptualizing architecture. Especially in the religious realm of architecture, the waka/ship/Ark was a popular Christian Maori appropriation because it corresponds to ideas in Maori cosmology and many other ideas important in a maritime culture that strongly adhered to waka traditions. Unfortunately, the transient lifestyle offered by boats and the knowledge pertaining to them (seafaring and navigation) have lost their significance even more since the colonial and postcolonial periods. In the colonial period, knowledge pertaining to seafaring was simply localised and applied to agriculture, 
hunting and even translated into architecture. ${ }^{41}$ Now, Maori have diverged even further from their fluid and transient existence, toward a lifestyle that is somewhat fixed and terrestrial. Consequently, Maori increasingly live in architecture that conforms to Western aspirations of durability, resistance, and permanency. Unlike the feeling of openness that pervaded Pacific and Maori architecture, Maori are now reduced to living in a society of enclosure. As a result, they are disconnected from time in connection to their past and their connection with the physical and natural world. This poses a serious loss to Maori as a culture, but also the loss of Maori architecture which has exciting potential to transform Western knowledge or conventional notions of architecture.

All is not lost if we appreciate how Christian Maori architecture in the colonial and post-colonial era adapted nautical symbols with hermeneutic meanings based on two different cosmologies. These formed bridges between the present and the past, and the known with the unknown. Thus learning from case study examples, I have discovered that cultural changes are inevitable and an important part of cultural evolution. In fact a culture gains its uniqueness by how they react to change by employing symbols. As termed by Obeyesekere, this is a process of "identity affirmation" (Neich, 1993, p. 152). Based on this idea, the wharekura is an educated semiotic interpretation and visual reiteration of nautical symbols in architecture in a way that ensures the survival and significance of seafaring and maritime history in contemporary Maori architecture. The most pre-dominant and overt symbolic statement is through the upturned waka on land. As I have discussed, this makes a strong statement about a maritime society who have comfortably transitioned to land. More importantly, the upturned waka links past and present theologies in order to sustain original beliefs and their significance in a current context. In this way, the wharekura not only celebrates a multitude of ideas associated with the waka. It also recognizes a new era of nautical architecture that distinguishes Maori from a terrestrial, Western society by flipping the boat upright and rejecting the waka as a form of enclosure. Following its skyward gesture, the wharekura offers an architecture of openness that is more familiar to spatial concepts in nautical Maori architecture. Furthermore, the waka is an easily distinguished symbol that is no longer masked with ambiguous Christian and Maori meanings. I think this is

${ }^{41}$ In Chapter three (sensing time in architecture rather than space) this research explains a parallel between the waka in the ocean and Christian Maori architecture in the landscape. 
important when we see how seldom nautical symbols represent purely nautical ideas in Christian Maori architecture. They are forever melded in ways which allow Maori to intelligibly maintain or understand how they have been misled by their symbolic universe and their place within it. Nautical symbolism in contemporary design (the wharekura) should no longer face the pressure of fitting into a Christian/European cosmology or Western notions of architecture. Instead, nautical architecture and symbolism should be celebrated and recognized for its ability to open new architectural possibilities that can challenge Western notions of building both pragmatically and metaphysically.

\section{Adding A METAPHysical Dimension to CONTEMPORARy ARCHITECTURE}

The symbolic form and structure of the waka is used as a strong visual statement and adds a strong metaphysical aspect to the space. However, the more powerful, semantic expressions of nautical architecture and symbolism are best explored in the wharekura through notions of time in Maori architecture. This is important because it challenges timeless notions of Western architecture by adding a further dimension of understanding to our perception of architecture; one that does not focus on the object, material, form, geometry or decoration. Instead the wharekura provides a metaphysical experience that is spatio-temporal through the use of paepae (thresholds) which echo oppositions between the terrestrial and celestial worlds. At the same time, architecture facilitates the sensual link between both space and place through contemporary technologies and materials and by celebrating the seasonal flux and flow of rainwater through the building. As a result, the wharekura is not intended to be seen as an object in the round, but is experienced in time rather than space. This design exploration is linked to research which suggests that concepts of time in architecture can be linked to the navigator who developed an acute sense of time at sea during his passage in time across vast oceans.

As it has been discovered in Christian Maori architecture, the relationship between the building and the surrounding landscape is comparable to the relationship between the waka in the ocean. The wharekura extends this concept by representing the idea of a voyage to Hawaiki and by applying navigational methods to help co-ordinate the site 
and contextual relationships in the wharekura. In this sense the wharekura mediates and responds to the surrounding physical, cultural and natural context. This allows the building to rest harmoniously within its context while also providing fluid links between the building, the occupant and environment. This contrasts with current rules and regulations that usually pre-determine how a building can utilize the site and even the levels of resistance it must achieve in order to build in an area. Before design even commences, one usually relies on representational data such as maps to comprehend boundaries, zoning regulations and so on. This requires a less direct immersion in the environment and ultimately leads to architecture that is removed from time. This is why contemporary architecture still focuses on the physical, three dimensional object in space that is disconnected from time. Fortunately the design of the wharekura is removed from the reality of restrictions and limitations in the Western world of architecture. This allowed for the freedom to design according to the physic territories known to the navigator. In this respect, the wharekura has a greater understanding of the environment that aspires to a much deeper or embedded engagement with the phenomenological world as well as much more complex mentalistic ${ }^{42}$ attitudes to space. Therefore, if contemporary architecture is going to be experienced from a metaphysical aspect, it needs to start with how to approach and understand the site that does away with all the restrictions and limitations before design has begun. From this, contemporary design also needs to consider how it will mediate these relationships discovered between the site, context and building. In doing so, the ephemeral condition of time is a natural discovery that responds the rhythm of the tides and seasons in our New Zealand context.

\footnotetext{
${ }^{42}$ Mentalistic: "The belief that some mental phenomena cannot be explained by physical laws". (Houghton Mifflin Company, 2009)
} 


\section{PRAGMATISM IN CONTEMPORARY ARCHITECTURE:}

Learning from research, it is understood that the appropriation of Christian symbols and Western notions of building did not represent the assimilation of Christian Maori architecture into European concepts of religious architecture and symbolism. Instead their religious architecture carefully selected and appropriated certain symbols, materials, and religious concepts that could meet or extend the possibilities for spiritual veneration (founded on Maori religious concepts) in their own architecture of faith. Similarly, the wharekura also carefully selects and appropriates contemporary technologies and materials to charge Western (terrestrial) notions of building with a pragmatic quality distinctly found in water-based architecture. The wharekura achieves this by integrating a high level of symbolism with pragmatism. This is important because it corresponds to the intellectual conditioning of water-based cultures who can "communicate instinctively and abstractly" through architecture. (Jumsai 1939, p. 72). In the wharekura this was achieved by integrating symbolism into structure and by using louver technologies to create a responsive architectural skin that denies the building as a closed surface. A high level of symbolic and practical co-ordination also made use of rain and water through the building in a way that was highly functional and symbolic. This demonstrates how contemporary design can be charged with poetic levels of pragmatism often seen in highly adaptable 'water-based' architectures. In doing so, the wharekura also takes on a quality that responds to an environment of flux and flow that is more familiar to the New Zealand environment as opposed to the contemporary buildings in New Zealand that are significantly more suited to 'land-based' civilizations. ${ }^{43}$ As a result of this design exploration nautical symbolism is used in a way where it is not incorporated into the body of Western knowledge or conventional (terrestrial) notions of architecture. Rather nautical architecture and symbolism is used to transform Western ideas of time, space, symbolism and pragmatism so that contemporary architecture responds better to our New Zealand climate and the lifestyle of our indigenous maritime society.

${ }^{43}$ Sumet Jumsai describes the architecture of land-based civilizations as mainly dependent on compressive materials that enable static and sedentary cultures and cities to be constructed. (Jumsai \& Fuller, 1988) 
THE LINK BETWEEN THE WAKA AND STARS THROUGH THE LEGEND OF TAMA-RERETI:

There are many stories that describe the distribution of whanau Marama, the shining ones. One version of particular interest is the story involving the distribution of the Milky Way by canoe. This entails the legend of Tama-rereti, Tane's younger brother, who sailed his canoe out on a lake and found himself lost as night was falling. There were no stars at this time which caused great risk from Taniwha who attacked in the darkness. Tama-reriti continued to sail by night, and in doing so caused the heavens to rain which scattered shiny pebbles from the lakeshore into the sky. This caused great delight in the sky god Ranginui who placed the canoe in the sky as a reminder of how stars were made. Thus the Milky Way is seen

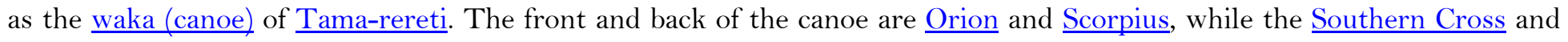
the Pointers are the anchor and rope. This mythological account reinforces the importance of stars in navigation to the extent that they were created for that very purpose. Therefore in Maori mythology, the stars gave way to a rich oral tradition - one which glorifies important navigation theory through a system of memory.

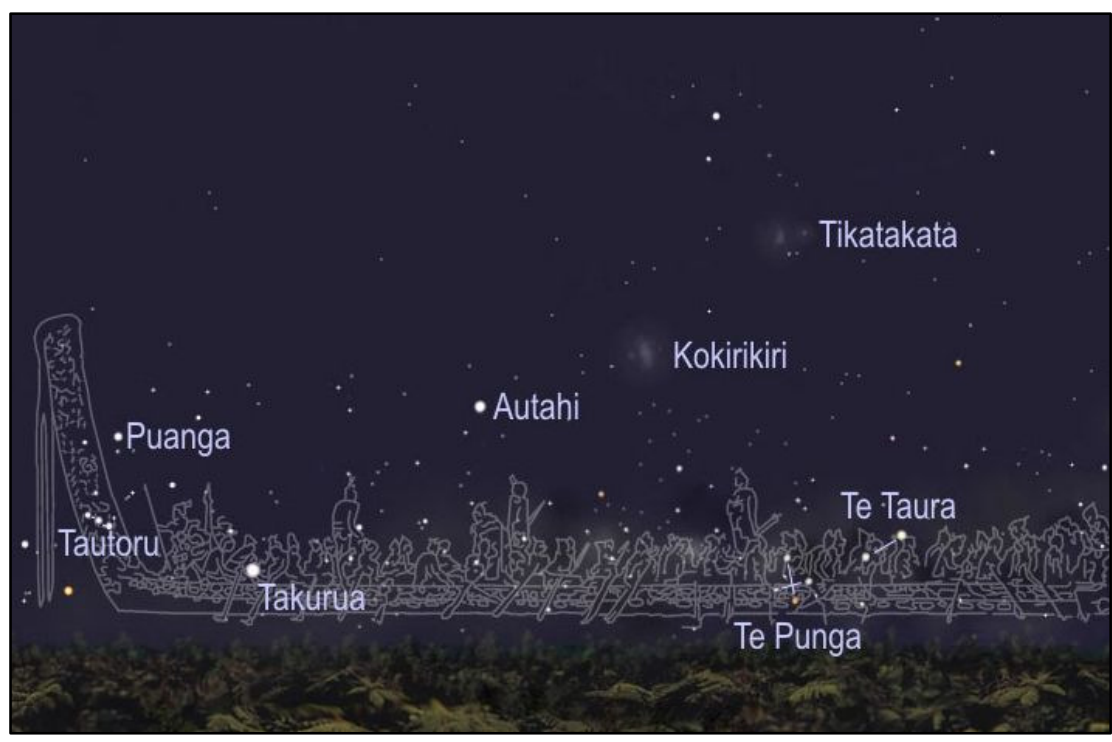

Image showing the Great Waka of Tama-rereti :There are many wakas in the sky but at the time of the Maori new year you can see the great waka of Tama-rereti in the south "at the eyebrow of the sky" (Southern Sky Charts). The waka is Te-Ika-roa (the southern Milky Way) and contains all of the important navigational stars.

Source: Leather, K., \& Hall, R. (2004). Tatai Arorangi Maori Astronomer. Work of the Gods. Paraparaumu: Viking Sevenseas NZ Ltd p. 24-25 
Incantations known as karakia were an important ritual aspect of the canoe. No canoe was fashioned without them, nor was a tree felled for a canoe. During the voyage various karakia may be recited to lessen the length of his journey and minimise danger. Here is an example of a Karakia for calming the sea, and securing prosperity for the voyage. The following is that for the "Aotea" canoe, when she started on her long voyage of some 2500 miles. Karakia is dictated by Hetaraka Tautahi, assisted by Werahiko Taipuhi, of Tauranga-a-ika near Waitotara, Nov. 1900., Translated and Annotated by S. Percy Smith. (Ko 'Aotea' Waka: The Journal of the Polynesian Society, Volume 9, No. 4, 221-223)

The Awa of "Aotea." "Aotea” is the canoe,

Turi is the man on board,

Te Roku-o-whiti is the paddle.

Close to the side, the paddle,

Encircle the side, the paddle,

Forward, standing, the paddle,

Forward, flying, the paddle,

Forward, springing, the paddle,

Forward, flapping, the paddle. 
The paddle! up is the paddle, O Rangi!

The paddle of whom?

'Tis the paddle of Te Kau-nunui,

$$
\text { The paddle of whom? }
$$

'Tis the paddle of Te Kau-roroa-

The paddle of Great Heavens above.

Now the (course of the) canoe rests

On Tipua-o-te-rangi-

On Tawhito-o-te-rangi-

On the place of Rehua's eyes

Horizontal will I place the handle

Of my paddle, Te Roku-o-whiti,

To cross over, rattling along,

To fly along, rattling along,

To be light, rattling along,

The up-rising, the up-lifting,

The thrusting in, the dragging hither,

The whirling, the turning round,

Of the spray of the water,

Of this paddle of mine.

Like the far-off sky,

Like the uplifted sky,

Like the great expanse of Tu,

Now does the way part.

The way of this first-born chief, 
The way of this section of a tribe,

The way of Great Heaven above.

Name the handle of my paddle, then,

(After) Kautu-ki-te-rangi.

'Tis the Heavens elevated.

'Tis the Heavens uplifted.

'Tis the Heavens that stretch thither.

'Tis the Heavens that extend hither.

'Tis the Heavens where stands Dread.

'Tis the Heavens where stands the thrust.

'Tis the Heavens where stands the power.

'Tis the Heavens where stands the tapu.

$$
\text { Be sacred! }
$$

Now does the way part,

The way of Tane-matohe-nuku,

The way of Tane-matohe-rangi,

The way of the Kau-nunui,

The way of the Kau-roroa,

The way of this chief,

The way of the great Heavens above,

Hold on (the course) to Rehua

To the son in the world of light,

O Rongo-ma-Tane!

Lift her up, Hae! 
Undoubtedly, the wharekura is an architectural interpretation that stems from Maori-Polynesian sea-faring instinct where a similar astronomical system was applied to the structural components of a canoe. On canoe railings, a star compass was marked out so the navigator could determine the arcs of the sun and stars crossing the sky. According to legend, the wharekura also measures the position of the rising sun and stars in relation to the building. Facing east, aligned with the equinox was the Post of Tane. Facing west, at the rear of the house, was the equinoctial post, Hine-nui-te po. The positions of the solstices were also marked out by the length of the paepae (or the shoulders of Rangi) where the roof meets the walls (Leather and Hall p.38). The four cardinal directions were also represented by the four walls/doors, the main entrance being Te tatau o te Po, where the sky meets the sea.

\section{West}

maaui 'left'

tama wahine 'female child, unsucessful'

noa 'unrestricted, common'

death

Celestial Equator

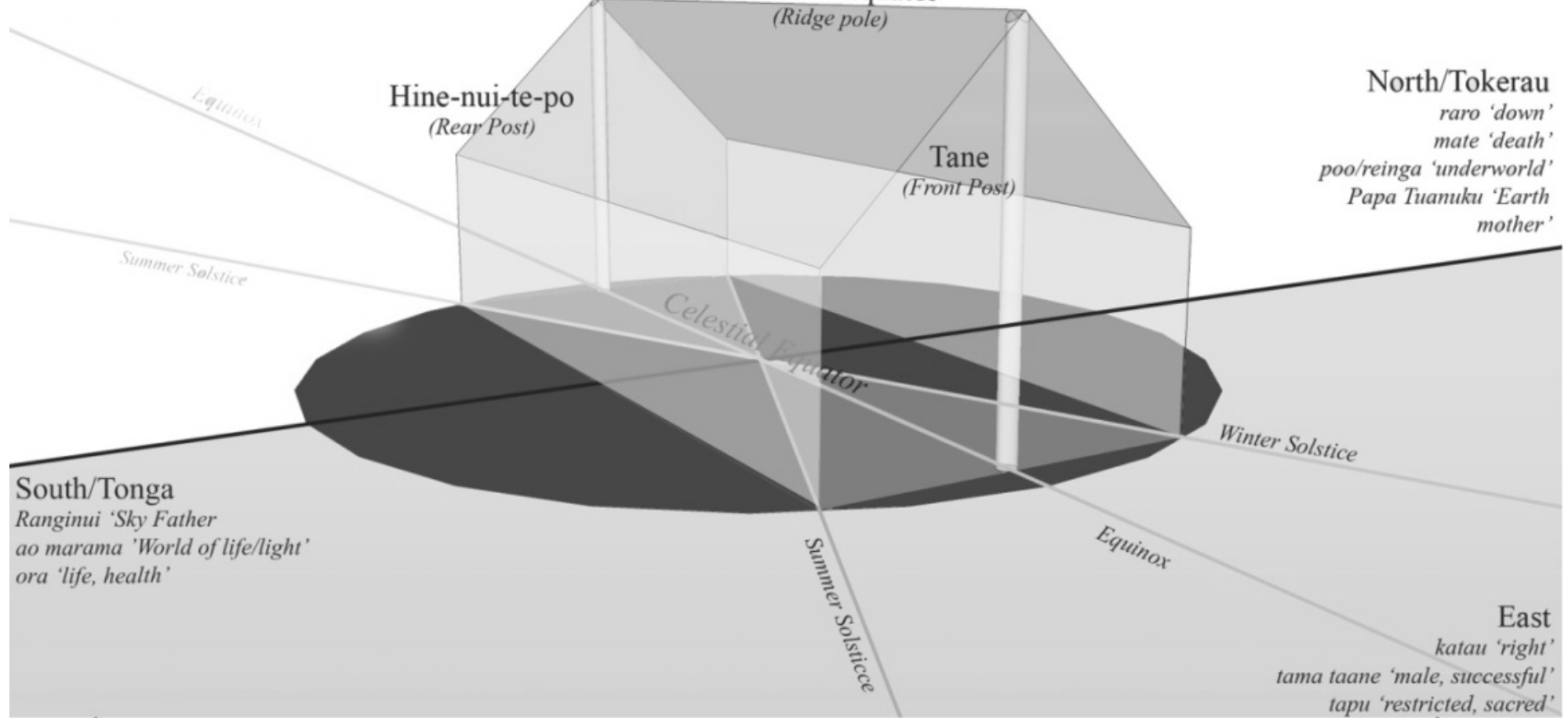


The following is an image and written extract by Anne which describes a symbolic system of orientation that is often applied to Maori architecture. These ideas have also been considered in the final design:

Source: Salmond, A. (1978). Te ao tawhito: a semantic approach to the traditional Maori cosmos. The journal of the Polynesian Society: Volume 87, No. 1, 5-28.

"This system of orientation, with north "down" and associated with the underworld, and south "up" is also expressed in the geographical metaphor of Ika a Maui 'Maui's Fish' - the North Island, which places the head of the fish at Wellington and its tail in Northland. After death a spirit travels "down" to the north, where it leaps over a cliff at Reinga to join dead kinsfolk in the underworld. It is somewhat surprising that north should be associated with darkness and gloom in this system and that the south should be the place of light, because in the southern hemisphere the opposite associations could be expected. It has been suggested to me that this might point to the antiquity of the system and a northern hemisphere homeland"

(Salmond, 1978, p. 11)

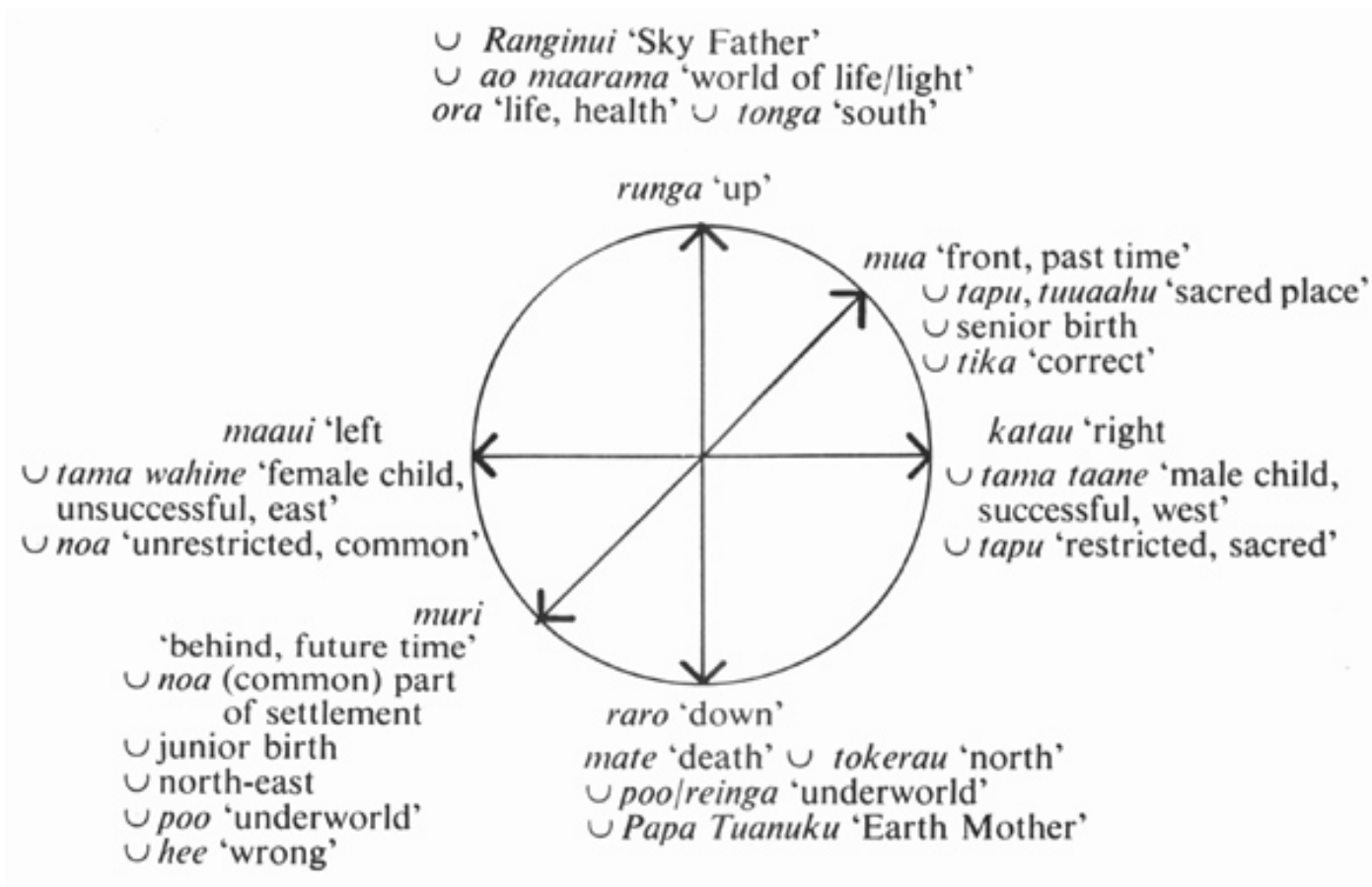

FIGURE 2

Orientation System. 
APPENDIX B 


\section{A BRIEF HISTORY OF POINT HALSWELL FROM TWO CULTURAL PERSPECTIVES}

\section{HISTORY OF SITE - MAOR}

The Wellington region was thought to be peaceful in the pre-contact era due to evidence of dwelling sites in vulnerable coastal positions. This is revealed by old middens and shell heaps of considerable size in areas impinging on the beach. This is certainly the case in Kau bay, near Point Halswell where coastal areas were used for occupation and cooking. (Adkin, 1957)(see map) Some of these cooking sites are said to belong to an old Maori village by the name of Kauwhakaarawaru. This was a kainga ${ }^{44}$ occupied by the Ngati Ira people ${ }^{45}$ specifically the Ngati-kai-tangata clan.

The site had gardens consisting of kumara (sweet potato) plantations. Fresh water was also provided by a nearby stream which kept food supplies cool and fresh as well as providing drinking water. (Love, Wellington Te Ara O Nga Tupuna, 2006, pp. 16, 27) It should also be noted that an important fishing ground and shellfish- gathering area for inner harbour tribes was located at Point Halswell. This area was formerly known as Rukatoa, because only skilled divers (ruka) could obtain shellfish due to the dangerous currents and rough waters prone in Wellington harbour. (Best, The Land of Tara and they who settled it. Part III,V,VI, Volume 27 1918, No. 108, p. 173)

\footnotetext{
${ }^{44}$ Kainga: An Unfortified village or place of residence

45 The chiefs daughter of Ngai Tara tribe (the tribe attributed to the Maori name for Wellington Harbour - Te Whanganui - a-Tara) married a chief of the Ngati Ira tribe from Hawke's Bay which lead to the amalgamation of the tribes, so that Ngai Tara eventually became known as Ngati Ira (Love, Te Ara o nga Tupuna, p. 1)
} 
Map of Miramar Peninsula, Wellington, published by Hector McLeod and Company in 1907 and titled "Miramar or Whataitai (Hataitai) In Maori times". Shows former Maori pa sites and lists artifacts found at each site. Sites include Kau-whakaara-waru village and pa, Te Mahanga village and pa, Matakikaipoinga $\mathrm{Pa}$ Kakariki $\mathrm{Pa}$, Maupuia $\mathrm{Pa}$, Te Akautangi $\mathrm{Pa}$ Taputerangi Pa, Oruaiti Pa. Includes illustrations.

Source: Alexander Turnbull Library, Reference Number: 1/2-003762

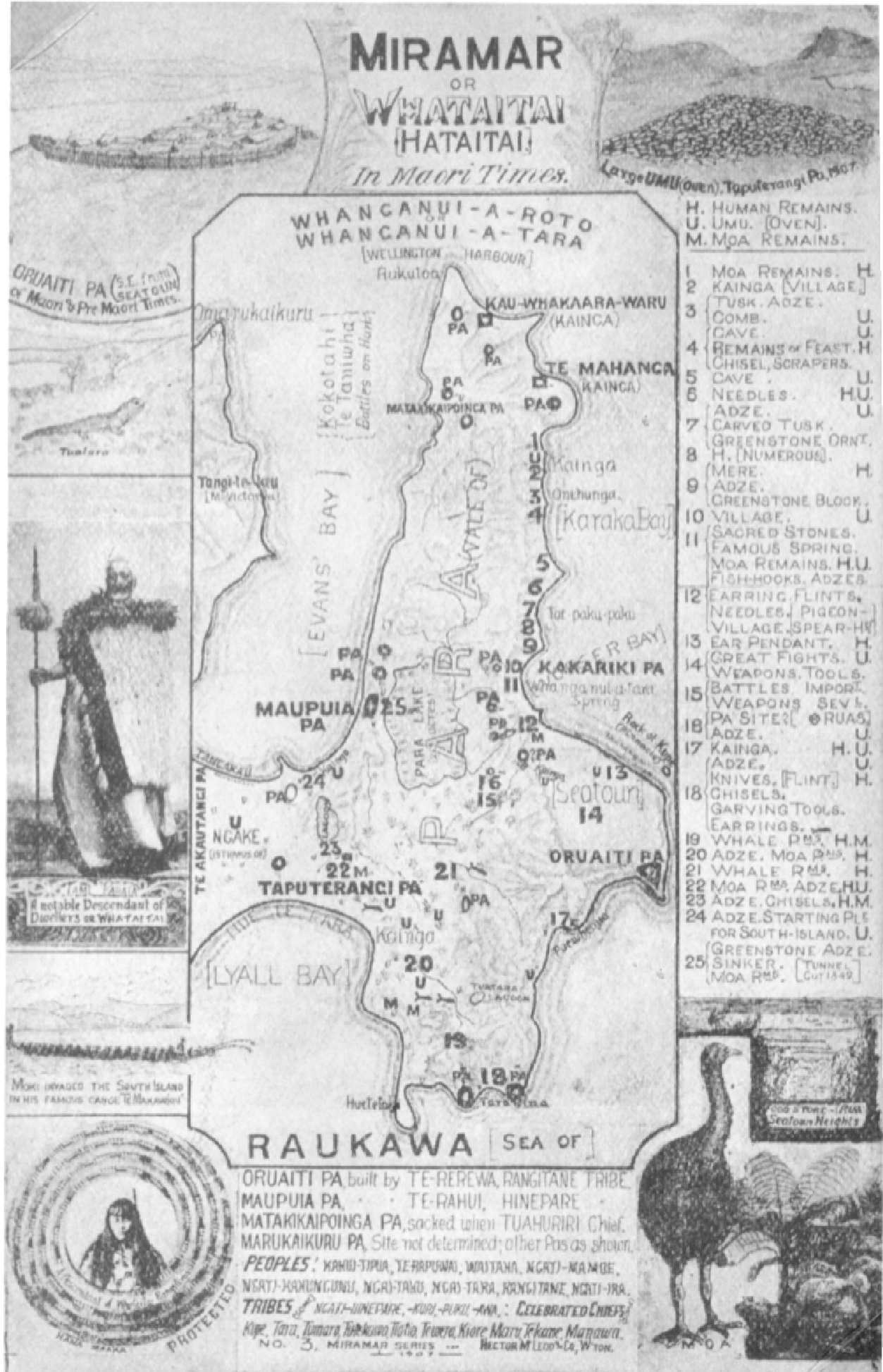


Most communities in Wellington lived in a village protected by a fence or stockade, but had a strongly fortified pa nearby that they could retreat to when necessary. This is likely to be the case for Kainga that were situated around Point Halswell where unidentified $p a$ sites have been found to exist on the ridges and spurs of the hill tops. It is likely that Kauwhakaarawaru was protected by the $p a$ sites immediately above it as outlined by figure 5 . Very little information can be found explaining the details of these occupied areas other than Eldon Best's brief description of Point Halswell in a journal article; The Land of Tara and they who settled it (Part VI):

"A number of hut sites, represented by small terraced formations, have been located on the spur extending upward from this point. Indistinct remains are, or were, seen at what is thought to be the site of the old time stockaded village of Mataki-kaipoinga. A few chains westward of this place, on a jutting spur north of Shelly Bay are a number of hut sites; old ovens are also in evidence. Owing perhaps to the rocky nature of the ground we see nowhere in this district any considerable terrace formations such as are seen in many other places. No long continuous terraces are here seen, but merely linchets of small area, often only large enough to accommodate one or two huts; occasionally one may be seen fifty feet in length; few are longer.”

Evidently, Miramar Peninsula was a desirable location to live. This is because the surrounding coastal areas of the Peninsula offered a transient lifestyle on their canoes. The surrounding sea also provided an abundant source of seafood gathered through fishing and diving. Pa sites may not have been used so much for defence, although it was likely they were still built to protect dwelling sites or gardens.46 Furthermore, the school will restore Maori use of land that had previously been seized for public purposes.

\footnotetext{
${ }^{46}$ In Māori society, a great pā represented the mana of a tribal group, as personified by a chief or rangatira and they were built in defensible locations to protect dwelling sites or gardens. These were almost always on prominent, raised ground which was then terraced. (Wikimedia Foundation, Inc., 2010)
} 


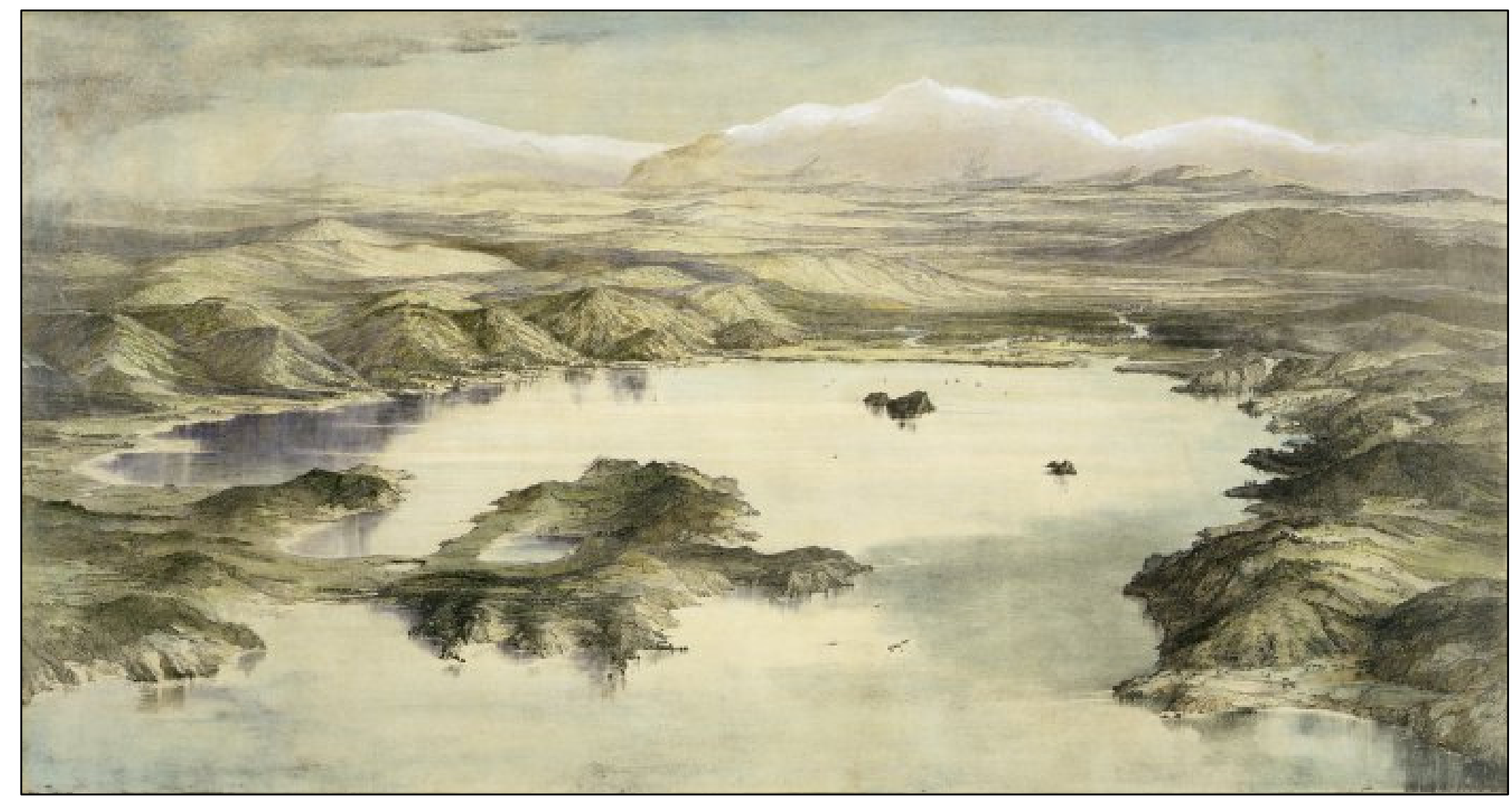

An aerial view of the harbour and site of the town of Wellington from south of Wellington Heads, with Pencarrow Heads at right foreground, the Hutt Valley in the middle distance to the right.

Source: Alexander Turnbull Library: Reference Number: C-029-006-B 


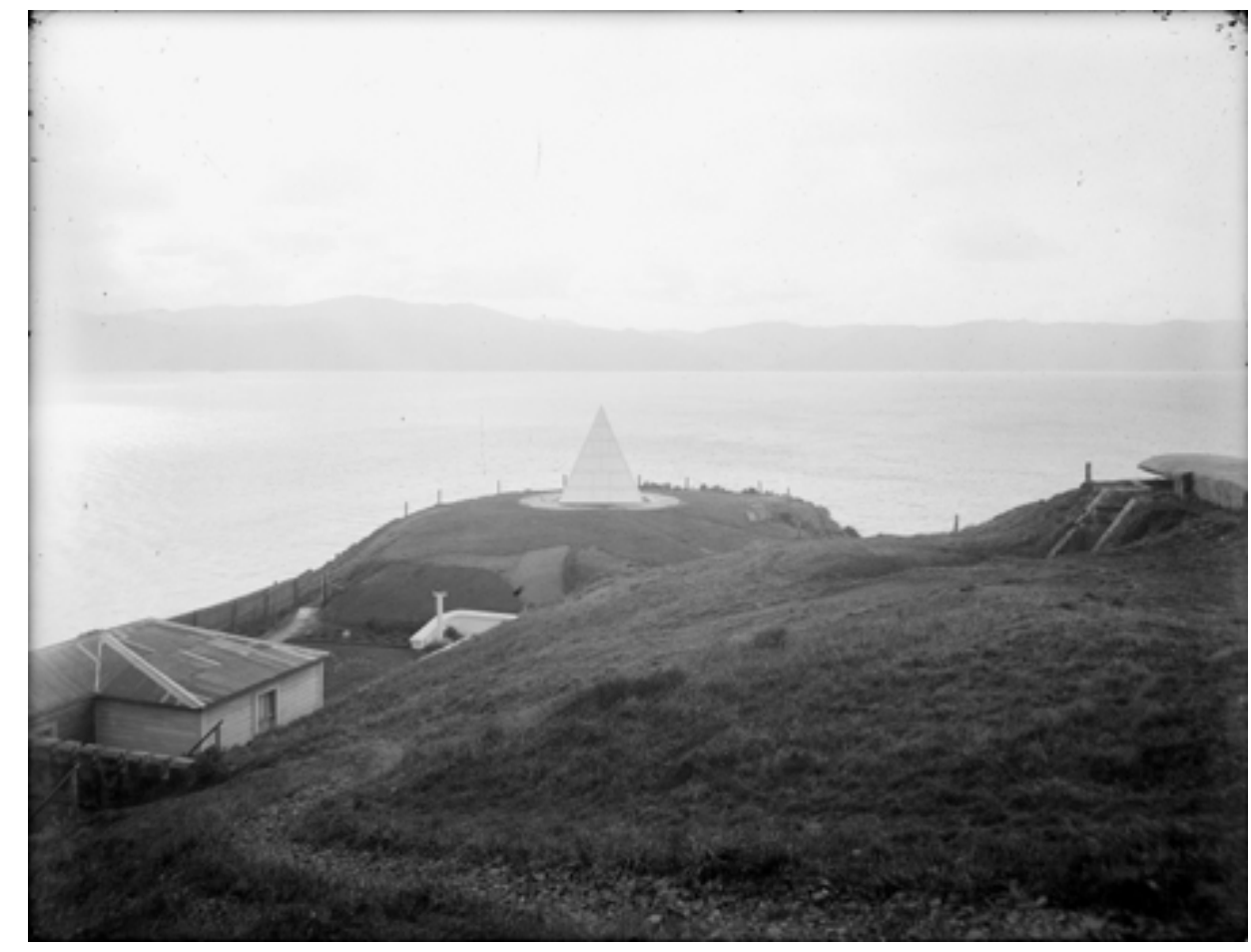

The Military Reserve, Point Halswell, Wellington, 1927. This shows the tomb of Prime Minister, Bill Massey comprising of a gun pit with a temporary cenotaph above it. Source: Ref no 1/1-006711, Alexander Turnbull library, National Library of New Zealand

\section{HISTORY OF SITE - PAKEHA}

Point Halswell is a site long associated with defence. Initially point Halswell was known as Rukutoa until 1841 when the land was taken from Maori by the crown for 'public purposes' and renamed after the Commissioner of Native Reserves, Judge Edmund Halswell. From 1885 the site was used for the Halswell Battery and barracks, one of a number of coastal defence forts built to protect Wellington after the Crimean War from the threat of Russian sea borne invasion. Other guns were mounted near Point Halswell and an infantry redoubt (earthwork fortification) was built on Mt Crawford to protect the rear of these forts which were all linked by a military road. Also, nearby, Shelly Bay became a strong base for naval activity in the 1930's, particularly for minesweepers and patrol boats. 
Ultimately, Point Halswell is an area associated with Wellington's Military history, Miramar peninsula being the largest and most concentrated military defence area in Wellington. (Enterprise Miramar Peninsula, 2008) The Massey memorial which now stands at Point Halswell traces the design of the battery below providing valuable insight into New Zealand's defence history. The paved walkway marks the location of the underground magazine area that is now used as a passageway to reach the vault.

The most prominent feature of the site is the Massey memorial. This has national significance as a war memorial, and also to William Ferguson Massey who governed New Zealand throughout the First World War. As well as political and sentimental significance, the memorial is of architectural significance. According to conservationist, Rebecca Obrien, the memorial illustrates "the pre-occupation with the virtues of the empire and the fashion for building elaborate and prominent memorials that characterized an early part of the twenty-first century." (O'Brien, 2002) The lead designer of Massey memorial was Samuel Hurst Seager, a well known designer of New Zealand war memorials. This is a fine example of his work which demonstrates his thoughtful siting and sober simplicity that characterizes his work. Overall the Massey memorial has a wide symbolic significance concerning value of place, the people it is associated with and an architectural trend throughout the western world (after the first world war) in erecting permanent stone monuments to the esteemed dead.
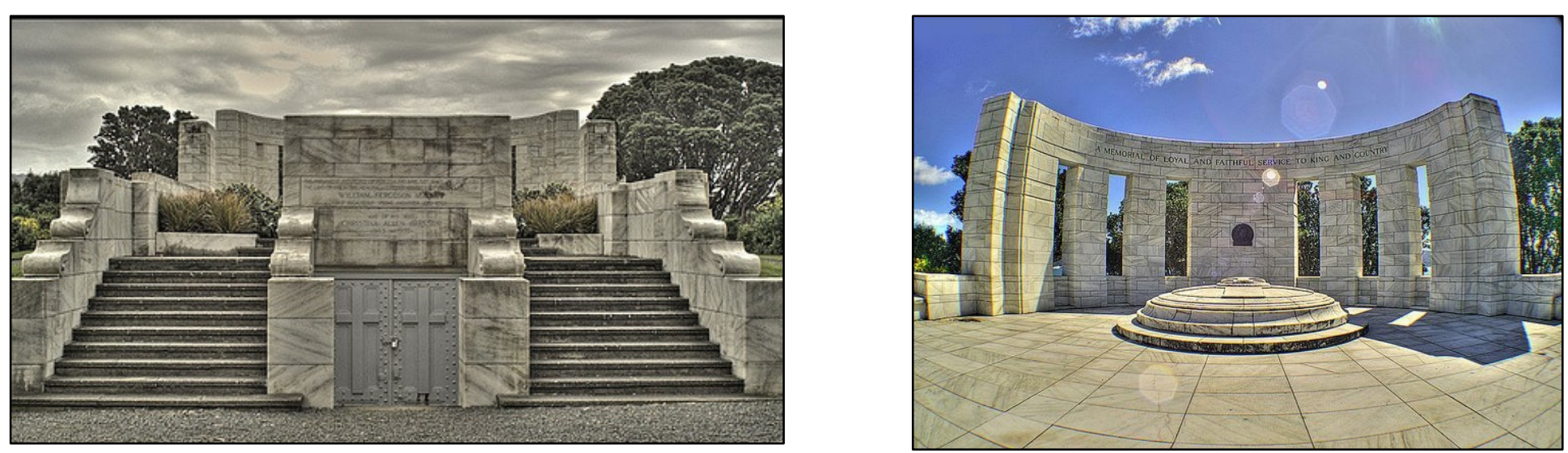

Massey war memorial at Point Halswell.

Both Images sourced from Fisticuff's photostream (2008, September 29). Massey Memorial (fisheyed) \& Massey Memorial Steps Retrieved February 22, 2011, from Flickr: http://www.flickr.com/photos/fisticuff/2897074133/ 


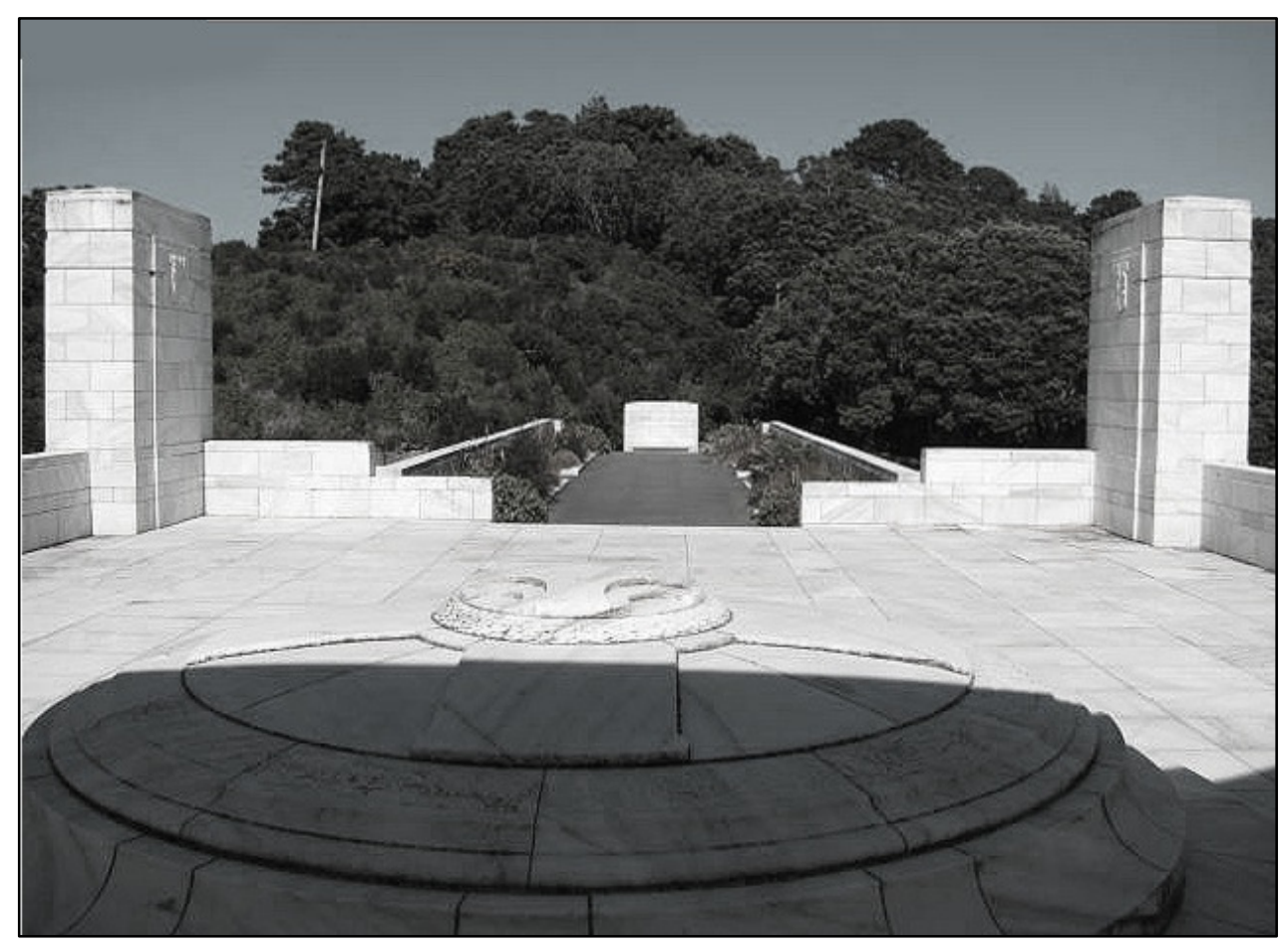

Massey Memorial toward hill behind, (Image by Author)

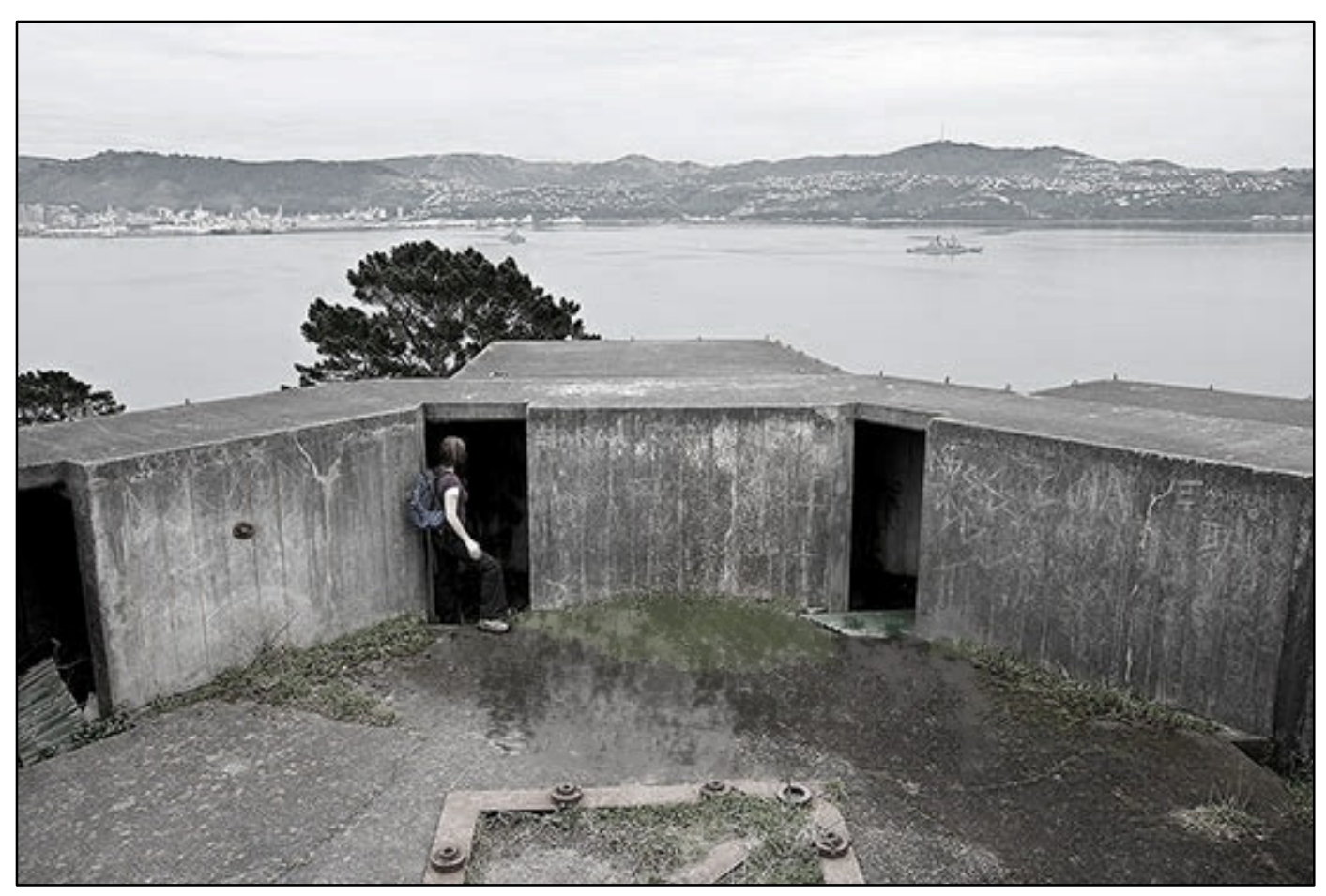

Gun barracks further up the hill (Image by Author) 
APPENDIX C 


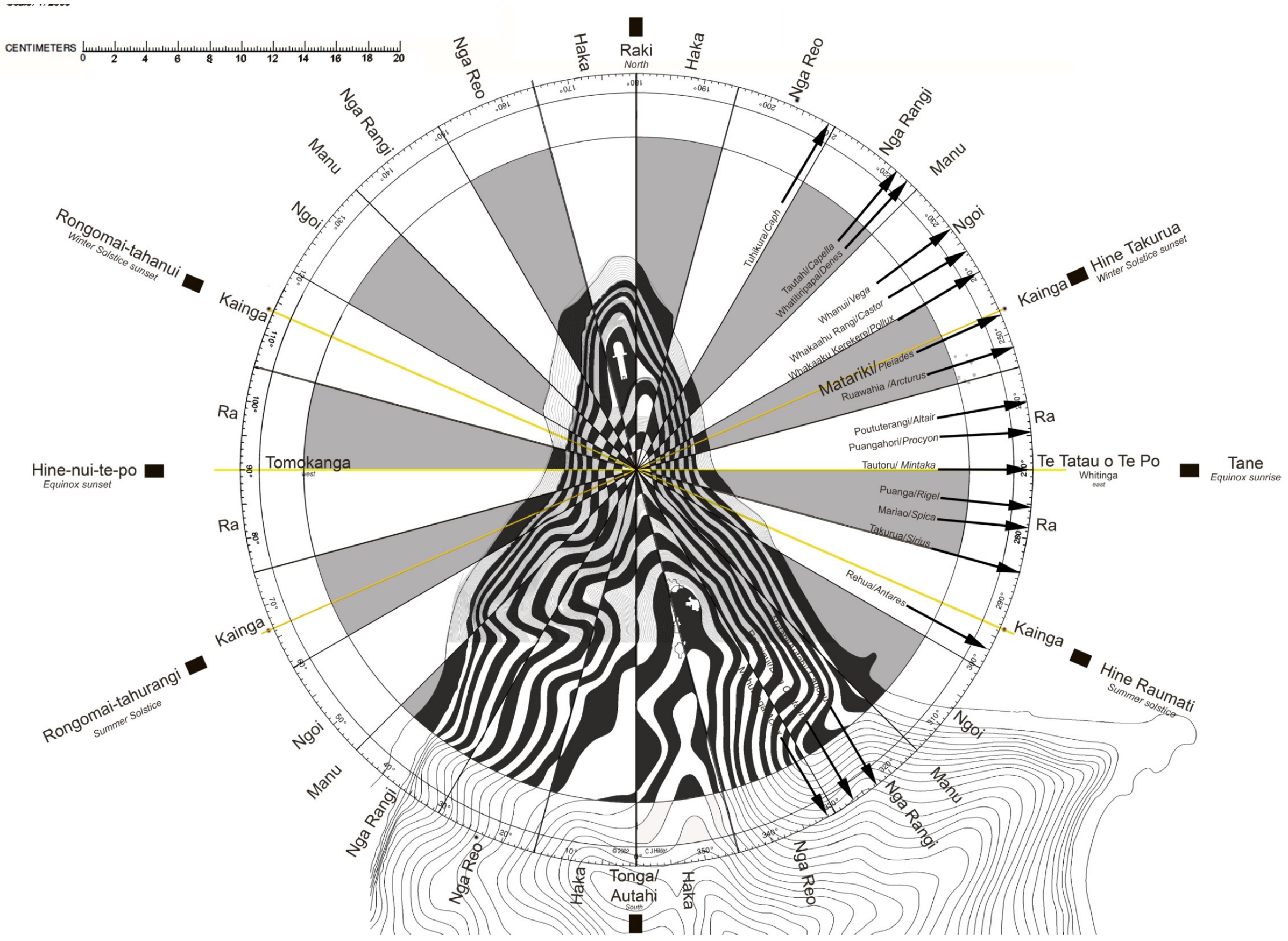

SUPERIMPOSED STAR COMPASS ON SITE SHOWING RISING POSITIONS OF SIGNIFICANT MAORI STARS THAT RISE IN THE EAST. 
Raki Tapararo

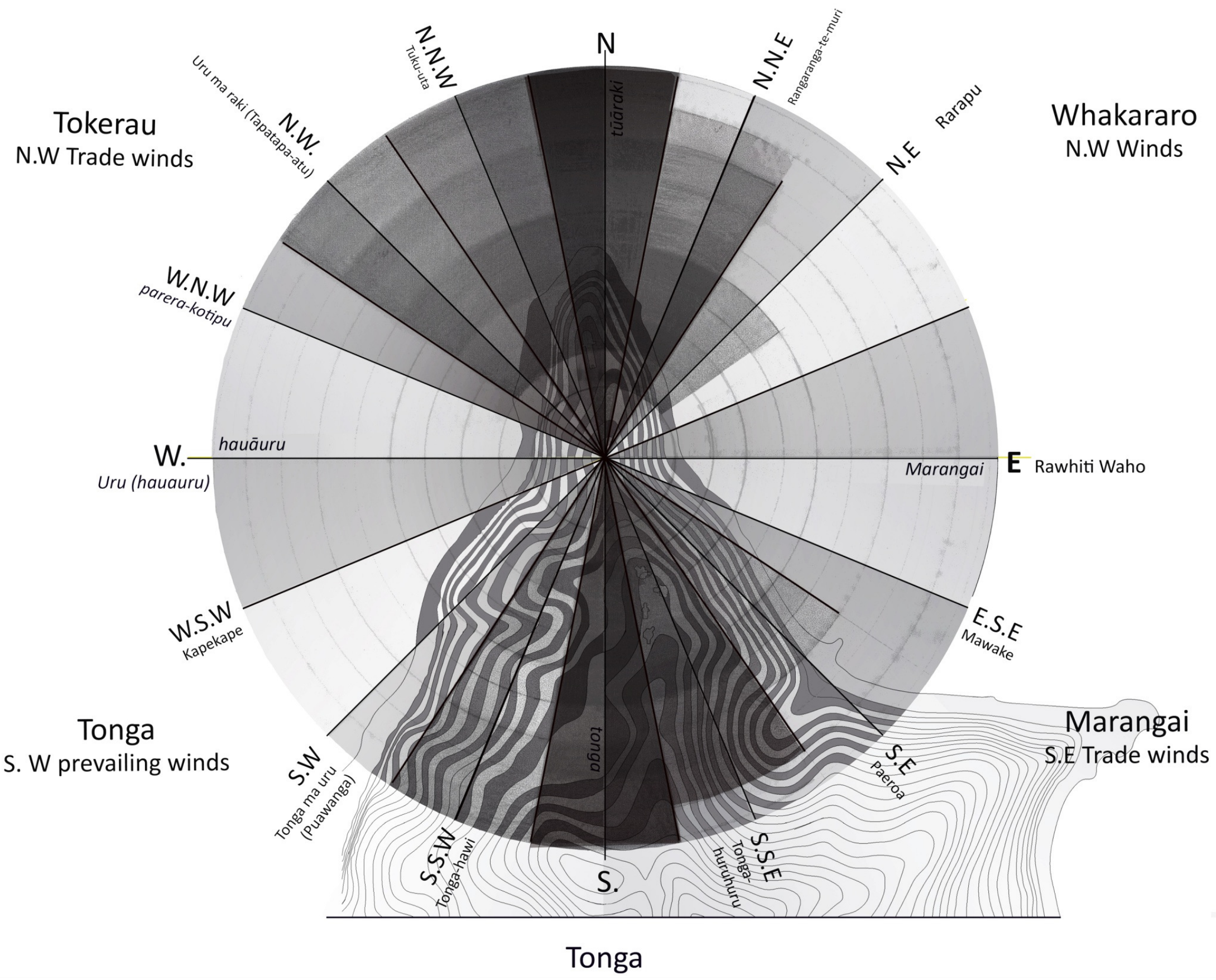

SUPERIMPOSED WIND COMPASS SHOWING PREVAILING WINDS. 

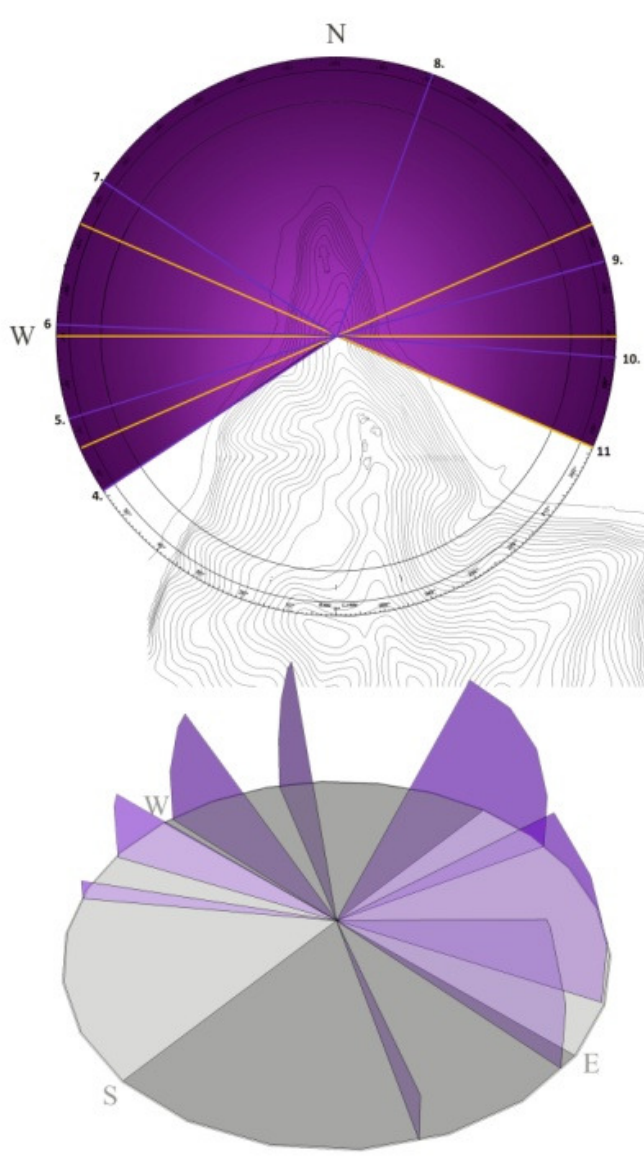

Rehua/Antares

Rehua is sometimes called the bird star, for its two companions are wings, one of
them broken. He has two wives, Ruhe and Whakongi-kai, with whom he resides in turm. When he is with Ruhe, she rests her left foot upon the Earth, and crops are crops dry up. Rechü was a lso sometimes spoken of as "Rehwa, entes on cause at the time of year when he was seen the crops had been gathered and the war-parties were out.
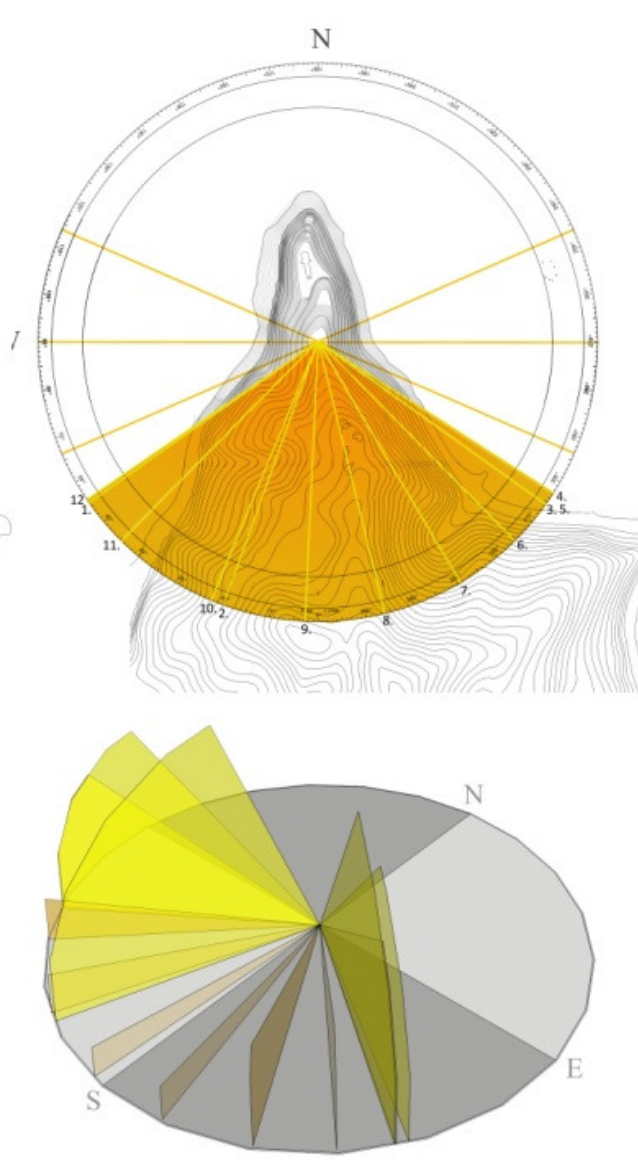

Autahi/Canopus

Autahi is the high chief of stars who hauls up the great anchor Te Punga, the viewed as a a very tapu star, hence he kecps apart from the other Children of
and unts were sung to it, it Before it was affiliated with hhe seasons, Autahi or Autatathi was a famous star among Maori-Polynesian:

"a steering-mark of old when the brown South Sea sailor covered the whole span of the Pacifict in his voyagings, from Papua to Hawaii and from Ponape to East Island... familiarly known among Maori as the "Star of the South."

"Autahi, shining there above us, is a weatherwise star, a foreteller of the winds and storms. Sometimes he twinkles more brightly on one side than the other. You

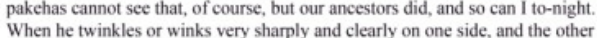
side is dimmer, then it is going to blow hard from the side on which the star flashing brightest. When I see Autahi winking shamply and brightly on the south sidc, as he frequently does, then I know that a strong southerly wind, often a (Cowan, 1930, p. 89)
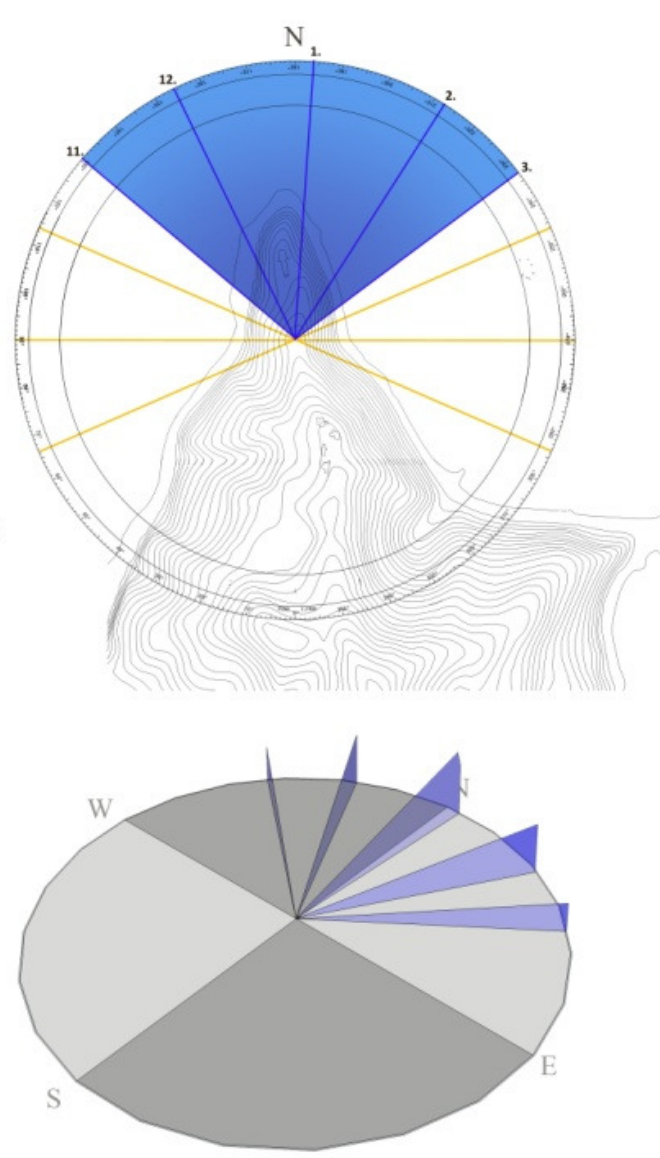

Matariki/Pleiades

Heralds the beginning of the Maori New Year. Matariki was also called Hoko,
because when she rose the seed-kumara were planted The Maori have names for the seven stars in the Pleiades, for we are told that Matariki and her six
fix the heavens, where their task is to Writing of stars in his Polynesian Researches Ellis says: "These were their only guides in steering their fragile barks across the deep. When setting out during the night. The Pleiades were a favourite guiding-star with these sonors, and by them, in the present voyage, we steered during the night." This was a short voyage from Tahit to Huahine. (Best, The Astronomical Knowledge

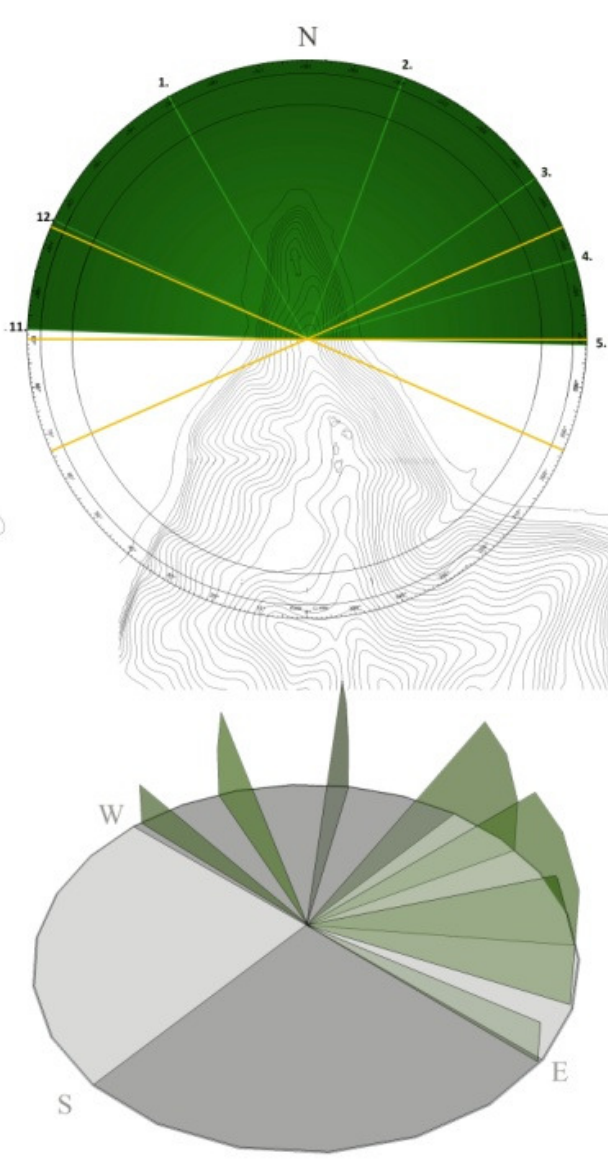

Puanga/Rigel

The bright bluc-white star in Orion known as Rigel also marked the com-
hencement of the new year in early June for the ill-fated Moriori. In the

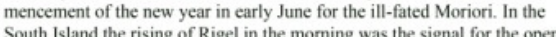
ing of the tapu School of Leaming as well as the commencement of the year (Best, The Maori Vol II, 1941, p. 214) A learned man of the Ngai-Tahu tribe gives the following description based on local lore about Puanga

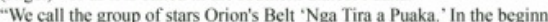
of June these stars are eagerly watched for. When Puaka rises out of the ocean it throws out unmistakable flashes. If these flashes are towards the north, it will be a year of plenty on land and in the sea. If they seem to flas wsual. This, in the tradition of our people, has always been an unfailing omen (tohu) of conditions in the new year." (Our month of June was the first

$\begin{array}{ll} & \\ \text { STAR PATH } & \text { Dee/Jan (1) } \\ \text { Date \& Time: } & \text { Dec. Iat lam (1) } \\ & \text { Dec. 15 at midnight } \\ & \text { Jan. I at I1pm } \\ & \text { Jan. 15 at 1 10pm }\end{array}$

Jan/Feb (2)
Jan. I at lam
Jan. 15 at midnig
Feb. 1 at midnight|

Feb. 1 at midnig
Feb. I at $11 \mathrm{pm}$ Feb. 1 at $11 \mathrm{pm}$ at $10 \mathrm{pm}$
Feb/March (3)
Feb. 15 at midnight Mar. 1 at $11 \mathrm{pm}$
Mar. 15 at $10 \mathrm{pm}$ Mar. 15 at $10 \mathrm{pp}$
April 1 at $9 \mathrm{pm}$ March/April (4)
Mar. 15 at $11 \mathrm{pm}$
April at $10 \mathrm{pm}$
April 15 at $7 \mathrm{pm}$
May 1 at $7 \mathrm{pm}$ 


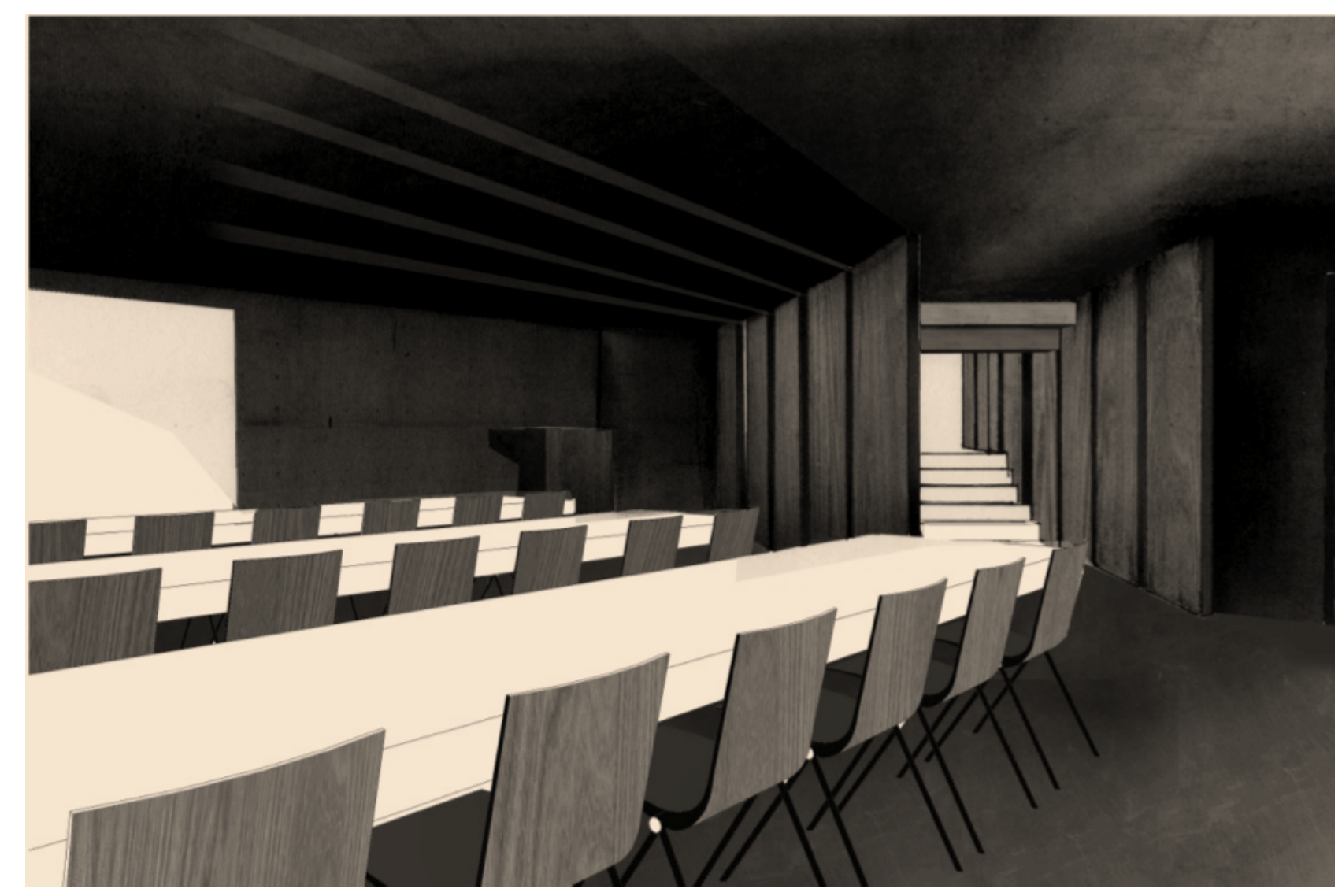

VIEW INSIDE TERRESTRIAL CLASSROOMS 
FLOOD GATE DETAIL
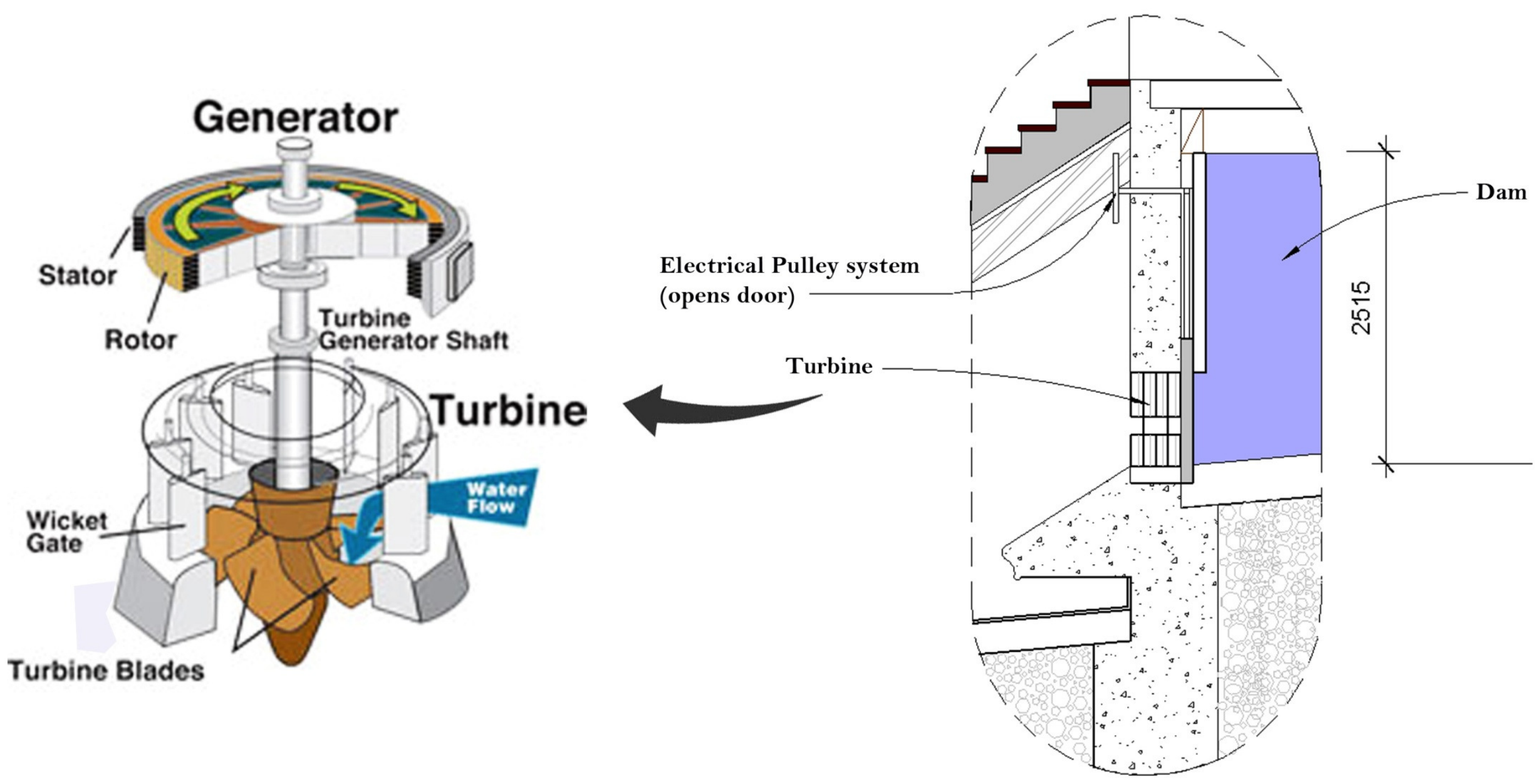

$1: 50$ 


\section{BIBLIOGRAPHY}

Tai Tokerau Maori and Cultural Tourism Association . Matariki: The Maori New Year. 2010. 2011 January 11 $<$ http://www.taitokerau.co.nz/matariki.htm>.

Appendix to the Journals of the House of Representatives. Papers relative to the Pai Marire or Hahau religion etc. 29 November 1864. 24 January 2011 <http://atojs.natlib.govt.nz/cgi-bin/atojs?a=d\&d=AJHR1864-I.2.1.6.12\&e=-------10--1-$---0--.>$.

Auckland museum. "kowhawhai Tuturu Maori.” 1998. Auckland museum online. 11 January 2011

<http://www.aucklandmuseum.com/site_resources/library/Education/Teachers_Guide/Teacher_Resources_Library/Ma ori_Education_Kits/Maori_O2Kowhaiwhai_1_.pdf>.

Austin, Mike and Jeremy Treadwell. "Constructing the Pacific Hut." Interstices: A Journal of Architecture and Related Arts, 10, (2009): 32-42.

Austin, Mike. “A description of the Maori marae.” Study Paper 30 (1980): 229-240.

—. "Pacific building - The construction of tradition." SAHANZ. Paper presented at the XIXth Annual Conference of the Society of Architectural Historians Australia and New Zealand. Brisbane: In J. Macarthur \& A. Moulis (Eds.) CD Rom ed., 2002. 4-7.

—. "Paradise to panorama: the rediscovery of the south Pacific." Panorama to paradise: Scopic Regimes in Architectural and Urban History and Theory, Proceedings of the XXIV Conference of the Society of Architectural Historians of Australia and New Zealand (CDROM). Adelaide: Society of Architectural Historians of Australia and New Zealand, 2007. 2 1-24.

—. "Pacific island migration." Cairns, Stephen. Drifting - Architecture and Migrancy . United Kingdom: Routledge, UK, 2003. 224-236. 
—. Polynesian Architecture in New Zealand. Auckland: Auckland Universtity Press, 1975.

Babbage, Stuart Barton. Hauhauism: An Episode in the Maori Wars 1863-1866. Wellington: Reed Publishing (NZ) Ltd, 1937.

Barrie, Thomas. The sacred in-between : the mediating roles of architecture. New York : Routledge, 2010.

Best, Elsdon. "Polynesian VoyagerThe Maori As A Deep-Sea Navigator, Explorer, And Colonizer." 1923. Knowledge Basket. 13 April $2010<\mathrm{http}$ ///io.knowledge-basket.co.nz.helicon.vuw.ac.nz/taonga/contents/taonga/text/dm/dm5.html>.

-. The Astronomical knowledge of the Maori, Genuine and Empirical. Wellington: Dominion Museum, 1923.

—. "The Land of Tara and they who settled it." The Journal of the Polynesian Society Part III,V,VI (Volume 27 1918, No. 108): 53-61,165-177.

—. The Maori Genius for personification. Wellington: F.N.Z Inst, 1921.

—. The Maori canoe. Wellington: A. R Shearer, Government printer, 1976.

—. Maori Religion and mythology, part 2. Wellington: P. D. Hasselberg, Government printer, 1982.

Binney, Judith. Redemption Songs. A life of Te Kooti Arikiangi Te Turuki. Auckland: Auckland University Press with Bridget Williams Books, 1995.

—. "The Ringatu traditions of predictive history.” The Journal of Pacific History Vol. 23 No. 2 (1988): 167-174.

-. (1990). Ancestral Voices Maori Prophet Leaders. Retrieved January 22, 201 1, from Genesis of Eden Diversity

Encyclopedia: http://www.dhushara.com/book/tane/binn/binney.htm

—. (1984). Myth and Explanation in the Rinagtu Tradition. Journal of the Polynesian Society, Volume 93, No. 4, 345-398.

Brand, Diane. "The space of the sea: hemispheric variation in navigational practice.” IMEHA2008 Congress of Maritime History (June 2008): University of Greenwich.

Brown, Deidre. “Intersecting Lines.” Interstices 4 (1998): CD-ROM.

-. Maori architecture: from fale to wharenui and beyond. 2009. 
—. Moorehu Architecture. Auckland: University of Auckland, 1997.

—. "The Maori response to Gothic architecture." Architectural History, Vol. 43 (2000): 253-270.

Carl G. Jung, M.L. Von Franz, Joseph L. Henderson, Jalonds Jacobi, Aniela Jaffe. Man and his symbols. New York: Dell Publishing Co., Inc, 1968.

Charlot, John. "The Maori-Christian theology of Michael Shires." The Journal of intercultural studies (2006): No. 33 18-27.

Clark, Paul. 'Hauhau' The Pai Marire search for Maori identity. Auckland: Wright and Carman Ltd, 1975.

Cowan, James. (1911). The Adventures of Kimble Bent . London: Whitcombe and Tombs Limited.

BIBLIOGRAPHY —. The Maori: Yesterday and To-day . Christchurch : Whitcombe and Tombs Limited, 1930.

—. "The New Zealand Wars: A history of the Maori Campaign and the Pioneering Period: Volume II: The Hauhau Wars, 186472." James Cowan, F.R.G.S. New Zealand Wars (1845-1872). Wellington: R.E. Owen, 1956.

Davis, Sir Tom. “non-instrument navigation.” Waka Moana symposium. Auckland: NZ National Maritime Museum Te Huiteananui-a-Tangaroa, 1999. 33-.

Earle, Augustus and edited by E.H. McCormick. Narrative of a Residence in New Zealand. Reprint. Oxford: Oxford University Press, 1966.

Eliade, Mircea and Willard R. Trask. The sacred and the profane: the nature of religion . New York: Harcourt, Brace, 1959.

Elsmore, Bronwyn. Like them that dream : the Māori and the Old Testament. Auckland: Reed Books, 2000.

—. Mana from Heaven. A century of Maori prophets in New Zealand. Tauranga: Moana Press, 1989.

Hagger, Arahi .R. Ratana history page introduction: T.W.Ratana's Theory. 8 November 2003. 11 January 2011

<http://www.theratanachurch.org.nz/history.html>.

Hall, Richard. Waka Voyaging Video - Matariki: Maori New Year . 9 June 2002. 22 January 2011

$<$ http://www.transitofvenus.co.nz/video/waka/Matariki_Part_1_56k.html>. 
Healy, Susan. Seeing the Treaty as a Sacred Covenant. 28 January $2011<$ http://www.socialjustice.org.nz/?sid=116>.

Hiroa, Te Rangi. The coming of the Maori. Wellington: Whitcombe and Tombs Ltd, 1950.

Jumsai, Sumet. Naga: cultural origins in Siam and the West Pacific. Singapore: Oxford UP, 1939.

Jung, Carl G. Man and his symbols . London: Random House Publishing Group, 1968.

Leather, Kay and Richard Hall. Tatai Arorangi: Maori Astronomer. Work of the Gods. Paraparaumu: Viking Sevenseas NZ Ltd, 2004.

Lethaby, William. Architecture mysticism and myth. London: The Architectural Press Ltd, 1974.

Lewcock, Ronald and Gerard Brans. “The Boat as an Architectural Symbol.” Oliver, Paul. Shelter, sign, and symbol.

London: Barrie \& Jenkins, 1975. 108-116.

Lewis, David. "Voyaging stars: aspects of Polynesian and Micronesian astronomy." Philosophical Transactions of the Royal Society of London. Series A, Mathematical and Physical Sciences (1974): 133-148.

Mckay, Bill and Deidre Brown. “Buildings of the Morehu: Te Ao Hou’ in M Linzey and R Jenner (eds).” Interstices 2: A Journal of Architecture and Related Arts (1992): 112-133.

McKay, Bill. “Maori Architecture: Transforming Western Notions of Architecture.” Fabrications (2004): December Vol 14, No $1 \& 2$,

—Mckay, Bill. "Maori Architecture: Transforming Western Notion of Architecture." Fabrications: Journal of the Society of Architectural Historian, Australis and New Zealand, Vol 14, No 1 \& 2 (2004): 1-12.

McLintock, A. H. (1966). Maori Flags. Retrieved May 6, 2010, from An Encyclopedia of New Zealand:

http://www.teara.govt.nz/en/1966/flags/6

McLintock, A. H. (1966). Maori Religious Movements: Hauhauism. Retrieved May 6, 2010, from An Encyclopaedia of New Zealand: http://www.teara.govt.nz/en/1966/maori-religious-movements/ 1

Michelis, P. A. "Space-Time and contemporary architecture.” Journal of Aesthtics and Art criticism Vol. 8, No.2 (1949): 71 86. 
Neich, Roger. Carved histories: Rotoroa Ngati Tarawhai woodcarving. Auckland: Auckland University Press, 2001.

Neich, Roger. Painted Histories. Early Maori figurative painting. Auckland: Auckland Unversity Press, 1993.

Newman, Keith. Ratana Revisited. An unfinished leagcy. Auckland: Reed Publishing (NZ) Ltd, 2006.

O'Brien, Rebecca. Massey Memorial Point Halswell, Wellington. 5 October 2002. 12 July 2010

<http://www.historic.org.nz/TheRegister/RegisterSearch/RegisterResults.aspx?RID=222\&m=advanced $>$.

Orbell, Margaret. Hawaiki: A new approach to Maori tradition. Canterbury University Press, 1991.

—. "The religious significance of Maori migration traditions." The Journal of the Polynesian Society (1975): Volume 84, No. 3 p 341-347.

Paul, Clark. Hauhau: The Pai Marire search for Maori identity. Auckland: Auckland University Press, 1975.

Peschel, Enid Rhodes. "Structural Parallels in two flood myths: Noah and the Maori." Folklore, Vol. 82, No.2 (1971): 116123.

Riley, Murdoch. Māori bird lore : an introduction. Paraparaumu: Viking Sevenseas NZ Ltd, 2001.

Rogers, Reginald Arthur Percy. "English Church Gothic.” The Irish Church Quarterly. Vol. 8, No. 29 (1915): 11-28.

Rosenfeld, Jean E. The Island Broken in two halves. Land and renewal movements Among the Maori of New Zealand. Pennsylvania: Pennsylvania State University Press, 1999.

Salmond, Anne. Hui: A study of Maori ceremonial gatherings. Auckland: Heinemann Reed, 1976.

—. "Te ao tawhito: a semantic approach to the traditional Maori cosmos." The journal of the Polynesian Society: Volume 87, No. 1 (1978): 5-28.

Schaniel, William C. "European technology and the New Zealand Maori economy: 1769-1840." The Social Science Journal ( 2001): Volume 38, Issue 1, Spring, 137-146.

Scott, Dr Timothy. Symbolism of the Ark:The universal symbolism of the receptacle of Divine Immanence. Louisville: Fons Vitae, 2008. 
Sedcole, Bruce. A temple for a prophet : (Ratana architecture). Wellington: Victoria University of Wellington, 1985.

Soanes, Catherine. The New Pocket Oxford Dictionary. Ninth Edition. New York: Oxford University Press, 2001.

Strongman, Dr Luke. “The dolphin and the sextant: Traditional knowledge and modernity in Polynesian navigation.” $\underline{\text { ASA, }}$ ASAANZ and AAS. Lower Hutt: Auckland, 2008 .

Taonui, Rawiri. “Waka Traditions: Some Post Fleet Considerations.” Proceedings of the Waka Moana Symposium 1996 : voyages from the past to the future. Auckland: New Zealand National Maritime Museum in partnership with Te Papa National Services, 1996. 87-94.

Walker, Ranginui. "A lot to learn about time." New Zealand Listener (1982): 59-60.

Walmsley, Antonia and Bill Mckay. "Maori Time: Notions of space, time and building form in the south pacific." $\underline{\text { IDEA }}$ (2003): 85-95.

Whatahoro, H.T. translated by Smith, Percy. "The lore of the whare-wanaga.Teachings of the Maori College on Religion, Cosmogony, and History Part2." Whatahoro, H.T. and Percy Smith. The whare wananga or house of teaching or learning; The Maori College. New Plymouth: Printed for the Society by Thomas Avery, 1913. 72-109.

Wilson, John. Te Ara Home: New Zealand in Brief: History. 3 March 2009. 2011 March 3

$<$ http://www.teara.govt.nz/en/history/1/1>. 


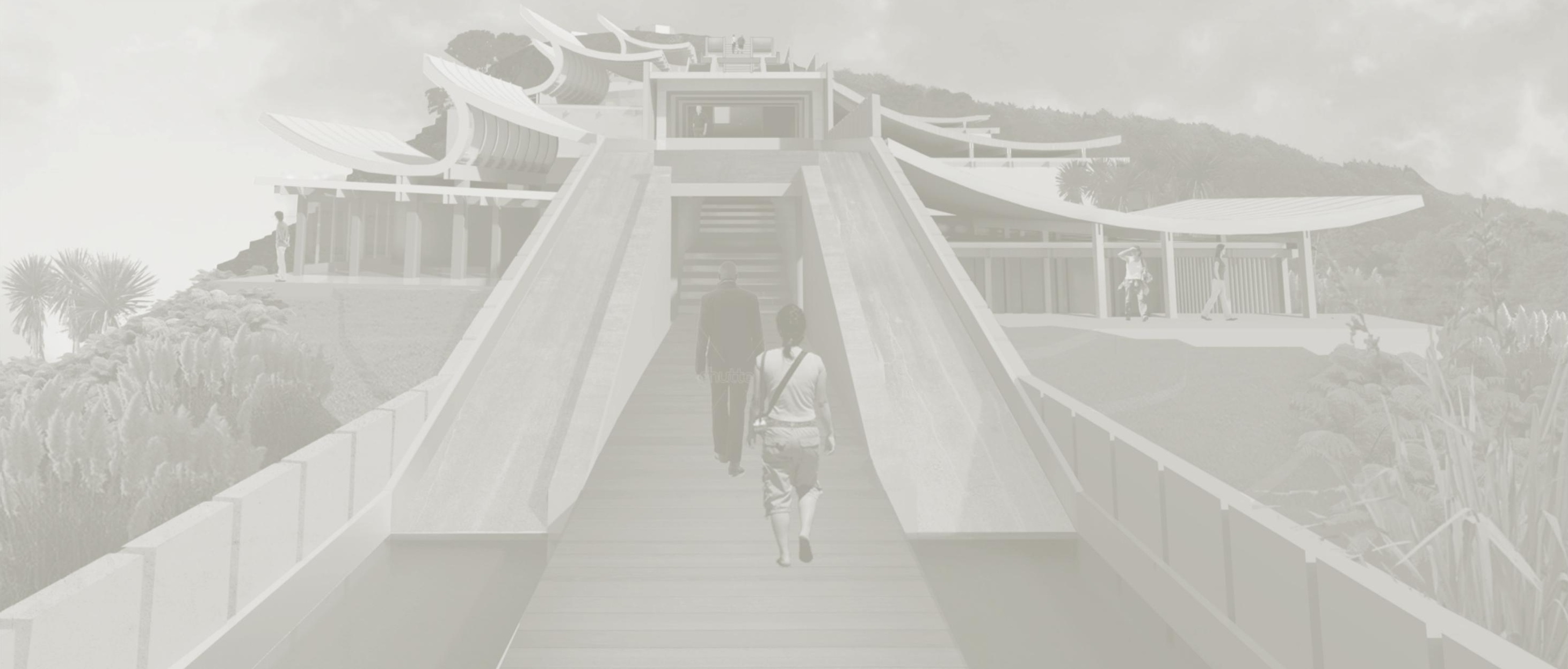

